VILNIUS GEDIMINAS TECHNICAL UNIVERSITY

leva MISIŪNAITÉ

\title{
STRUCTURAL BEHAVIOUR AND STABILITY OF STEEL BEAM-COLUMN ELEMENTS IN UNDER-DECK CABLE-STAYED BRIDGE
}

DOCTORAL DISSERTATION

TECHNOLOGICAL SCIENCES, CIVIL ENGINEERING (02T)

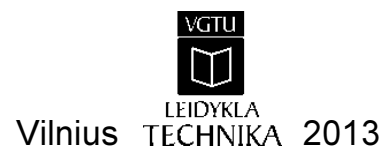


Doctoral dissertation was prepared at Vilnius Gediminas Technical University in 2009-2013.

\section{Scientific Supervisor}

Assoc Prof Dr Algirdas JUOZAPAITIS (Vilnius Gediminas Technical University, Technological Sciences, Civil Engineering - 02T).

VGTU leidyklos TECHNIKA 2217-M mokslo literatūros knyga http://leidykla.vgtu.lt

ISBN 978-609-457-605-8

(C) VGTU leidykla TECHNIKA, 2013

(C) Ieva Misiūnaitè, 2013

ieva.misiunaite@ymail.com 
VILNIAUS GEDIMINO TECHNIKOS UNIVERSITETAS

leva MISIŪNAITÉ

PLIENINIŲ PASPYRINIŲ TILTŲ

GNIUŽDOMŲ LENKIAMŲ ELEMENTŲ

ITEMPIỤ DEFORMACIJŲ BŪSENA

IR STABILUMAS

DAKTARO DISERTACIJA

TECHNOLOGIJOS MOKSLAI,

STATYBOS INŽINERIJA (02T)

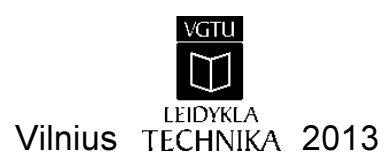


Disertacija rengta 2009-2013 metais Vilniaus Gedimino technikos universitete.

\section{Mokslinis vadovas}

doc. dr. Algirdas JUOZAPAITIS (Vilniaus Gedimino technikos universitetas, technologijos mokslai, statybos inžinerija - 02T). 
Dedicated to my Mom and Beloved Ones 



\section{Abstract}

The dissertation investigates the issues addressed to Under-Deck Cable-Stayed (UDCS) bridge, analyses its in-plain structural behavior and stability verification with an approach of Advanced Analysis.

The main objects of research include effective form-finding of steel UDCS bridge, structural behaviour and stability analysis by means of beam-column elements based on the Direct Analysis Method.

The study approaches a few main tasks such as a new form of UDCS bridge by accounting for the economical and efficient structural design criteria; dealing with the generalized calculation models of the additionally restrained steel beam-column elements; the development of the computational method for the direct analysis of the steel structures and especially bridges using generalized calculation models and outlining practical guidelines for UDCS bridge design.

The dissertation consists of five parts including Introduction, 4 chapters, Conclusions, References and 3 Annexes.

The introduction reveals the investigated problem, importance of the thesis and the object of research and describes the purpose and tasks of the study, research methodology, scientific novelty, the practical significance of results examined in the thesis and defended statements. The introduction ends in presenting the author's publications on the subject of the defended dissertation, offering the material of made presentations in conferences and defining the structure of the dissertation.

Chapter 1 revises used literature. At the end of the chapter, conclusions are drawn, and tasks for the dissertation are reconsidered.

Chapter 2 develops a new structural form for the UDCS bridge, deals with the calculation models of initially perfect beam-column with additional elastic restraint and suggests computational method for the solution of the non-linear problem verifying the stability of the under-deck cable-stayed bridge.

Chapter 3 improves computational method, which has been proposed in Chapter 2, by accounting for imperfections. Moreover, this chapter suggests the new technique for the structural response control and practical guidelines for such structures design. model.

Chapter 4 provides experimental investigation of three scale UDCS bridge

6 papers focusing on the subject of the discussed dissertation are published: one paper - in the Thomson ISI register, one paper - in conference material in Thomson ISI database, one paper - in journal quoted by Inspect database, three papers - in material reviewed during international conferences. 4 presentations on the subject have been given in conferences at international level. 


\section{Reziumè}

Disertacijoje nagrinejama paspyrinių tiltų konstrukcijų plokštuminė elgsena ir stabilumas, taikant inovatyvius analizès metodus. Pagrindinis disertacijos tikslas - atlikti naujos paspyrinès konstrukcijos paiešką ir pasiūlyti skaičiavimo metodiką ir algoritmus naujosios konstrukcijos gniuždomų lenkiamų elementų itempių ir deformacijų analizei bei stabilumo vertinimui taikant, visuminei analizei keliamus reikalavimus. Disertacijoje taip pat siekiama pateikti metodiką paspyrinių konstrukcijų įrąžų reguliavimui.

Darbe sprendžiamos kelios grupès uždavinių, kurių pirmoji skirta naujos paspyrinès konstrukcijos ir jos elgseną reikiamu tikslumu nusakančio apibendrinto gniuždomo lenkiamo elemento su tarpine paslankia atrama skaičiuojamojo modelio netiesinei elgsenos ir stabilumo analizei. Antroji siejama tu patikslintais skaičiuojamaisiais modeliais ir analizes metodais atsižvelgiant ị visuminei analizei keliamus reikalavimus.

Disertaciją sudaro ịvadas, 4 skyriai, rezultatų apibendrinimas, naudotos literatūros ir autoriaus publikacijų disertacijos tema sąrašai ir 3 priedai.

Ivadiniame skyriuje aptariama tiriamoji problema, darbo aktualumas, aprašomas tyrimų objektas, formuluojamas darbo tikslas bei uždaviniai, aprašoma tyrimų metodika, darbo mokslinis naujumas, darbo rezultatų praktinė reikšmé, ginamieji teiginiai. Ivado pabaigoje pristatomos disertacijos tema autoriaus paskelbtos publikacijos ir pranešimai konferencijose bei disertacijos struktūra.

Pirmas skyrius skirtas literatūros apžvalgai nagrinèjamos problemos tematika.

Antrajame skyriuje pasiūloma nauja skaičiavimo metodika paremta paspyrinių tiltų konstrukcijų ir jų elgseną atitinkančių gniuždomų lenkiamų elementų su tarpine paslankia atrama skaičiavimo modelių netiesinei analizei.

Trečiajame skyriuje patikslinama antrajame skyriuje pasiūlyta metodika ir suformuotas apibendrintasis gniuždomo lenkiamo elemento su tarpine paslankia atrama skaičiuojamasis modelis, atsižvelgiant i galimas nuokrypas. Skyriaus antrojoje dalyje pateikiama metodika naujos formos paspyrinio tilto įrąžu reguliavimui ir praktinès rekomendacijos projektavimui.

Ketvirtajame skyriuje aprašomi paspyrinio tilto modelio eksperimentinio tyrimo tikslas, uždaviniai, taikyta metodika ir gauti tokių tyrimų rezultatai.

Disertacijos tema paskelbti 6 straipsniai: 1 - straipsnių rinkinyje, įtrauktame i Thomson ISI sąrašą, 1 - konferencijų medžiagoje, referuojamoje Thomson ISI duomenų bazejje, 1 - kitose domenų bazèse cituojamame žurnale, 3 recenzuojamose tarptautinių konferencijų medžiagose. Disertacijos tema perskaityti 4 pranešimai tarptautinèse Lietuvos bei kitų šalių konferencijose. 


\section{Symbols}

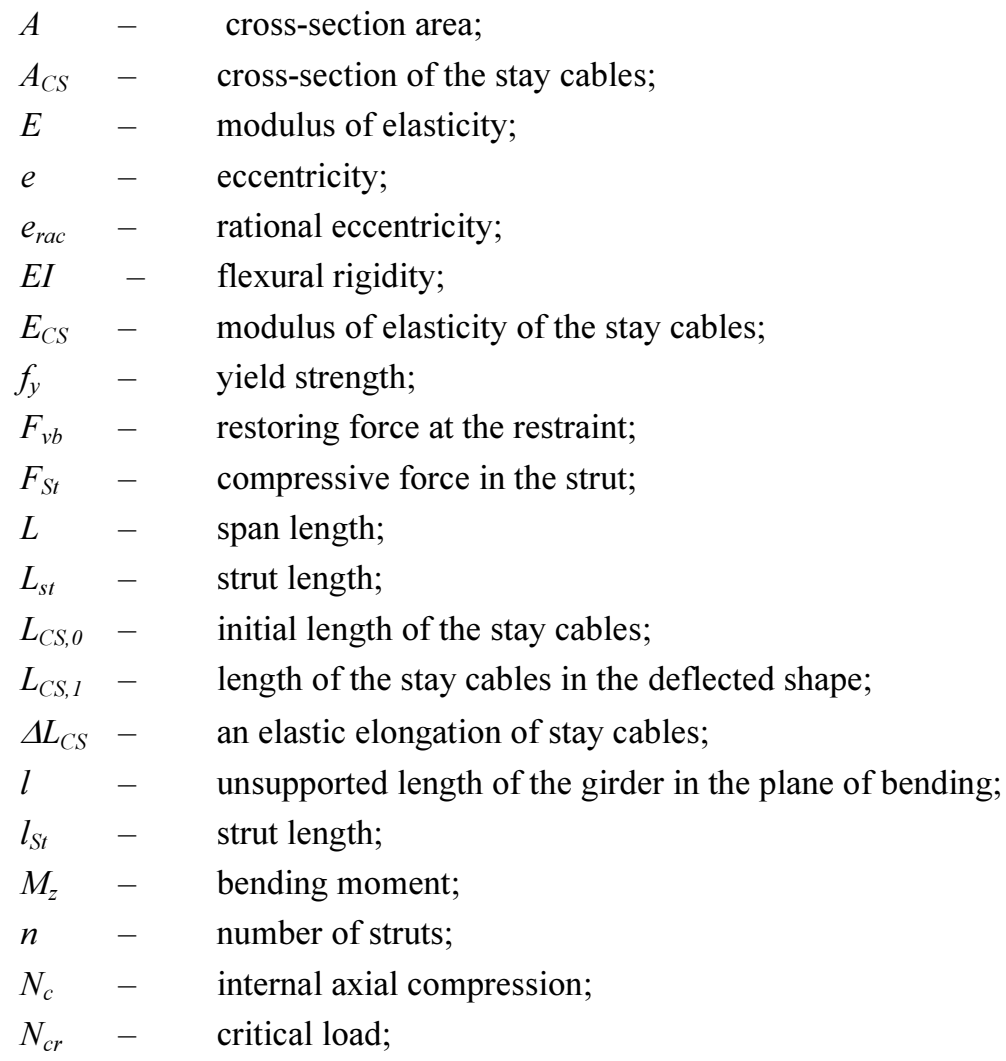




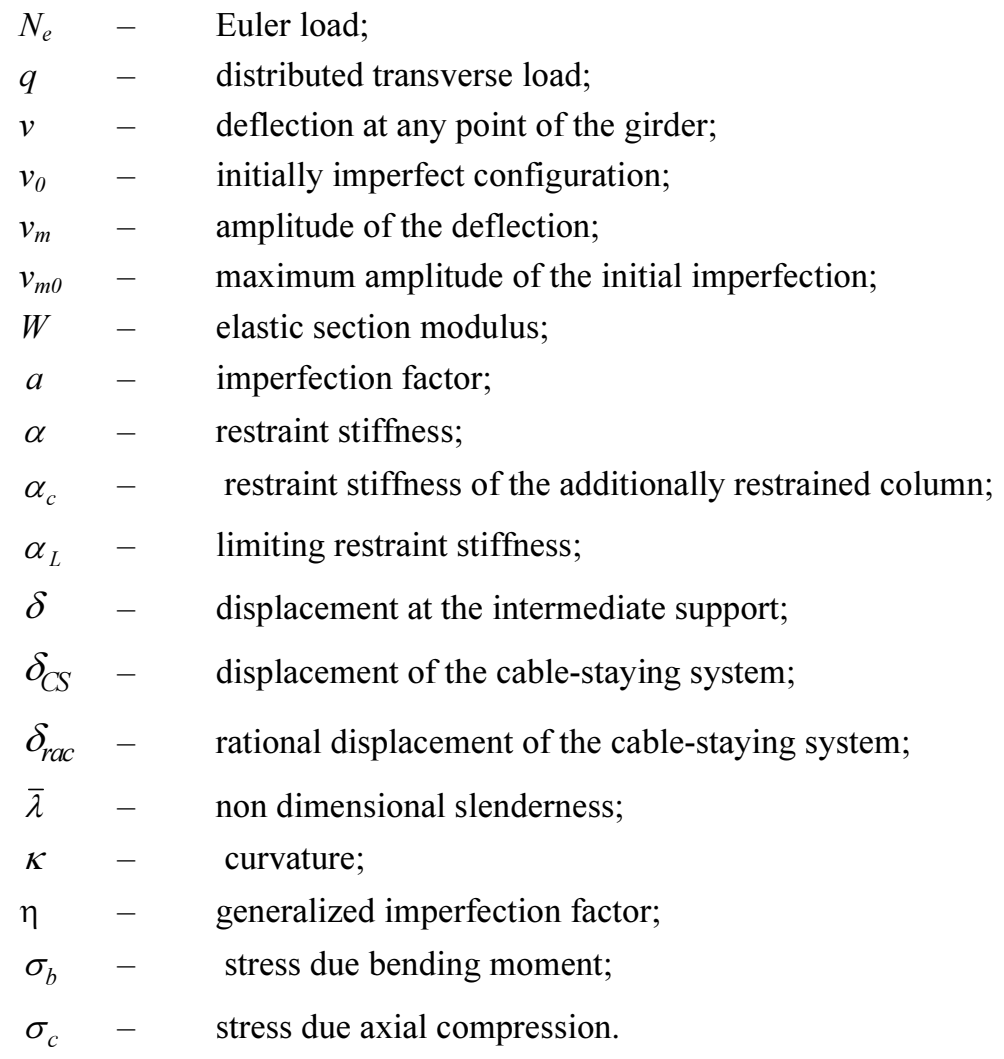

\section{Abbreviations}

$\mathrm{CS} \quad-\quad$ cable-staying;

BCIR - beam-column with intermediate restraint;

$\mathrm{FE} \quad-\quad$ finite element;

GNA - geometrically non-linear analysis

GNIA - geometrically non-linear elastic analysis with imperfections;

LA - linear analysis;

LBA - linear bifurcation analysis;

$\mathrm{RB} \quad-\quad$ rigid beam;

UDCS - under-deck cable-stayed. 


\section{Contents}

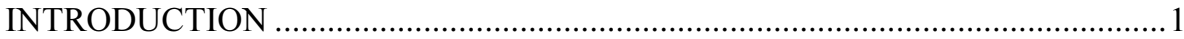

The Investigated Problem ..................................................................................... 1

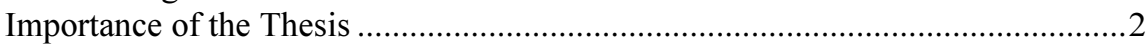

The Object of Research ...................................................................................

The Main Objective of the Thesis .........................................................................

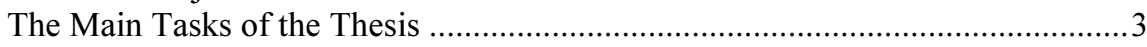

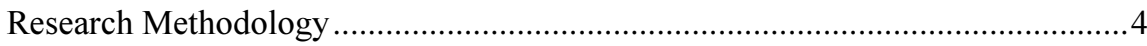

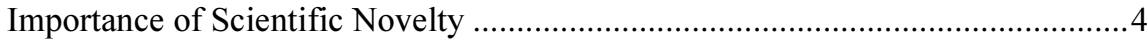

Practical Significance of Achieved Results .........................................................

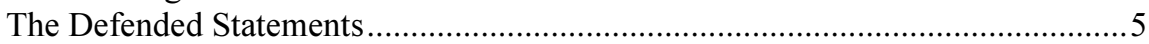

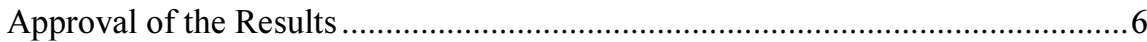

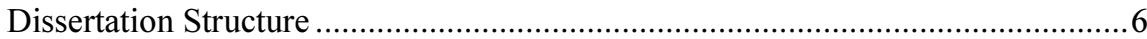

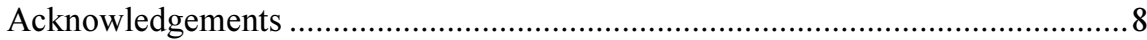

REVIEW OF THE STRUCTURAL BEHAVIOUR AND DESIGN OF UNDER-DECK CABLE-STAYED BRIDGES..................................................

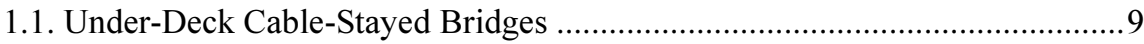

1.1.1. Concept ................................................................................... 11

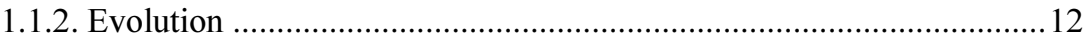

1.1.3. Structural arrangement.................................................................... 14

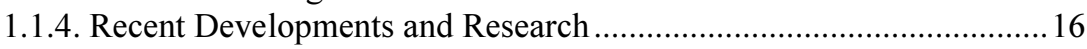

1.1.5. Structural Response and Design Criteria ............................................... 17

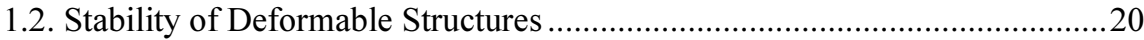




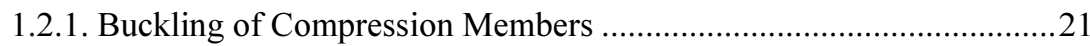

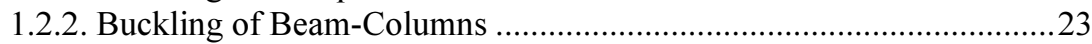

1.2.3. Effect of Intermediate Lateral Restraint.............................................25

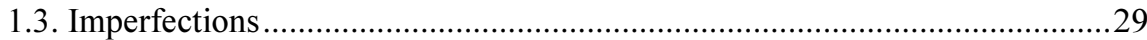

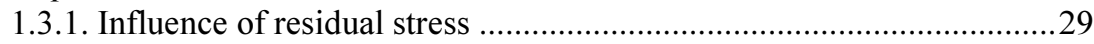

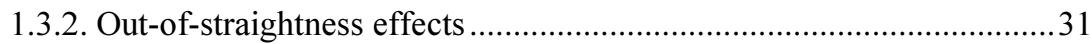

1.4. Concepts for Columns and Beam-Columns Design ........................................33

1.4.1. The Effective Length Concept ............................................................33

1.4.2. Multiple Column Curves Concept …………………............................37

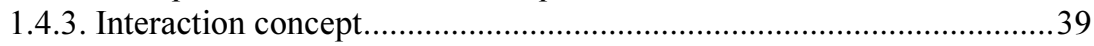

1.4.4. Second-order effects and moments amplification.................................40

1.5. Overall System Buckling Versus Individual Member Buckling ....................42

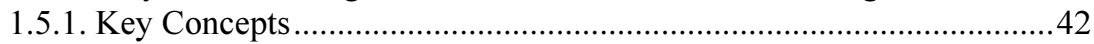

1.5.2. Methods of Analysis ........................................................................... 44

1.6. Advanced analysis for Steel Structures in Current Design Standards ............47

1.6.1. European Standards and Global Analysis ............................................48

1.6.2. North-American Standards and Direct Analysis.................................49

1.6.3. Australian/New Zealand and Canadian Standards ................................50

1.7. Concluding Remarks of Chapter 1 ............................................................50

FORM-FINDING FOR UNDER-DECK CABLE-STAYED STEEL BRIDGE .....53

2.1. Double-Level Cable-Staying System .......................................................53

2.1.1. Structural Schemes of a Rigid Beam .................................................55

2.1.2. Morphology of the Cable-Staying System..........................................57

2.2. Parametric Studies of Elastically Restrained Beam-Column..........................58

2.2.1. Computational Method ..................................................................58

2.2.2. Calculation Model of Elastically Restrained Beam-Column ...............59

2.2.3. Boundary Solutions of Beam-Column ..................................................60

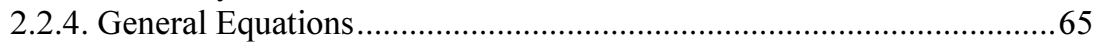

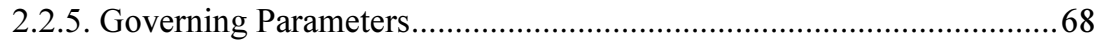

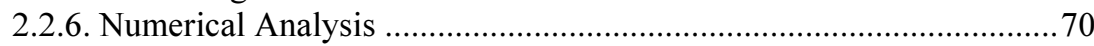

2.3. Parametric Studies of Double-Level Under-Deck Cable-Stayed Bridge........74

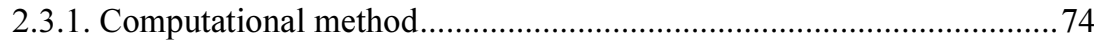

2.3.2. Evaluation of Geometrical Nonlinearities............................................75

2.3.3. Numerical Evaluation ....................................................................... 77

2.3.4. Evaluation of Axial Force .................................................................. 78

2.3.5. Algorithm of Geometrically Nonlinear Analysis for Double-Level Under-Deck Cable-Stayed Bridge .....................................................

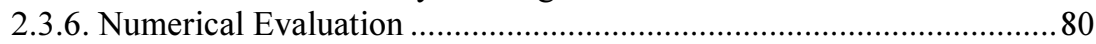

2.4. Comparison Analysis of Under-Deck Cable-Stayed Bridges .........................81

2.4.1. Finite Element Analysis.................................................................... 82

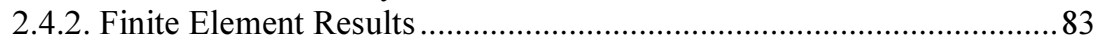

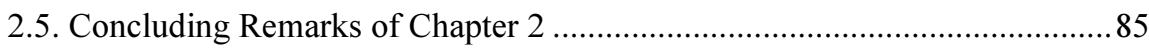


DIRECT STABILITY ANALYSIS AND STRUCTURAL DESIGN OF

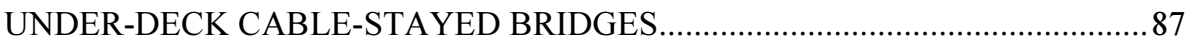

3.1. Direct Stability Analysis of Beam-Column with Intermediate Elastic Restraint .88

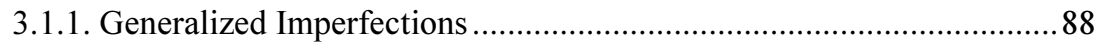

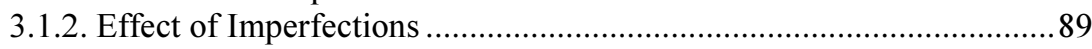

3.1.3. Improvements on Generalized Calculation Model of Beam-Column with Intermediate Elastic Restraint.......................................................91

3.1.4. Governing Equations .....................................................................92

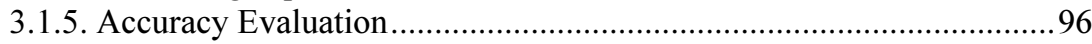

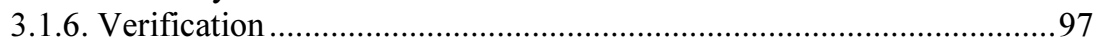

3.1.7. Evaluation of Current Design Practices ................................................99

3.1.8. Evaluation of Buckling Resistance of Beam-Column with Intermediate Elastic Restraint........................................................... 102

3.2. Direct Stability Analysis of Under-Deck Cable-Stayed Bridge .................. 105

3.3. Structural Response Control Analysis of Under-Deck Cable-Stayed Bridge 109

3.3.1. Calculation Model of Simple-Span Under-Deck Cable-Stayed Bridge 109

3.3.2. Linear Evaluation of Structural Response Control ..............................110

3.3.3. Direct Modelling of Structural Response Control ...............................112

3.3.3.1. Accounting for Nonlinearities.......................................................... 112

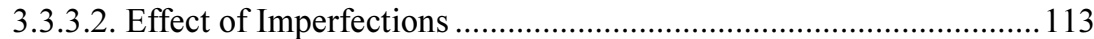

3.3.3.3. Determination of Rational Eccentricity …………………................ 115

3.3.4. Variables for Parametric Analysis ...................................................... 116

3.3.5. Simple-Span Double- Level Under-Deck Cable-Stayed Bridge........ 117

3.3.6. Simple-Span and Semi-Continuous Double-Level Under-Deck Cable-Stayed Bridge........................................................................ 123

3.4. Practical Guidelines for the Geometrically Nonlinear Analysis of Under-Deck Cable-Stayed bridges ............................................................. 127

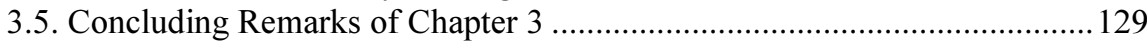

EXPERIMENTAL INVESTIGATION OF UNDER-DECK CABLE-STAYED

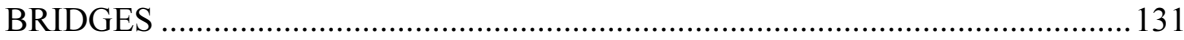

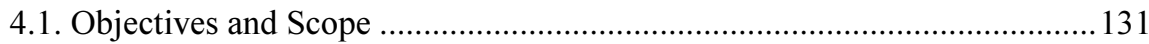

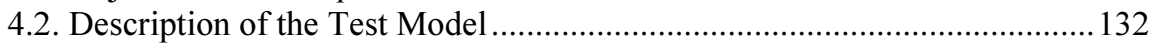

4.3. Loads and Load Combinations .................................................................. 134

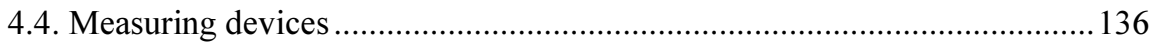

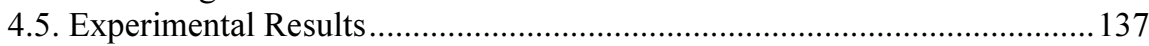

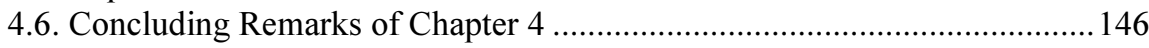

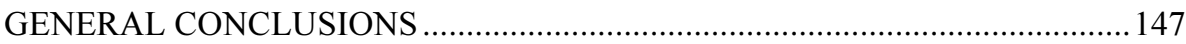

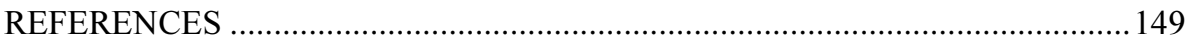


THE LIST OF SCIENTIFIC AUTHOR'S PUBLICATIONS ON THE SUBJECT

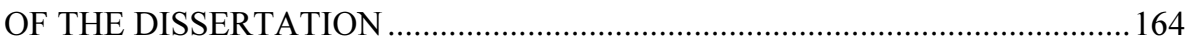

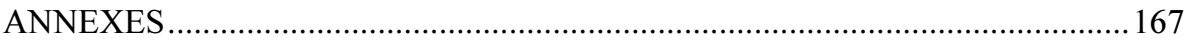

Annex A. Examples of Under-Deck Cable-Stayed Bridges ................................ 167

Annex B. Results of Geometrically Nonlinear Analysis with Imperfections on Elastically Restrained Beam-Column ......................................................175

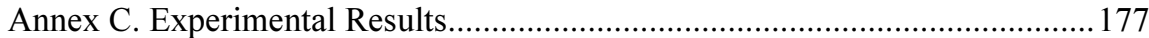




\section{Introduction}

\section{The Investigated Problem}

Bridges stay as the main connections of transportation infrastructure. The architecture of the bridge is not some kind of treatment added to or performs on the structural design of a bridge. The architecture should emerge from and should be given by the bridge's primary function. The function of a bridge is to span physical obstacles for the purpose of providing passage for road users. The form of a bridge must express the basic function. The main task of civil engineers is to find the form which best reflects bridge's function and makes it environmental friendly as refers to aesthetic requirements.

It is frequently the case, especially in the bridge's design that a structure is required to be so slender that is actually no longer suitable for the intended span. Extra abutments could be added, but that is not the intention in the context of today's design of structures, namely, to span a large distance with a structure which is "too slender". Therefore, indirect intermediate supports are the only way of overcoming this problem. The concept of increasing the span with indirect intermediate supports and eliminating the intermediate piers reflects structural form of bridge namely under-deck cable stayed (UDCS) bridge. In UDCS bridges, the stay cables are located below the RB and self-anchored into it. Despite highly efficient structural and aesthetic potential, which has been 
proven by the interest of architects and civil engineers who have taken part into the design of this type of bridge, UDCS bridges have some drawbacks.

Due to direct anchorage of the cable-staying system, RB of UDCS bridge is simultaneously subjected to axial compression and bending. The presents of an effect of axial compression makes it essentially non-linear problem and refers to stability verification. The analysis of steel structures is based upon calculation model and basic assumptions, which reflect the structural behaviour of the considering structure. The calculation model best reflecting structural behaviour of considering structures is beam-column with intermediate elastic supports.

Moreover, design of innovative structures requires application of advanced analysis methods. All leading international design codes contain provisions for Advanced Structural design, but actual use is still limited, primarily because of the lack of practical implementation. The sufficiency of the method cannot be doubted, but as a matter of fact practitioners rarely use it. However, in the absence of a strong background of standardization, the method of Advanced Design remains a possibility and problem of the researchers rather than a practical tool.

\section{Importance of the Thesis}

When under-deck cable-stayed schemes are designed and constructed no specific scientific and technical references are available. To date, there is no consolidated body of knowledge dealing with this type of structure, or at least none that has been clearly set out or presented. This is confirmed by the fact that no books or studies have been published on the subject of the structural behaviour and design criteria of this type of bridge (with the exception of one doctoral thesis in Spanish in 2010) and that only few research papers exist.

This study contributes in development of steel structures and particularly bridges by proposing the new structural forms, providing a better understanding of the complex structural response found in the rigid beam (RB) by means of beam-column elements and practical application of the advanced design methods for considering structures stability verification. It deals with the calculation models which may be widely used for the structural behaviour analysis of the braced steel structures, proposes computational methods for the general solution of nonlinear structural behaviour problems of steel elements subjected to simultaneous bending and compression. Thesis outlines the practical guidelines on stability verification based upon direct method by accounting material and geometrical nonlinearities lately being one of the most considering issue related to steel structures in scientific and engineering society. 


\section{The Object of Research}

The object of present study is in-plane structural behaviour of imperfect steel beam-column elements embedded in UDCS bridge.

\section{The Main Objective of the Thesis}

The main objective is to study structural behaviour and stability verification of the steel beam-columns by considering a new structural arrangement of underdeck cable-stayed bridge.

\section{The Main Tasks of the Thesis}

The accomplishment of the objective involves considering a number of particular tasks that are described in the following:

1. To review structural behaviour of the existing forms and types of UDCS bridges as well as the structural response design criteria and the governing parameters for the verification of the stability of the bridges and their structural elements: rigid beam and cable-staying system separately.

2. To find a new form of steel UDCS bridge and compare it to conventional ones considering both symmetric and asymmetric load cases.

3. To develop computational method for geometrically nonlinear analysis of additionally elastically restrained steel beam-column accounting geometrical and physical imperfections and considering the interaction of bending and axial compression effects.

4. To determine governing parameters and define governing equations for predicting flexural and deformational response of the rigid beam of steel UDCS bridge under case of symmetric and asymmetric loading.

5. To describe the algorithm of an iterative procedure for determining axial response in the rigid beam of steel UDCS bridge.

6. To perform structural behaviour analysis and stability verification using proposed computational method and appropriate calculation model of the beam-column element.

7. To carry out experimental investigation of UDCS bridge model and evaluate the accuracy of proposed computational method.

8. To propose the technique for structural response control of rigid beam of under-deck cable-stayed bridge and determine its limits of efficiency. 


\section{Research Methodology}

The objective of the research was achieved using the following methodology:

- Literature review as outlined in Chapter 1 was undertaken to develop the required knowledge, define the gaps and drawbacks in this research field.

- Form-finding of the UDCS bridge aiming to increase the efficiency of its structural response.

- Structural modelling according the requirements of the Direct Analysis and generalization of the calculation model for the beam-column in UDCS bridge.

- Accounting for geometrical imperfections.

- Evaluating the effect of geometrical imperfections and residual stress by applying generalized imperfection concept.

- Applying FE code ANSYS for geometrically imperfect elements modelling and solving nonlinear problems in order to evaluate the accuracy of the proposed computational method.

- Applying the concept of the equal extreme values of the hogging and sagging moments to obtain rational eccentricity and develop efficient technique for structural response control of the UDCS bridges.

- Experimental investigation.

- Comparative analysis of in order to evaluate the accuracy of the results.

\section{Importance of Scientific Novelty}

The aspects of scientific novelty of theoretical and numerical research of nonlinear structural behaviour of steel RB of UDCS bridge by means of beamcolumn with accounting for initial imperfections and second order effects are as follows:

- As a limited number of researchers on structural behaviour of steel under-deck cable-stayed bridges have been reported so far, new data has been obtained on non-linear buckling and stability verification of such structures. Prior to analysis of the bridge structures, computational and FEM analysis on structural behaviour and stability of beam-column elements with arbitrary support and restraint conditions were performed.

- A computational method has been proposed for deriving governing equations to predict structural behaviour and verify the stability of UDCS bridge using generalized calculation models of beam-column elements. The proposed method based on the requirements of the direct 
method (i.e. effect of deformed geometry and geometrical and material imperfections) for steel structures advanced analysis. To account for a deformed geometry effect, the governing equations derived using equilibrium equations by applying moderately large displacement theory and for simulation of geometrical and material imperfections generalized imperfection concept was applied.

- An efficient computational technique has been proposed for structural response control analysis of simple-span UDCS bridge.

\section{Practical Significance of Achieved Results}

The practical significance of the achieved results research embodies:

- Generalized calculation models of beam-column elements, which could be used for simulation various engineering problem of steel braced structures for both computational and computer-aided analysis.

- Outlined practical guidelines for application of Direct Analysis Method performing both computational and computer-aided analysis on steel structures and individual elements.

- Detailed implementation of geometrical and material imperfections by applying generalized imperfections concept for computational estimates, as well as FE simulations in commercial software.

- Proposed efficient technique for the achievement of efficient bending moment's distribution in the simple-span additionally supported steel structures what reflects to economical aspects of steel structures and especially bridges design.

\section{The Defended Statements}

The following propositions based on the results of the present study may serve as the official defending statements:

1. New form of UDCS bridge stays on triangle cable-system elevation and solves the problem of unacceptable deflection shape under the case of asymmetric loading.

2. The proposed computational method eliminates the effective length and limitations of eigenvalue analysis for steel structures design.

3. The developed computational method for structural behaviour analysis of beam-column elements with intermediate elastic restraint takes into account initial imperfections. 
4. Developed generalized calculation model of the beam-column element with intermediate restraint is relevant due to generalization of calculation models of column with intermediate elastic restraint and beam-column with rigid intermediate restraint as superposition is irrelevant solving essentially nonlinear problems.

\section{Approval of the Results}

6 papers focusing on the subject of the discussed dissertation are published: one paper - in the Thomson ISI register (Misiūnaitè, Daniūnas and Juozapaitis 2012), one paper - in the journal quoted by Inspect data base (Misiunaite, Juozapaitis, Merkevicius 2013), one paper - in conference material in Thomson ISI data base (Misiunaite, Juozapaitis, Daniunas 2013), three papers - in material reviewed during international conferences (Misiunaite, Juozapaitis 2012 and 2013). 4 presentations on the subject have been given in conferences at international level:

- Eleventh international conference "Computational Structures Technology" 2012 Dubrovnik, Croatia;

- Seventh international conference "Structural Engineering and Construction (ISEC-7)" 2013 Honolulu, US;

- Eleventh international conference "Modern Building Materials Structures and Techniques (MBMST)" 2012 Vilnius, Lithuania;

- Fifth international conference "Structural Engineering, Mechanics and Computation (SEMC)" 2013 Cape Town, South Africa.

\section{Dissertation Structure}

Dissertation excluding annexes consists of 164 pages, within the text 111 numbered formulae, 63 figures and 18 tables used. Dissertation refers to 211 references.

The dissertation is structured around 4 main chapters, General Conclusions and 3 Annexes. Figure 1 sketches the structure of the dissertation. Chapter 1 reviews literature related to the investigating problem.

Chapter 2 develops new structural arrangement for Under-deck cable-stayed bridge and presents innovative computational method for its structural behaviour and stability analysis. Chapter 3 presents the improvements on innovative computational method and calculation model of elastically restrained beamcolumn described in Chapter 2 by performing geometrically nonlinear analysis with imperfections (GNIA) and giving practical employment of Direct Method 
(reviewed in Chapter 1). Additionally, the structural response technique for structural response control of UDCS bridges has been proposed.

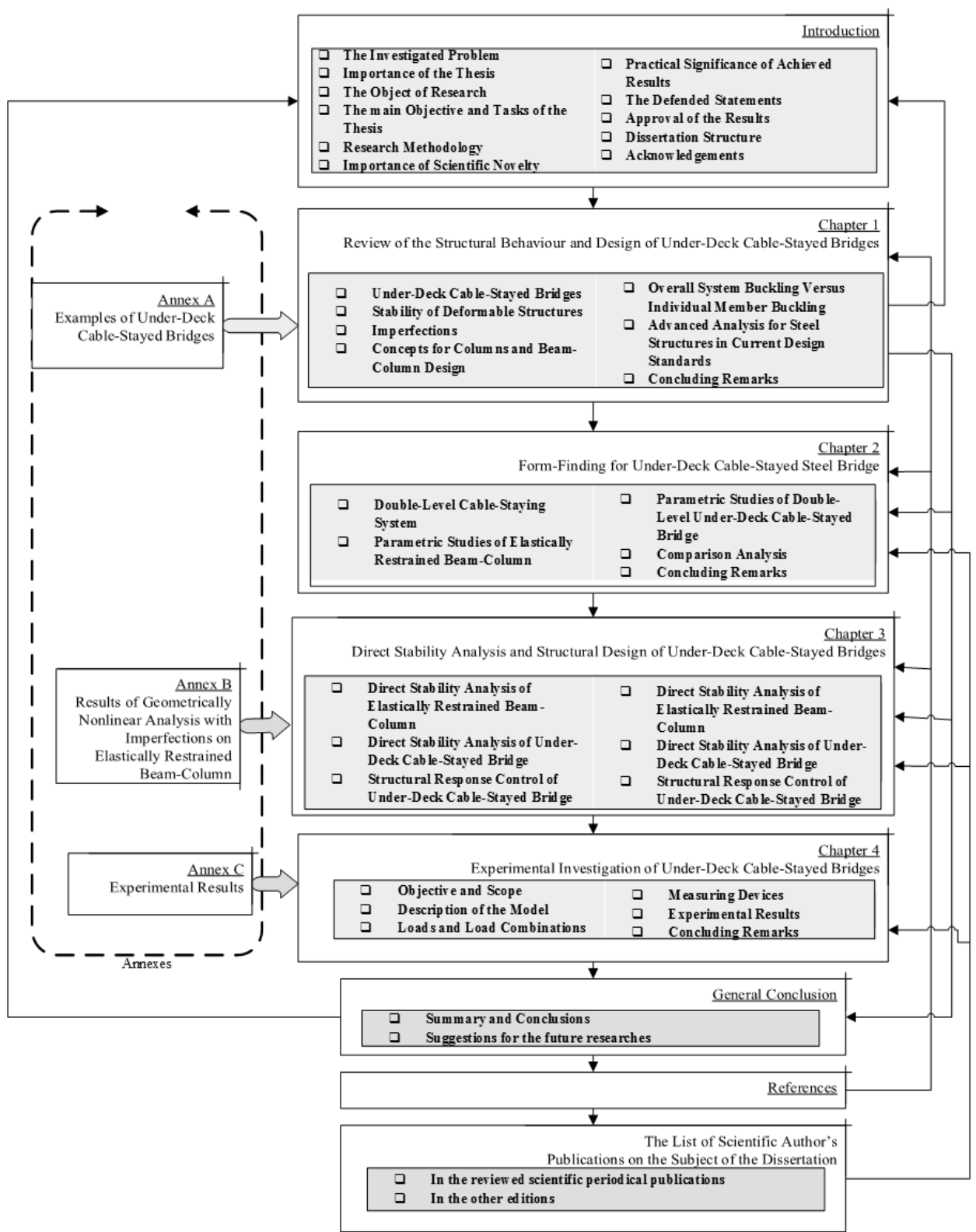

Fig. 1. Dissertation structure 
Chapters 4 present objective, tasks, methodology and results of the experimental investigation of the three scale UDCS bridge model. General conclusions and recommendations for further research summarises the present study. It is followed by the list of references and scientific author's publications on the subject of the dissertation.

\section{Acknowledgements}

The author expresses her sincere gratitude and acknowledgement to her supervisor, Professor Algirdas Juozapaitis, Professor of the Department of Bridges and Special Structures of Vilnius Gediminas Technical University and Dean of the Civil Engineering Faculty, for providing a guidance and assistance along the way.

Special gratitude and thanks is given to Professor Kim Rasmussen, Head of School of Civil Engineering and Chairmen, Centre for Advanced Structural Engineering of University of Sydney, for his help and friendship during the internship at University of Sydney.

The countenance and assistance provided by Laurynas Kentra is sincerely acknowledged.

The author expresses sincere gratitude to the Research Council of Lithuania that has provided her with the financial support. 


\section{1}

\section{Review of the Structural Behaviour and Design of Under-Deck Cable-Stayed Bridges}

This Chapter reviews the concept of under-deck cable-stayed bridges, evolution, structural arrangement and parameters governing the differences of considering bridge elevation. Moreover, presents currently performed researches on the structural response analysis and governing parameters of the considering bridge. Different approaches described considering deformational behaviour of the rigid beam. Various calculation models of the column and beam-column elements with arbitrary support conditions discussed with regard to non-linear buckling problem. Current steel structures Specifications considered regarding methods incorporated for the stability verification of structures as whole and their independent parts by means of beam-column elements. This Chapter concludes in the defining of the main objective and tasks of the present research.

\subsection{Under-Deck Cable-Stayed Bridges}

Under-deck cable stayed bridge (UDCS) is the term that has been coined to describe structure formed by deck, in this case particularly, rigid beam and the 
unconventional placement of supporting system. There is no agreement on the term to be used for this type of bridges in the literature. Besides UDCS the same structural type could be named as underslung beam bridge (Schulitz 2000), underspanned suspension bridge (Peters 1987, Brawn 2005) or bridges suspended by prestressed tubes (Muttoni 2002). The term which is going to be used in this study first was proposed by Ruiz-Teran and Aparicio (2007a) and the best reflects the concept of the structure. The bearing structure consists of $\mathrm{RB}$ which serves as a deck and supporting system placed below it. Supporting system is formed of the cable-stays which are not necessary supposed to be cables it could be steel bars or very slender steel strips or even profiles and the struts. In the study of Ruiz-Teran and Aparicio on UDCS bridges it was stated that cables supposed to be prestressed for self-anchored under-deck suspension bridge to become a UDCS bridge. In this study which focuses particularly on the steel bridges cable-stays have not necessary supposed to be prestressed, they just have to keep their straight position contrary to sagging cables of the suspension bridge.

Recently, the form-finding of bridge design and the analysis of structural behaviour have been highly considered. The development of new forms encouraged the implementation of innovative steel and reinforced concrete bridges (Troyano 2003; Virlogeux 1999; Nakamura et al. 2002, 2009). Subsequently, there are a significant number of the new forms of footbridges (Fib 2005) among which suspension and cable-stayed bridges (Strasky 2005) appear as highly efficient. Form-finding is an incessant process causing continuity in bridge design applying it for innovative bridges (Tanaka et al. 2002; Rohde-Babarigos et al. 2010; Juozapaitis et. al. 2006, 2010; Sandovič et al. 2011).

If to examine the reasons for constructing bridges with unconventional layout of cable-staying system, it would be found the following four trends (Ruiz-Teran and Aparicio 2007a):

- Elimination of piers in viaducts (Weitingen viaduct, Roxburgh Viaduct, Losa del Obispo and Osormort bridges).

- Supporting the deck by means of cable-staying system and to obtain the required length of the span with the lighter structure than using conventional elevation of cable-stayed bridges, thus gain economical efficiency in foundation construction (Tobu recreation resort footbridge), use lighter self-launching form carriers (Osormort bridge), or decrease the seismic actions, for example with the proposal for the Vinalopo River bridge (Rui-Wamba et al. 1991) and Torizaki footbridge (Kamazawa et al. 2002). 
- Design of structures by means of emphasizes their aesthetic application through the use of cable-staying system (Jumet, Miho Museum, Zauthaven, Waschhaussteg, and Hiyoshi footbridges).

- Design of structures with the minimum visual impact on the environment (Living bridge).

- Construction of bridges over deep valleys (Takehana Bridge) or wide rivers (Glacis bridge) without requiring falsework.

Furthermore, Sir Ove Arup said, "A bridge is architecture with a clear and simple formulated function" (2009). It supposes to be obvious but is all too often forgotten in attempts to find more expressive forms of the bridge. The general concept for bridge design is that simplicity is beautiful. The bridge should clearly show how it works and impact on overall feeling of stability (Norris 2010). The UDCS bridges fulfil these requirements through their clear structural arrangement and efficient structural behaviour.

\subsubsection{Concept}

The structural system used for the under-deck cable-stayed bridge is as early as the beginning of the $19^{\text {th }}$ century. Due to the technological improvement in the field of prestressing elements and high structural efficiency, this structural concept has regained significance in the recent years. The concept of the simple under-slung supporting system was first presented in 1819 by the architect Friedrich Arnold in his book "Manual for the wooden structures design with regard to the bridge construction" (Muttoni 2002). At the same time the underslung system has been adjusted for the suspension steel bridges. This sequent development in conventional suspension bridge design refers to the possibility of eliminating intermediate piers.

Many bridges are, structurally speaking, beams, this study is performed on this point of view. It is frequently the case, especially in the light structures design, that a beam is required to be so slender that is actually no longer suitable for the intended span. The common solution of the increasing the depth of the cross-section is not desirable, thus intermediate supports are the only possible alternative. Extra piers or other kind of abutments could be added but that is not the intention in the context of today's design of structures, namely, to span a large distance with a beam which is "too slender". Therefore, indirect intermediate supports are the only way of overcoming this problem (Shulitz 2000).

One or more supports to the beam may be provided by adding hangers or struts, in tension or compression respectively which in turn are held in place by a subsystem subjected to tension or compression. In the case of prototype of 
UDCS bridge consider the beam with additional struts in compression and subsystem subjected to tension respectively. This subsystem is anchored back to the beam itself, thus embodying closed system of initial forces. When applying the external loads beam deflects due to bending and initiates tension in subsystem, which in turn determines the compression in the beam. The analysis and design of elements considering axial compression as one of the effects makes it essentially a non-linear problem, in which axial force participation in flexural response need to be considered (Bay and Loureiro 2001).

\subsubsection{Evolution}

The principle of carrying loads by suspending a rope, chain or cable across an obstacle has been known since ancient times. However, it was not until 1820 that the first new type of suspension bridge for crossing the River Almond at Crammond, North West of Edinburgh was designed by British engineer Robert Stevenson. It wasn't constructed but the concept led to the development of the self anchored under-spanned suspension bridge principle, and by 1850 numerous small-span bridges were constructed to this basic plan in Britain, some of them still remain. Roxburgh Viaduct (also called Teviot Viaduct) was built across the River Teviot by the North British Railway in 1850. Roxburgh Viaduct, which no longer carries trains, is notable for the principle of unconventional position of supporting system. The Viaduct's four river piers are extended to one side to support a low-level footbridge, of a type which while supposedly once common, has very rarely survived.

Principle proposed by Stevenson was one of the experimental variants abandoned in the course of the early development. Underspanned suspension bridge is similar in appearance to the underspanned beam. However for the first attempts to design this type of structures the lower tension cable was anchored in a separate abutment rather than self-anchored to the deck (see Fig. $1.1 \mathrm{a}$ )). The suspension bridge supported by cables or chains under the deck was abandoned around mid-nineteenth century because the closely related underspanned beam did not need expensive anchorages. However, it would still be viable for long span bridges over deep gorges. The type intrigued French engineer Guillaume Henri Dufour, and he designed four such bridges, two of which were built. The Bergues Bridge of 1834 over the Rhone in Geneva and the Coulouvreniere Bridge over the city rampart of 1837 were the two that were built, while daring proposals for the La Caille Bridge in 1823 and Fribourg Bridge in 1825 remained projects.

Underspanned suspension is a type of bridge which is much under-used, although there are a number of very modern examples (Ganmon, Ayumi, 
Johnson Creek, Limerick, Jumet bridges and etc, see Annex A). Starsky's book (2005) on stress ribbon bridges features several unconventional cable-stayed bridges, mostly in Japan (Morino-Wakuwaku, Tobu, Inachu, Ganmon, Ayumi), and a recent papers by Ruiz-Teran and Ruiz-Teran Aparicio (2010, 2007a and 2010) survey a number of others.

For almost a hundred years of bury in oblivion underspanned suspension bridge revives as a new type but the same concept of bridge in 1978 as Weitingen Viaduct designed by German engineer Fritz Leonhard. Underspanned suspension bridges can be considered as the predecessor of UDCS bridges. When the cables of underspanned suspension bridge are self anchored in the RB it becomes a self anchored underspanned suspension bridge. In addition, when the RB is very slender, with relatively low flexural stiffness, both bridge types (the self anchored underspanned suspension bridge and the UDCS bridge) become the same bridge type (Ruiz-Teran and Aparicio 2011). The act of selfanchoring the stay cables in the deck in an underspanned suspension bridge significantly changes its structural behaviour. The advantages of self-anchoring are followed of struggles of nonlinear behaviour and difficult response mechanism (Ruiz-Teran and Aparicio 2007b), promoting geometrically nonlinear behaviour. However, when the appropriate design procedure is applied these bridges feature a highly efficient structural behaviour (Ruiz-Teran and Aparicio 2007b).

a)

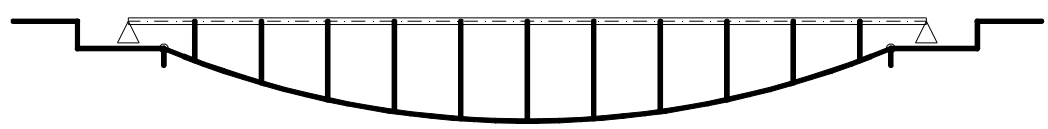

b)

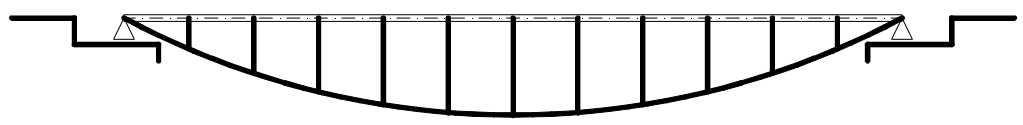

Fig. 1.1. Underspanned suspension bridge: a) earth-anchored, b) self-anchored

It is true that for this type of bridge stability is an issue, and not that many bridges have been constructed in this way, but some have been, and mostly footbridges as they cannot carry such a heavy load compared to the basic design. Recently when aesthetics and structural impact on the environment become principal requirements in the footbridge design UDCS bridges featuring strong aesthetic characteristics (Ruiz-Teran and Aparicio 2008) start to gain leading positions. Aesthetics seems to be a mystery for engineers as it cannot be defined using any design standards or computational methods. In the category of the 
most impressive bridges the first place usually goes for cable-stayed or suspension bridges, though there are examples that UDCS bridges could equally compete with those two. The main advantage of the UDCS bridges is highly effective structural behaviour and easily fulfilled aesthetic requirements. Recently, Arup engineers in collaboration with Wilkinson Eyre architects designed the bridge, which spans the River Shannon at the University of Limerick of the name of Living Bridge. The Living Bridge has been deemed a huge success and has won three awards (Norris 2010):

- the IStructE Structural Award for Pedestrian Bridges;

- the Most Beautiful Steel Bridges Category French Steel Construction Syndicate; and

- Association of Consulting Engineers of Ireland, ACEI, 2008 Bridge Award.

\subsubsection{Structural arrangement}

As described in Chapter 1.1., a UDCS structure is formed by slender deck by means of RB that is supported by cable-staying system self anchored in the RB directly and deviated by struts (see Fig 1.1). Therefore the elevation of the bridge can have a different arrangement corresponding to the number and position of the struts. The bridge can have one or more spans. The most common UDCS bridge system has one span, though referring to the concept of the bridge it becomes a semi-continuous one.

It is possible to design a multi-span structure. But, for the economical reasons, this solution makes sense only in combined under-deck cable-stayed and cable-stayed structure. In continuous bridges (Ruiz-Teran and Aparicio 2008b) UDCS systems are not efficient, when they are designed with eccentricities that are suitable from an aesthetic point of view. The lack of eccentricity of cable-staying system in UDCS bridges at the supporting sections courses the moment resistance to be relieved by flexural response of the RB, thus arising a large hogging moments in the RB (Ruiz-Teran 2010). In order to increase the efficiency of the cable-staying system it is necessary to provide the cable-staying system layout with eccentricity at the support sections, thus finding the combined cable-stayed bridges.

Classical UDCS structures have continuous spans that are supported by one or number of struts and cable stays joining them (see Fig. 1.2). The struts can be vertical or inclined as shown in Figure 1.2. At least one strut is needed for the deviation of cable stays and for the design of mono-strut cable staying system having the form of triangle. With increasing the number of struts the layout of the cable staying system gradually changes from triangle to polygonal and 
finally to parabola. The length of sub-span depends on the number of struts. The optimum sub-span length of the side sub-spans is usually less than the main subspan.

The stay cables can have different arrangement, as shown in Figure $1.2 \mathrm{a}$ ), b), e) and i). While a statically superior radial arrangement (see Fig. 1.2 d)) causes structural difficulties because the stays have to be anchored at the one point, a statically less advantageous polygonal arrangement (see Figs $1.2 \mathrm{e}$ )-h)).

a)

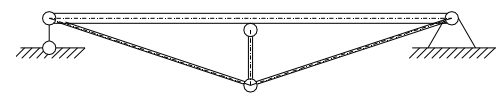

c)

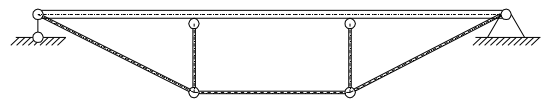

e)

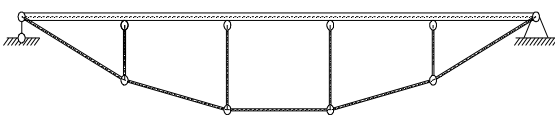

g)

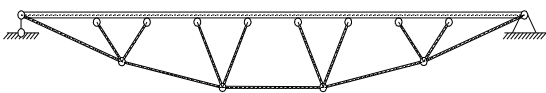

i)

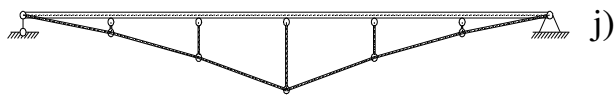

b)

d)

f)

h)
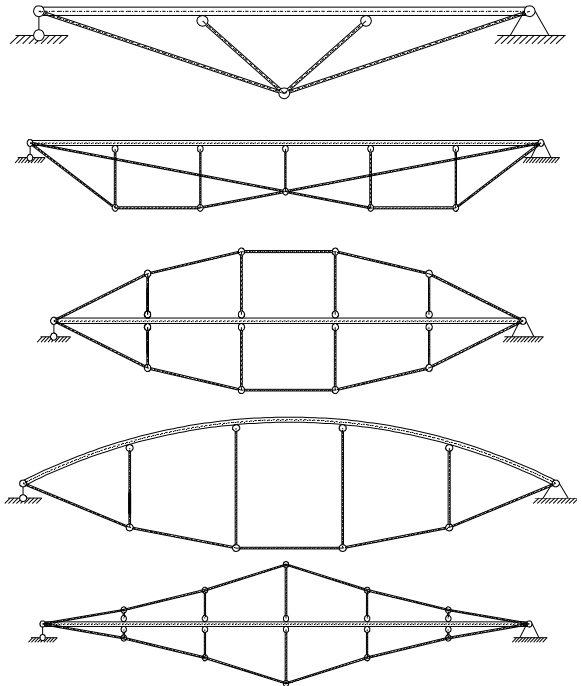

Fig. 1.2. Structural arrangement of one span UDCS bridge

It is possible to support a sub-span and form the simple spanned UDCS structures as shown in Figure 1.3. For the case of simple spanned structure the additional stay cables are needed (compare Figs. $1.2 \mathrm{~h}$ ) and 1.3), that the bridge remains stable. This arrangement is more suitable for the case of passive structural response control as described in Chapter 3.3, and normally just cause the difficulties when designing the joints.

a)

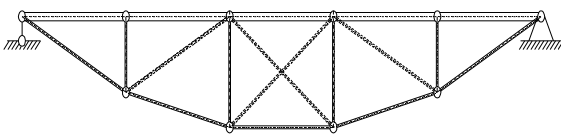

b)

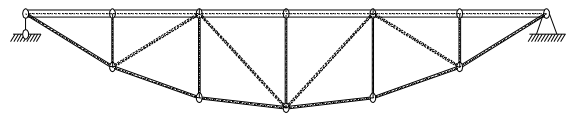

Fig. 1.3. Structural arrangement of simple-span UDCS bridges 


\subsubsection{Recent Developments and Research}

Despite functionality and successful practical implementation (Norris 2010, Tsunomoto and Ohnuma 2002, Holgate 1997, Cazet 1992, Schlaich and Werwigk 2001, Watanabe 2002) from a design point of view UDCS bridges still remain incompletely explored engineering problem. A significant contribution to this case was made by Ruiz-Teran and Aparicio. Studying the unconventional cable-stayed bridges Ruiz-Teran presented a PhD thesis (2005) on such type bridges structural behavior and design criteria. Supervised by professor Aparicio researcher declared the state of art of two new types of bridges known as underdeck cable-stayed bridges and combined cable-stayed bridges (2007a), obtained the governing parameters and analyzed structural behavior of considering bridges (2007b, 2008a, 2008b). Moreover, some attention was paid to the issues related to the dynamic behavior by means of amplification factors (Ruiz-Teran and Aparicio 2007c), accidental breakage of stay cables (Ruiz-Teran and Aparicio 2009a) and vibration (Ruiz-Teran and Aparicio 2009b). Before research of Ruiz-Teran and Aparicio the issues addressed to the structural behavior of the UDCS structures concern mostly the externally prestressed concrete slabs or beams (Menn and Gauvreau 1987, Virlogeux et al. 1994, Harajli et al. 1999, Aravinthan et al. 2005, Fürst and Marti 1999, Lou et al. 2012). However, there are some works performed by Muttoni (1997, 2002) drawing attention to the novelty of an unconventional position of the cablestaying system. It should be noted that, in most of these studies, structural behavior of the deck is analyzed by means of prestressed concrete element. This study considers the deck of the bridges as RB by means of steel beam-column element. The particular case of steel UDCS structures was mostly considered with the approach of roof beam-string structures (Juozapaitis and Kvedaras 1999, Wu 2008, Xue and Liu 2009, Saitoh and Okada 1999).

Very few studies have been conducted with regard to unconventional cablestayed bridges. Some of those are based on experimental tests performed in connection with attempts to increase the eccentricity of active reinforcements in the beams having external prestressing (Menn, Gauvreau 1990; Umezu et al. 1998; Aravinthan et al. 2005; Zhang, Fu 2009). Other authors deal with these structures as new structural types maintaining their own identity (Laffanchi, Marti 1999; Muttoni 2002; Saito, Wadee 2009; Park et al. 2010).

Muttoni (2002) identifies the influence of the morphology of the structure and the number of struts on reducing bending moments in the deck due to live load compared with that for a bridge without stay cables. Ruiz-Teran and Aparicio (2007a, 2010) presents the state of art and parameters governing the response of under-deck cable-stayed bridges. There is a possibility of applying 
the control of passive behaviour described by Michalopoulos et al. (2005) by prestressing stay cables.

\subsubsection{Structural Response and Design Criteria}

Ruiz Teran and Aparicio have established a full set of design criteria and guidelines for UDCS bridge type (Ruiz-Teran 2005, Ruiz-Teran and Aparicio 2008a, 2008b, 2009a). The design criteria and structural response embody both aspects related to structural arrangement of this type of bridges (such as: structural elements; suitable number, location, orientation and geometry of the discrete structural elements, as well as the connections between the discrete structural elements; etc.) (Ruiz-Teran 2010) and the loading conditions, mostly referring to symmetric or asymmetric distribution of transverse force (See Fig. $1.4)$.

a)

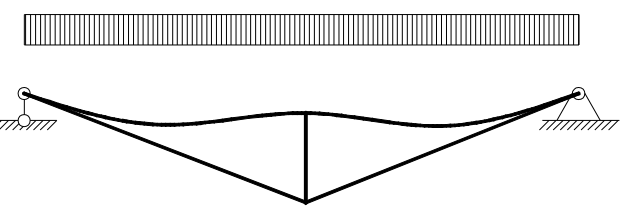

b)
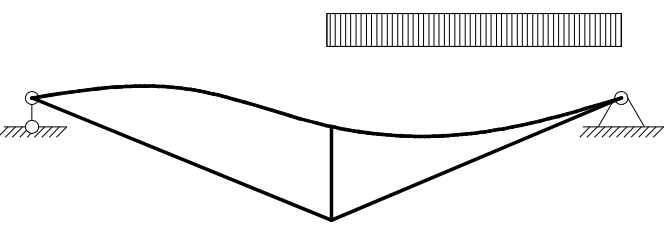

c)

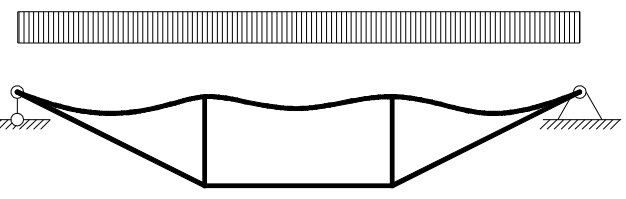

d)
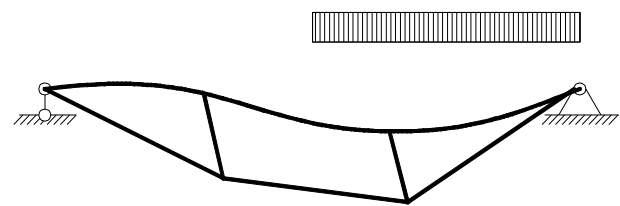

Fig. 1.4. Deformational response of UDSC bridge: a) with one strut under symmetric loading; b) with one strut under asymmetric loading; c) with two struts under symmetric loading; d) with two struts under asymmetric loading 
The number of struts not just makes significant changes on the elevation of the UDCS bridge but influences its structural behaviour a well. A. Muttoni investigated that the number of struts has the big influence on the stress distribution in the RB of the UDCS bridge and, at the same time also on the constructive complexity of the load-bearing structure. As regards dead loads cause additional struts to reduce effective span of the bridge, so that the bending stress of the RB gradually decreases.

In the specific case of an UDCS bridge with three struts, a particular arrangement and arbitrary support conditions, which prevent deck from the axial shortening, Lemaitre and Kobler (2005) show that the axial response of the structure is determined by a function that depends exclusively on two parameters (Ruiz-Teran and Aparicio 2007b):

$$
f\left(\frac{E I}{E_{S C} A_{S C} L^{2}}, \frac{L_{S}}{L}\right)
$$

where $E I$ is the flexural rigidity of the deck; $E_{S C} A_{S C}$ is the tensile rigidity of the stay cables; $L$ is the span of the bridge; and $L_{S}$ is the length of the strut at the mid-span. Ruiz-Teran and Aparicio (2007b) obtained the parameters that govern the response of UDCS bridges in general for both one strut and multiple struts types of structures.

Previously, Muttoni obtained that in the case of the plastic design of the RB, the bending stress is proportional to (Muttoni 2002):

$$
\frac{1}{(n+1)^{2}}
$$

Where $n$ is a number of the struts.

Figure 1.5 presents the graphical interpretation of the relation between bending stress and number of struts obtained by Muttoni.

Under variable loads, and especially in the case of concentrated loads, the effect of the additional struts on the loads reduction is well represented in Figure 1.5. In Figure $1.5 \mathrm{~b}$ ) three different arrangements of struts presented: a) fixed connections between struts and RB; b) hinged connections between struts and $\mathrm{RB}$; c) hinged connections between inclined struts and RB. With increasing the number of struts and decreasing the length of the sub-span the redistribution of bending moments is increased and thus the value of the bending moment decreased.

Self-anchoring of stay cables in the deck determines two response mechanisms in the under-deck cable-stayed bridge: the axial response (tension of the stay cables and compression of the rigid beam and the flexural response 
(bending of the rigid beam) as shown in Figure 1.6. In their study Ruiz-Teran and Aparicio investigated that in the case of concrete deck of the under-deck cable-stayed bridge if the axial response is reinforced and therefore the flexural response is reduced, much slender structures can be built (2007b).

a)

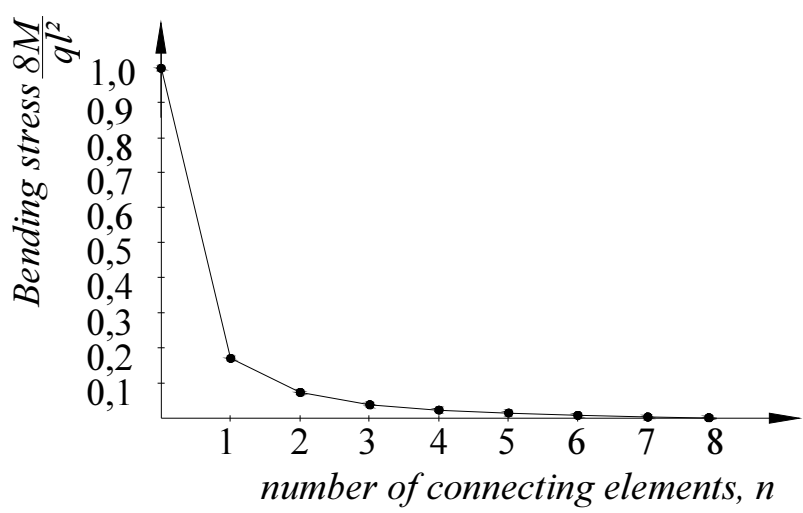

b)

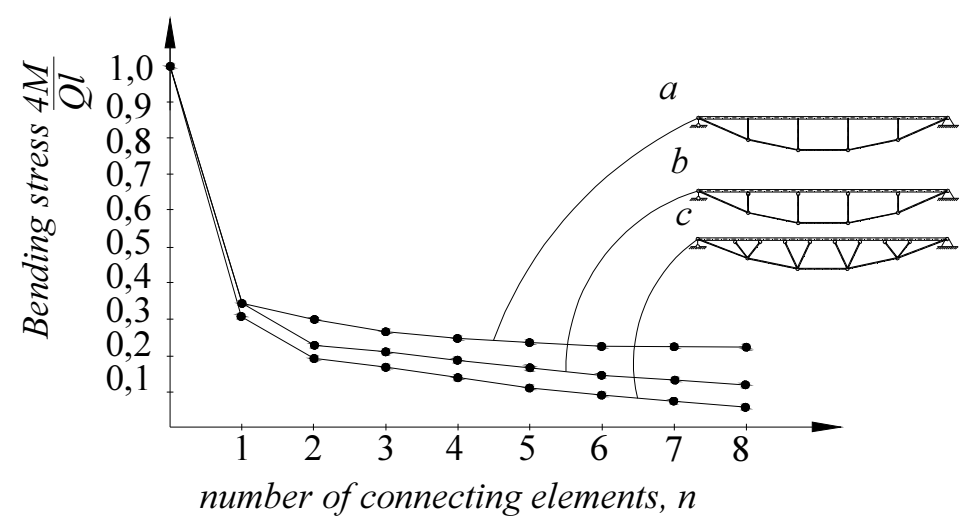

Fig. 1.5. Bending stress of RB according to plastic design as function of the number of connecting elements ( $n=0$ represents the girder without suspension): a) uniformly distributed dead load; b) concentrated service load Q (Muttoni 2002)

In Figure 1.6 moment resisted by the deck $=\mathrm{M}$ and refers to flexural response, moment resisted by the stay cables $=\mathrm{H} \mathrm{x}$ (strut length) and reflects axial response, thus isostatic moment at the mid-span is equal to the sum of the moment resisted by the deck and moment resisted by the stay cables. 
a)

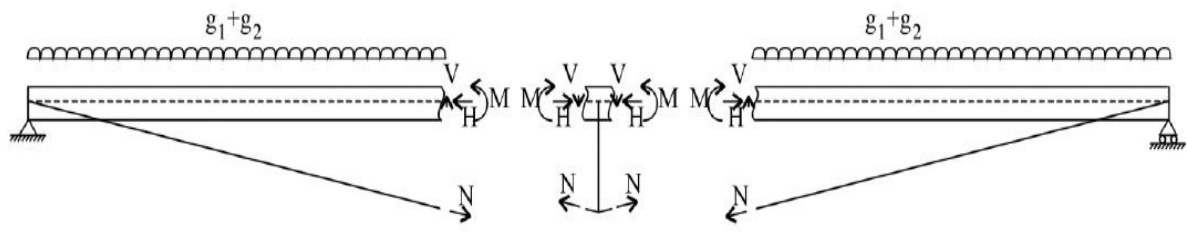

b)

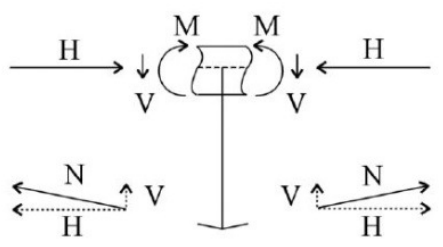

Fig. 1.6. a) Response mechanisms of an UDCS bridge; b) amplification (RuizTeran and Aparicio 2007b)

The compressive force in the RB makes analysis of structural behaviour of the UDCS bridge essentially nonlinear problem.

\subsection{Stability of Deformable Structures}

In the design and analysis of steel structures, stability is an important consideration. The modern use of steel in engineering structures, especially in bridges has made elastic stability a problem of great importance. Vital practical requirements have given increase in recent years to extensive investigations, both theoretical and experimental, of the conditions governing the stability of deformable structural elements.

Allowable stress design codes control the stress which may be not be the key parameter for failure due to stability which depends more on Young's modulus.

For tension and very short columns, the stress is proportional to load and the failure is equal to the yield stress area. For members under compression, the failure load is less than plastic load or squash load. This is due to buckling.

The term buckling is used loosely in the literature. In some cases, it is strictly associated with bifurcation, while in others it indicates a rapid change of geometry as the load approaches a critical value, and such may be used both in the context of bifurcation and snap behaviour, as well non-linear behaviour. While "buckling" thus has several meanings, the focus of this study is on buckling by meaning of member losing the state of stable equilibrium or unstable equilibrium. 


\subsubsection{Buckling of Compression Members}

Structural elements that are subjected to axial compressive forces only are called columns. The strength and behaviour of columns is one of the longest lasting, continuous research endeavours in the fields of structural engineering (Bjorhovde 2010). From the classical studies of Euler, Tredgold, Tetmajer, Considere, Engesser, von Karman, Shanley and others until today (Johnston 1981), the level of knowledge has advanced from understanding the characteristics of the elastic member to the current treatment of columns with material and geometric nonlinearities.

A variety of column strength formulas have been developed over the years, being based on theoretical models or the results of column tests or combinations thereof. Some of these have appeared in design codes (also referred to a specifications or standards in this chapter), but most have not survived the tests of time and usefulness. However, even the most advanced of some of these approached have suffered from certain drawbacks, whether caused by complexity in formulation, limited applicability or consistency from all types of members, or any number of other reasons.

In the late $60 \mathrm{~s}$ and early $70 \mathrm{~s}$ the "political" question of the steel structural research was the column problem. The industry and the academic groups investigated a lot into the laboratory tests of compressed columns. On the base of many hundreds tests the research community had agreed to use the buckling curves established by ECCS. The curves were verified by numerical computations using a Monte Carlo method (Strating and Vos 1973). The Eurocode 3 implemented the reduction factor called Rondal-Maquoi formula.

The basic mechanistic models of column strength and behaviour have been categorized by Bjorhovde (2010) as follows, in ascending order of complexity:

i. Individual pinned-end column, initially curved, inelastic material and/or structural response, incorporating residual stress, for example.

ii. Individual column with restrained ends, initially curved, inelastic material and/or structural response, incorporating end restraint developed by members that frame into the column, for example.

iii. The column is no longer an individual element, but part of a planar sub-assemblage of the structure. This consists of the member itself, with initial curvature, and at least the immediately adjacent columns in the frame (above and below or in the same story). Actual end restraint effects may be taken into account by using the properties of actual connections, although the original model used rigid joints (Julian and Lawrence 1959; Galambos and Surovek 2008). 
iv. The column is one of the elements of the original planar structure, including all of the individual effects. The overall stability influence of framed and leaning columns is accounted for in this model.

v. The column is part of a three-dimensional sub-assemblage, which incorporates end restraint, initial curvature and inelastic response characteristics, failure may occur as flexural buckling about any axis, or as flexural - torsional buckling.

vi. The column is one of the elements of a three-dimensional frame. The model encompasses all conceivable strength and stiffness parameters, including the influence of leaning columns.

Model i was used by Euler for his classical solution. Model ii is that of the Engesser and Considere tangent modulus formulation, and Model iii was the state-of-the-art in the early 1970s (Bjorhovde 1972; Johnston 1981; Galambos 1988, 1998; Ziemian 2010). Various forms of Model iv were developed through an intensive, international research effort in the 1980s that led to realistic modelling and quantification of the restraint effects, including criteria for code implementation and design (Jones et al. 1980; Sugimoto and Chen 1982; Bjorhovde 1984; Bjorhovde et al. 1988, 1992).

Common to Model $\mathrm{i}$ through iv is the fact that they provide detailed theoretical solutions for the column strength, and the influences of the strength parameters are covered explicitly.

Model $\mathrm{v}$ through viii reflects progressively more accurate, but also significantly more complex approaches to the evaluation of the stability of columns as part of frameworks. In its original form, Model $\mathrm{v}$ was developed as an idealized, elastic buckling solution for a three-story column, with beams framing into the member with rigid connections (Julian and Lawrence 1959; Galambos 1988; Galambos and Surovek 2008). Using a slop-deflection analysis, the characteristic equation for the column as part of the sub-assemblage was obtained for the sway and non-sway cases. This led to the development of the well-known K-factor or effective length alignment chart (nomograms), which have been used extensively in design.

A number of studies examined the Model $v$ solution of Julian and Lawrence (1959), assessing the effects of the assumptions that had been made. For example, Yura (1971) modified the elastic treatment to take into account inelastic buckling; this led to the formulation of the concept of the inelastic Kfactor. Combined with the restraining effect of columns and the appropriate stiffness of beams and the far end support conditions, Johnston (1966) formulated a much-improved solution for columns in frames, and Yura expanded on this approach. This has since been expanded significantly (Hellesland and Bjorhovde 1996a, 1996b). 
Last, but by no means least, Yura (1971) defined the concept of leaning columns, and provided a solution that considered their influence on overall frame stability. This has become increasingly important as a result of refinements in structural analysis techniques and computational equipment, as well as the advent of limit states design. Contemporary design codes take these influences into account through the so-called Direct Analysis Method (AISC 2005a; CSA 2009; CEN 2005).

In the last several years, a number of studies have addressed the issue of using realistic connection restraint characteristics in the assessment of column stability. Some of this has been in the criteria for the strength of individual columns, as discussed for Model iv. However, a major body of work has been devoted to incorporating such properties into the stability of columns in frame sub-assemblages. Numerous studies have offered improved understanding of the buckling mechanisms as well as how the end restraint concepts may be implemented in practice. The advantages of this approach is that it ties directly into what has been common practice for years, with well-defined physical modifications of known and accepted methods.

For almost structural types, notably those with substantial gravity and/or lateral loads from wind or seismic action, second order effects are critical. This applies whether the frame is braced or un-braced, although the latter tends to be more affected. The original research work and the solution for these P-delta effects were provided by $\mathrm{P}$. F. Adams while he was a $\mathrm{Ph}$. D graduate student at Lehigh University; details of the historical evolution have been provided by Galambos (1988).

\subsubsection{Buckling of Beam-Columns}

Beam-Columns used frequently in structural steel frameworks have been subject to extensive research in the past 50 years. One of the characteristic research aspects was the Advanced Analysis. Attempts have been made among others by Attala et al. (1996) to extend the traditional plastic hinge method to the nonlinear frame analysis with beam-column behaviour expressed as torsionalflexural buckling. However, the plastic hinge methods have not been proved accuracy enough for the practical use. Basic investigation was made by Barsoum and Galagher (1970) and later Rajasekaran and Murray (1973) on finite element formulation of beam-columns using nonlinear elastic material law. Chen and Atsuta (1977) published a well-established thin-walled beam-column finite element developed by Rajasekaran who expressed the stiffness matrix in explicit form. Later some attempts have been made developing plastic zone methods to take the spread of plasticity in planar steel frames among others by White 
(1986). Meek and Lin (1990) included the geometric and material nonlinearity using the updated Lagrangian formulation. Bild et al. (1992) applied the total Lagrangian formulation to predict the ultimate load for bi-axial bending and torsion. More and more sophisticated procedures have been published - Izzudin and Smith (1996) adapted the Eulerian approach for large displacement analysis of thin walled frames. However, most of the research on spread-of-plasticity analysis focused on member behaviour and planar frames. One of the most recent investigations on large-scale 3D steel frames was published by Jiang and co-authors (2002) using mixed element technique: elastic beam-column element is used for elastic-behaviour; spread-of-plasticity finite element is used at certain members where the plasticity is often concentrated. More recent research is in progress to extend the capability of the advanced analysis to include the inelastic behaviour associated with full 3D deformation (interaction of column buckling, lateral-torsional buckling and local buckling).

In 2006, Vrcelj and Bradford described the elastic restrained distortional buckling analysis of a simply supported doubly symmetric I-section beamcolumn subjected to combined uniform axial force and moment gradient. They developed a simple method using the numerical solutions of predicting the elastic restrained distortional buckling loads of beam-column for use in design.

The non-linear large-deflection analysis and post-buckling behaviour of beam-columns has been investigated using the exact expression for the curvature in the differential equation of the deflection curve (Timoshenko and Gere 1961) or using the approximate $2^{\text {nd }}$ order analysis such as the Finite Element Method (FEM) with large deflections and with or without large strains (Torkamani et al. 1997, Hori, Sasagawa 2000, Wendel, Richard 2000).

Aristizabal-Ochoa (2001) developed an approximate algorithm based on the classical Timoshenko stability functions for the large-deflection small-strain analysis of beam-column with semi-rigid connections including the effects of out-of-plumbness, axial strains and lateral bracing. Later, Aristizabal-Ochoa (2001) presented an analytical method for the non-linear large-deflection stability of slender beam-column of symmetrical cross section with semi-rigid connections (linear and non-linear) and side-sway uninhibited under end loads including the effects of axial load eccentricities and out-of-plumbness. Recently, Aristizabal-Ochoa (2007) developed a complete algorithm based on the "modified" Timoshenko stability functions for the large-deflection analysis and post-buckling behaviour of beam-column with semi-rigid connections subjected to conservative and non-conservative end loads including the effects of out-ofplumbness, shear deformations, the induced transverse component of the applied axial force, axial strains and lateral bracing. Extending works of AristizabalOchoa, Vega-Posada with co-workers (2011) presented the large-deflection analysis and post-buckling behaviour of slender beam-columns of symmetrical 
cross sections with both supports partially restrained against rotation and sidesway totally inhibited or uninhibited subjected to end loads including the effects of out-of-plumbness.

Since beam-columns may act as if isolated, as in case of eccentrically loaded compression members, or they may form part of a frame (Bjorhovde et al. 2008), or even more complex structure like bridge and etc., their structural behaviour and attempts to find even more accurate method for stability verification remain an issue for investigations.

\subsubsection{Effect of Intermediate Lateral Restraint}

The behaviour of both columns and beams when provided with some form of intermediate lateral restraint may best be illustrated by taking the example of an axially loaded column and considering two situations of central restraint and distributed restraint, as illustrated in Figure 1.7. The central "spring" restraint may or may not constrain the deformation of the column at mid-height. Considering the equilibrium of a centrally braced column of length $L$ leads to the approximate relationship between the enhanced elastic critical force $N_{c r}$ and the stiffness of the spring restraint $K_{T}$ as:

$$
N_{c r}=N_{e}+\frac{3}{16} K_{T} L
$$

where $N_{e}$ is the Euler load of the unrestrained column.

If $K_{T}$ exceeds a value of:

$$
K_{T}=\frac{16 \pi^{2} E I}{L^{3}}=\frac{16 N_{e}}{L}
$$

the column will buckle in the second mode (two half sine waves), with the result that further increases in $K_{T}$ will not produce corresponding increases in $N_{c r}$ (Timoshenko and Gere 1961, Trahair et al. 2008). The column therefore effectively becomes restrained at its mid-height, and $N_{c r}=4 N_{e}$ (see Figure 1.7).

When a perfect column buckles in the second mode there is no force in the restraint. However, since columns are not perfectly straight, the spring stiffness $K_{T}$ should be considerably higher than the value given by Equation (1.4) in order that the springs are fully effective as restraints and the forces that they attract are not excessive. A number of analytical studies of imperfect columns with intermediate elastic restraints have been performed, (Al-Shawi 1998, Banti 2002, Trahair 1999) and relationships between the forces experienced by the restraints and the load in the column have been derived. 


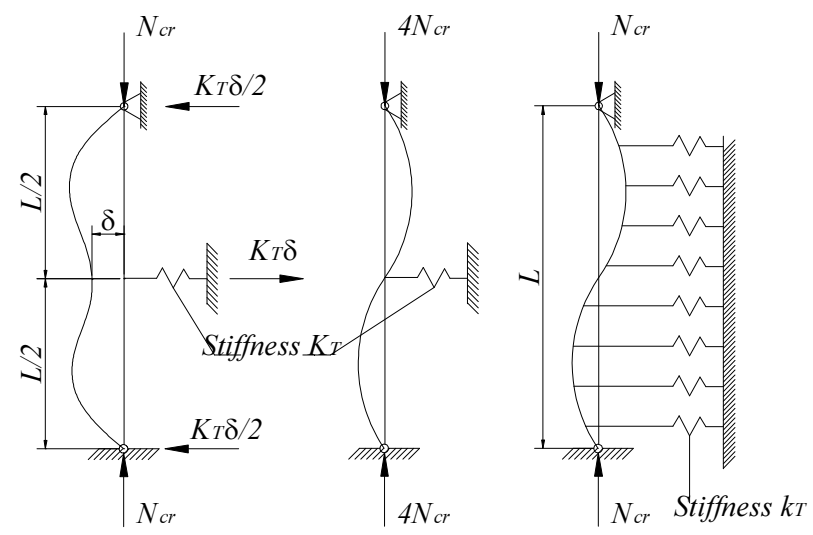

Fig. 1.7. Column with intermediate elastic restraint (Gardner 2011)

For a pin-ended column with a single central intermediate lateral restraint and a sinusoidal imperfection of amplitude $e_{0}$, the ratio of the restraint force $F$ to the axial load $N$ in the member is given by (Banti 2002):

$$
\frac{F}{N}=\frac{e_{0} / L}{\left(\frac{N_{e}}{N}-1\right)} \times \frac{1}{\frac{N}{K_{T} L}+\frac{1}{2 \pi \sqrt{N / N_{e}}} \tan \left(\frac{\pi}{2} \sqrt{\frac{N}{N_{e}}}\right)-\frac{1}{4}}
$$

Similar expressions for other scenarios, including non-central restraints, multiple restraints and different imperfections and conditions are also available (Al-Shawi 2001).

Figure 1.8 shows the relationship between restraint force $F$ and stiffness $K_{T}$ for various levels of axial load $N$ on a centrally restrained column. The graph has been derived from Equation (1.5), assuming the basic initial bow imperfection $e_{0}=L / 500$ given in Section 5.3.3 of BS EN 1993-1-1 when a single is to be restrained; the typical fabrication tolerance for hot-rolled steelwork is $L / 1000$. From Figure 1.8, it may be observed that a restraint stiffness of the minimum theoretical value required for a perfect column to buckle into two half sine waves $\left(K_{T}=16 N_{e} / L\right)$ results in large restraint force in the presence of an imperfection, and that to avoid such large restraint forces, the restraint stiffness has to be significantly greater than this value. This analysis provides a useful indication of the degree of bracing stiffness necessary in practice to restraint members against buckling. 


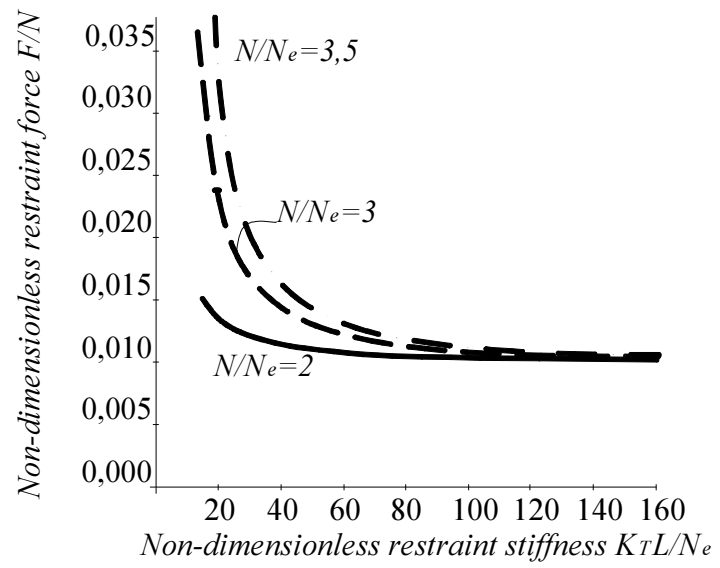

Note: These curves have been derived assuming that $e_{0}=L / 500$

Fig. 1.8. Relationship between restraint force and stiffness for various levels of axial load in a centrally restraint column (Gardner 2011)

For the case of continuous elastic restraint shown in Figure 1.7, the relationship between $N_{c r}$ and $k_{T}$ is defined (Timoshenko and Gere 1961) as follows:

$$
N_{c r}=N_{e} \sqrt{k_{T} L^{2} / \pi^{2} N_{e}}\left[\frac{m^{2}}{\sqrt{k_{T} L^{2} / \pi^{2} N_{e}}}+\frac{\sqrt{k_{T} L^{2} / \pi^{2} N_{e}}}{m^{2}}\right]
$$

where $k_{T}$ is the stiffness of restraint per unit length of the column and $m$ is the number of half-waves into which the column buckles.

In the case, $N_{c r}$ will continue to increase with increasing values of $k_{T}$ as shown in Figure 1.8. Moreover, progressive changes in buckled shape will occur, with the column buckling into an increasing number of half-waves as the stiffness of the restraint is increased. Thus no equivalent of a limiting value of $K_{T}$ as defined by Equation (1.4) exists.

However, a lower bound result for all cases, as shown in Figure 1.8, is obtained from:

$$
N_{c r}=2 \sqrt{k_{T} E I}
$$

For a series of discrete restraints at a spacing $L_{R}$, the stiffness $k_{T} L_{R}$ requires to achieve $N_{c r}=\pi^{2} E I / L_{R}^{2}$ is given by rearrangement of Equation (1.7) as: 


$$
k_{T} L_{R}=\pi^{4} E I / 4 L_{R}{ }^{3}=24,3 E I / L_{R}{ }^{3}
$$

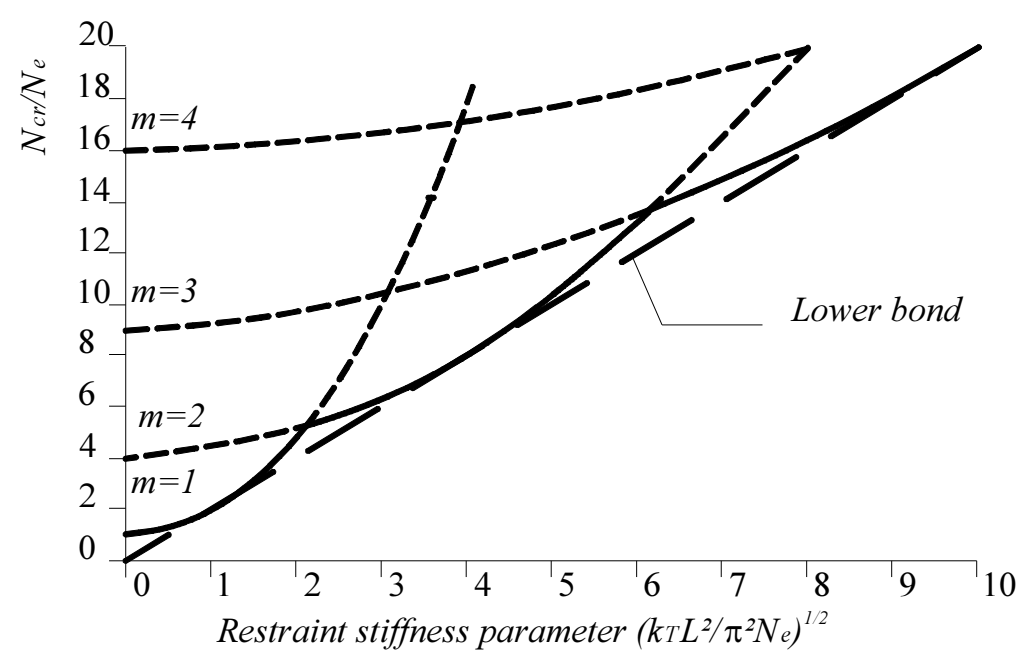

Fig. 1.9. Effect of bracing stiffness on critical load for the arrangement shown in Figure 1.7 (Gardner 2011)

It may be noted that a minimum stiffness for intermediate restraint of $40 E I / L_{R}{ }^{3}$ is given in PD 6695-2 (2008), Clause 5.3.

In 2008, Tan and Yuan, studied the buckling of elastically restrained steel columns with the approach of longitudinal non-uniform temperature distribution. They derived close-form solution to enable engineers to quickly ascertain the elastically restrained column stability under a non-uniform temperature distribution, without recourse to finite element modelling. Li (2000) proposed an exact solution to study the buckling of a non-uniform column with spring supports under combined concentrated and distributed loads. In his work he obtained the exact solutions which are used to derive the eigenvalues equation for buckling of multi-step non-uniform column with spring supports by using the transfer matrix method.

Similar analyses may be performed for beams (Trahair 1984) to obtain analogous relationships between critical bending moment and restraint stiffness. In the case, the problem is inherently more complex because restraints may act to limit lateral deflection, twist, or both, and beams may be subjected to variety of different forms of loading. 
However, the different buckling characteristics of beams in comparison to columns leads to an appropriate minimum restraint stiffness of around 10 times the lateral bending stiffness of the beam when bracings are attached to the compression flange (Wang and Nethercot 1989).

Theoretically, all structural members may be regarded as beam-column, since the common classification of elements subjected to axial load, and bending moment are merely limiting examples of beam-column (Bjorhovde et al. 2008). Thus, the consideration of the structural behaviour of the element with the intermediate elastic restraint under simultaneous bending and compression is, therefore, the practical interest.

Wang and Nazmul presented buckling capacities of braced columns (1991) and comprehensive set of stability criteria for Euler columns with an intermediate elastic restraint (2003). Gambhir considered the case of Euler strut with an added elastic central support with potential energy approach (2004). Trahair with co-workers used differential equation method (2008) for the solution of the same structural model. Saha and Banu developed the method to identify the buckling load of beam-column based on 'Multi-segment Integration technique' (2007).

However, it has to be noted that, in the most performed studies, the authors deal with the problem either in the case when restrained stiffness approaches infinity (Goncalves, Camotim 2004) or transverse force vanishes (Davis 1990, Trahair, Rasmussen 2005, Wang, Ang 1988). Thus structural behaviour of beam-column still remains an issue for research.

\subsection{Imperfections}

It is well known that structural elements are affected by residual stresses and geometric imperfections (absence of straightness and homogeneity) produced during the manufacturing process (Bayo, Loureiro 2001).

\subsubsection{Influence of residual stress}

The presence of residual stresses in an intermediate length steel compression member may cause a significant reduction in its buckling resistance. Very well known and documented, through extensive tests and analyses, residual stress is one of the main column strength parameters. Residual stress data are available for a variety of shapes, sizes, grades of steel and manufacturing practices. Residual stresses are established during the cooling of a hot-rolled or welded steel member (and during plastic deformation such as 
cold-rolling). It has been shown (Bjorhovde, R. and Tall, L. 1971, Alpsten, G.A. and Tall, L. 1970, Bjorhovde, R., Brozzetti, J., Alpsten, G.A., and Tall, L.1972) that the influence of welding on the residual stresses in the shape decreases as the size of the shape increases. Thus, the percentage of the final residual stresses which can be attributed to the welding process becomes less as the shape becomes larger (Bjorhovde 1972). In general, the shrinking of the late-cooling regions of the member induces residual compressive stresses in the early-cooling regions, and these are balanced by equilibrating tensile stresses in the latecooling regions. In hot-rolled I-section members, the flange - web junctions are the least exposed to cooling influences, and so these are the regions of residual tensile stress, while the more exposed flange tips are regions of residual compressive stress (Trahair et al. 2008). In a straight intermediate length compression member, the residual compressive stresses cause premature yielding under reduced axial loads and the member buckles inelastically at a load which is less than the elastic buckling load.

Several experimental works have been conducted to find the residual stress pattern of hot-rolled I-sections but few of them report the static characteristics of such data. The statics of residual stress at flange tips, flange centre and web centre have been reported by Fukumoto and Itoh (1980) for hot-rolled steel Isections. Residual stress distributions used for common hot-rolled doubly symmetric shapes are provided in the literature, including ECCS (1984) and Ziemian (2010). In most cases, the maximum compressive residual stress is $30 \%$ to $50 \%$ of the yield stress.

Column formulas around the world have incorporated the influence of residual stress since the 1950-s. The initial applications were all based on tangent modulus formulations (Johnston 1981).

Adequate computational modelling of residual stresses is troublesome for analysts. Inclusion of residual stresses (at the integration points of the model for instance) may be complicated. Selecting an appropriate magnitude is made difficult by a lack of data. As a result, residual stresses are often excluded altogether, or the stress-strain behavior of the material is modified to approximate the effect of residual stresses. In hot-rolled steel members residual stresses do not vary markedly through the thickness, in cold-formed members residual stresses are dominated by a 'flexural', or through thickness variation. This variation of residual stresses leads to early yielding on the faces of coldformed steel plates. This important aspect of the load carrying behavior is completely ignored unless residual stresses are explicitly considered in the analysis (Schafer, Perkoz 1998).

Lately, the residual stress started to be treated as a random quantity in the advanced analysis of steel structures as they may vary considerably from profile to profile (Buonopane 2008, Kala and Kala 2003). It is shown by Buonopane 
(2008) that randomness in residual stresses has a significant impact on the strength and reliability of steel frames by increasing lateral deflections and thereby second-order effects. A new perspective was developed by Shayan et al. (2013) as random variable in advanced analysis of steel frames.

\subsubsection{Out-of-straightness effects}

Lack of straightness was recognized early as a major factor in the column strength equation, but the difficulty of obtaining closed form solutions prevented it from being adopted into design codes. The most common approach was to use a variable factor of safety to account for the effects of the crookedness. This solution was chosen by a number of design standards.

Current limit states design criteria (AISC 2005; CSA S16-09 2009; EN 1993-1-1 2005) cover the crookedness effects explicitly by using the column maximum strength as the basic criterion. This was made feasible when computer technology allowed for numerical solutions of the inelastic load-deflection column problem. Some standards have focused on the maximum value of the initial out-of-straightness; this is commonly around 1/1000 of the member length. The Canadian (CSA S16-09 2009) and the European (EN 1993-1-1 2005) codes have chosen this approach. The American limit states standard (ANSI/AISC 360-05) uses the mean value of $1 / 1500$ of the length, on the premise that in the first order, second moment approach to limit states design, all parameters use the mean as the key central tendency. The value of $1 / 1500$ is based on probabilistic evaluations of the out-of-straightness effects (Bjorhovde 1972) and originates from experimental measurements (Wong, K.C., Temple, M.C. 1982, De Araujo, R.R., et al.2006). The latest version of AISC (ANSI/AISC 360-10) states that: initial out-of-straightness need not be considered explicitly in the analysis as long as it is within the limits specified in the AISC Code of Standard Practice, which provides that the variation in straightness shall be equal to or less than $1 / 1000$ of the axial length between points that are to be laterally supported. As for the global analysis the values of $1 / 150$ to $1 / 350$ depending on buckling curve are derived for the relative initial local bow imperfections of members for flexural buckling (EN 1993-1-1 2005).

One more way for accounting of geometric imperfections in AISC recommendations and EC3 is by the application of notional loads, which are a proportion of the gravity load applied laterally, or equivalent horizontal forces, which regards to relative initial local bow imperfections, respectively.

One more standardized methods for evaluation of initial geometric imperfections in EC3 as an alternative to relative initial local bow imperfections and equivalent horizontal forces the shape of elastic critical buckling mode of 
the structure may be applied as unique global and local imperfection. Some drawbacks given by applying previously mentioned method on the steel columns and frames were attained by Serna and co-workers (2009).

Currently, there is much research work on influence of element imperfections on stability performance of steel structures, from which some directions may be abstracted, such as curved member modelling, equivalent imperfection concept and reduced tangent modulus.

In the study of Austin and Ross (1976), Wen and Lange (1981, 1991), and Elias and Chen (1988), it is proposed that curved elements can be used to simulate the initial curvature with only one element for one member. Lui and Chen (1986) have proposed a more rigorous cubic lateral displacement function expressed with the usual cubic Hermite polynomial, combined with two new shape functions. These new shape functions represent respectively a symmetric first buckling mode and an asymmetric second buckling mode of a fixed ends beam. Investigating the same problem, Chan and Zhou (1998) have proposed a more relevant fifth order polynomial function for the displacement field. The curved element method is direct but complicated, and the actual member initial curvature is rather small. Therefore, it's not suitable to use element with large bending (Zhou et al. 2009). Then, Chan and Zhou (1995) point out that additional moment caused by increase of lateral deflection can be considered based on self-equilibrium (Point equilibrium polynomial) straight beam element (Zhou et al. 2009). In Kondoh and Atluri's work (1986), the explicit straight beam element that can consider influence of axial force is deduced, but such element cannot take the influence of imperfection into consideration. If such an element is used to analyse the influence of initial curvature, one member need to be divided into two or more elements and the initial perturbation should be imposed on mid-nodes of the member. And again such method will be rather complicated and too inaccurate to simulate the initial curvature for complex structures. Recently, Chan and $\mathrm{Gu}(2000)$ have proposed an exact solution for an imperfect beam-column by using the stability function approach. In this study the authors have used Timoshenko's theory (1966) and extended this theory to take into account the effect of the initial curvature along the element length.

An alternative for AISC recommendations explicit geometric imperfections modelling and notional loads method is reduced tangent modulus method. The idea of using the reduced tangent modulus method is to further reduce the tangent modulus to account for geometric imperfections. The reduced tangent modulus method is capable of eliminating somewhat tedious work such as explicit imperfection modelling or notional load input (Kim and Chen 1996, Chen 2000).

EC3 (EN 1993-1-1 2005) states that the influence of member imperfections may be allowed for either in the individual member buckling check - indirect 
method - or by incorporating member equivalent geometric imperfections in the second-order global analysis - direct method. The concept of equivalent imperfection can be traced back as far as the $19^{\text {th }}$ century when Ayrton and Perry (1886) specified the initial curvature and end eccentricities that should be considered in column design. Much more recently, Ronald and Maquoi (1979) introduced the concept of equivalent (initial) bow imperfection, which is embedded in the current EC3 buckling curves and corresponds to the adoption of a sinusoidal initial imperfection with an amplitude equal to (Goncalves, Camotim 2005):

$$
e_{0}=\alpha(\bar{\lambda}-0,2) \frac{W}{A}
$$

where $\alpha$ is an imperfection factor defining a particular buckling curve, $W$ is the elastic section modulus, $A$ is the cross-section area, $\bar{\lambda}$ is the column normalised slenderness. This equivalent bow imperfection amplitude is obtained from PerryRobertson formula (Ronald, Maquoi 1980), where $\alpha$ values were calibrated on the basis of a large number of column test results. However, there is no clear information available on the extension of equivalent imperfection concept to more general cases, such as isolate columns with arbitrary support conditions or columns integrated in frames, a fact leading to a fair amount of ambiguity and also to rather frequent misinterpretations of the EC3 rules. In order to clarify the matter and contribute to overcome the above problems, Goncalves and Camotim (2005) recently proposed a general and constant method to evaluate appropriate equivalent critical mode shape initial imperfections complying with the EC3 provisions, which is based on using closed-form analytical expressions to evaluate their amplitudes (Goncalves, Camotim 2001).

\subsection{Concepts for Columns and Beam-Columns Design}

\subsubsection{The Effective Length Concept}

The concept of the effective length factors of columns has been well established and widely used by practicing engineers and plays an important role in compression member design. The most structural design codes and specifications have provisions concerning the effective length factor.

Mathematically, the effective length factor or the elastic $K$-factor is defined as: 


$$
K=\sqrt{\frac{N_{e}}{N_{c r}}}=\sqrt{\frac{\pi^{2} E I}{L^{2} N_{c r}}}
$$

where $N_{e}$ is the Euler load, the elastic buckling load of a pin-ended column; $N_{c r}$ is the elastic buckling load of an end-restrained framed column; $E$ is the modulus of elasticity; $I$ is the moment of inertia in the flexural buckling plane; and $L$ is the unsupported length of column.

Physically, the $K$-factor is a factor that when multiplied by actual length of the end-restrained column (Figure $1.10 \mathrm{a}$ )) gives the length of an equivalent pinended column (Figure $1.10 \mathrm{~b}$ )) whose buckling load is the same as that of the end-restrained column. It follows that effective length, $K L$, of an end-restrained column is the length between adjacent inflection points of its pure flexural buckling shape. Specifications provide the resistance equations for pin-ended columns, while the resistance of framed columns can be estimated through the $K$-factor to the pin-ended columns strength equation. Theoretical $K$-factor is determined from an elastic eigenvalues analysis of the entire structural system, while practical methods for the $K$-factor are based on an elastic eigenvalues analysis of selected sub-assemblages. The effective length concept is the only tool currently available for the design of compression members in engineering structures, and it is an essential part of analysis procedures.

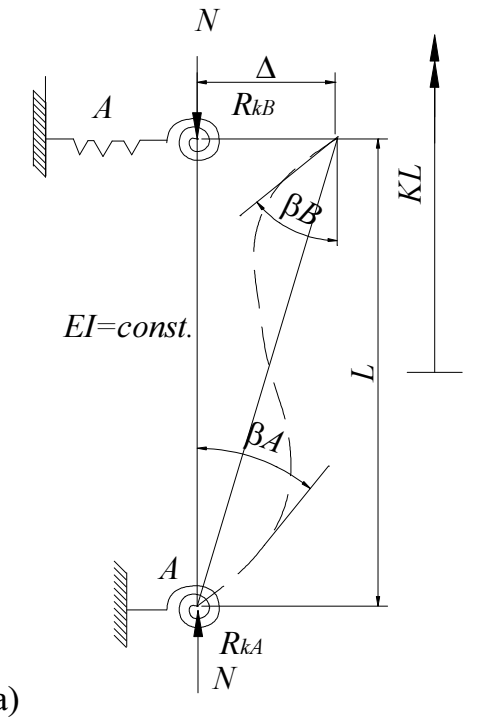

b)

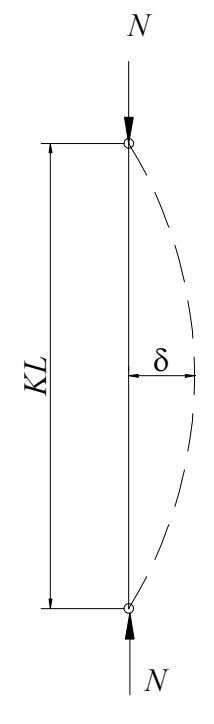

Fig.1.10. $K$-factor physical interpretation: a) end-restrained column; b) pin-ended column 
From an eigenvalues analysis, the general $K$-factor equation of an endrestrained column as shown in Figure 1.10 is obtained as:

$$
\operatorname{det}\left|\begin{array}{ccc}
C+\frac{R_{k A} L}{E I} & S & -(C+S) \\
S & C+\frac{R_{k B} L}{E I} & -(C+S) \\
-(C+S) & -(C+S) & 2(C+S)-\left(\frac{\pi}{K}\right)^{2}+\frac{T_{k} L^{3}}{E I}
\end{array}\right|=0
$$

where the stability functions $C$ and $S$ are defined as:

$$
\begin{gathered}
C=\frac{(\pi / K) \sin (\pi / K)-(\pi / K)^{2} \cos (\pi / K)}{2-2 \cos (\pi / K)-(\pi / K) \sin (\pi / K)} \\
S=\frac{(\pi / K)^{2}-(\pi / K) \sin (\pi / K)}{2-2 \cos (\pi / K)-(\pi / K) \sin (\pi / K)}
\end{gathered}
$$

The largest value of $K$ that satisfies Equation (1.13) gives the elastic buckling load of an end-restrained column. Figure 1.11 (AASHTO 1994, AISC 1989, AISC 1993, EN 1993-1-1, AS100 1998, CSA S16-09) summarizes the theoretical $K$-factors for columns with some idealized end conditions. The recommended $K$-factors are also shown in Figure 1.11 for practical design applications. Since actual column conditions rarely comply fully with idealized conditions used in buckling analysis, the recommended $K$-factors are always equal to or greater than their theoretical counterparts.

The effective length factor accounts for the influence of the column end conditions on the flexural buckling resistance, including interactions with other members in the structure. Figure 1.11, from AISC (2005), AASHTO (2010) and Ziemian (2010), summarizes the theoretical $K$-factor values for cases in which the rotational and/or translational restraints at the ends of a column are either full (i.e., effectively rigid compared to the column stiffness) or nonexistent. Recommended design values are also provided. These values are simple modifications of the ideal values, taking into account the fact that the physical end translations and rotations can never be perfectly fixed or perfectly unrestrained.

In numerous other cases, $K$ values are often specified based on established practice. For instance, Ziemian (2010) recommends the use of $K=0,85$ for inplane buckling of web members in bridge trusses. This is because the position of live load that produces the maximum force a given web member typically causes 
less than the maximum force in the adjacent members. Therefore, the adjacent members are able to provide some rotational restraint. In lieu of analysis, AASHTO (2010) allows a more liberal value of $K=0,75$ for any truss or frame member that has bolted or welded end connections and is braced against lateral translation at its ends, with the exception of single angle members where $\mathrm{K}=1,0$ is suggested. One can observe from Figure 1.11 that $K=0,75$ implies no translation and nearly rigid end rotational restraints. Thus, it would appear that this assumption is appropriate only for relatively light web members compared to the truss chords. Ziemian (2010) suggests $K=0,9$ for in-plane buckling of an interior panel of the compression chord of a constant depth truss, when the chord has the same cross-section along its entire length. In the out-of-plane direction, Ziemian (2010) suggests $K=0,7$ and 0,8 for the web compression members of a through truss when a substantial knee brace is provided in the cross-frames at both chords and at only one chord respectively. When the cross-frames depend only on their flexural stiffness and frame action to resist side sway, $K$ is greater than one for the web compression members in the out-of-plane direction. Also, in these cases, the compression chord has a $K$ greater than one. The $K$ factor is greater than one in general for the compression chord of pony trusses and halfthrough trusses. The reader is referred to Ziemian (2010) and Johnston (1976) for further discussion of appropriate $K$ calculations in these cases.

\begin{tabular}{|c|c|c|c|c|c|c|}
\hline $\begin{array}{l}\text { Buckled shape of column } \\
\text { is shown by dashed line }\end{array}$ & 1) & (b) & $\left.\right|_{1} ^{(c)}$ & 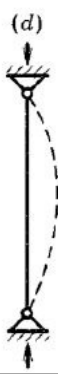 & $\begin{array}{l}(e) \\
\vdots \\
\vdots \\
\vdots \\
i \\
i \\
i \\
1 \\
1\end{array}$ & 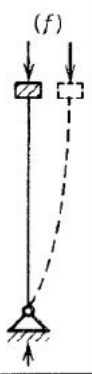 \\
\hline Theoretical $K$ value & 0.5 & 0.7 & 1.0 & 1.0 & 2.0 & 2.0 \\
\hline $\begin{array}{l}\text { Recommended } K \text { value } \\
\text { when ideal conditions } \\
\text { are approximated }\end{array}$ & 0.65 & 0.80 & 1.2 & 1.0 & 2.10 & 2.0 \\
\hline End condition code & $\begin{array}{c}4 \\
4 \\
4 \\
9 \\
9\end{array}$ & \multicolumn{5}{|c|}{$\begin{array}{l}\text { Rotation fixed, Translation fixed } \\
\text { Rotation free, Translation fixed } \\
\text { Rotation fixed, Translation free } \\
\text { Rotation free, Transiation free }\end{array}$} \\
\hline
\end{tabular}

Fig. 1.11. K-factor for different end conditions 
In theory, the effective length factor $K$ for any column in a framed structure can be determined from a stability analysis of the entire structural analysiseigenvalues analysis. Methods available for stability analysis include the slopedeflection method (Chen and Lui 1991, Galambos 1968, Winter 1948), threemoment equation method (Bleich 1952), and energy methods (Johnson 1960). In practice, however, such analysis is not practical, and simple models are often used to determine the effective length $K$-factors for framed columns (Gurfinkel and Robinson 1965, Kavanagh 1962, Lu 1962, Wood 1974). One such practical procedure that provides an approximate value of the elastic factor is the alignment chart method (Julian and Lawrence 1959). This procedure has been adopted by the AISC (2010) and AASHTO (2010) specifications, among others. At present, most engineers use the alignment chart method in lieu of an actual stability analysis.

In many situations where rotational restraint exists at the ends of a single bridge column or at the ends of the columns in a bridge frame, e.g. pier columns integral with bridge girders, the traditional side sway inhibited or side sway uninhibited alignment charts (AASHTO 2010; AISC 2010; Kavanagh 1962) provide acceptable solutions for $K$-factor. However, it is essential to recognize that the alignment charts are based on idealized assumptions that in certain cases make their application invalid.

\subsubsection{Multiple Column Curves Concept}

The main problem connected with the column design lies in the implementation of the physical imperfections, simpler - residual stresses. A variety of deterministic methods aimed at the implementation of more rational and accurate methods. Some of these are related to the manufacture of the columns, while others are based on theoretical developments (Bjorhovde 1972). The main issue connected with the manufacture-related approaches refers to the formulation of requirements that will properly consider all relevant factors. Most important among theoretically based methods is the one that utilizes several column strength curves, namely multiple column curves concept, and was presented in very simple form for the first time by the German specification for design of columns DIN 4114 (1959).

To resolve the problem aroused from the physical nonlinearities of the columns, a huge number of buckling tests were performed in various research centres in order to standardize and codify the design processes (Janns et al. 1992, Galambos 1995). Researches in Northern-America under sponsorship of the Structural Stability Research Council (SSRC) (Johnston 1976), and in Europe under the sponsorship of the European Convention of Constructional 
Steelwork (ECCS) (Jacquet 1970, Sfintesco 1970), each performed a series of tests covering different classes of column (Rotter 1981). Experimental studies held in Europe were conducted to verify and supplement the theoretical studies of Beer and Schulz (1970) in arriving at the ECCS, now the Eurocode 3 column curves (CEN 2005).

The theoretical background was also developed quickly, focusing mainly on the deterministic behaviour of columns, a wide review can be found in (Chen, Atsuta 1977). There were also attempts to reproduce the probabilistic results of the experimental research using numerical methods (Fukumoto et al. 1976, Fukumoto and Itoh 1983, Hall 1983, Strating, Vos 1973). As a main outcome of these efforts experimentally and theoretically verified design criteria for column strength were developed (Bjorhovde 1972, Beer and Schulz 1970).

Unfortunately, the form in which multiple column curves were presented to designers in both Europe and Northern-America has made them relatively difficult to use (Rotter 1981). Thus, a number of studies have aimed at devising mathematically simple equations and curves that approximate those with an engineering theory background, but otherwise offer no physical interpretation. The work of Rondal and Maquoi (1979) and Rotter (1982) are the most comprehensive of these efforts.

Many such column curves have been developed over the years. For example, the formula of the Column Research Council (CRC), the so-called CRC Curve, was used for many years as the basis for the allowable stress design specification in Northern-America. It reflected the tangent modulus solution for a perfectly straight column with residual stress. The three SSRC Curves that were developed by Bjorhovde $(1972,1988)$ were maximum strength solutions, taking into account residual stress as well as initial out-of-straightness, and also incorporated the random nature of all of the column strength parameters. These curves were a perfect fit for a code that would be based on limit states principles, which was done for the Northern-America in the late 1970-s and early 1980-s (Johnston 1976; Galambos 1988, 1998; Ziemian 2010). The Canadian steel design code adopted SSRC Curve 2 in 1974; subsequently SSRC Curve 1 was added, such that the CSA code has used two column curves since 1989 (CSA S16-09 2009). Finally, SSRC Curve 2P has been the column curve for the limit states (LRFD) criteria of the US since 1986 (AISC 2005).

The Australian Steel Structures Code AS1250-1975 was based on the work of Godfrey (1962). This work assumed that it is possible to define a single column strength curve which would be satisfactory for all sections (Rotter 1981). The single curve used in latest version of Australian Steel Standard AS100-1998 has the shape close to SSRC Curve 2.

The ECCS initially produced three closely spaced curves; two additional curves were later added tentatively (Rotter 1981). The ECCS and SSRC column 
curves are of similar shape. ECCS curve b and SSRC Curve 2 match closely, as do ECCS Curve d and SSRC Curve 3.

\subsubsection{Interaction concept}

The effect of the combined action of axial compression and bending is taken into account in design codes by formulae that are based on the interaction concept shown in Figure 1.12 (Taras, Greiner 2010).
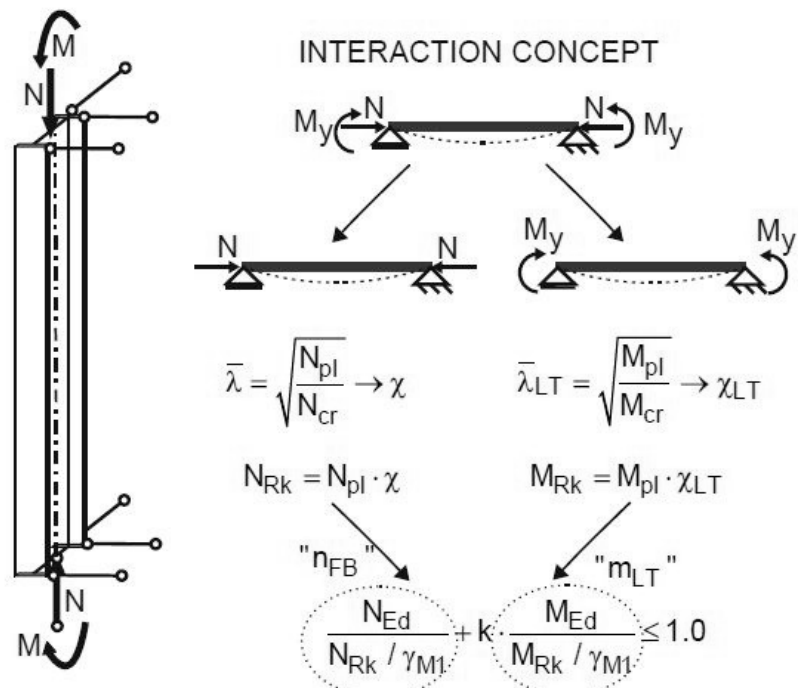

Fig. 1.12. Graphical interpretation of interaction concept (Taras, Greiner 2010)

Based on investigation done in Germany, the ENV-version of Eurocode 3 (1993) provided interaction formulae for members subjected to combined axial compression and bending. This first attempt to predict structural behaviour of beam-column by interaction often provided conservative strength estimates, leading to moderately uneconomical design, especially in members subjected to biaxial bending and compression (Lindner 2003, Goncalves and Camotim 2004). In order to correct this drawbacks, Technical Committee 8 of the European Convention for Constructional Steelwork (ECCS-TC 8), led by Lindner, presented a design concept providing a 3-step approach, which regards the priorities of different design situations and intended levels of accuracy and present design rules of different complexity on three levels. The Level 1 
formulae were developed by an Austrian-German research team (Greiner et al. 1999, Greiner and Lindner 2007, Greiner and Ofner 1999, Greiner and Lechner 2002, Greiner 2001, Lindner 2001) whose approach is based on theoretical investigations combined with the test results originally available at the time and covers standard cases of I-sections and hollow sections by simplified interaction formulae. The Austrian-German research team carried out numerical simulations of the elastic-plastic behaviour of single members, taking into account geometric nonlinearity, initial imperfections, residual stresses and plastic zones along the length of the member (Ofner 1999, Ofner 2003). The results were evaluated statically (Lindner 2001). The physical effects of the instability problems were taken into account by means of compact coefficient which makes the Level 1 formulae simple and user-friendly for the practical design (Greiner 2001). The Level 2 formulae, which were developed by a French-Belgian research team (Boissonnade et.al 2002, Boissonnade 2004) and are based on a second-order in plane elastic theory, have been progressively extended to spatial and elasticplastic behaviour and incorporates more complex cases of members by set of comprehensive formulae. Each constitutive coefficient is normally associated with a single physical effect of instability, which gives the Level 2 formulae a physical transparency (Boissonnade 2004). The two levels of interaction formulae were included in the new Eurocode 3 (EC3) (EN 1993-1-1 2005) as Method 1 for Level 2 and Method 2 for Level 1. Both levels of interaction formulae do not incorporate the cross-section resistance. Level 3 is related to general numerical FE-analysis (Greiner 2002).

In contrast, the AISC LRFD (AISC LRFD 1994, ANSI/AISC 360/10) gives a simple bi-linear interaction formula to assess all the possible modes of failure, namely cross-section resistance and members buckling resistance (Yong et al. 2006). AISC LRFD formulae may be derived following the procedures shown by Liew and co-workers (1991) and has its origin in the experimental work performed by Kanchanalai (1977). A comparison of general philosophies and procedures for the design of beam-column was presented by White and Clarke (1997).

\subsubsection{Second-order effects and moments amplification}

Most structural analysis methods are based on the assumption that the deformation of the member does not affect its internal load or stress distribution. This is usually referred to as first-order analysis. However, for flexible structural systems the extra forces or stresses induced by the deformation may be quite significant, and cannot be ignored. This phenomenon is usually called the second-order effect (Chen and Wang 1999). To accomplish the second-order 
design requirements most of those days design specifications provides an approximate method to account for the second-order effect based on first-order analysis, where moment amplification factors $1 /\left(1-N / N_{c r}\right)$ due to second-order effects appears on the bending terms in interaction formulae. Indeed, the appropriate amplification factor for constant first-order bending moment is $1 /\left[\cos (\pi / 2) \sqrt{N / N_{c r}}\right]$, as shown in (Maquoi et al. 2001). If both expressions give close results when applied axial load is small compared to critical load, the difference becomes significant when axial compression gets closer to critical value (Boissonnade et al. 2004, Duan et al. 1989). The correction of drawbacks given by amplification factor may be taken into consideration through the adoption of appropriate values for the equivalent moment factor. During the years there were number studies carried out on this issue accompanied by proposals for equivalent moment factor. The most common calculation model used for the considering problem was a simply supported member subjected to end moments and axial force (Chen and Wang 1999, Boissonnade et al. 2004, Greiner, Lindner 2006). The concept of equivalent moment is a quite usual one as far as beam-columns are considered. The equivalence is such that the maximum amplified moment resulting from the application of the axial compression force in the actual member is equal to the maximum amplified moment in a similar column subjected to the uniform or sinusoidal equivalent moment distribution (Boissonnade et al. 2002).

This concept brings significant simplification as the maximum amplified equivalent moment is located at the mid-span (Boissonnade et al. 2002).

From the theoretical consideration, the exact expression of the equivalent moment factor was derived in DIN 18800 (1988). For calculation model of simply supported member subjected to equal end moments detail derivation of second order effect can be found from Salmon and Johnson (1996) or Chen and Lui (1987). For the case when end moments are not equal, an equation proposed by Salmon and Johnson or Chen and Lui was rearranged by Chen and Wang (1999). Villette and co-workers (Bureau et al. 1999, DIN 18800 1988, Maquoi, Ronald 1982, Villette 1997), extensively studied the problem, and derived a simple approximate expression, which allows accounting for the previously mentioned theoretical error, which was incorporated in the proposal for the improvement of the interaction formulae in Eurocode 3. The fundamental differences between the theoretical value of the Villette and the group version of equivalent moment factor with other well-known definitions, i.e. Austin (1961) and Massonnet (1959) was outlined by Boissonnade and co-workers (2002).

Despite all number of the proposal the most popular is Austin one, which has been incorporated into many those days' standard codes, such as AISC 
recommendations, European (Method 2), Australian and Canadian codes (Austin 1961).

$$
0,6-0,4 \frac{M_{1}}{M_{2}} \geq 0,4
$$

Where $M_{l}$ and $M_{2}$ calculated form a firs-order analysis are the smaller and larger moments, respectively, at the ends of that portion of the member unbraced in the plane of bending under consideration.

In attempt to improve the interaction formulae of the ENV-rules the final version of Eurocode 3 provides two alternatives for the buckling check of beamcolumns by interaction formulae, which are called there Method 1 and Method 2. The equivalent moment of Method 2 differs from the analogous factor in the previous ENV-version and it differs also from the factor of Method 1, which takes the sinusoidal shape of the moment diagram as its basic form. In Method 2 the approach of the widely used "Austin formula" (Austin 1961) has been applied for reasons of simplicity in practical use (Greiner, Lindner 2006).

Differences in the meaning of the equivalent moment factors, which are used in the case of flexural buckling, refer to method for accounting of nonuniform moment distribution. While the factors of Method 2 are based on equivalent uniform moments and follow the Austin-formula as in many other international codes (AISC recommendations, AS100-1998, CSA S16-09). The equivalent moment factors of Method 1 are based on equivalent sinusoidal moments, and these moments being derived from the elastic buckling theorydepend on the critical flexural buckling load. Because of these different basic assumptions the equivalent moment factors are generally different in magnitude (Greiner, Lindner 2006).

\subsection{Overall System Buckling Versus Individual Member Buckling}

\subsubsection{Key Concepts}

One question that has been raised by numerous organizations in the recent past is what type of analysis and/or AASHTO provision checks are sufficient to assess the overall stability of a bridge structural system during construction. For instance, what constitutes a sufficient check of the overall stability of a straight tub girder that does not have a full-length top lateral bracing system? At issue is the fact that in most cases, the overall stability of stringer-type bridges is ensured 
by checking member buckling resistances for the unbraced lengths between the cross-frame or diaphragm locations (White 2012). However, checking of the top flanges of a single tub girder in this fashion does not generally represent an adequate assessment of the overall stability of the structure. For this type of system, a direct global assessment of the buckling load of the full structure is necessary. Yura and Widianto (2005) discuss a number of approximate and refined solutions for assessment of the overall buckling of tub girders that do not have a full-length top-flange bracing system. In addition, an expanded set of related recommendations have been published recently for I-girders by Yura et al. (2008). Yura and Widianto demonstrate that the overall elastic buckling of individual tub-girders with no top-flange bracing is represented accurately, for the case of uniform bending $(C b=1)$, by the analytical solution for a singlysymmetric open-section member. This solution may be written concisely as

$$
\left.M_{c r}=\frac{\pi^{2} E I_{y}}{L^{2}} \frac{\beta_{x}}{2}+\sqrt{\left(\frac{\beta_{x}}{2}\right)^{2}+\frac{C_{w}}{I_{y}}\left[1+0,039 \frac{J}{C_{w}} L^{2}\right]}\right\}
$$

(White and Jung 2003b), where $\beta_{x}$ and $C_{w}$ are respectively the coefficient of mono-symmetry and the warping constant for the cross-section. These constants are determined from thin-walled open-section beam theory, e.g., see Galambos (1968). The properties $I_{y}$ and $J$ are the moment of inertia of the tub section about the axis orthogonal to the axis of bending and the St. Venant torsional constant, and $L$ is the overall span length. Yura and Widianto (2005) also illustrate that modified forms of Equation (1.16), which accounts for the influence of pre-buckling displacements on $M_{c r}$, have little practical significance because of necessary stress and deflection limits. In addition, they point out that the alternate modified forms are not appropriate for cambered girders. The Engineer should note that Equation (1.16) applies only to tub girders that do not have top-flange bracing. Tub girders designed with a full-length top lateral bracing system satisfying the AASHTO (2010) requirements do not need to be checked for overall lateral-torsional buckling. In addition, it should be noted that this equation applies to both straight and curved tub-girders. Similar to the fact that the in-plane elastic flexural buckling of a beam-column is relatively insensitive to the applied bending moments (McGuire 1968), the overall elastic buckling load of structural members generally is insensitive to horizontal curvature. Yura and Widianto (2005) and Yura et al. (2008) also show that twin-I-girder systems also can be susceptible to overall lateral-torsional buckling in some cases where the spacing between the girders is small relative to the span length. That is, their equations show that in some cases, the stability of two I-girder assemblies connected together by cross-frames 
may be governed by overall buckling rather than by buckling of the individual I-girders between the cross-frame locations.

Bridge I-section members are commonly non-prismatic (e.g., they have cross-section transitions), they are subjected to non-constant bending moment along their lengths, and I-girder pairs are not necessarily composed of equal-size I-section members. Nevertheless, the above are useful base equations that are helpful for gagging when overall system buckling may govern relative to the common design assumption of buckling of the girders between the brace points. For realistic practical cases involving deep, closely-spaced, narrow-flange I-section members, the Engineer should consider running a refined buckling analysis to check the lateral-torsional buckling capacity of girder assemblies during construction. If the governing elastic buckling load is sufficiently large relative to the applied loads, then neither local nor global stability is an issue.

\subsubsection{Methods of Analysis}

Analysis shall be based upon calculation models of the structure that are appropriate for the limit state under consideration. The calculation model and basic assumptions for the calculations shall reflect the structural behaviour at the relevant limit state with appropriate accuracy and reflect the anticipated type of behaviour of the cross sections, members, joints and bearings (EN 1993-1-1 2005). Figure 1.14 reflects the possible calculation models for the steel structures design.

Analysis of the structures could be classified according many points of view the most common one is considering material non-linearities. From this aspect the internal forces and moments may be determined using either:

a) elastic global analysis;

b) inelastic global analysis.

Elastic global analysis may be used in all cases and it could be classified secondly:

LA: Linear elastic analysis;

LBA: Linear bifurcation analysis;

GNA: Geometrically non-linear analysis;

GNIA: Geometrically non-linear analysis elastic with imperfections included. 


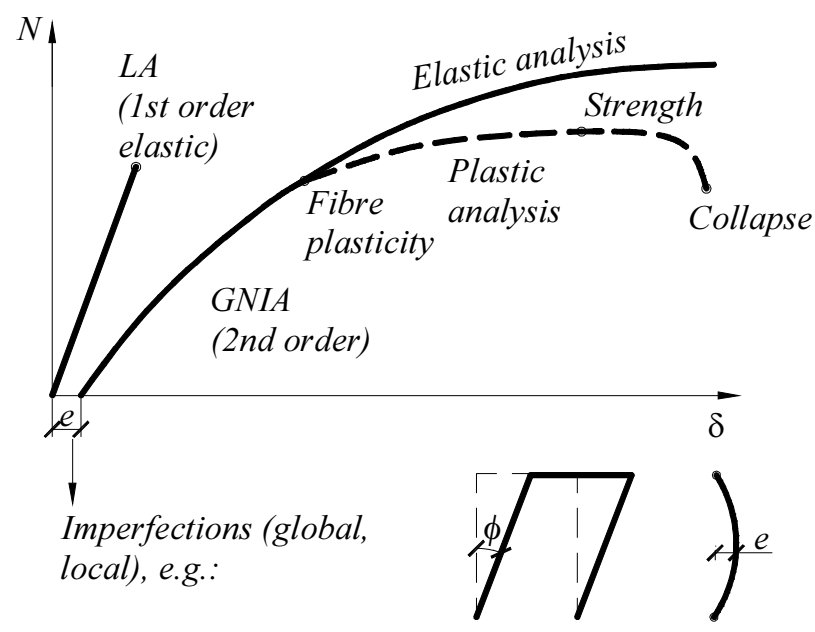

Fig. 1.14. Calculation models for steel structures design

Both the first-order linear (LA and LBA) and second-order non-linear (GNA and GNIA) analysis methods can be used. But it is needed to ensure the effects of change of geometry and buckling effects in the case the methods of linear analysis is chosen otherwise the second-order analysis must be used. Simplified GNA (using equilibrium equation on deformed structure but the same "small deflections" as in common LA) is called second-order analysis. Such analysis is usually sufficient for investigation of buckling in steel frame structures. Simplified scheme of elastic analyses is shown in Figure 15 a).

LA ( $1^{\text {st }}$ order analysis) has its benefits and drawbacks. The main benefit of it is that it is a convenient tool for engineers and practitioner as superposition is valid easily. Though it gives an approximate solution and it is necessary to include imperfections, both global and local, and $2^{\text {nd }}$ order effects in other ways like by reduction coefficients for buckling.

One step forward to more accurate stability verification of structures is LBA (linear bifurcation analysis). This analysis uses $2^{\text {nd }}$ order analysis, introducing, however, zero initial imperfections and zero non-axial loading. The resulting critical forces are expressed in the form:

$$
N_{c r, i}=\alpha_{c r, i} N_{E d}
$$

where $i \in(1 ; \infty)$ and $N_{E d}$ represents initial set of axial forces.

It should be noted that in on-linear bifurcation analysis the GNIA is used and bifurcation occurs by snap-through of initial imperfection shape. 
Furthermore, the design of irregular and slender structures should adopt the second-order analysis with appropriate values of initial imperfections. In this case the most suitable choice is either GNA or GNIA (or $2^{\text {nd }}$ order analysis). These two analyses already represent the type of advanced analyses, but they do have their benefits and drawbacks as well. The main benefit of them is that the direct solution of elastic buckling cavers the behaviour of slender structures such as cables. However a benefit of $1^{\text {st }}$ order analysis becomes a drawback of the $2^{\text {nd }}$ order one - superposition cannot be used and the software is necessary.

a)

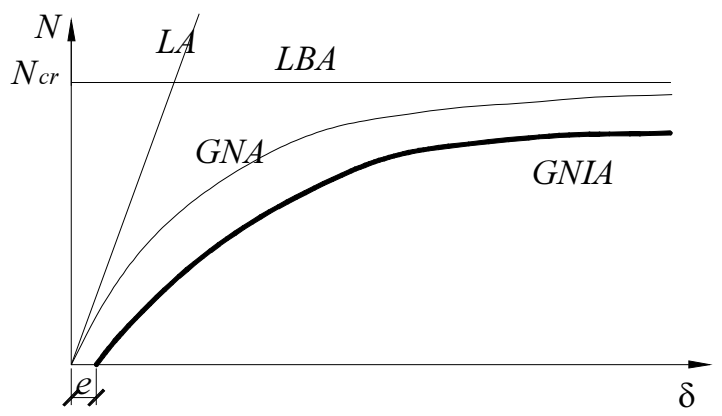

b)

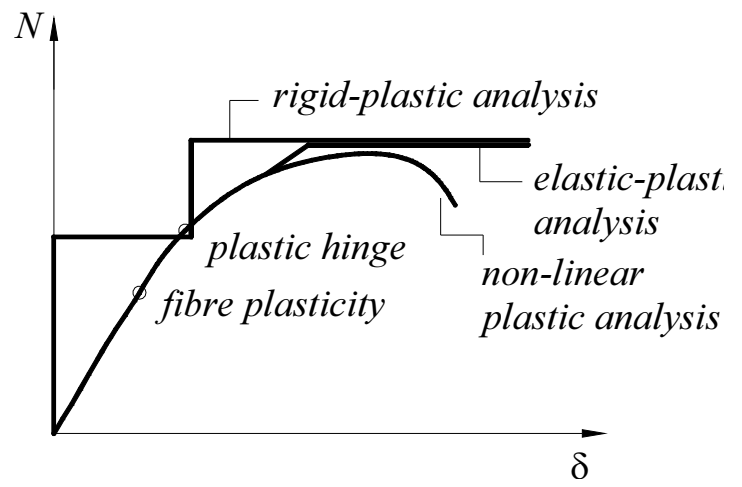

Fig. 1.15. Simplified scheme of analyses: a) elastic analysis, b) plastic analysis

Figure $1.15 \mathrm{~b}$ ) represents the second set of the analysis methods which consider the material non-linearities and is known as inelastic or plastic analysis. MNA (plastic analysis) provides a possibility to obtain a higher strength capacity otherwise may only be used provided that:

- $\quad$ steel is sufficiently ductile $\left(f_{u} / f_{y} \geq 1,1 ; \delta \geq 15 \% ; \varepsilon_{u}>15 \varepsilon_{y}\right)$; 
- for global analysis may be used only where the structure has sufficient rotation capacity (EN 1993-1-1 2005 ;

- in global analysis the stability of members at the actual location of the plastic hinge (EN 1993-1-1 2005);

- software for plastic global analysis is desirable.

Concluding further plastic global analysis models could be abstracted:

- non-linear plastic analysis considering the partial plastification of members in plastic zones (Teh and Clarke 1999),

elastic-plastic analysis with plastified sections and/or joints as plastic hinges (an example of the latter is provided by Ziemian and McGuire (2002) and Ziemian et al. (2008), in which the flexural stiffness of members are reduced according to the amount of axial force and major and minor axis bending moments being resisted)

- rigid-plastic analysis neglecting the elastic behaviour between hinges.

Plastic zone methods have been used to develop benchmark solutions for testing the more efficient but less accurate plastic hinge methods (White, Chen 1993, Liew et al. 1993, Yau, Chan 1994, Chan, Chui 2000, Liew, Chen 2000), in which yielding effects are concentrated at a few cross-sections, and residual stress and geometrical imperfection effects are approximated by using reduced stiffnesses. The computational efficiency of the plastic hinge method is enhanced when the effects of geometrical nonlinearities can be accurately allowed for by using one element per member (Chan, Zhou 1995, Chan, Zhou 2000). Some attempts have been made to extend these plastic hinge methods to allow for semi-rigid rather than rigid joints between members (Ho, Chan 1993, Nethercot 1994, Yau, Chan 1994, Fang et al. 1999). However, while this method is extremely accurate, it is computationally very complex, improvident, and slow (Trahair, Chan 2003).

\subsection{Advanced analysis for Steel Structures in Current Design Standards}

All major international design codes (ANSI/AISC Standard 360/10, EN 1993-11 2005, AS4100 commentary 1999, CSA S16-09 2009) contain provisions for Advanced Structural design, but actual use is still limited, primarily because of the lack of practical implementation. The sufficiency of the method cannot be doubted, but as matter of fact practitioners rarely use it. However, in the absence of a strong background of standardization, the method of Advanced Design remains a possibility (and problem of the researchers) rather than a practical tool. 


\subsubsection{European Standards and Global Analysis}

The latest version of the European code for steel structures design (EN 1993-1-1:2005) has introduced the general method for beam-column elements stability verification. Chapter 5.2 of EN 1993-1-1 (2005) code, Global analysis, states that the verification of the stability of structures should be carried out considering imperfections and the effects of the deformed geometry (secondorder effects) if they increase the action effects significantly or modify significantly the structural behaviour.

According to Eurocode 3 an appropriate allowances should be incorporated in the structural analysis to cover the effects of imperfections, including residual stresses and geometrical imperfections such as lack of verticality, lack of straightness, lack of flatness, lack of fit and any minor eccentricities present in joints of the unloaded structure. This can be accomplished by means of equivalent geometric imperfections (see Chapter 1.3.2) with values reflecting all types of imperfections (Serna et.al. 2009). The following imperfections should be taken into account (EN 1993-1-1 2005):

- global imperfections for frames and bracing systems;

- local imperfections for individual members.

Furthermore, both in and out of plane buckling including torsional buckling with symmetric and asymmetric buckling shapes should be taken into account in the most unfavourable direction and form.

European code gives couple possibilities for determining individual bow imperfections of members:

- relative initial bow imperfections of members for flexural buckling, which refer to buckling curve and either elastic or plastic analysis;

- initial bow imperfections may be replaced by system of equivalent horizontal forces.

As an alternative to the previous two the shape of elastic critical buckling mode of the structure may be applied as unique global and local imperfections.

There were performed couple comparative studies on the application of the presented methods for the direct analysis of simple structures which presented some drawback of these methods (Bayo, Loureiro 2001, Serna et al. 2009). The most notable are, that method of equivalent geometric imperfections requires the definition of the direction of both global and local imperfections. On the other hand, the method of unique global and local imperfections, which scales the shape of the buckling mode, which offers a solution to that difficulty, defines a scaling factor difficult to obtain since it requires the determination of the structural critical cross section and the buckling mode curvature. 


\subsubsection{North-American Standards and Direct Analysis}

The 2005 AISC specification provides a new method for stability design of steel structures termed the direct analysis method (DM). By the time of 2005 the DM method is provided as an alternative for the classic design methods. The latest version of AISC specifications addresses the requirements for the design of structures for stability and DM is presented therein as the prior design method and effective length and first-order analysis methods become alternative. The $\mathrm{DM}$ is the only one of the above three procedures that is generally applicable to all types of frames. Since mainly DM is considered as major innovation in steel frames stability assessment and design (Surovek-Maleck et al. 2005, Deierlein 2003, White et al. 2007).

The direct analysis method is a powerful tool that eliminates the need for calculation of effective length factor. The effective length factor $K$ can be assumed as 1,0 for all calculations as long as an accurate second-order analysis is conducted (Eröz et al. 2008). DM involves two simple modifications to the $2^{\text {nd }}$ order elastic analysis (White et al. 2006):

- the use of a nominal reduced elastic stiffness;

- the inclusion of nominal initial out-of plumbness.

These two devices are adjustments to the analysis that approximate the internal forces and moments from the type of distributed plasticity analysis. For hot-rolled compact I-section members, ASCE (1997), Deierlein (2003), and Surovek - Maleck and White (2003 \& 2004) have shown that distributed plasticity analysis closely replaces the in-plane AISC LRFD beam-column strengths based on an exact inelastic effective length, for a comprehensive range of end conditions, when the following nominal geometrical imperfections, residual stresses and material idealizations are included in the analysis (White et al. 2006):

- A sinusoidal or parabolic out-of straightness with a maximum amplitude of $\delta_{o}=L / 1000$, where $L$ is the unsupported length in the plane of bending.

- An out-of-plumbness of $\Delta_{o}=L / 500$, the maximum tolerance specified in the AISC (2005b) Code of Standard Practice.

- The Lehigh (Galambos and Ketter 1959) residual stress pattern.

- An elastic-perfectly plastic material stress-strain response.

These results are not surprising, since interaction formulae were originally developed in part based on calibration to results from this type analysis (ASCE, 1997; Surovek-Maleck and White, 2004). 


\subsubsection{Australian/New Zealand and Canadian Standards}

The preceding Chapter described the attempts which were made by researcher to incorporate DM into AISC recommendations; the same analysis method exists in Australian Standards under name of Advanced Structural Analysis (ASA) as well as Canadian Standards name in Detailed Analysis (DA). DA analysis in CSA S16-09 is divided into second-order analysis and DM, which refers to bracing systems design.

Advanced analysis methods, first permitted in the 1990 edition of the Australian steel structures standard AS4100 (1998), simplify the design of two dimensional steel frames for which local and lateral buckling are prevented. Recently, ASA is provided in AS4100 commentary Appendix D so as to allow a more precise method of structural analysis to be used to predict the loaddeformation behaviour of the structures. It is sated that this method might be used for the special or exceptional structures, or for the existing structures whose capacity is in doubt, or in the investigation of a structural failure (AS4100 commentary 1999).

The general part of Appendix D refers to the competence of the engineers and usage of commercial computer programs, thus the use of the ASA may require special expertise in the modelling of the structure so as include the effects of yielding, instability, and residual stresses and initial crookedness. Contrary to DM in AISC recommendations ASA and DA have preceding requirements and no possible ways of their implementation.

\subsection{Concluding Remarks of Chapter 1}

Chapter 1 draws following main conclusions:

1. Despite of outstanding structural engineers interest in designing the UDCS bridges and successfully realised projects, there is still a lack of consolidate body of knowledge on structural behaviour and design principles for this type of bridges.

2. UDCS bridges experience a highly efficient structural behaviour and are able to span the same length distance in comparison to conventional cable-stayed bridges and avoid erection of additional abutments.

3. Increasing the number of struts the elevation of cable-staying system changes from triangle to polygonal, thus under symmetric loading bending moments distribute between struts and extreme value decreases and multiple-struts UDCS bridges gain advantage to mono-strut structures. Though, under the case of asymmetric loading multiple-struts 
UDCS bridges experience unacceptable deflection shape, which consists of a complete sine wave.

4. UDCS system is more suitable for one span or independent spans continuous bridges than for conventional continuous UDCS bridges. Transverse loading invokes large hogging moments at the support sections of continuous UDCS bridge and they govern flexural behaviour of the bridge and decreases its efficiency.

5. Direct anchoring of cable-staying system into the RB under transverse loading causes simultaneous bending and compression and reflects structural behaviour of beam-column element with intermediate restraints (BCIR).

6. There are the limited number solutions of structural behaviour problems based on calculation model of BCIR. Additionally, all of the conducted studies can be divided into two main cases when either transverse loading vanishes as refers to column with intermediate elastic restraint or stiffness of the intermediate restraint approaches infinity as refers to beam-column with rigid intermediate restraint, thus the generalized solution is still an issue for research.

7. Considering unconventional structures, such as UDCS bridges the conventional design methods for steel structures provided by recent design specifications draw significant errors, especially using methods based on effective length factor as it is hardly predictable for advanced structures. Major those days steel structures design specifications alongside classical design methods provide alternative advanced methods, however they have the form of requirements and recommendations rather than practical guidelines and simplified modifications refer to linear buckling and multiplying coefficient based on Euler critical load.

On the basis of the literature review following issues should be considered:

1. Finding a structural form for UDCS bridge spanning the same length as multiple-struts one and experiencing an acceptable deformational behaviour under the case of asymmetric loading.

2. Developing computational method to obtain governing equations for structural behaviour, as well as obtain governing parameters and derive main relationships.

3. Improving generalized calculation model of BCIR accounting for both initially deformed geometry of structure and effect of residual stresses and computational method by performing GNIA as refers to requirements of advanced methods application. 
4. Collect data on structural behaviour and stability of UDCS structures and suggest technique to increase efficiency on designing such kind of structures.

5. Outlining guidelines for UDCS steel structures practical design referring to Direct Method. 


\section{2}

\section{Form-Finding for Under-Deck Cable-Stayed Steel Bridge}

This chapter contributes to developing the UDCS bridges from both architectural and engineering point of view. An investigation on dealing with the formfinding of considering structure is reported and new structural form proposed on the concept of increasing the span length with avoiding conventional struts number increase and polygonal layout of cable staying layout and unacceptable complete sine wave deflection shape. Moreover, chapter proposes computational method based on GNA and generalized calculation model of BCIR. Computational method derives governing equations for structural response of UDCS structures and obtains governing parameters and main relationships. The accuracy of the proposed method validated by performing numerical comparison analysis between results obtained derived governing equations and non-linear solver of finite element code ANSYS.

\subsection{Double-Level Cable-Staying System}

This section deals with the issue of increasing the span of UDCS bridges. Preceding Section 1.1.1 described the concept of UDCS bridges and the 
conventional solution for the increasing of the span, which refers to the increased number of the struts. Figure 2.1 details how this section deals with the considering issue.

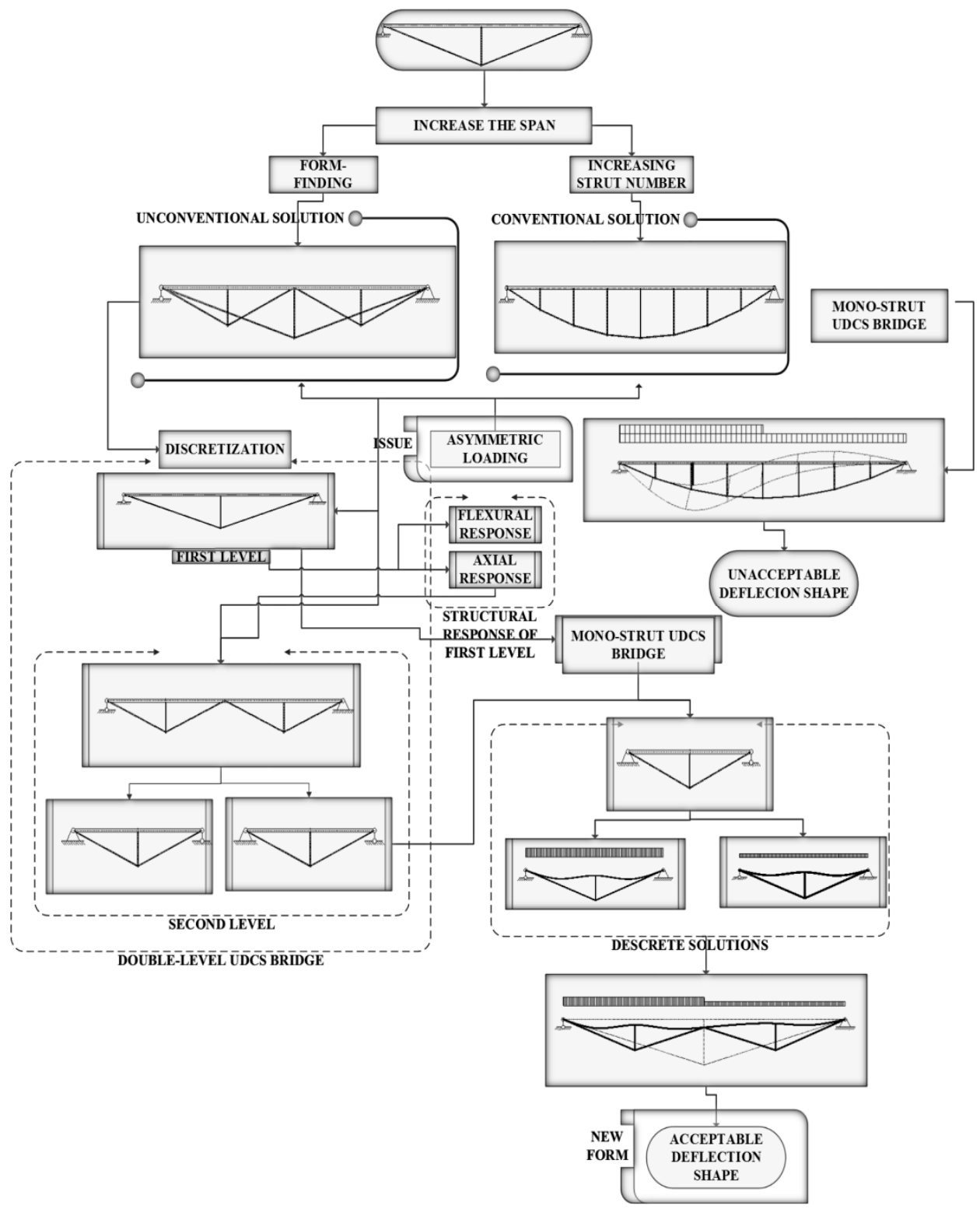

Fig. 2.1. Flowchart of double-level UDCS bridge form-finding 
Classical arrangement of the UDCS bridge with more than one strut refers to rearrangement of the layout of the cable-staying system from triangle to polygonal. Considering deformational response of UDCS bridge with polygonal layout of the cable-staying system, the main problem arose under the case of asymmetric loading as the structure has a full sine wave deflection shape, which is unacceptable for steel structures design as requires additional expenses on decrement of hogging part of the structure. The unconventional solution for this problem refers to the form-finding procedure. The detailed form-finding procedure resulting in a new form of the UDCS bridge shown in Fig. 2.1. The proposed layout of the cable-staying system is based on the triangle arrangement of structural elements, which is known as the most stable one. Furthermore, discretization of the proposed structural form of the UDCS bridge refers to simplified structural design. New elevation form of UDCS bridge shown in Fig 2.1 is named Double-Level. The first level of the proposed bridge form is monostrut UDCS bridge with the required length of the span. Second level of the bridge is formed of couple simple mono-strut UDCS sub-structures. The substructures of the second level is of the half span length of the whole bridge. Second level substructures embedding in the first level the Double-Level elevation shown in Fig. 2.1 is obtained.

\subsubsection{Structural Schemes of a Rigid Beam}

According to a variation in connections between struts and girder of the bridge and arbitrary support conditions three different structural schemes of main girder can be obtained. When main girder is subdivided into independent elements between discretely hinged braced cross-sections by means of struts and is simply supported at the end sections it gains a scheme of simple-supported structure. In order to assess structural scheme of continuous bridge, rigid beam has pinsliding supports at the end sections and remains incessant along the span. Due to morphology of considering UDCS bridge it is possible transitional variation between simple-span and continuous structural schemes namely semicontinuous system. The semi-continuous structural scheme is formed assuming hinge connection at the place where the first level CS system strut meets the main girder. Thus, the subdivision of the span of the girder is made, and two independent spans of a half of the whole length of the span are designed. By applying one strut cable-staying system to both independent spans, the second level of new morphology is developed. The second level stay cables are selfanchored to the deck at the abutments and midspan of the deck and are deviated by one strut at the $1 / 4^{\text {th }}$ and $3 / 4^{\text {th }}$ of the span respectively. Fig. 2.2 shows all previously described variations of structural scheme of the RB. 
a)

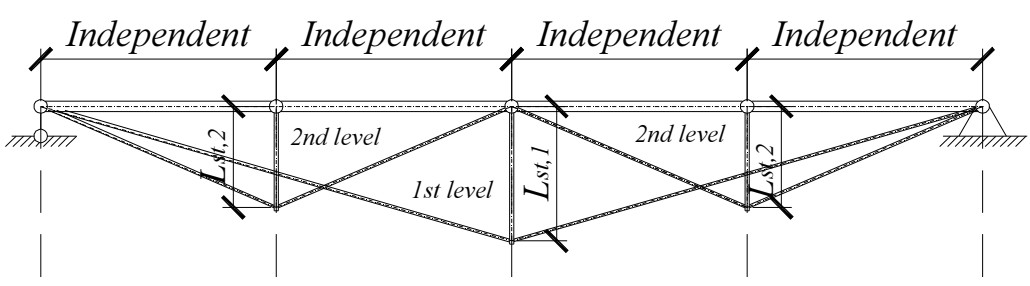

b)

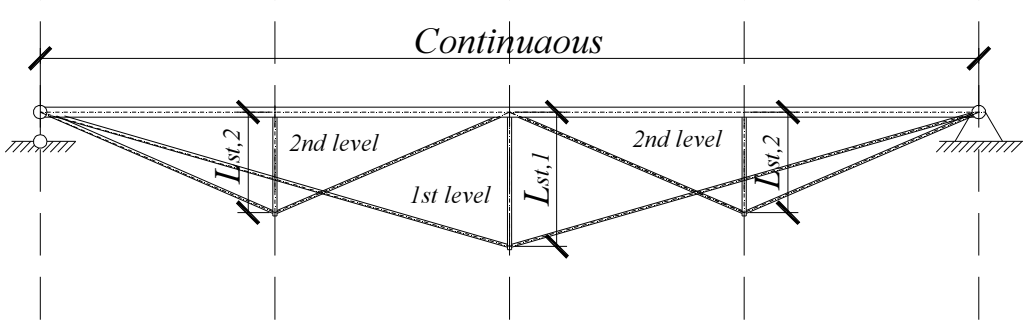

c)

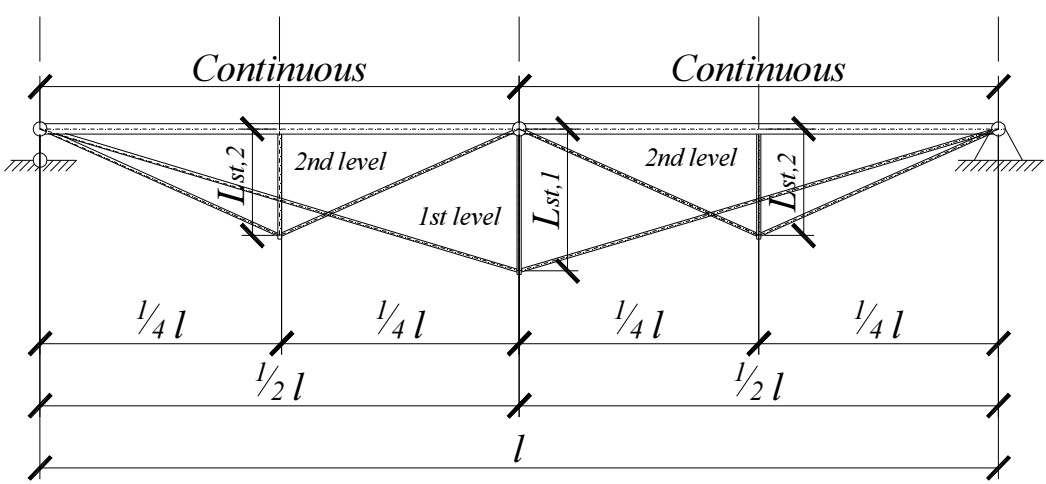

Fig. 2.2. Structural schemes of a rigid beam: a) simple-span, b) continuous, c) semicontinuous

This study considers simple-span and semi-continuous structural schemes of Double-Level UDCS bridge shown in Figure 2.2. a) and c). As described in the preceding chapter of literature review the continuous structural scheme for UDCs bridge was assumed as objectionable due to inefficient bending moments distribution and much higher extreme values of hogging bending moments at the support section compare to sagging bending moments at the midspan, which governs structural response of the whole structure. 


\subsubsection{Morphology of the Cable-Staying System}

Fig. 2.3. shows the variation in the elevation of Double-Level UDCS bridge by changing the strut length of the first level cable-staying system.

a)

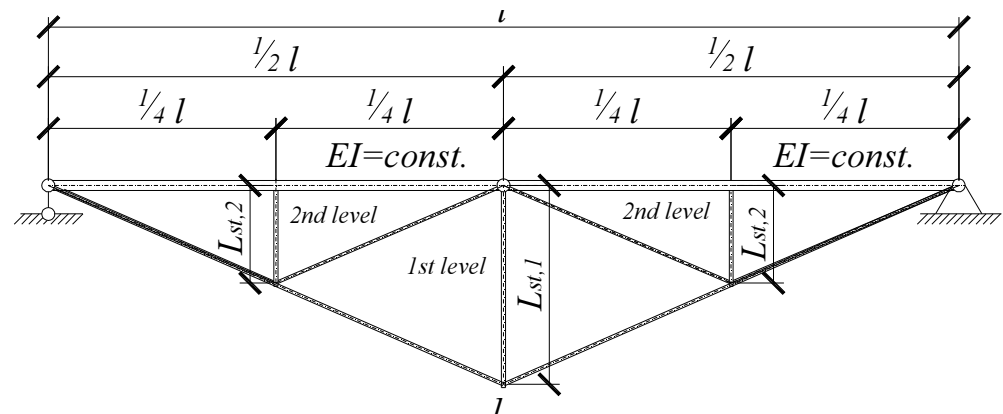

b)

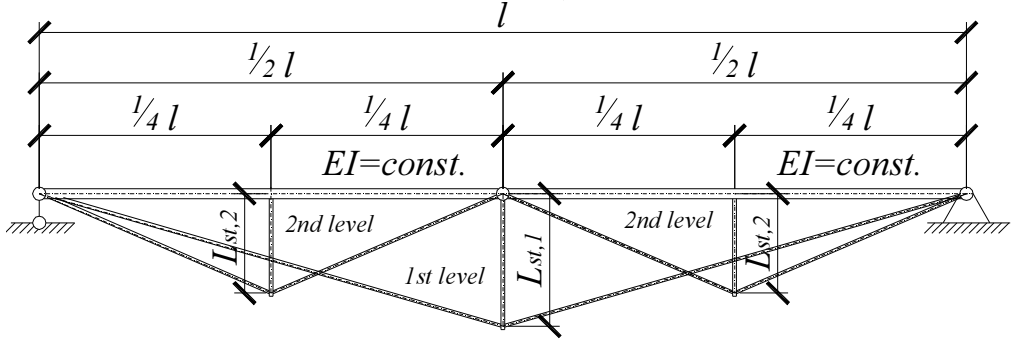

c)

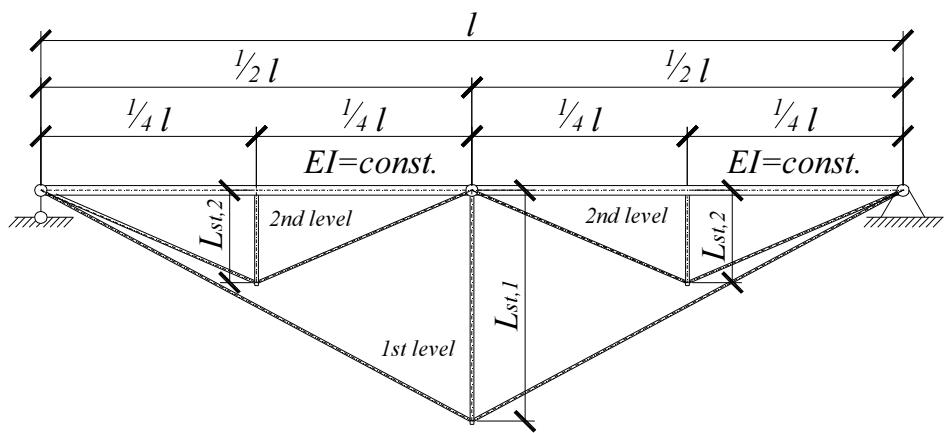

Fig. 2.3. Structural arrangement of CS system: a) intersecting first level, b) passing first level, c) framing first level

Variation of the strut length of the first level CS not just causes changes in elevation of considering structure, but as well governs structural response. For the efficient internal loads distribution, the relation between intermediate strut length and the length of independent span $\left(L_{S t, i} / l\right)$ of UDCS bridge varies from 
$1 / 9$ to $1 / 11$. In the case of modelling first and second level CS system of the same intermediate strut to relative span ratio, the intersecting elevation obtained. Decreasing and increasing the length of the intermediate strut of the first level $\mathrm{CS}$ the axial response in the RB increases and decreases, respectively.

\subsection{Parametric Studies of Elastically Restrained Beam-Column}

This section presents the computational method for the generalization of a problem of GNA of a BCIR varying restraint stiffness and loading conditions. The method obtainable in this section is based on the solution of the equilibrium equations by performing GNA and thus accounting the effects of the deformed geometry and considering the interaction of both compression and bending effects. Proposed method validated by comparing results obtained using derived governing equations and those obtained by the Finite Element Non-linear Elastic analysis using ANSYS software. Finally, a new analysis method based on the generalised model of BCIR introduced. The method can be easily applied using the provided governing equations and parameters.

\subsubsection{Computational Method}

The displacements and internal forces of a structure subjected to external loads may be determined by the equilibrium equations. The equilibrium equations rely on GNA when determining the internal and external stresses acting on a considering element. Determining the equilibrium equations by applying GNA the effects of the deformed geometry are considered as the structure is in equilibrium, in its deformed state. While it may not be necessary to consider displacements when these are assumed to be negligible, it is imperative that displacements be taken into account in formulating buckling and geometric nonlinear analyses. Structural models of simply supported beam with intermediate rigid restraint and beam-column with intermediate elastic restraint will be considered to present the possibility of particular superposition shown by governing equations of the general case. Finally, the structural model of simply supported additionally elastically restrained steel beam-column will be used to obtain governing parameters and equations for the geometric non-linear analysis of the structure. 


\subsubsection{Calculation Model of Elastically Restrained Beam-Column}

Analysing structural behaviour of the structures, the main issue, becomes to create calculation model as close as possible to simulate a real behaviour of the structure. Considering the loading conditions it turns that most of the structural elements in a steel structures are subjected to bending moment and axial force simultaneously. In some particular cases, one of the two effects can be relatively small compared to the other and for the sake of simplicity may be ignored. Although, in the general case, the interactive behaviour of both components must be considered. Therefore, it is not adequate to analyse the beam-column elements exclusively as a beam or column by ignoring one of the two load components. The analysis and design of the elements considering axial compression as one of the effects makes it essentially a non-linear problem, in which axial force participation in flexural response need to be considered (Bayo 2001).

As supporting systems are widely used both providing stability within the length of the steel structures and creating spans as long as possible with the relatively slender beams, the effect of additional restraint should be included for the sake of extension of the general calculation model. For convenience, the supporting system may be replaced by the equivalent additional restraint. In the most cases, the additional restraint is not absolutely rigid, but elastic. Thus, the consideration of the structural behaviour of the element with the intermediate elastic restraint under bending and compression is, therefore, the practical interest.

Consider calculation model of the simple supported beam-column of the length $l$ with constant flexural rigidity $E I$ subjected to a distributed lateral load $q$ and axial compression $N_{c}$ shown in Figure 2.4.

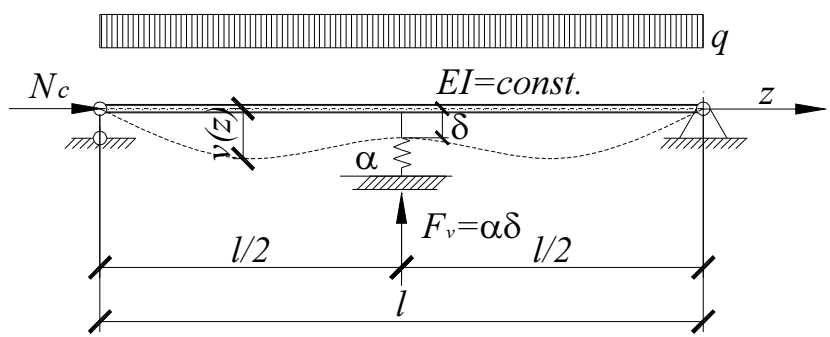

Fig. 2.4. Calculation model of the elastically restrained continuous beam-column 
An additional lateral restrained at the midspan is provided to prevent it from the lateral displacement. The stiffness $\alpha$ of the restraint is defined by the restoring force $F_{v b}$ acting on the restraint and thus the free movement of the member is restricted to greater or lesser extent $\delta$.

\subsubsection{Boundary Solutions of Beam-Column}

Calculation model has shown in Fig. 2.4 generalizes two engineering problems addressed to the cases when restraint stiffness approaches infinity and lateral load vanish.

The calculation model has shown in Fig. 2.5 reflects a beam-column with the midspan lateral restraint of the stiffness $\alpha$ approaching infinity and becoming absolutely rigid. The applied distributed transverse force $q(z)$ causes deflection $v(z)$, which corresponds to the bending moment $M(z)$, amplified by axial compression causing a moment $N_{c} v(z)$, along the member. Requiring force and moment equilibrium of the element leads to:

$$
M(z)^{\prime \prime}+\left(N_{c} v(z)^{\prime}\right)^{\prime}+q=0 .
$$

The moment is related to the curvature by:

$$
M(z)=E I \kappa(z)
$$

where $E I$ is the flexural rigidity of the column and $\kappa(z)$ is the curvature. Curvature may be written in terms of the deflection by:

$$
\kappa(z)=-v(z)^{\prime \prime}
$$

and thus:

$$
M(z)=-\operatorname{EIv}(z)^{\prime \prime}
$$

By substituting Equation (4) into Equation (1) and integrating twice leads to:

$$
\operatorname{EIv}(z) "+N v(z)=C_{1} z+C_{2}+v_{\text {part }}
$$

Where $C_{1}$ and $C_{2}$ are arbitrary constants to be determined from the boundary conditions and $v_{\text {part }}$ is an arbitrary solution to the homogeneous equation. The solution to the homogeneous differential equation is:

$$
v(z)_{h}=C_{3} \sin k z+C_{4} \cos k z
$$


where

$$
k=\sqrt{\frac{N_{c}}{E I}}
$$

When the transverse distributed force is constant, the particular solution can be taken as:

$$
v_{\text {part }}=\frac{q}{2 E I k^{2}} z^{2}
$$

Thus the complete solution is:

$$
v(z)=C_{3} \sin k z+C_{4} \cos k z+C_{1} z+C_{2}+\frac{q}{2 E I k^{2}} z^{2}
$$

Obtained solution is generally applicable to considering beam-column with arbitrary support conditions. In general, the problem should be treated in two parts: one considering the beam-column to the left of central restraint ( $0 \leq z \leq l / 2$ ) and other to the right $(l / 2 \leq z \leq l)$. However, as the loading, boundary and continuity conditions are equal to both parts structural model can be simplified to one of the parts with arbitrary support conditions as shown in Figure 2.5.

a)

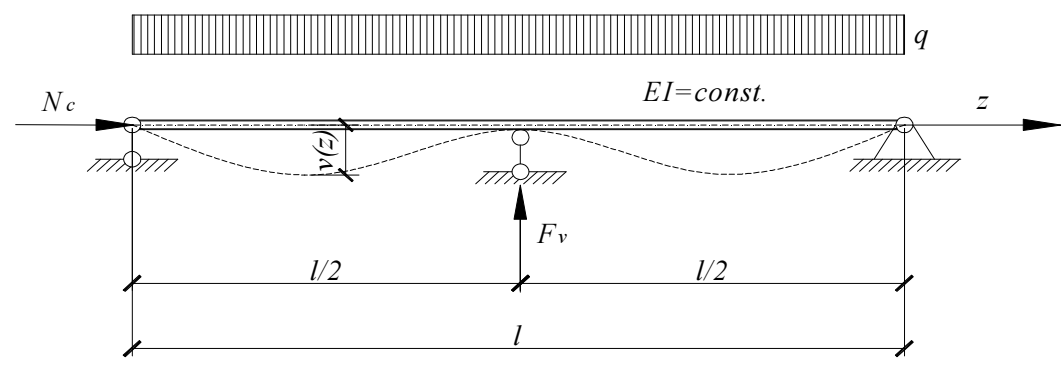

b)

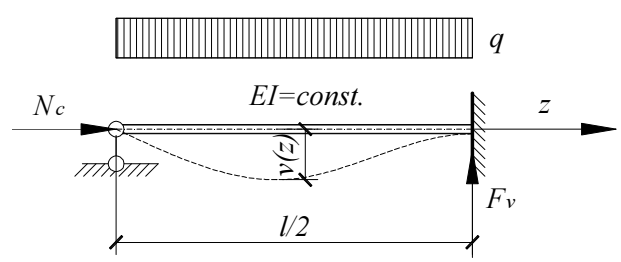

Fig. 2.5. Calculation model of the inelastically restrained continuous beam-column: a) calculation model of whole structure, b) calculation model of half of structure 
The boundary conditions of the considering half of structural element, are:

$$
v(0)=v(0)^{\prime \prime}=0 \text { and } v(l / 2)=v(l / 2)^{\prime}=0
$$

By substituting Equation (2.9) into Equation (2.10), a linear set of homogeneous equations for determining $C_{1}-C_{4}$ are obtained.

The solution of Equation (2.9) which satisfies the boundary conditions is deflected shape:

$$
\begin{aligned}
& v(z)=\frac{1}{N_{c}}\left[\frac{F_{v b} l}{2}\left(\frac{z}{l}-\frac{\sin k z}{k l \cos \frac{k l}{2}}\right)+\frac{q l^{2}}{(k l)^{2}}\left(\operatorname{tg} \frac{k l}{2} \sin k z+\cos k z-1\right)-\right. \\
& \left.-q z\left(\frac{l}{2}-\frac{z}{2}\right)\right]
\end{aligned}
$$

The bending moment of considering structural element is the solution of Equation (2.4), which satisfies the boundary conditions:

$$
M(z)=\frac{q l^{3}}{(k l)^{2}}\left(\operatorname{tg} \frac{k l}{2} \sin k z+\cos k z-1\right)-\frac{F_{v b} l}{2 k l} \frac{\sin k z}{\cos \frac{k l}{2}}
$$

In the case of rigid intermediate restraint, the extreme value of the bending moment is at the point of restriction and it never shifts from hogging to sagging. Restoring force introduced by intermediate support can be obtained from:

$$
\begin{aligned}
& F_{v b}=E I v^{\prime \prime \prime}=-E I C_{1} k^{3} \cos k z+E I C_{2} k^{3} \cos k z= \\
& =E_{I} k^{3}\left(C_{2} \cos k z-C_{1} \cos k z\right)
\end{aligned}
$$

When the solution of Equation (2.13) satisfies the boundary conditions:

$$
F_{v b}=2 \frac{q l}{k l}\left[\frac{1+\left(\frac{k l}{2}\right)^{2} / 2-1 / \cos \frac{k l}{2}}{\frac{k l}{2}-\operatorname{tg} \frac{k l}{2}}\right]
$$

Restoring force never turns equal to zero due to dependence on the slenderness parameter $k l$, which is set as non-zero variable.

Figure 2.6 shows structural model of simply supported column with an elastic intermediate restraint, which prevents it from deflecting at its centre and 
introduce restoring force $F_{v b}$. The structural model presents the other boundary problem when distributed transverse load approaches zero and the member tend to become axially loaded strut. According to the previous assumption, the structural model can be simplified to the part on the left from the intermediate support $(0 \leq z \leq l / 2)$.

Moment equilibrium is defined by moment about an arbitrary point at a distance $z$ as shown in Figure 2.6. When the axial load $N_{c}$ is compressive the differential equilibrium equation of bending of the member is:

$$
M(z)=\frac{F_{v b} z}{2}-N_{c} v(z)
$$

a)

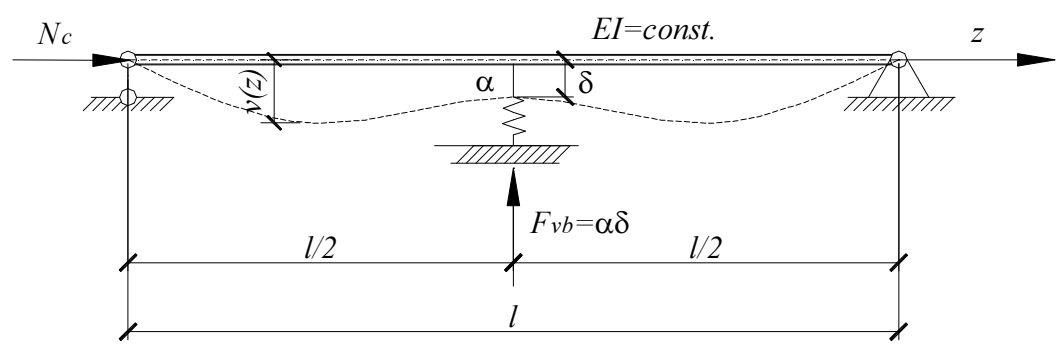

b)

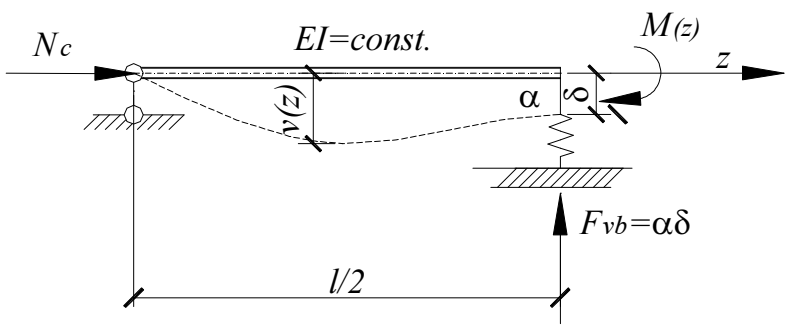

c)

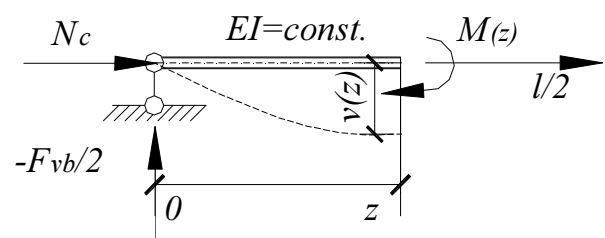

Fig. 2.6. Calculation model of the compression member with an elastic intermediate restraint: a) whole structure, b) half part of the structure, c) considering discrete part of the structure 
This equation states that for equilibrium, the internal moment of resistance must exactly balance the external disturbing moment at any point along the length of the member.

With constant $E I$ and substituting $k^{2}=\frac{N_{c}}{E I}$ the Equation (2.15) reduces to:

$$
v^{\prime \prime}(z)+k^{2} v(z)=\frac{F_{v b} z}{2 E I}
$$

When this equation is satisfied at all points, the displacement position is one of equilibrium. The solution of Equation (2.16):

$$
v(z)=C_{1} \sin k z+C_{2} \cos k z+\frac{F_{v b} z}{2 E I k^{2}}
$$

The boundary condition at the end support $z=0$ is satisfied when $v(z)=0$ and at the intermediate restraint $z=l / 2$ is satisfied when:

$$
v^{\prime}(z)=C_{1} k \cos k z-C_{2} k \sin k z+\frac{F_{v b}}{2 E I k^{2}}=0
$$

The solution of the Equation (2.17) which satisfies the boundary conditions is given by:

$$
v(z)=\frac{F_{v b} l}{2 N_{c}}\left(\frac{z}{l}-\frac{\sin k z}{k l \cos k l / 2}\right)
$$

Accordingly, by substituting second derivative of Equation (2.17) into Equation (2.4), the moment is given by:

$$
M(z)=-\frac{F_{v b} l}{2 k l} \frac{\sin k z}{\cos \frac{k l}{2}}
$$

Since the displacement at the intermediate restraint $\delta=v(l / 2)$, it follows that:

$$
\delta=\frac{F_{v b} l}{2 N_{c}}\left[\frac{\frac{k l}{2}-\operatorname{tg} \frac{k l}{2}}{k l}\right]
$$


By Equation (2.21) the relation between displacement at the restraint and restoring force can be obtained as follows:

$$
F_{v b}=2 N_{c} \frac{\delta}{l} \frac{k l}{\left(\frac{k l}{2}-\operatorname{tg} \frac{k l}{2}\right)}
$$

Equation (2.22) gives non-trivial solution as both restoring force and displacement at the restraint are not the constants, but variables. Since the restoring force depends on the displacement at the support, this method refers to the general case and accounting of interaction of the simultaneous bending and compression. Despite the bending effects being so small to be ignored, the simulation of flexure with infinitesimal distributed transverse load leads to the possibility of using governing equation of the general case and gives the desirable result due to previously described particular superposition.

Although, the restoring force relies not only on the displacement $\delta$, but also restraint stiffness $\alpha$ and the latter can be obtained by Equation (2.21) as:

$$
\alpha_{c}=\frac{2 E I}{l^{3}} \frac{(k l)^{3}}{\left(\frac{k l}{2}-\operatorname{tg} \frac{k l}{2}\right)}
$$

The restraint stiffness obtainable by Equation (2.21) gives the possibility of predicting the buckling modes of the compressive element with the intermediate elastic restraint.

\subsubsection{General Equations}

In previous sections, two structural models; an additionally inelastically restrained beam-column and column with the intermediate elastic restraint were assumed as boundary cases. Those boundary cases can be generalised and accounted by the calculation model shown in Figure 2.4. Main derivations for the considering problem will be obtained by determining the equilibrium equations and applying GNA.

By combining Equations $(2.1,2.9)$ with the boundary and continuity conditions of the simply supported beam-column shown in Figure 2.4:

$$
\begin{aligned}
& v^{l}(0)=v^{l} "(0)=0, v^{l}(l / 2)=v^{r}(l / 2)=\delta, v^{l}(l / 2)^{\prime}=v^{r}(l / 2)^{\prime}, \\
& v^{l}(l / 2) "=v^{r}(l / 2) ", v^{r}(l)=0, v^{r}(z)^{\prime \prime}=0
\end{aligned}
$$


where superscriptions " $l$ " and " $r$ " indicates respectively the left and the rights sides of the element accordingly to intermediate restraint.

The deflection is obtained as:

$$
\begin{aligned}
& v^{l}(z)=\frac{1}{N_{c}}\left[\frac{1}{2} F_{v b} l\left(\frac{z}{l}-\frac{\sin k z}{k l \cos \frac{k l}{2}}\right)+\frac{q l^{2}}{(k l)^{2}}\left(\operatorname{tg} \frac{k l}{2} \sin k z+\cos k z-1\right)-\right. \\
& \left.-q z\left(\frac{l}{2}-\frac{z}{2}\right)\right]
\end{aligned}
$$

and

$$
\begin{aligned}
& v^{r}(z)=\frac{1}{N_{c}}\left[\frac{1}{2} F_{v b} l\left(\frac{\cos k l \sin k z-\sin k l \cos k z}{k l \cos \frac{k l}{2}}-\frac{z}{l}+1\right)+\right. \\
& \left.+\frac{q l^{2}}{(k l)^{2}}\left(\operatorname{tg} \frac{k l}{2} \sin k z+\cos k z-1\right)-q z\left(\frac{l}{2}-\frac{z}{2}\right)\right]
\end{aligned}
$$

Accordingly, by Equation (2.13), the restoring force is given by:

$$
F_{v b}=2\left[\frac{q l}{k l} \frac{\left(1+\left(\frac{k l}{2}\right)^{2} / 2-1 / \cos \frac{k l}{2}\right)}{\left(\frac{k l}{2}-\operatorname{tg} \frac{k l}{2}\right)}+N_{c} \frac{\delta}{l} \frac{k l}{\left(\frac{k l}{2}-\operatorname{tg} \frac{k l}{2}\right)}\right]
$$

The derivation of restoring force by Equation (2.27) presents the possibility of superposition of previously described boundary cases as its first term is equal to Equation (2.14) and the second one to Equation (2.22).

By substituting the restoring force in terms of $F_{v b}=\alpha \delta$ in to Equation (2.27), the displacement at the restraint may be obtained as:

$$
\delta=\frac{q l^{4}}{E I(k l)^{4}} \frac{\left(1+\left(\frac{k l}{2}\right)^{2} / 2-1 / \cos \left(\frac{k l}{2}\right)\right)}{\left(\alpha / \alpha_{c}-1\right)}
$$


where $\alpha_{c}$ is restrained stiffness of the calculation model of the compressive element with the intermediate elastic restrained, obtained by Equation (2.23).

Alternatively, Equation (2.28) can be rearranged to express the relationship between the restoring force and the relative restraint stiffness as:

$$
F_{v b}=2 \frac{q l}{k l} \frac{\left(1+\left(\frac{k l}{2}\right)^{2} / 2-1 / \cos \frac{k l}{2}\right)}{\left(\frac{k l}{2}-\operatorname{tg} \frac{k l}{2}\right)} \times\left[1+\frac{1}{\left[\alpha / \alpha_{c}-1\right]}\right]
$$

The bending moment due to simultaneous effect of distributed transverse load and axial compression can be obtained by:

$$
M^{l}(z)=\frac{q l^{2}}{(k l)^{2}}\left(\operatorname{tg} \frac{k l}{2} \sin k z+\cos k z-1\right)-\frac{F_{v b} l}{2 k l} \frac{\sin k z}{\cos \frac{k l}{2}}
$$

and

$$
\begin{aligned}
& M^{r}(z)=\frac{q l^{2}}{(k l)^{2}}\left(\operatorname{tg} \frac{k l}{2} \sin k z+\cos k z-1\right)-\frac{F_{v b} l}{2 k l} \times \\
& \times\left(\frac{\cos k l \sin k z-\sin k l \cos k z}{\cos \frac{k l}{2}}\right)
\end{aligned}
$$

The deflection and moment are shown in Figures 2.7 a) and $2.7 \mathrm{~b}$ ), respectively. Curves are shown for $k l=0$ (refers to linear theory), $2 \pi \sqrt{0,25}$, $2 \pi \sqrt{0,5}$ and $2 \pi \sqrt{0,75}$ which correspond to $N_{c} / N_{e}=0,0,25,0,5$ and 0,75 since:

$$
k l=\pi \sqrt{\frac{N_{c}}{N_{e}}}
$$

Buckling load for symmetrical mode of considering element, varies from $\pi^{2} E I / l^{2}$, when restraint is of zero stiffness to approximately $\pi^{2} 8 E I / l^{2}$ (Trahair et al. 2008), when the restraint is rigid. Accordingly to assumed limiting restraint stiffness, as described in previous section, the Euler buckling load could be taken as: 


$$
N_{e}=\frac{4 \pi^{2} E I}{l^{2}}
$$

For $N_{c} / N_{e}=0$ the values of non-dimensional deflection and moment are obtained on the basis of a linear theory.

It can be seen that the deflection and bending moment increases rapidly as the axial force $\left(N_{c}\right)$ approaches the Euler force value $\left(N_{e}\right)$. The increase in bending moment due to additional $N_{c} v(z)$ - moment developing as the beamcolumn deflects and the applied axial force becomes eccentric to the element axis.

a)
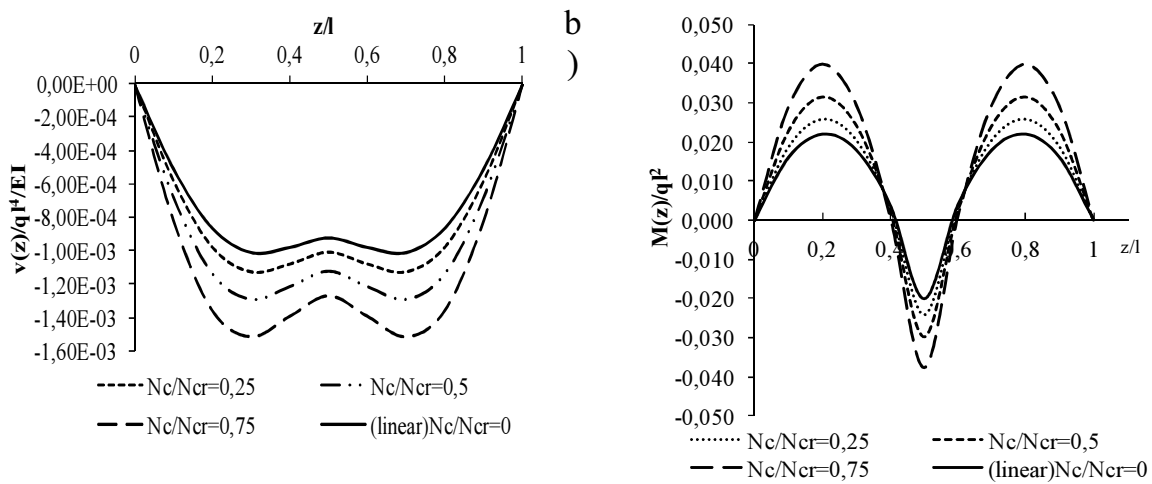

Fig. 2.7. a) Non-dimensional deflection and b) bending moment of beam-column with intermediate elastic restraint for various $N_{c} / N_{e}$ values

\subsubsection{Governing Parameters}

It can be seen that in all governing equation of considering structural element is an undetermined variable $k l$. This variable is assumed as the governing parameter in performing geometric non-linear analysis of beam-column and is named - slenderness parameter. The slenderness parameter relates to the axial load, the flexural rigidity and the length of the element and can be expressed as:

$$
k l=l \sqrt{\frac{N_{c}}{E I}}
$$


The deformation response of simply supported and an additionally elastically restraint beam-column can be expressed with the variation either of the displacement or the bending moment with the slenderness parameter. It's relation to buckling load was presented in the previous section. It should be noted that, for the correctness of this method, the slenderness parameter must be taken as non-zero variable.

The invariable lateral load $q(z)$ applied on an axially compressed element causes initial eccentricity which increase the stress, but it does not affects the elastic stability of the system (Gambhir 2004). Whereas in case of elastic restraint, it results in a deflection dependent lateral load and a restoring force as the deflection takes place. Thus the additional elastic restraint affects the elastic stability and even small restraint stiffness may cause a considerable increase in elastic stability of the member (Gambhir 2004). By combining Equations (2.23, 2.32) the particular values of restraint stiffness can be expressed as:

$$
\begin{gathered}
N_{c r}=\frac{\pi^{2} E I}{l^{2}}, k l=\pi, \alpha=\frac{2 E I}{l^{3}} \frac{(\pi)^{3}}{\left(\frac{\pi}{2}-\operatorname{tg} \frac{\pi}{2}\right) \rightarrow \infty} \rightarrow 0 \\
N_{c r}=\frac{8 \pi^{2} E I}{l^{2}}, k l=2 \sqrt{2} \pi, \alpha=\frac{2 E I}{l^{3}} \frac{(2 \sqrt{2} \pi)^{3}}{\left(\frac{2 \sqrt{2} \pi}{2}-\operatorname{tg} \frac{2 \sqrt{2} \pi}{2}\right) \rightarrow 0} \rightarrow \infty \\
N_{c r}=\frac{4 \pi^{2} E I}{l^{2}}, k l=2 \pi, \alpha=\frac{2 E I}{l^{3}} \frac{(2 \pi)^{3}}{\left(\frac{2 \pi}{2}-\operatorname{tg} \frac{2 \pi}{2}\right)}=16 \pi^{2} E I / l^{3}=\alpha_{L}
\end{gathered}
$$

The variation with the dimensionless retrained stiffness $\alpha l^{3} / 16 E I$ of the dimensionless buckling load was given by Trahair and co-workers, (2008) and the restraint stiffness value obtained by Equation (2.37) was assumed to be limiting as an additionally elastically restrained compression element buckles in the asymmetrical second mode.

In the general case when distributed lateral load $q(z)$ applied without reference to its value when the restraint stiffness exceeds the minimum value given by Equation (2.37) it cause significant changes of the deformational shape of the member. 


\subsubsection{Numerical Analysis}

The numerical analysis was carried out of the structural element shown in Figure 2.4 and using governing equations derived of the calculation model described in Section 2.1. For the comparison and affirmation of accuracy of the proposed method Finite Element analysis has been performed using non-linear solver of ANSYS program.

The considering beam-column has the following dimensions: $7530 \mathrm{~mm}^{2}$ cross-section, $10,0 \mathrm{~m}$ length and $1,157 \cdot 10^{13} \mathrm{Nmm}^{2}$ constant flexural rigidity. The boundary conditions are chosen to verify the simply supported conditions, and additional elastic support provided at the midspan of the element. The limiting value of the restraint stiffness accordingly by Equation (2.37) set equal to 1827 $\mathrm{N} / \mathrm{mm}$.

By considering the variation of the distributed lateral load from $2,5 \mathrm{~N} / \mathrm{mm}$ to $20 \mathrm{~N} / \mathrm{mm}$ and the relative restraint stiffness from 0,25 to 20,0 the deformational and flexural behaviour of the beam-column is shown in Figures 2.8 and 2.9 , respectively. GNA is performed increasing slenderness parameter from 0,5 to 6,0 by the increment of 0,5 .

Table 2.1 shows a comparison between the results obtained from the finite element analysis and the governing equation of the proposed method.

Table 2.1. Numerical values and errors

\begin{tabular}{|l|l|l|l|l|l|l|}
\hline \multicolumn{7}{|c|}{ Computational method/ANSYS } \\
\hline$q=1 \mathrm{~N} / \mathrm{mm}$ and $\alpha / \alpha_{L}=0,25$ & \multicolumn{1}{|c|}{$q=10 \mathrm{~N} / \mathrm{mm}$ and $\alpha / \alpha_{L}=1,0$} \\
\hline$k l$ & 3,00 & 3,14 & 3,50 & 3,00 & 3,14 & 3,50 \\
\hline \multicolumn{7}{|c|}{ Restoring force } \\
\hline $\mathrm{F}_{\mathrm{vb}}, \mathrm{kN}$ & $5,73 / 5,73$ & $6,37 / 6,36$ & $9,12 / 9,11$ & $61,8 / 61,8$ & $63,6 / 63,5$ & $69,1 / 69,0$ \\
\hline Errors, $\%$ & $-0,10$ & $-0,11$ & $-0,16$ & $-0,10$ & $-0,11$ & $-0,14$ \\
\hline$q=5 \mathrm{Nmm}$ and $\alpha / \alpha_{L}=0,5$ & $q=5 \mathrm{Nmm}$ and $\alpha / \alpha_{L}=0,75$ \\
\hline \multicolumn{7}{|c|}{ Bending Moment } \\
\hline $\begin{array}{l}M(z=l / 4), \\
\mathrm{kNm}\end{array}$ & $35,0 / 35,0$ & $37,0 / 37,0$ & $43,8 / 43,8$ & $26,6 / 26,6$ & $27,7 / 27,7$ & $31,0 / 31,0$ \\
\hline Errors, $\%$ & 0,00 & 0,00 & 0,00 & 0,02 & 0,02 & 0,03 \\
\hline$q=5 \mathrm{Nmm}$ and $\alpha / \alpha_{L}=0,75$ & & & \\
\hline \multicolumn{7}{|c|}{ Displacement } \\
\hline$v(z=l / 4)$, & $17,4 / 17,4$ & $18,0 / 18,0$ & $21,1 / 20,1$ & $27,0 / 27,0$ & $27,8 / 27,8$ & $30,3 / 30,2$ \\
\hline
\end{tabular}




\begin{tabular}{|l|l|l|l|l|l|l|}
\hline $\mathrm{mm}$ & & & & & & \\
\hline Errors, \% & $-0,08$ & $-0,09$ & $-0,11$ & $-0,08$ & $-0,09$ & $-0,11$ \\
\hline$\delta, \mathrm{mm}$ & $22,4 / 22,4$ & $23,2 / 23,2$ & $25,9 / 25,9$ & $33,8 / 33,8$ & $34,9 / 34,8$ & $37,9 / 37,8$ \\
\hline Errors, \% & $-0,10$ & $-0,10$ & $-0,14$ & $-0,10$ & $-0,11$ & $-0,14$ \\
\hline
\end{tabular}

It can be concluded from the Table 2.1 that, there is an acceptable agreement between the randomly chosen values of deflection, bending moment and restoring force obtained using governing equations of computational method and that obtained by the finite element analysis.

The relationship between slenderness parameter and either displacement or bending moment is non-linear and approaches the value of the slenderness parameter equal to 6,0 as it refers to gradually increasing compression force. Furthermore, the Figure 2.8 and Figure 2.9 show the increase of the deformation and the flexural response respectively with the increase of the lateral distributed load.

When the ration of the displacements is greater than 1,0 the restrained deflection shape of the element approaches the unrestrained deflection shape. When the relative displacement exceeds 1,0 and decreases the deflection of the element approaches the braced deflection shape.

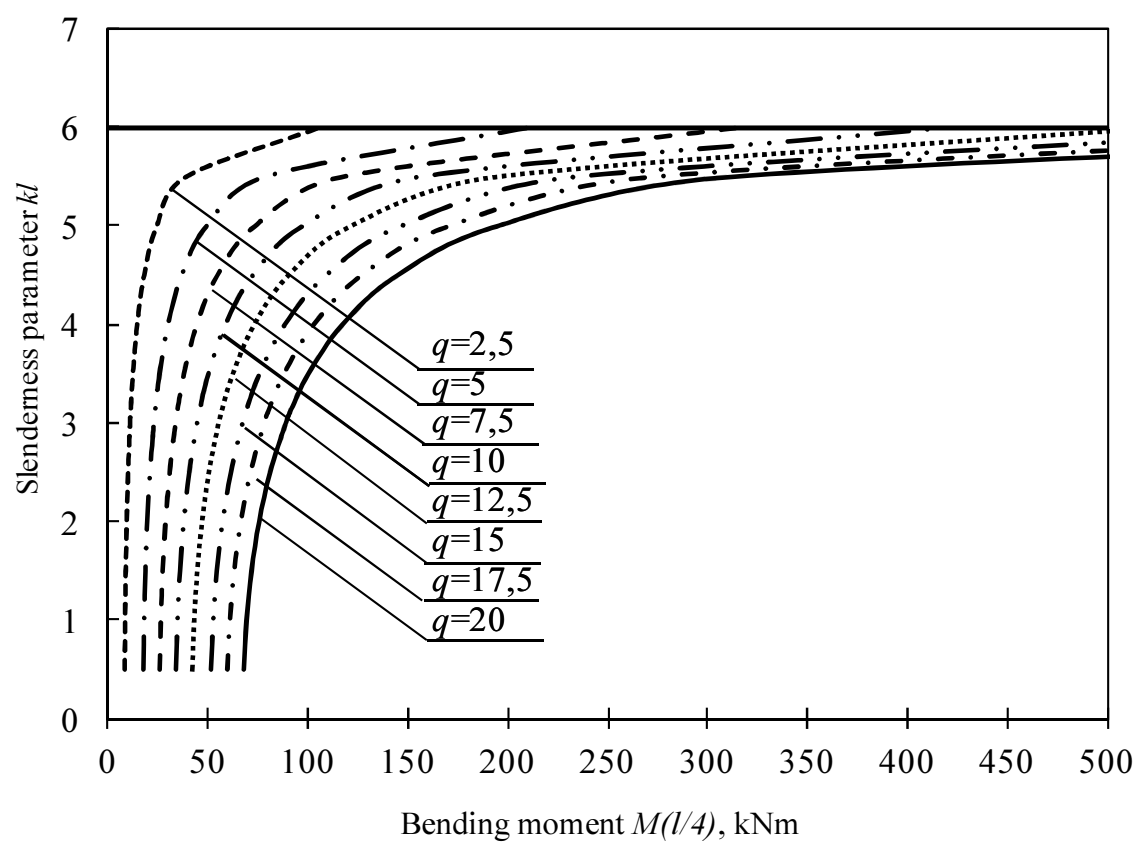


Fig. 2.8. The variation of the deformational response with the slenderness parameter

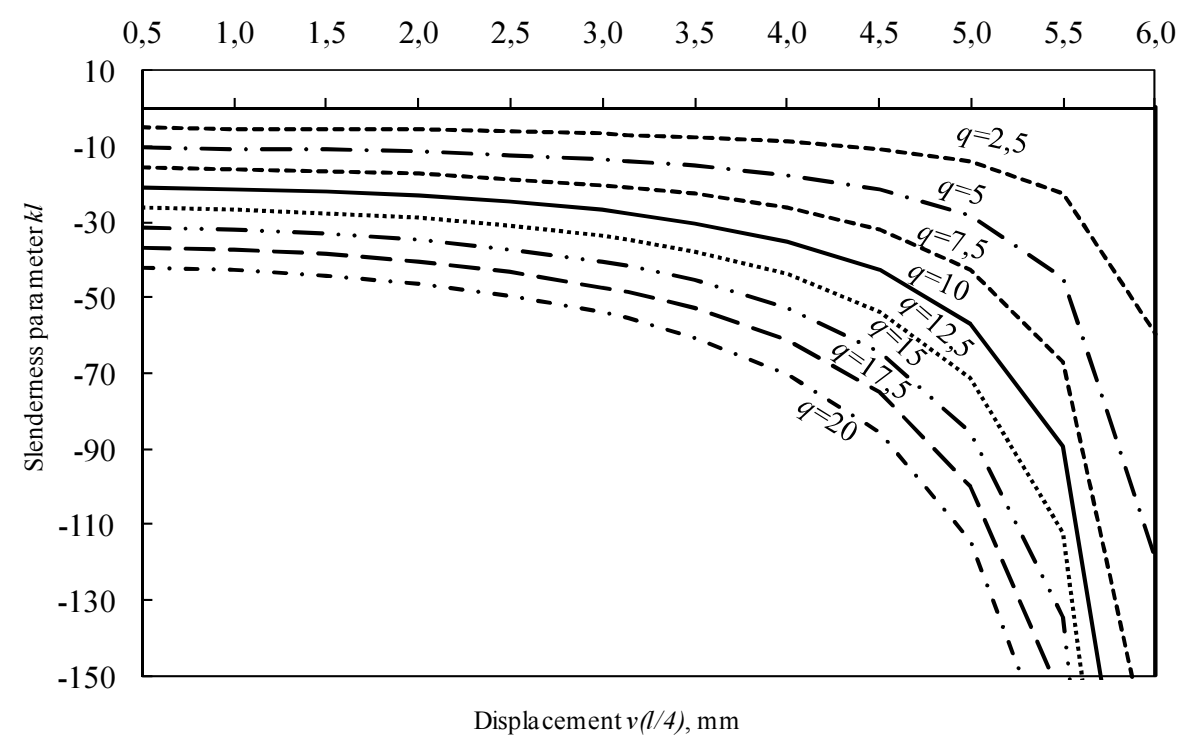

Fig. 2.9. The variation of the bending moment with the slenderness parameter

Figure 2.10 shows the variation of the dimensionless deflection $\delta / v(l / 4)$ with the relative stiffness $\alpha / \alpha_{L}$. The variation was obtained for the different values of the slenderness parameter and the constant lateral distributed load of $10 \mathrm{~N} / \mathrm{mm}$. Between the values of the relative restraint stiffness of 2 to 4 for any value of the slenderness parameter, the ratio of the restrained deflection and the deflection at the sagging part of the deflection shape becomes less than 1,0 . The value of the deflection ratio equal to 1,0 was assumed as the limiting value for the significant changes of the deflection shape of the element.

The variation of the dimensionless bending moment with the relative restraint stiffness for the different values of the slenderness parameter and the distributed lateral load of $10 \mathrm{Nmm}$ is shown in Figure 2.11. The ratio of the bending moments at the restraint and at the centre of the midspan respectively was taken to present the changes of the bending moment distribution relative to the restraint stiffness. When the ration of the restraint stiffness exceeds 1,0 , the bending moment changes the sign. The change of the sign from positive to 
negative presents the change of the bending moment at the restraint from disturbing to restoring.

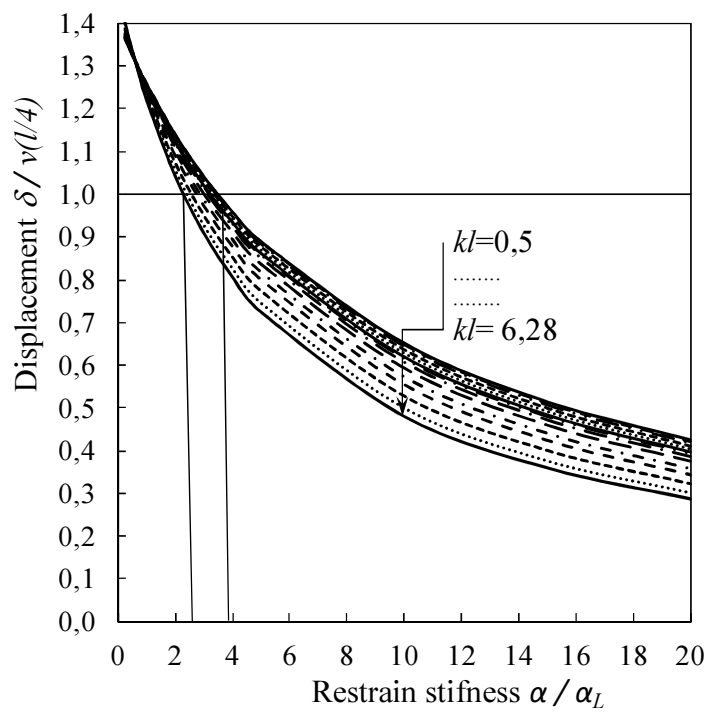

Fig. 2.10. The variation of the relative displacement with the relative restraint stiffness

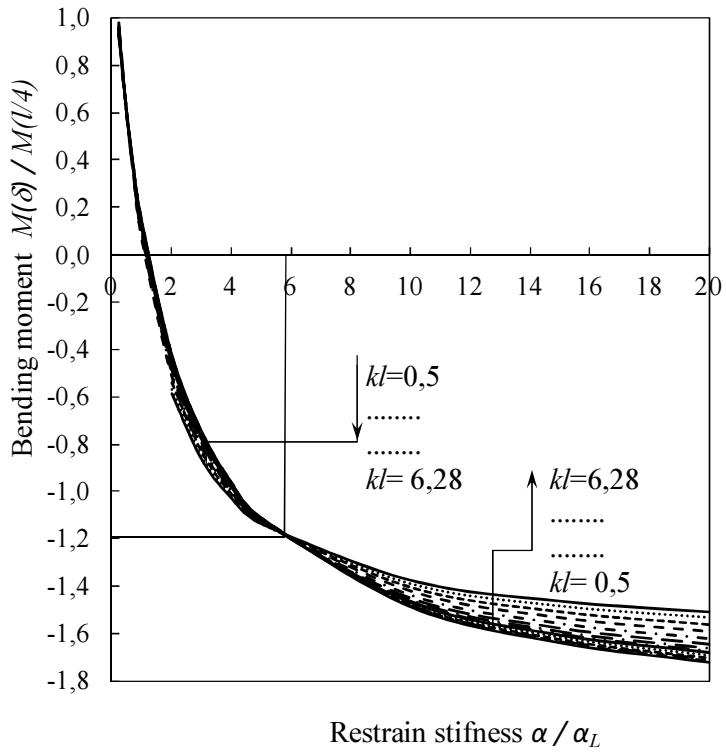


Fig. 2.11. The variation of the relative bending moment with the relative restraint stiffness

It can be seen that the variations of the greater slenderness parameter vanishes from the positive part of the chart this corresponds to the constant restoring moment at the support. The intersection of the graphs at the particular values of the relative restraint stiffness and the ratio of the bending moment shows the change of the acceleration of the restoring moment increase for the less values of the slenderness parameter. Furthermore the ration of the bending moment grater that- 1,0 presents the extreme values of the bending moment shifting from sagging to hogging.

\subsection{Parametric Studies of Double-Level Under-Deck Cable-Stayed Bridge}

\subsubsection{Computational method}

There are two response mechanisms in the under-deck cable-stayed bridge considering the action of vertical loads: axial response (tension of stay cables and compression of the deck and struts) and flexural response (bending of the deck) (Ruiz-Teran, Aparicio 2007b). Fig. 2.12 describes these mechanisms of structural response in the under-deck cable-stayed bridge with one strut at the midspan under the action of uniform distributed vertical load. The same structural response can be found in a simply supported continuous beam additionally restrained in the centre. Such structural members are termed an additionally restrained beam-column.

Axial compression and restraint stiffness are related to the structural response of the CS system. For a correct solution, the structural response of the CS system has to be analyzed following an appropriate procedure and correctly implemented in the calculation model of the additionally restrained beamcolumn. Fig. 2.12 shows the calculation model of such element.

When considering the interaction between the cable-staying system and the rigid beam, the axial response of the CS system can be sub-divided into horizontal and vertical components respectively and implemented into the calculation model. The horizontal component $H_{t}$ of axial force in the cablestaying system can be introduced to the beam-column as compression load $N_{c}$ and the vertical can be found as compression force in strut $F_{S t}$. The strut at the midspan of the deck prevents it from lateral deflection and can be implemented 
as elastic restraint in the calculation model with appropriate stiffness $\alpha$. Lateral restraint restricts the deflection of the member to a greater or lesser extent $\delta$. The deflection of the structural element due to external loading develops restoring force $F_{v b}$ at the restraint related to an axial response of strut $F_{S t}$. Finally, the analysis procedure of the developed calculation model is based upon the solution of appropriate differential equations.

a)

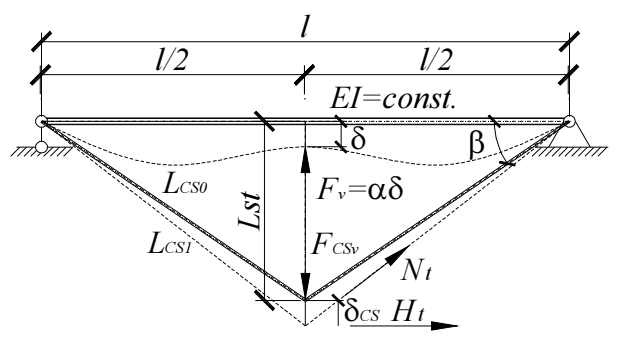

b)

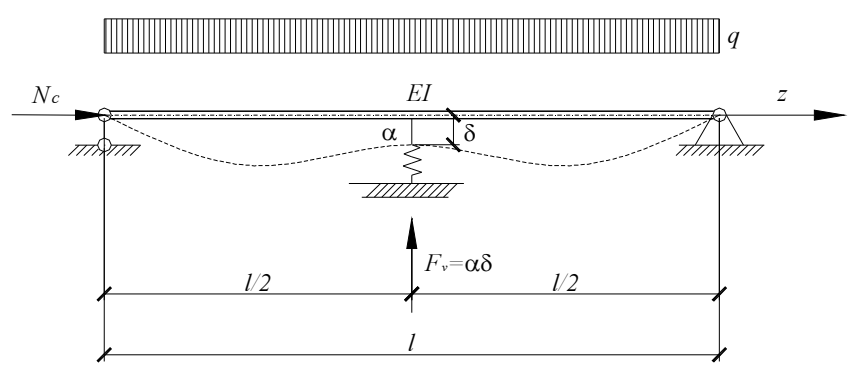

Fig. 2.12. Structural response in UDCS bridge: a) the interaction between the cablestaying system and the rigid beam, b) calculation model of the simply supported additionally restrained continuous beam-column

\subsubsection{Evaluation of Geometrical Nonlinearities}

This section contributes in emphasizing the necessity of GNA considering steel structures with supporting system. The numerical analysis performed considering mono-strut semi-continuous UDCS structure as shown in Figure 2.12 varying the slenderness parameter what results in variation of axial force in RB. The slenderness parameter variation in UDCs structure can be performed by varying the length of the strut as described in Section 2.1.2. Data obtained using randomly chosen European I sections for RB of the UDCS structure. Figure 2.13 a) and b) presents comparison between deformational and flexural response, respectively performing linear and non-linear analysis by FE code ANSYS. 
Figure 2.12 shows the comparable results. It can be seen that for the case of very stocky elements as refers to slenderness parameter from 0,5 to 2,5 linear analysis draws the errors less than $10 \%$, this points to inaccuracy, but still can be assumed as allowable.

a)

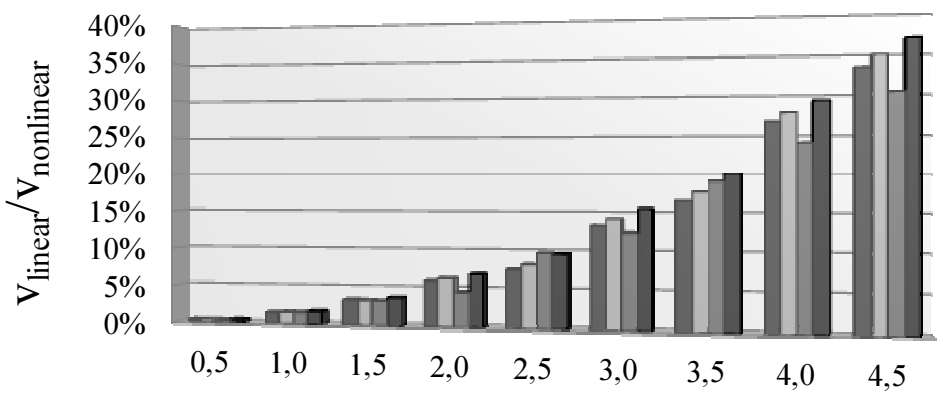

\begin{tabular}{|l|c|c|c|c|c|c|c|c|c|}
\cline { 2 - 9 } \multicolumn{1}{c|}{$k l$} & 0,5 & 1 & 1,5 & 2 & 2,5 & 3 & 3,5 & 4 & 4,5 \\
\hline$\square$ IPE 240 & $0 \%$ & $1 \%$ & $3 \%$ & $6 \%$ & $8 \%$ & $13 \%$ & $17 \%$ & $27 \%$ & $33 \%$ \\
\hline$\square$ HEA 200 & $0 \%$ & $2 \%$ & $3 \%$ & $6 \%$ & $8 \%$ & $14 \%$ & $18 \%$ & $28 \%$ & $35 \%$ \\
\hline$\square$ IPE 270 & $0 \%$ & $2 \%$ & $3 \%$ & $5 \%$ & $10 \%$ & $13 \%$ & $19 \%$ & $24 \%$ & $30 \%$ \\
\hline$\square$ IPE 220 & $0 \%$ & $2 \%$ & $4 \%$ & $7 \%$ & $10 \%$ & $15 \%$ & $20 \%$ & $29 \%$ & $37 \%$ \\
\hline
\end{tabular}

b)

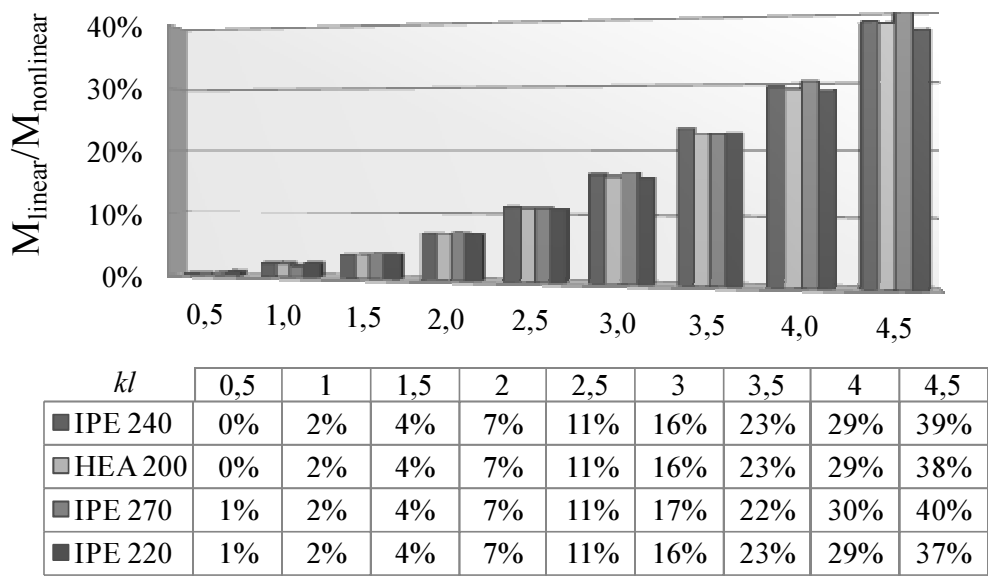

Fig. 2.13. Evaluation of geometrical nonlinearities: a) deformational response,

b) flexural response 
However, when the slenderness parameter exceeds the value of 2,5 the errors gradually increase and already at the value of 3,0 draws the errors of $15 \%$ and for the value of 4,5 even $40 \%$. At this point, the limits for the possibility of neglecting geometrical nonlinearities of considering structures can be assessed. Between the values of slenderness parameter of 0,5 to 2,5 the linear analysis can be used and further just GNA gives safe results for structural response of considering structures. Even though the linear analysis is allowable this section shows that it is not accurate and safe.

\subsubsection{Numerical Evaluation}

To test the accuracy of the proposed computational method, numerical evaluation was carried out. The calculation model of the under-deck cablestayed bridge with one strut cable-staying system shown in Fig. 2.12 b) was used. In the calculation model, the span of the bridge assumed of $18 \mathrm{~m}(l=18)$ and the properties of the cross-section were taken as follows: $A=14282 \mathrm{~mm}^{2}, I=$ $0,242 \cdot 10^{9} \mathrm{~mm}^{4}, h=300 \mathrm{~mm}, E=210000 \mathrm{~N} / \mathrm{mm}^{2}$. The cable-staying system of two stays, each with a cross-section of $A_{C S}=7848 \mathrm{~mm}^{2}$ and the modulus of elasticity $E=210000 \mathrm{~N} / \mathrm{mm}^{2}$ was self-anchored into the deck and deflected by one strut at the midspan subdividing it into two equal parts. The strut was $3 \mathrm{~m}$ long; thus, the eccentricity of the cable-staying system was $1 / 12$ th of the span. The cross- section of the strut was $A_{S}=5184 \mathrm{~mm}^{2}$, the modulus of elasticity $E$ $=210000 \mathrm{~N} / \mathrm{mm}^{2} \mathrm{~N} / \mathrm{mm}^{2}$ and had a pin connection with the deck.

Subsequently, the same structural scheme was used for solving the problem of the nonlinear solver of finite element software ANSYS.

Table 2.2 shows the numerical results of the flexural response of the deck by means of the bending moment and deflection at the point of $z=9 \mathrm{~m}$.

Table 2.2. The results of the numerical example

\begin{tabular}{|l|l|l|l|}
\hline Structural Response & $\begin{array}{l}\text { Proposed } \\
\text { computational } \\
\text { method }\end{array}$ & $\begin{array}{l}\text { FE model with } \\
\text { ANSYS }\end{array}$ & $\begin{array}{l}\text { Difference, } \\
\%\end{array}$ \\
\hline Bending moments in the deck & $-185,8$ & $-186,9$ & 0,60 \\
\hline Maximum, kNm & 139,7 & 140,9 & 0,87 \\
\hline Minimum, kNm & 26,98 & 27,07 & 0,35 \\
\hline Deflection &
\end{tabular}


Axial response in the strut

\begin{tabular}{|l|l|l|l} 
Compression load, $\mathrm{kN}$ & 225,4 & 226,1 & 0,27
\end{tabular}

Furthermore, restoring force at the restraint was calculated using governing equations of the proposed computational method. In parallel with parametric analysis, the results of the same governing parameter were obtained by running the non-linear solver of FE software ANSYS. The results of ANSYS give the axial response of the strut instead of restoring force obtained by combining governing equations and the calculation model. Although, it can be seen that differences are less than one percent, thus, restoring force in the calculation model approaches axial compression in the structural scheme. The last column in Table 2.2 shows that all differences are acceptable to represent the computational method to be accurate and relevant.

\subsubsection{Evaluation of Axial Force}

The interaction between the rigid beam and the cable-staying system under distributed vertical load presented in Fig. 2.12 a) results in the axial force in the rigid beam. By applying the iteration process to an axial response of the CS system developed by non-linear analysis, axial force can be obtained as follows

$$
N_{c}=\frac{F_{S t} l}{4\left(L_{S t}+\delta_{C S}\right)}
$$

For the first iteration, the vertical component of axial force in cable-staying system $F_{S t}$ may be assumed to be constant and equal to restoring force at restraint $F_{v}$. Accordingly, taking into account Equation (2.27), restoring force may be obtained as one of boundary solutions when central deflection $\delta$ approaches zero.

The deflection of cable-staying system $\delta_{C S}$ can be found by constitutive equations

$$
L_{C S, 1}=L_{C S, 0}+\Delta L_{C S}
$$

where $L_{C S, 0}$ is the initial length of stay cables as shown, in Fig. 2.12 a)

$$
L_{C S, 0}=2 \sqrt{L_{S t}^{2}+0,25 l^{2}}
$$

$L_{C S, 1}$ is the length of stay cables in the deflected shape 


$$
L_{C S, 1}=2 \sqrt{\left(L_{S t}+\delta_{S C}\right)^{2}+0,25 l^{2}}
$$

and $\Delta_{C S}$ is an elastic elongation of stay cables

$$
\Delta L_{C S}=\frac{H_{t} l}{E_{C S} A_{C S} \cos ^{2} \beta}
$$

where $\beta$ is the angle between stay cables and the rigid beam shown in Fig. 2.12 a); $E_{C S}$ and $A_{C S}$ are the modulus of elasticity and the cross-section of stay cables, respectively.

Furthermore, the deflection of the cable-staying system may be obtained approximately by

$$
\delta_{C S}=\frac{F_{S t} l^{3}}{16 E_{C S} A_{C S} L_{S t}{ }^{2}\left(1+F_{S t} l^{3} / 16 E_{C S} A_{C S} L_{S t}{ }^{3}\right)}
$$

Assuming that the deflection of cable-staying system corresponds to the restrained deflection of the rigid beam at the end of the iteration, a convergence check of restoring force $F_{v}$ and the vertical component of axial force in cablestaying system $F_{v C S}$ is carried out

$$
\left|F_{S t}\right|-\left|F_{v b}\right| \leq \varepsilon
$$

Parameter $\varepsilon$ depends on acceptable tolerance, i.e. the desirable accuracy of the iteration process.

\subsubsection{Algorithm of Geometrically Nonlinear Analysis for Double-Level Under-Deck Cable-Stayed Bridge}

For the application of the proposed computational method of the mono-strut cable-staying system to the structural scheme with the double-level cablestaying system, the following algorithm can be used.

- The whole structural scheme is sub-divided into three individual structural schemes. One of those incorporates the geometry of the first and two others of the second-level cable-staying system respectively. According to the structural schemes, two calculation models of an additionally restrained beam column have to be used.

- When using general equations for the non-linear analysis of the considered structure, the first and the second calculation models are 
used separately. The interaction must be assessed with reference to the iteration process.

- Compression force implemented in the calculation model to obtain the structural response of the whole structure must be calculated following a two step procedure. First, non-liner analysis is performed combining the first calculation model of the additionally restrained beam-column and axial compression obtained performing the first level-cable system analysis. Then, the obtained axial force is amplified analysing the second level cable-staying system and the convergence of axial forces.

- The iteration process has to be repeatedly carried out for both the accuracy of axial force and restrained deflection and implemented into the second calculation model. Then, general equations can be used for obtaining the governing parameters.

\subsubsection{Numerical Evaluation}

This section runs a numerical example of the under-deck cable-stayed bridge with the unconventional cable staying system. The problem was solved using both the computational method and commercial software ANSYS based on a non-linear algorithm.

Consider the structural scheme and geometrical parameters used for the numerical example provided in Section 2.3.3. According to the layout of the cable-staying system shown in Fig. 2.3 b), two mono-strut structural schemes, are used for the elevation of the second-level cable-staying system. Implementing two mono-strut structural schemes into the whole structure, the span of the bridge gets the length of $36 \mathrm{~m}$.

The stay cables of the first level are divided by the strut of the $4 \mathrm{~m}$ length, which is the $1 / 9^{\text {th }}$ of the span. The numerical value of a cross-section of stay cables has been taken the same as the one for the second level stay cables and is presented in Section 2.3.3.

Both symmetric and asymmetric load cases are considered to obtain the flexural response of the RB. In case of symmetric loading, transverse load $q=20$ $\mathrm{kN} / \mathrm{m}$ is applied to the whole structure. Accordingly, considering the case of asymmetric loading, transverse load $q=20 \mathrm{kN} / \mathrm{m}$ acts on a half of the span and $q=10 \mathrm{kN} / \mathrm{m}$ on the other one, respectively.

Table 2.3 shows the extreme values of hogging and sagging bending moments and the maximum values of the deflection of the RB. For the case of symmetric loading, the deformation response of the RB is presented in the first column of Table 2.3. Applying asymmetric load, the deformation response of the 
$\mathrm{RB}$ is the combination of the results given in the first and second columns in Table 2.3 , respectively.

Table 2.3. The results of the numerical example

\begin{tabular}{|l|l|l|l|l|l|l|}
\hline \multicolumn{7}{|c|}{ Asymmetric loading } \\
\hline $\begin{array}{l}\text { Structural } \\
\text { response }\end{array}$ & $\begin{array}{l}\text { Proposed } \\
\text { comp. } \\
\text { method }\end{array}$ & $\begin{array}{l}\text { FE } \\
\text { model } \\
\text { with } \\
\text { ANSYS }\end{array}$ & $\begin{array}{l}\text { Diff. } \\
\%\end{array}$ & $\begin{array}{l}\text { Proposed } \\
\text { comp. } \\
\text { method }\end{array}$ & $\begin{array}{l}\text { FE } \\
\text { model } \\
\text { with } \\
\text { ANSYS }\end{array}$ & $\begin{array}{l}\text { Diff. } \\
\%\end{array}$ \\
\cline { 2 - 7 } & $\begin{array}{l}\text { Multispan with applied load: q } \\
=20 \mathrm{kN} / \mathrm{m}\end{array}$ & $\begin{array}{l}\text { Multispan with applied load: q } \\
10 \mathrm{kN} / \mathrm{m}\end{array}$ \\
\hline \multicolumn{7}{|c|}{ Bending moments in RB } \\
\hline $\begin{array}{l}\text { Maximum, } \\
\text { kNm }\end{array}$ & $-186,9$ & $-186,7$ & $-0,11$ & $-87,55$ & $-87,53$ & $-0,03$ \\
\hline $\begin{array}{l}\text { Minimum, } \\
\text { kNm }\end{array}$ & 136,7 & 136,6 & $-0,06$ & 69,30 & 69,28 & $-0,03$ \\
\hline Displacement & 64,6 & 64,6 & $-0,01$ & 75,55 & 75,53 & $-0,08$ \\
\hline $\begin{array}{l}\text { Maximum, } \\
\text { mm }\end{array}$ & 64,03 & \\
\hline
\end{tabular}

Differences presented in Table 2.3 declare the accuracy of the computational method comparing to the non-linear solver of FE software ANSYS. As the differences are less than one percent, the computational method can be safely used for the structural response analysis of the UDCS bridge with the double-level cable-staying system both for symmetric and asymmetric loading.

\subsection{Comparison Analysis of Under-Deck Cable-Stayed Bridges}

To highlight the stability of the proposed morphology, structural schemes for the UDCS bridge with double-level and multiple struts cable-staying systems were analysed using FE software ANSYS. 


\subsubsection{Finite Element Analysis}

Double-level cable-staying system. For the structural scheme of the under-deck cable-stayed bridge with the double-level cable-staying system, geometrical parameters were taken as described in Section 2.3.6. Alternatively, the structural scheme of the length of $36 \mathrm{~m}$ span bridge with the length of intermediate strut of $4 \mathrm{~m}$, which is the $1 / 9^{\text {th }}$ of the span is analysed.

Multiple-struts cable-staying system. The structural scheme with multiple struts has the parabolic layout of the cable-staying system. Elevation has been designed of 7 struts and previously described length of the strut at the midspan. Alternative structural schemes are shown in Fig. 2.14 a) and b).

a)

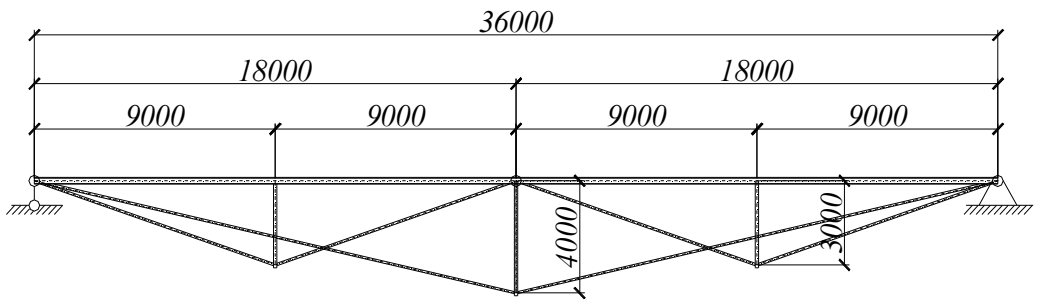

b)

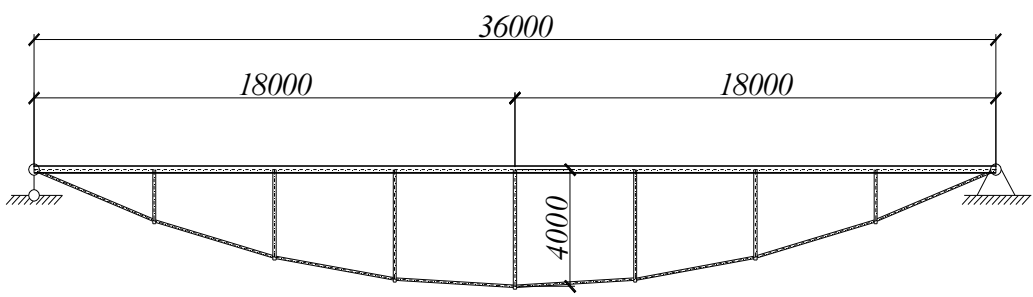

Fig. 2.14. Comparative morphology of UDCS bridges: a) double-level;

b) multiple-struts

The cross-section parameters of the structural elements of the cablestaying system and the deck of the bridge with the multiple struts cable-staying system were taken as described in preceding Section 2.3.3.

In case of a permanent state, dead load $g=10 \mathrm{kN} / \mathrm{m}$ is applied. According to possible live load models for footbridge design, the cases of symmetric and asymmetric loading are considered and configurations of load $q=10 \mathrm{kN} / \mathrm{m}$ were used as shown in Fig. 2.15.

The limit value of maximum displacement of the structure to satisfy serviceability limit state and aesthetic requirements is set to $90 \mathrm{~mm}$. 
The deformation response of the alternative structural schemes is obtained performing the GNA of the structure to compare and contrast the considering schemes of the UDCS bridges.

a)

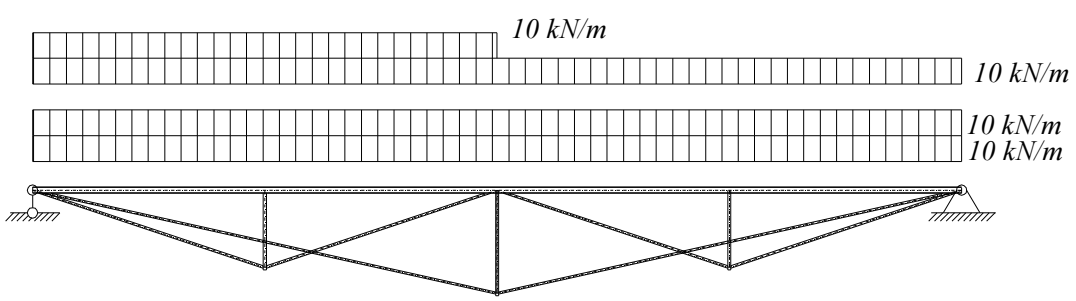

b)

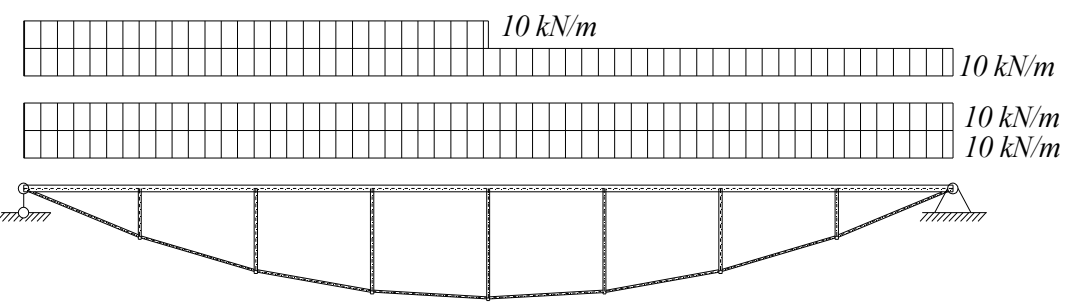

Fig. 2.15. Loading conditions for comparative UDCS bridges: a) double-level;

b) multiple-struts b

\subsubsection{Finite Element Results}

The numerical values of extreme bending moments in the RB and a deformed shape of both analyzed structural schemes under symmetric and asymmetric loading are presented in Fig. 2.16 and 2.17, respectively.

In case of symmetric loading, the extreme bending moments in the underdeck cable-stayed bridge with conventional cable-staying system are less than those in the bridge with unconventional cable-staying system. Thus, the conventional cable-staying system becomes more efficient. According to a greater number of struts, the subdivision of the deck increases. An increase in the subdivision of the span localizes bending moments and decreases the flexural response of the deck.

In case of asymmetric loading, the unconventional double-level cablestaying system causes less flexural response of the deck by means of lower extreme values of bending moments compared to the conventional bridge.

A comparison of deformations of alternative schemes points out that the double-level cable-staying system is more stable than the multiple struts cablestaying system. The aspect of stability has significant importance for designing 
bridge structures, which indicates that the structural scheme with multiple struts is sensitive to asymmetric loading and deforms in the asymmetric shape. Furthermore, deflection exceeds the limit value to satisfy requirements for serviceability limit state. Thus, the flexural rigidity of the deck has to be increased, and the moment of inertia set to $I=0,559 \cdot 109 \mathrm{~mm}^{4}$ to get the displacement of $86,54 \mathrm{~mm}$ which fits into the established limits.

Economy was not the key aspect of comparison analysis. However, the flexural rigidity of the steel beam used for designing the deck in case of the multiple struts structural scheme has to be increased in order to fit the limit value of displacement, and that causes an increase in the cross-section. The growth of the cross-section of the beam causes an increase in active steel and a decrease in economic efficiency.

a)

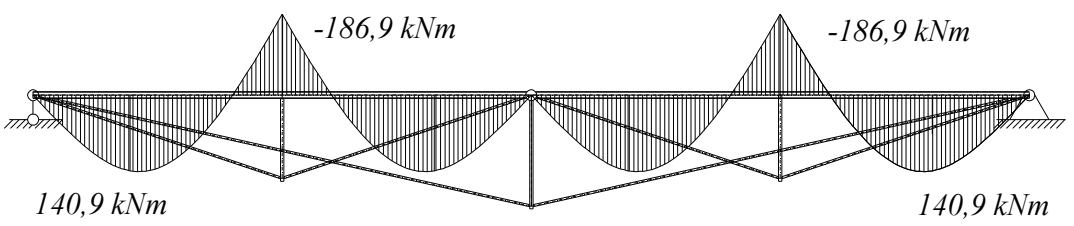

b)

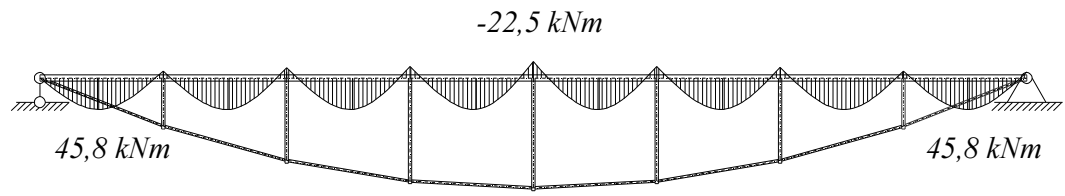

c)

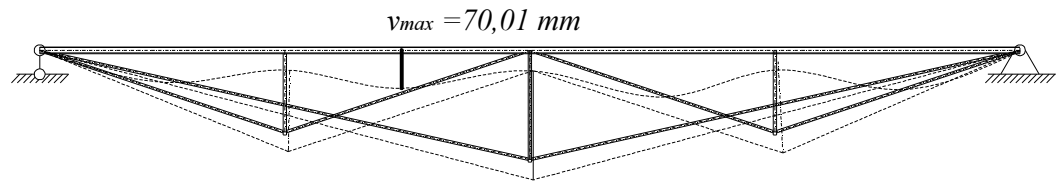

d)

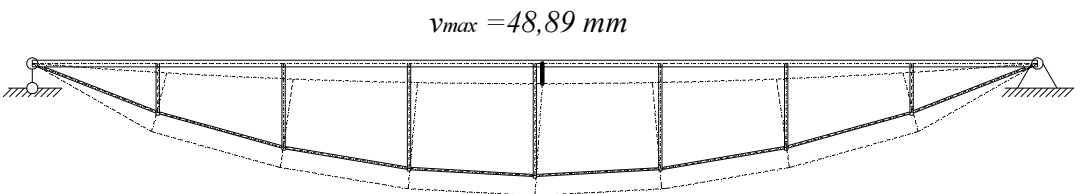

Fig. 2.16. Structural response of comparative UDCS bridges under symmetric loading: flexural response in UDCS double-level bridge a); flexural response in UDCS multiple-struts bridge b); deformational response in UDCS double-level bridge c); deformational response in UDCS multiple-struts bridge d) 
a)

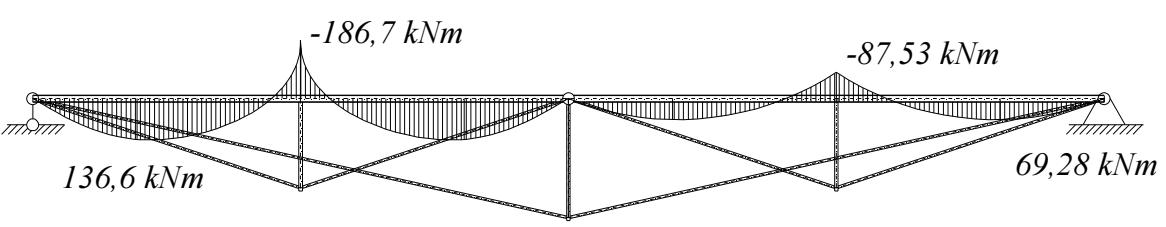

b)

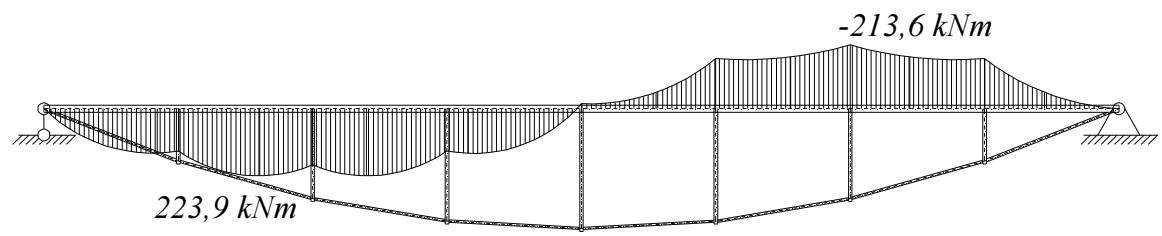

c)

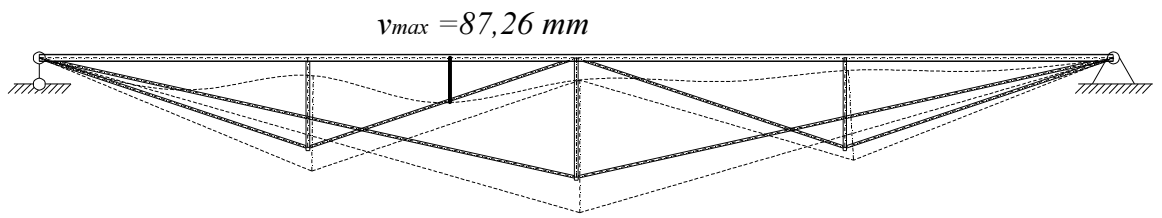

d)

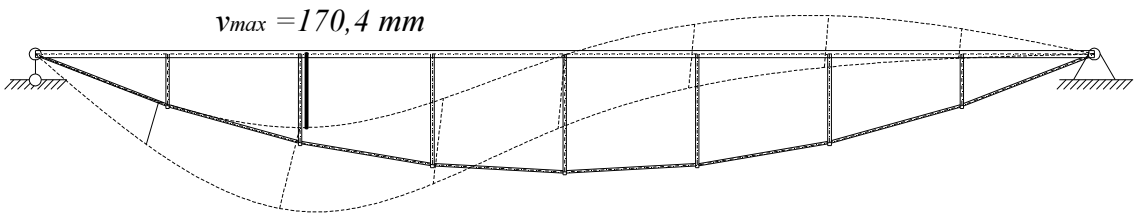

Fig. 2.17. Structural response of comparative UDCS bridges under asymmetric loading: a) flexural response in UDCS double-level bridge; b) flexural response in

UDCS multiple-struts bridge; c) deformational response in UDCS double-level bridge; d) deformational response in UDCS multiple-struts bridge

\subsection{Concluding Remarks of Chapter 2}

Chapter 2 draws the following conclusions:

1. Section 2.1 develops the new arrangement of the cable-staying system for the UDCS bridge. New form solves the problem of the deformational response of the UDCS structures under the case of asymmetric loading. Discretization of the Double-Level UDCS bridge provides simplified design procedure based on calculation model of mono-strut UDCS bridge, which refers to calculation model of BCIR.

2. Results of the FE analysis were found to be in an acceptable agreement with the analytical solution. 
3. Study on the elastically restrained beam-column element resulted in a generalized calculation model and a new computational method based on GNA for the accurate and safe structural analysis of the BCIR.

4. Parametric study defined parameters governing the structural response of BCIR and presented the appropriate relationships. Comprehensive numerical analysis on the structural response of the BCIR resulted in the required data describing the influence of the governing parameter on the deformational and flexural behaviour of the BCIR. Particularly, the influence of the additional restraint stiffness on the deflection shape of the structural element has been discussed. It has to be noted that the provided elastic restraint results in a deflection dependant lateral load and increases its influence on the elastic stability of the considering element.

5. Generalized calculation model of BCIR closely reflects structural behaviour of mono-strut UDCS bridge and can be used for simplified structural analysis based on GNA.

6. Comparison analysis between linear and nonlinear procedures applied analysing structural behaviour of UDCS bridge outlined the limits of GNA necessity in accordance to obtain safe and accurate results. It was shown that for slenderness parameter varying between 0,5 and 2,5 the linear analysis is possible despite that it is inaccurate, but exceeding the value of the slenderness parameter of 2,5 the errors increase gradually from $15 \%$ and can result in $40 \%$ under arbitrary value of the slenderness parameter.

7. Due to discretization of a new form of UDCS bridge to mono-strut substructure the generalized calculation model structural analysis of the considering bridge can be analysed with the approach of BCIR. Applying appropriate iterative algorithm for the axial response evaluation of the Double-Level UDCS bridge the results obtained performing GNA of BCIR can be directly obtained for the whole structure as well as their sub-parts separately.

8. Verification of the adequacy of the proposed computational method for the Double-Level UDCS bridge performed through numerical example using governing equations and FE ANSYS code. The errors obtained through the comparison analysis have not exceed $0,11 \%$ both for deformational and flexural response.

Finally, a comparative analysis of conventional and unconventional UDCS bridges shown in Fig. 2.14 was performed. In case of asymmetric loading, analysis shows that the unconventional cable-staying system is more stable than the conventional one with multiple struts as stability is the main issue on bridges design. 


\section{Direct Stability Analysis and Structural Design of Under-Deck Cable-stayed Bridges}

This chapter details the improvements done on calculation model of the beamcolumn element with indirect intermediate supports by accounting for initial geometric imperfections and residual stresses. Generalized imperfections embedded into the considering calculation model for the evaluation of the amplitude of the initial curvature of the beam-column element. Adjusted generalized calculation model used to evaluate structural behaviour of BCIR and UDCS bridges as refers to Direct Method Analysis. Moreover, this chapter deals with effective technique for structural response control of simple-span UDCS bridges and outlines the limits of efficiency by comparison analysis with multistrut UDCS brides. 


\subsection{Direct Stability Analysis of Beam-Column with Intermediate Elastic Restraint}

This section deals with the improvements, which have to be done on the generalized calculation model of BCR performing structural analysis based on the Direct Method.

\subsubsection{Generalized Imperfections}

Appropriate allowances shall be incorporated in the structural analysis to cover the effects of imperfections, including residual stresses and geometrical imperfections.

Residual stresses are introduced into structural shapes as a result of the production. The direct inclusion of the residual stresses in the analysis is connected with the manufacture-related approaches, which lies in the formulation of requirements that will appropriately consider all relevant factors; thus it becomes a task so complex as to be impossible. Theoretical values, for example, of the residual stresses in a shape, can be used, but this may impair the quality of the results. There are other methods based on the theoretical developments. The most important among the theoretical based methods is the one that utilizes several column strength curves. It has been included in methods proposed in many those days modern design codes. For the sake of simplicity in the proposed computational method, the residual stresses are accounted by the concept of equivalent geometric imperfections, with values which reflect both geometrical and material imperfections and are based on the column strength curves.

Geometrical imperfections are inherent in all structures. Small unavoidable eccentricities of loading and lack of initial straightness can be simulated mathematically by assuming initial curvature, which produces a small central deflection $v_{m 0}$. According to equivalent geometric imperfections concept central deflection is modified on the basis of generalized imperfection factor. The generalized imperfection factor was introduced in the Perry-Robertson formula. The value of the generalized imperfection factor originally obtained by Robertson in 1925 has varied over the years and rearranged in the form of:

$$
\eta=0,001 a\left(\lambda-\lambda_{0}\right)>0
$$

where $a$ varies from 2 to 8 depending on the shape of the section and limiting slenderness ratio: 


$$
\lambda_{0}=0,2 \sqrt{\frac{\pi^{2} E}{f_{y}}}>0
$$

where $E$ is Elastic modulus; $f y$ is yield strength.

Substituting Equation (3.2) into Equation (3.1) and introducing nondimensionless slenderness:

$$
\bar{\lambda}=\frac{\lambda}{\sqrt{\frac{\pi^{2} E}{f_{y}}}}
$$

hence:

$$
\eta=\alpha(\bar{\lambda}-0,2)
$$

where $\alpha=0,001 a\left(\pi^{2} E / f_{y}\right)^{1 / 2}$ is an imperfection factor based on the column strength curves and the multiplier 0,001 presents the maximum tolerance on elements out of straightness specified in many design codes.

The magnitude of the equivalent geometric imperfections by introducing generalized imperfection factor can be obtained (Ronald and Maquoi 1979):

$$
v_{m 0}=\alpha(\bar{\lambda}-0,2) \frac{W}{A}
$$

where $A$ is cross section area; $W$ is section modulus.

\subsubsection{Effect of Imperfections}

This section is a sequence for the section 2.3.2 and contributes in emphasizing the influence of the imperfections considering steel structures with supporting system. The numerical analysis performed considering mono-strut semicontinuous UDCS structure as shown in Figure 2.12 varying the slenderness parameter what results in variation of axial force in RB. The slenderness parameter variation in UDCs structure can be performed by varying the length of the strut as described in Section 2.1.2. Data obtained using randomly chosen European I sections for RB of the UDCS structure. Figure 3.1 presents comparison between deformational and flexural response, respectively performing GNA and GNIA analysis by FE code ANSYS. 
a)

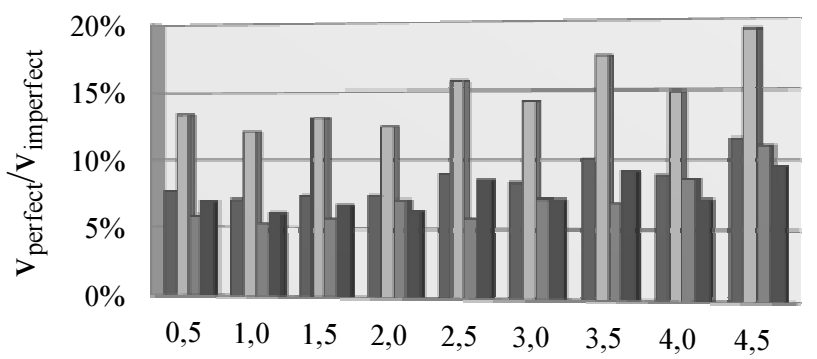

\begin{tabular}{|c|c|c|c|c|c|c|c|c|c|}
\hline & 0,5 & 1 & 1,5 & 2 & 2,5 & 3 & 3,5 & 4 & 4,5 \\
\hline 40 & $8 \%$ & $7 \%$ & $7 \%$ & $7 \%$ & $9 \%$ & $8 \%$ & $10 \%$ & $9 \%$ & 2 \\
\hline 0 & $13 \%$ & $12 \%$ & $13 \%$ & $12 \%$ & $16 \%$ & $14 \%$ & $17 \%$ & $15 \%$ & 19 \\
\hline 0 & $6 \%$ & 570 & $6 \%$ & $7 \%$ & $6 \%$ & $7 \%$ & $7 \%$ & $9 \%$ & $11 \%$ \\
\hline IDE? & $70 \%$ & $6 \%$ & $7 \%$ & $6 \%$ & $9 \%$ & $7 \%$ & $9 \%$ & $7 \%$ & $0 \%$ \\
\hline
\end{tabular}

b)

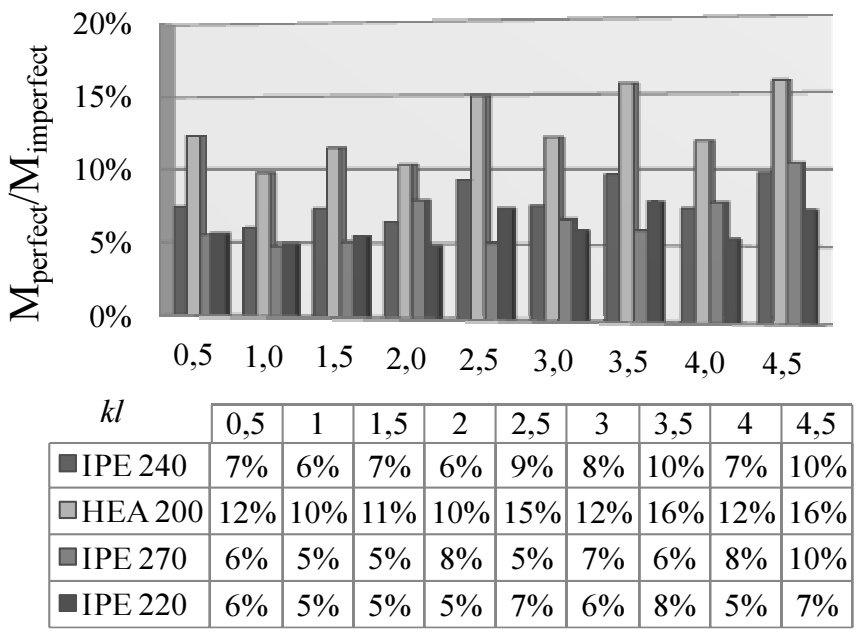

Fig. 3.1. Evaluation of imperfections: a) deformational response, b) flexural response

Figure 3.1 shows the comparable results. It can be seen that for the crosssections which are less sensitive to residual stresses and refers to a buckling curve a (See Section 1.4.2) the influence of the imperfections varies from $6 \%$ to $12 \%$ and does not much change increasing slenderness parameter. For the crosssections more sensitive to residual stresses as refers to a buckling curve $b$ the influence of imperfections varies from $10 \%$ to $19 \%$ under the variation of slenderness parameter. 
It can be assumed that for the cross-sections referring to a buckling curve $a$ the influence of the imperfections can be neglected for the sake of simplicity with the drawback around $10 \%$. The contrary case seems to be with the crosssections referring to a buckling curve $b$ and higher. The influence of imperfections varies around $15 \%$ and neglecting them significantly influences the accuracy and safety of the steel structures analysis.

\subsubsection{Improvements on Generalized Calculation Model of Beam-Column with Intermediate Elastic Restraint}

The most fundamental theoretical formulation in the verification of the elastic stability of structures is the Euler formula, which defines the elastic axial buckling strength of an individual member and essentially refers to the structural analysis based on the individual member check. The theory assumes that the member is perfectly straight, behaves in-plane elastically and has a pinned ends. These assumptions all are commonly violated in real structures. In practice, elements are out-of straightness between braced points due to fabrication tolerances. Residual stresses are presented that cause inelastic behavior. Further, as a structure is loaded, deformations also occur, adding second-order forces and moments. Furthermore, it should be noted the fact that buckling always involves both an axial force and bending effects. The considering calculation model formed to implement all previously mentioned effects and moreover, the beamcolumn shown in Figure 3.1 has an intermediate restraint to cover the case when the structure is additionally supported at the mid-span, thus obtaining the semicontinuous structure.

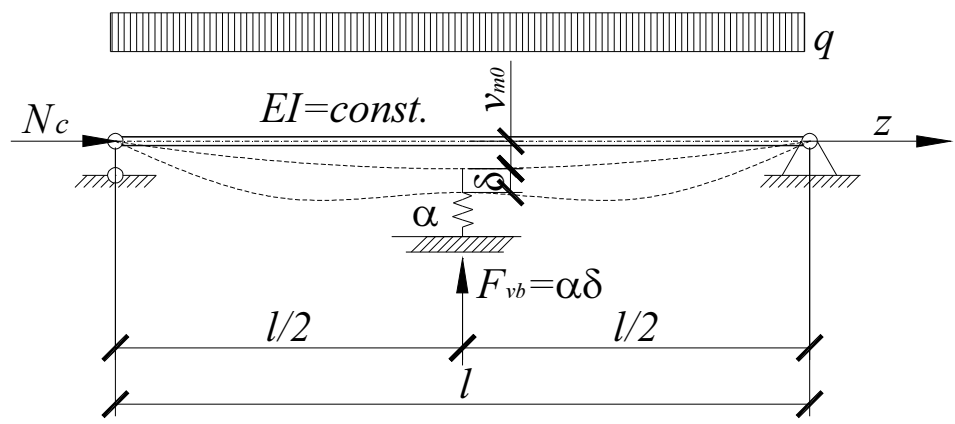

Fig. 3.3. Improved calculation model of a simply supported BCIR 
To widen the application of the proposed calculation model the calculation model of the simply supported beam-column shown in Figure 3.3 extended and the end support assumed to be elastic. The verification of the stability of the beam-column shown in Figures 3.3 and 3.4 performed with the approach of the Direct Analysis Method based upon GNA.

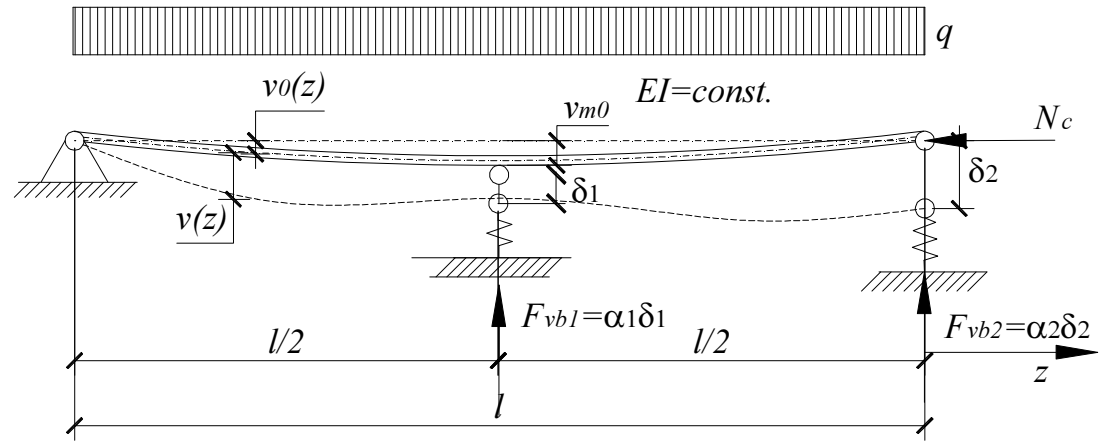

Fig. 3.4. Calculation model of a beam-column with an intermediate elastic restraint and an elastic end support

\subsubsection{Governing Equations}

The governing equations for the stability verification of the beam-column presented in Figures 3.3 and 3.4 derived considering the equilibrium by approach of moderately large displacement theory. Determining the equilibrium equations by moderately large displacement theory the structure is in equilibrium, in its deformed state; thus the second order effects will be accounted.

By considering simultaneous bending and compression with applying axial load $N_{c}$ the deflection at $z$ is increased by $v$ and the differential equation of bending becomes:

$$
M^{\prime \prime}-N_{c}\left(v-v_{0}\right) "+q=0
$$

By adopting a sinusoidal function for an initial lack of straightness:

$$
v_{0}=v_{m 0} \sin \left(\frac{\pi z}{l}\right)
$$

and introducing axial force-flexural rigidity relationship expressed by Equation (2.1), the Equation (3.6) can be rewritten as: 


$$
v(z)^{i v}+k^{2} v(z)^{\prime \prime}=\frac{q}{E I}-k^{2} v_{0}(z)^{\prime \prime}
$$

General solution of the Equation (3.8) is:

$$
v^{l(r)}=C_{1(5)} \sin k z+C_{2(6)} \cos k z+C_{3(7)}+C_{4(8)}+v_{\text {part }}
$$

where superscriptions $l$ and $r$ indicates left and right sides of the calculation model respectively.

When the transverse distributed force is assumed to be constant and introducing:

$$
n=\frac{(k l / 2)^{2}}{(\pi / 2)^{2}-(k l / 2)^{2}}
$$

the particular solution can be taken as:

$$
v_{\text {part }}=\frac{q z^{2}}{E I k^{2}}+n v_{m 0} \sin \frac{\pi z}{l}
$$

When combining Equations (3.9) with the boundary conditions for the left side of calculation model of the beam-column shown in Figure 3.3.1 $0 \leq z \leq l / 2$ (referring to continuity and symmetry, between left and right side of the whole structure, it is allowable to consider one of the parts) :

$$
v(z)=v(z)^{\prime \prime}=0 \text { at } z=0 \text { and } v(z)=\delta, v(z)^{\prime}=0 \text { at } z=l / 2
$$

the deflection is obtained as:

$$
\begin{aligned}
& v(z)=\frac{1}{N_{c}}\left[\frac{1}{2} F_{v b} l\left(\frac{z}{l}-\frac{\sin k z}{k l \cos k l / 2}\right)+\frac{q l^{2}}{(k l)^{2}}(\mathrm{tg} k l / 2 \sin k z+\right. \\
& \left.\cos k z-1)-\frac{q z}{2}(l-z)\right]+n v_{m 0} \sin \pi z / 2
\end{aligned}
$$

Accordingly, by Equation (2.4), the moment is given by

$$
\begin{aligned}
& M(z)=\frac{q l^{2}}{(k l)^{2}}(\operatorname{tg} k l / 2 \sin k z+\cos k z-1)-\frac{F_{v b} l}{2 k l} \frac{\sin k z}{\cos k l / 2}+ \\
& +E I\left(\frac{\pi}{l}\right)^{2} n v_{m 0} \sin \pi z / l
\end{aligned}
$$


Restoring force $F_{v b}$ introduced by intermediate restraint in Equations (3.13 and 3.14) is defined by Equation (2.13) and becomes:

$$
\begin{aligned}
& F_{v b}=2\left[\frac{q l}{k l} \frac{\left(1+(k l / 2)^{2} / 2-1 / \cos k l / 2\right)}{(k l / 2-\operatorname{tg} k l / 2)}+\frac{\left(\delta-n v_{m 0}\right)}{l} \times\right. \\
& \left.\times N_{c} \frac{k l}{(k l / 2-\operatorname{tg} k l / 2)}\right]
\end{aligned}
$$

Equations (3.13-3.15) closely refer to thus for the initially straight additionally elastically restrained beam-column, derived in Section 2.2.4 except last term covering initial imperfections.

For the extended calculation model of beam-column shown in Figure 3.4 boundary and continuity conditions are as follows:

$$
\left.\begin{array}{c}
v^{l}=v^{l} "=0 \text { at } z=0, \\
v^{l}=v^{r}=\delta_{1} \\
v^{l \prime}=v^{r \prime} \\
v^{l "}=v^{r}
\end{array}\right\} \text { at } z=l / 2,
$$

Then by combining Equation (3.9) with the conditions (3.16) the deflection of the left and right sides of the beam-column is obtained as:

$$
\begin{aligned}
& v^{l}=\frac{q l^{4}}{E I} \frac{1}{(k l)^{2}}\left[\frac{1}{(k l)^{2}}\left(\frac{\cos (k l / 2-k z)}{\cos k l / 2}-1\right)-\frac{F_{v b, 1}}{2 q l} \times\right. \\
& \left.\times\left(\frac{\sin k z}{k l \cos k l / 2}-\frac{z}{l}\right)-\frac{z}{2 l}\left(1-\frac{z}{l}\right)\right]+\delta_{2} \frac{z}{l}+n v_{m 0} \sin \frac{\pi z}{l}
\end{aligned}
$$




$$
\begin{aligned}
& v^{r}=\frac{q l^{4}}{E I} \frac{1}{(k l)^{2}}\left[\frac{1}{(k l)^{2}}\left(\frac{\cos (k l / 2-k z)}{\cos k l / 2}-1\right)-\frac{F_{v b, 1}}{2 q l} \times\right. \\
& \left.\times\left(\frac{\sin (k l-k z)}{k l \cos k l / 2}+z / l-1\right)-\frac{z}{2 l}\left(1-\frac{z}{l}\right)\right]+\delta_{2} \frac{z}{l}+n v_{m 0} \sin \frac{\pi z}{l}
\end{aligned}
$$

Accordingly, by Equation (2.4), the moments are given by:

$$
\begin{aligned}
& M^{l}=\frac{q l^{2}}{(k l)^{2}}\left(\frac{\cos (k l / 2-k z)}{\cos k l / 2}-1\right)-\frac{F_{v b, 1} l}{2} \frac{\sin k z}{k l \cos k l / 2}+ \\
& +E I\left(\frac{\pi}{l}\right)^{2} n v_{m 0} \sin \pi z / l \\
& M^{r}=\frac{q l^{2}}{(k l)^{2}}\left(\frac{\cos (k l / 2-k z)}{\cos k l / 2}-1\right)-\frac{F_{v b, 1} l}{2} \frac{\sin (k l-k z)}{k l \cos k l / 2}+ \\
& +E I\left(\frac{\pi}{l}\right)^{2} n v_{m 0} \sin \pi z / l
\end{aligned}
$$

The restoring force $F_{v b, 1}$ in Equations (3.17-3.20) can be obtained by Equation (2.13):

$$
\begin{aligned}
& F_{v b, 1}=\frac{q l}{k l} \frac{\left(1+(k l / 2)^{2}-1 / \cos k l / 2\right)}{k l / 2-\tan k l / 2}+\frac{E I(k l)^{3}}{l^{2}(k l / 2-\tan k l / 2)} \times \\
& \times \frac{\left(\delta_{1}-\delta_{2} / 2-n v_{m 0}\right)}{l}
\end{aligned}
$$

Elastic support at the middle of the considering beam-column shown in Figure 1 restrains its displacement to $\delta_{l}$. Thus restoring force $F_{v b, l}$ can be expressed as a product of $\delta_{l}$ and restraint stiffness $\alpha_{l}$, substituting it into Equation (3.21) restrained displacement may be obtained as: 


$$
\delta_{1}=\frac{q l^{4}}{E I(k l)^{4}} \frac{\left(1+(k l / 2)^{2}-1 / \cos k l / 2\right)}{\alpha_{1} / \alpha_{c}-1}-\frac{\left(\delta_{2} / 2+n v_{m 0}\right)}{\alpha_{1 / \alpha_{c}}-1}
$$

where $\alpha_{c}$ is restraint stiffness for the column with intermediate elastic restraint. The variation with the dimensionless restraint stiffness $\alpha_{d} / \alpha_{L}$ of the dimensionless buckling load on the basis of simply supported additionally elastically restrained compressed element was described in Section 2.2.6 and was assumed to be limiting as considering element buckles in the asymmetric second mode.

It follows from Equation (3.22) that intermediate restraint stiffness supposed to be non-equal and greater than $\alpha_{c}$, otherwise restrained deflection approach infinity and turns to unrestrained one. Furthermore, the shift from the unrestrained deflection shape to restraint one asserts between the values of 2 to 4 of the relative restraint stiffness $\alpha_{d} / \alpha_{L}$ depending on the slenderness parameter $k l$.

\subsubsection{Accuracy Evaluation}

The accuracy evaluation of the proposed method for the stability verification of the additionally elastically restrained beam-column element with arbitrary end conditions presented in Figure 3.2 performed on the basis of the finite element method by nonlinear solver of the software ANSYS. The large displacement static analysis performed, and full Newton-Raphson option used for the solution. Initial sinusoidal configuration of the imperfect shape of the element simulated using B-spline which reflects to sinusoidal function.

The imperfection factor chosen on the basis of central member strength curve, due to compatibility among design codes. The central member strength curves introduced in many design codes are of similar shape and match closely (Rotter 1981). The geometric characteristics of European I-sections rely on considering member strength curve assumed on performing comparison analysis. The magnitude of the initial equivalent geometrical imperfection varies from $43,0 \mathrm{~mm}$ to $52,0 \mathrm{~mm}$ rely on slenderness of the element referring to geometric characteristics of considering shapes, as the length of the beamcolumn is taken $18,0 \mathrm{~m}$ for all cases being analyzed.

Calculation model of the beam-column element shown in Figure 3.2 reflects to the structural behavior of the element subjected to a compressive axial force $N_{c}$, which rely on slenderness parameter, and a constant distributed load $q=20$ 
$\mathrm{kN} / \mathrm{m}$. The analysis performed for $k l=3,0,4,0$ and 5,0. The stiffness of the end restraint is assumed to be equal to limiting restraint stiffness and may be obtained by Equation (2.37). The restraint stiffness ratio $\alpha_{l} / \alpha_{L}$ set to be equal to 5,0 implementing restrained deflection shape of the considering structural element.

The numerical values of the restoring force at the intermediate support, extreme bending moments and deflections for the $z=l / 4$ and $z=3 l / 4$ are obtained both by using governing equations derived in Section 3.1.4 and nonlinear solver of ANSYS. Table 3.1 presents the relative errors.

Table 3.1. Results of accuracy evaluation

\begin{tabular}{|l|l|l|l|l|l|}
\hline \multirow{2}{*}{ Profile } & \multicolumn{5}{|l}{ Errors Governing equations/ANSYS, \% } \\
\cline { 2 - 6 } & Fvb, 1 & $\mathrm{vl} / 4$ & $\mathrm{Mmin}$ & $\mathrm{v} 31 / 4$ & Mmax \\
\hline \multirow{4}{*}{ HEB 300 } & 0,65 & 0,16 & $-3,23$ & $-0,68$ & 1,49 \\
\cline { 2 - 6 } & 1,43 & $-1,16$ & $-7,38$ & 0,23 & 3,86 \\
\cline { 2 - 6 } & 2,48 & $-3,03$ & $-13,34$ & 1,67 & 7,56 \\
\hline \multirow{4}{*}{ HEB 360 } & $-0,01$ & $-2,41$ & 0,47 & $-2,43$ & $-7,87$ \\
\cline { 2 - 6 } & $-0,11$ & $-2,94$ & 1,59 & $-4,49$ & $-11,84$ \\
\cline { 2 - 6 } & $-0,22$ & $-4,38$ & 3,05 & $-7,57$ & $-14,18$ \\
\hline \multirow{4}{*}{ HEA 360 } & 0,09 & $-2,52$ & 0,16 & $-2,21$ & $-7,54$ \\
\cline { 2 - 6 } & 0,08 & $-3,16$ & 0,95 & $-3,59$ & $-10,80$ \\
\cline { 2 - 6 } & 0,08 & $-4,72$ & 2,00 & $-6,42$ & $-12,99$ \\
\hline \multirow{4}{*}{ HEM 320 } & $-0,34$ & $-1,85$ & 1,33 & $-2,85$ & $-8,90$ \\
\cline { 2 - 6 } & $-0,80$ & $-1,75$ & 3,44 & $-5,08$ & $-13,67$ \\
\cline { 2 - 6 } & $-1,31$ & $-2,25$ & 6,21 & $-9,23$ & $-15,33$ \\
\hline
\end{tabular}

Table 3.1 shows that the proposal is safe and efficient and that the errors obtained are in the desirable limits of accuracy.

\subsubsection{Verification}

Considering the beam-column element of the length of 18,0 $\mathrm{m}$ shown in Figure 3.4 which is subjected to an axial force $N_{c}$ rely on the slenderness parameter $\mathrm{kl}$. The verification of stability is carried out with the variation of the slenderness parameter from 2,0 to 6,0 with an increment of 1,0. The deflection and bending 
moment are obtained using governing equations and shown in Figures 3.5 and 3.6 , respectively. The transverse distributed load is assumed to be constant with the numerical value of $20 \mathrm{kN} / \mathrm{m}$. The geometrical and material characteristics of the considering beam-column are assumed to be equal to that of a section HEB 300 , and the magnitude of the initial imperfections $v_{m 0}=43 \mathrm{~mm}$.

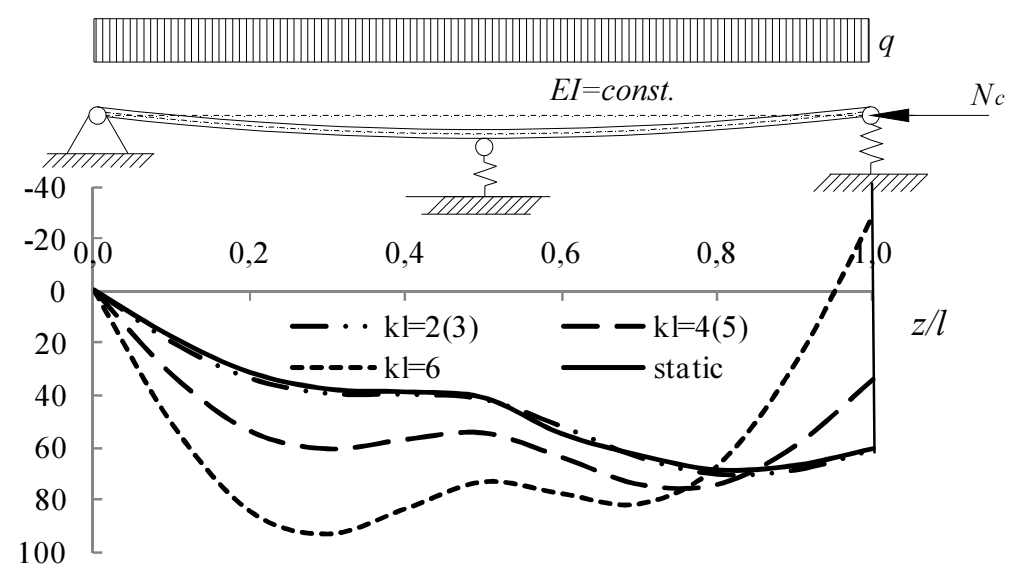

Fig. 3.5. Verification of the deformational response of the beam-column

Figure 3.5 shows that the deflection shapes of the considering element with the values of the slenderness parameter 2,0 and 3,0 slightly differs from the results obtained on the basis of small displacement static theory. A sudden increase of the deflection at the slenderness parameter values of 4,0 and 5,0 indicates the element shift from the stable to unstable behavior and with the value of 6,0 it becomes unstable. The increase of slenderness parameter increases the axial response rather than flexural and the deformational shape of beam-column approaches the restraint shape of simply supported element with the intermediate elastic restraint.

Figure 3.6 presents the flexural response of the BCIR with the arbitrary end conditions presented in Figure 3.4. The increase of the slenderness parameter and on it relying axial force in the considering beam-column element determines the increase of the extreme values of the bending moments. The significant shift of the extreme values of the bending moments at the values of 6,0 of the slenderness parameter can be assumed as the stability loss of the element. 


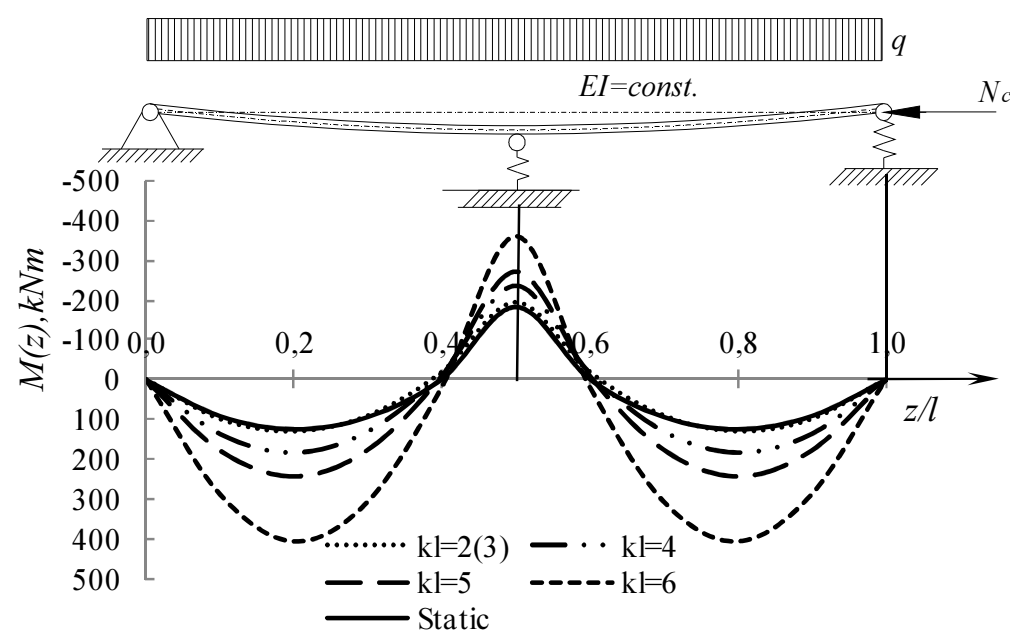

Fig. 3.6. Verification of the flexural response of the beam-column

\subsubsection{Evaluation of Current Design Practices}

EN1993-1-1 provides two alternatives called Method 1 and Method 2 for the stability verification of members subjected simultaneously to axial compression and bending by interaction formulae (Greiner and Lindner 2006, Boissonnade, et al. 2005). Structural analysis of a simply supported beam-column shown in Figure 3.7 was performed by nonlinear solver of software ANSYS. Analysis used calculation model of curved element and the initial equivalent imperfections were modelled by spline which refers to the assumption that the curvature of the imperfect member being sinusoidal. The magnitude of the initial equivalent imperfections obtained using generalized imperfection concept expressed by Equation (3.5).

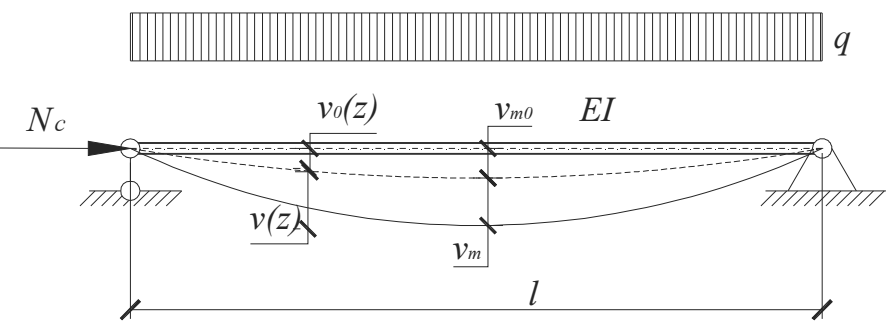

Fig. 3.7. Imperfect Beam-Column 
Table 3.2 gives geometrical and physical characteristics of members and loading used for comparison. In addition, it presents the obtained errors between design methods given in design code and results of GNIA performed with FE code of ANSYS.

Table 3.2. Results of alternative methods evaluation on beam-column calculation model

\begin{tabular}{|c|c|c|c|c|c|c|}
\hline Profile & $\alpha$ & $\begin{array}{l}\mathrm{v}_{\mathrm{m} 0}, \\
\mathrm{~mm}\end{array}$ & $\mathrm{~N}_{\mathrm{c}} / \mathrm{q}$ & $\begin{array}{l}\sigma_{\mathrm{b}}, \\
\mathrm{N} / \mathrm{mm}^{2} \\
\text { ANSYS }\end{array}$ & $\begin{array}{l}\sigma_{b}, \mathrm{~N} / \mathrm{mm}^{2} \\
\text { EC3(Method 1/ } \\
\text { Method 2) }\end{array}$ & $\begin{array}{l}\text { Errors, } \\
\%\end{array}$ \\
\hline \multirow[t]{2}{*}{ HEM 200} & \multirow[t]{2}{*}{0,34} & \multirow[t]{2}{*}{27} & \multirow[t]{2}{*}{1,67} & \multirow[t]{2}{*}{246} & 248 & 0,97 \\
\hline & & & & & 250 & 1,75 \\
\hline \multirow[t]{2}{*}{ IPN 220} & \multirow[t]{2}{*}{0,21} & \multirow[t]{2}{*}{16} & \multirow[t]{2}{*}{1,00} & \multirow[t]{2}{*}{260} & 261 & 0,48 \\
\hline & & & & & 257 & $-0,97$ \\
\hline \multirow[t]{2}{*}{ HEB 200} & \multirow[t]{2}{*}{0,34} & \multirow[t]{2}{*}{28} & \multirow[t]{2}{*}{1,00} & \multirow[t]{2}{*}{258} & 259 & 0,39 \\
\hline & & & & & 260 & 0,77 \\
\hline \multirow[t]{2}{*}{ HEM 180} & \multirow[t]{2}{*}{0,34} & \multirow[t]{2}{*}{27} & \multirow[t]{2}{*}{0,8} & \multirow[t]{2}{*}{287} & 287 & 0,11 \\
\hline & & & & & 287 & 0,20 \\
\hline \multirow[t]{2}{*}{ IPN 200} & \multirow[t]{2}{*}{0,21} & \multirow[t]{2}{*}{17} & \multirow[t]{2}{*}{0,75} & \multirow[t]{2}{*}{262} & 263 & 0,38 \\
\hline & & & & & 260 & $-0,77$ \\
\hline \multirow[t]{2}{*}{ HEB 180} & \multirow[t]{2}{*}{0,34} & \multirow[t]{2}{*}{29} & \multirow[t]{2}{*}{1,00} & \multirow[t]{2}{*}{241} & 244 & 1,08 \\
\hline & & & & & 247 & 2,27 \\
\hline \multirow[t]{2}{*}{ HEA 180} & \multirow[t]{2}{*}{0,34} & \multirow[t]{2}{*}{30} & \multirow[t]{2}{*}{1,00} & \multirow[t]{2}{*}{252} & 254 & 0,88 \\
\hline & & & & & 259 & 2,80 \\
\hline
\end{tabular}

Table 3.2 presents acceptable agreement between conventional methods based on the interaction formulae and equivalent moment factor. It should be noted that both of these methods were derived on the calculation model of a simply supported beam-column as refers. 
The sequent numerical analysis performed on the same basis using generalized calculation model of BCIR shown in Fig. 3.3 the results obtained running numerical analysis presented in Table 3.3.

Table 3.3. Results of alternative methods evaluation on BCIR calculation model

\begin{tabular}{|c|c|c|c|c|c|c|}
\hline Profile & $\alpha$ & $\begin{array}{l}\mathrm{V}_{\mathrm{m} 0} \\
(\mathrm{~mm})\end{array}$ & $\mathrm{N}_{\mathrm{c}} / \mathrm{q}$ & $\begin{array}{l}\sigma_{\mathrm{b}}, \\
\mathrm{N} / \mathrm{mm} 2 \\
\text { ANSYS }\end{array}$ & $\begin{array}{l}\sigma_{\mathrm{b}}, \mathrm{N} / \mathrm{mm} 2 \\
\text { EC3 } \\
\text { (Method1/ } \\
\text { Method 2) }\end{array}$ & Errors \\
\hline \multirow{2}{*}{ HEM 200} & \multirow{2}{*}{0,34} & \multirow{2}{*}{27} & \multirow{2}{*}{6,0} & \multirow{2}{*}{199} & 226 & 11,9 \\
\hline & & & & & 191 & $-4,2$ \\
\hline \multirow{2}{*}{ IPN 220} & \multirow{2}{*}{0,21} & \multirow{2}{*}{16} & \multirow{2}{*}{3,6} & \multirow{2}{*}{293} & 311 & 5,8 \\
\hline & & & & & 225 & $-30,2$ \\
\hline \multirow{2}{*}{ HEB 200} & \multirow{2}{*}{0,34} & \multirow{2}{*}{28} & \multirow{2}{*}{7,0} & \multirow{2}{*}{180} & 213 & 15,5 \\
\hline & & & & & 190 & 5,3 \\
\hline \multirow{2}{*}{ HEA200 } & \multirow{2}{*}{0,34} & \multirow{2}{*}{27} & \multirow{2}{*}{3,0} & \multirow{2}{*}{203} & 218 & 6,9 \\
\hline & & & & & 179 & $-13,4$ \\
\hline \multirow{2}{*}{ HEM 180} & \multirow{2}{*}{0,34} & \multirow{2}{*}{27} & \multirow{2}{*}{3,0} & \multirow{2}{*}{185} & 222 & 16,7 \\
\hline & & & & & 182 & $-1,6$ \\
\hline \multirow{2}{*}{ IPN 200} & \multirow{2}{*}{0,21} & \multirow{2}{*}{17} & \multirow{2}{*}{1,6} & \multirow{2}{*}{325} & 325 & 0,0 \\
\hline & & & & & 250 & $-30,0$ \\
\hline \multirow{2}{*}{ HEB 180} & \multirow{2}{*}{0,34} & \multirow{2}{*}{29} & \multirow{2}{*}{4,0} & \multirow{2}{*}{198} & 223 & 11,2 \\
\hline & & & & & 191 & $-3,7$ \\
\hline \multirow{2}{*}{ HEA 180} & \multirow{2}{*}{0,34} & & & & 273 & 5,5 \\
\hline & & 30 & 2,4 & 258 & 226 & $-14,2$ \\
\hline
\end{tabular}

Table 3.3 presents controversial results, and both applied alternative methods draws significant errors in comparison to results of GNIA. Results of Method 1 are conservative and give the reserve rather than Method 2. Errors of Method 2 arise the doubts of its suitability for the safe steel structures designing. 


\subsubsection{Evaluation of Buckling Resistance of Beam-Column with Intermediate Elastic Restraint}

This section contributes in outlining the limits of the applicability of the eigenvalue analysis (linear buckling). Eigen value analysis predicts the theoretical buckling strength of a structure which is idealized. For a basic structural configuration, structural eigenvalues are computed from constraints and loading conditions. Buckling loads are then derived, each associated with a buckled mode shape which represents the shape a structure assumes under buckling. In a real structure, imperfections and non-linear behaviour keep the system from achieving the theoretical buckling strength. GNIA (nonlinear buckling) provides greater accuracy wider applicability. Applied loading incrementally increases until a small change in load level causes a large change in displacement. This condition indicated that a structure has become unstable. Nonlinear buckling analysis is a static method which accounts for material and geometric nonlinearities, geometric imperfections and etc.

Major conventional methods provided by the steel structures design codes for the case of stability refer to a linear buckling. Widely used effective length concept is based on a linear buckling, as well. Furthermore, the attempts to simplify the direct method are based on linear buckling mode shapes and buckling length. Despite its wide usage linear buckling analysis has the significant drawbacks.

Running numerical analysis the main critical points of the linear buckling are outlined and presented in Figure 3.8.

The case studied is a BCIR which geometry and loading are shown in Figure 3.3. In this study, the buckling shapes of BCIR are obtained both using eigenvalue analysis and a non-linear solver of FE code ANSYS and varying the relative restraint stiffness $\alpha / \alpha_{L}$. Restraint stiffness of a considering beamcolumn $\alpha$ relies on a limiting restrained stiffness $\alpha_{L}$ described in Section 2.2.5. At the value of limiting restraint stiffness a column supposed to buckle in the second buckling shape of two sine waves under the buckling load $N_{c r}=4 \pi^{2} E I / L^{2}$ and have a restraint at the mid-length. Actually it buckles close to the shape presented in Figure 3.9 b). Galambos and Surovek (2008) derived expressions for the stiffness and strength of the lateral brace required to force a node of the buckling shape of a column at its centre, so the buckling load will equal Euler load. The same equations were derived by Winter (1958) by employing a simpler intuitive model. The models of the determination of the limiting required bracing stiffness and of the required bracing strength have been used to derive design criteria in the AISC Specifications. Applying GNIA the two steps procedure for designing the ideal supporting (bracing) system can be 
utilized as there is no necessity that buckling load equal Euler load. Moreover, it should be noted that direct consideration of beam-column elements by eigenvalue analysis is not possible; it is suitable just for compressed elements. Distinctive buckling shapes at different relative restraint stiffness are presented in Figure 3.9.

Figure 3.8 shows that nonlinear buckling load is always smaller than Euler buckling load, it becomes closer just when relative restraint stiffness is in the limits of 1,57-3,14. At the Euler load when buckling shapes given by eigenvalue analysis shifts from first to the second mode, the buckling shape obtained by GNIA is still of the shape presented in Fig. 3.9 a). The second Euler buckling load BCIR gains just at the value of the restraint stiffness 3,14. Exceeding this value the considering element at the critical load buckles in the restraint first mode and the value of critical load is almost twice higher than Euler. The same notice was made by Trahair and co-workers (2008) for the considering compressed elements. When the relative restraint stiffness exceeds the value of 15, the buckling shape of BCIR turns back to the one presented in the Figure 3.9 b).

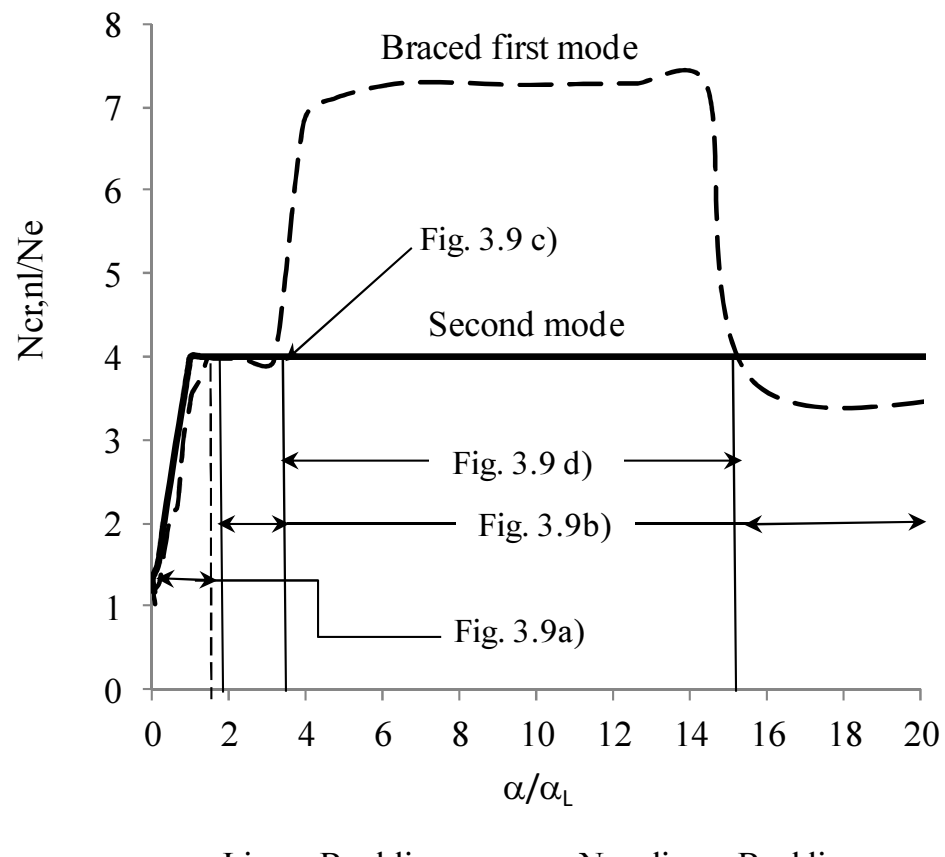

— Linear Buckling — - Non-linear Buckling

Fig. 3.8. Comparison between Eigenvalue and Non-linear analyses 
Furthermore, Figure 3.9 shows that the efficient length based on eigenvalue analysis will draw significant errors considering BCIR. Thus, considering complex structures the GNIA is highly recommended. The critical buckling values of the presented numerical example obtained by GNIA provided in Annex B.

a)

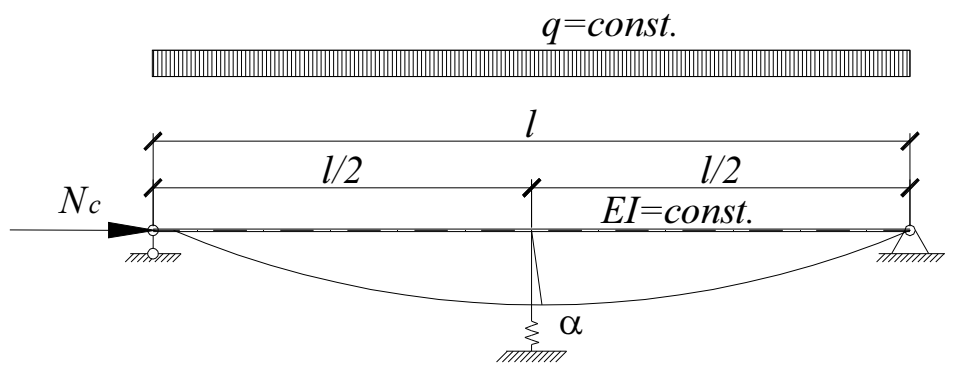

b)

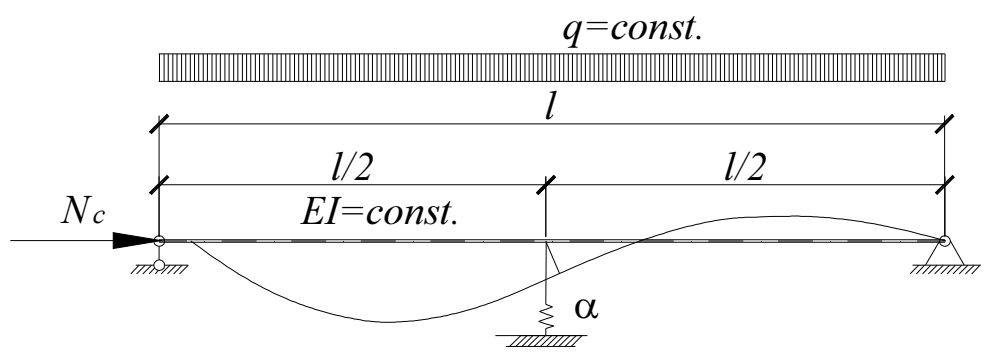

c)

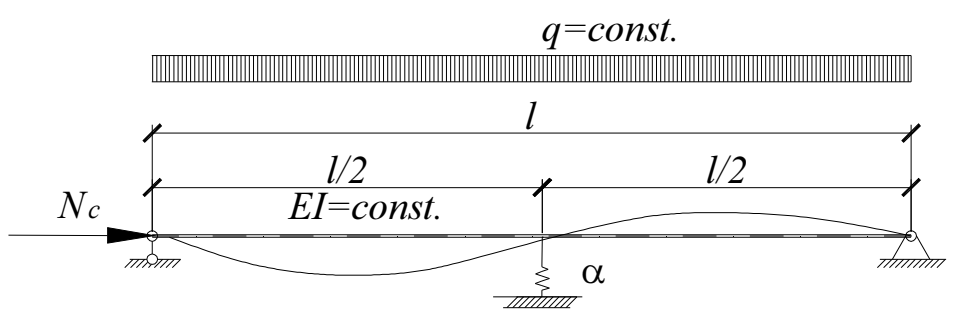

d)

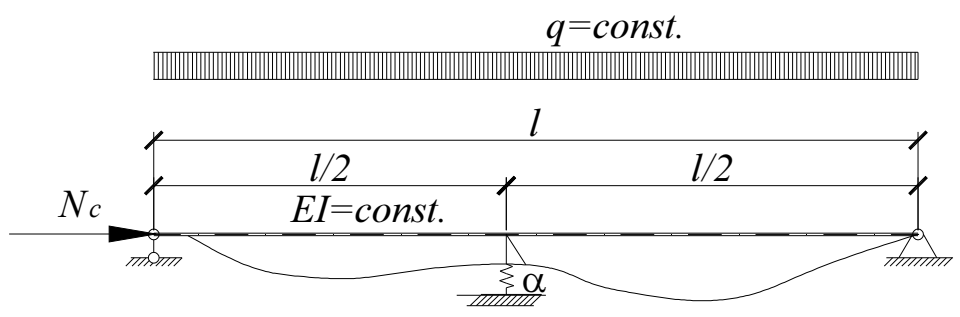

Fig. 3.9. Buckling Shapes of GNIA: a) unbraced first mode b) complete sine with displaced centre c) centred complete sine-second mode d) braced first mode 


\subsection{Direct Stability Analysis of Under-Deck Cable-Stayed Bridge}

This section presents verification analysis of the simple-span UDCS bridge to declare accuracy of the computational method presented in Section 3.1.3. The flexural and deformational response obtained both using governing equations derived in Section 3.1.4 and non-linear solver of the software ANSYS.

Consider the structural scheme and geometrical parameters of UDCS bridge shown in Fig. 3.10. The geometrical and material characteristics of the main girder are assumed to be equal to that of a section HEB 300. The cross-section area of cable stays and struts assumed to be equal to $7848 \mathrm{~mm} 2$ and $5184 \mathrm{~mm} 2$, respectively for both level cable-staying systems. The stiffness of elastic restraints for arbitrary calculation model of beam-column refers to axial rigidity and deformations of cable-straying systems. The load subjected to the structure assumed to be both symmetric asymmetric and equal to $2 q$ and $q$ respectively (its numerical value presented in Fig. 3.10).

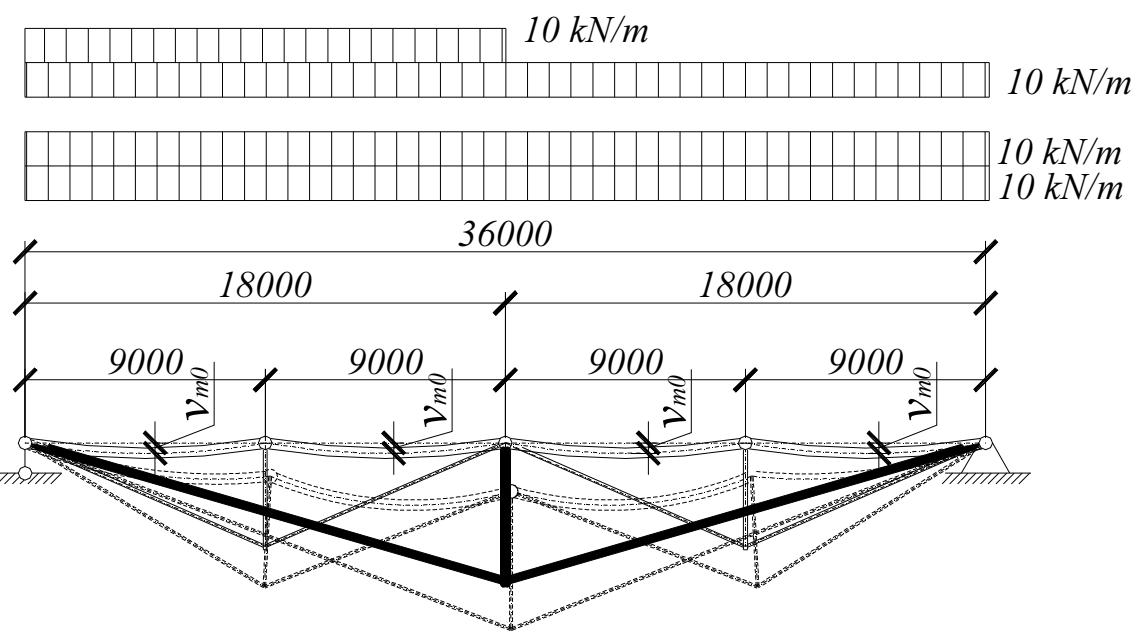

Fig. 3.10. Calculation model of UDCS bridge

Due to multi-span structural scheme of the bridge and joints between independent members of the main girder according to EC3 initial imperfections should be applied in all relevant directions. The typical possible combinations of the main girder of the bridge taking into account initial local imperfection of the jointed independent members presented in Fig. 3.11. The computer-aided nonlinear analysis with all possible configurations of the main girder of the 
UDCS bridge was performed to determine the most adverse case. The numerical values of flexural and deformational response under symmetric and asymmetric loading considering combinations of local bow imperfections of the girder presented in Table 3.4.
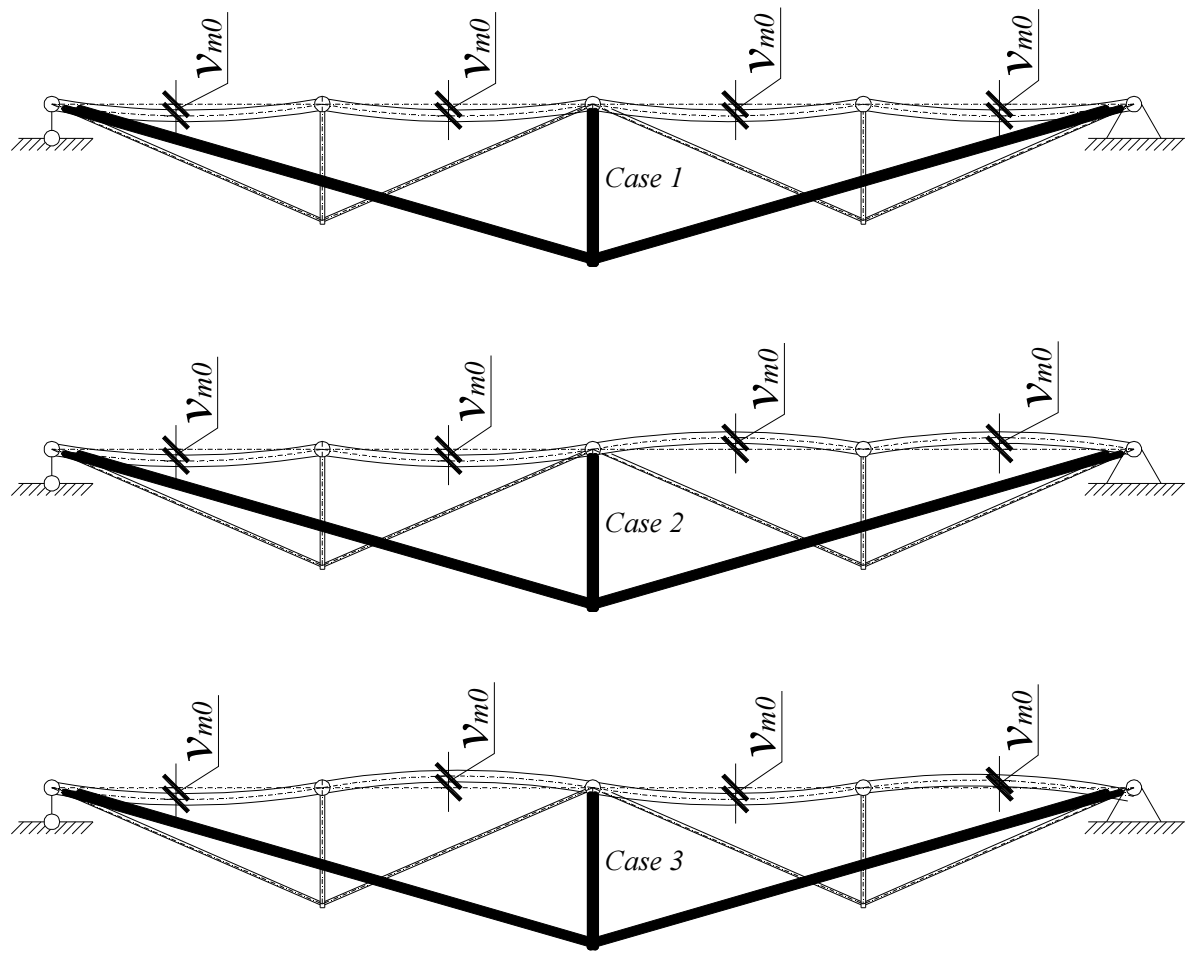

Fig. 3.11. Combinations of local bow imperfections

As seen in the Table 3.4 the direction of imperfection applications makes no significant sense to extreme value of the bending moments of the whole structure as they distribute between independent spans of the girder. It should be noted that the direction of the initial imperfections makes influence on the bending moment of the discrete element by decreasing or increasing its value. Though, for the structural analysis, the most critical value should be considered, and thus the most adverse configuration of the whole structure assumed. The maximum value of the whole structure displacement rather than moment depends on the separate combinations of the initial imperfections. As shown in Table 3.4 the most adverse case is Case 1, and it will be consider for the structural behavior analysis of the UDCS bridge. 
Table 3.4. Results of the analysis evaluating direction of the local bow imperfections

\begin{tabular}{|c|c|c|c|}
\hline \multicolumn{4}{|c|}{ Symmetric loading } \\
\hline Structural Response & Case 1 & Case 2 & Case 3 \\
\hline Bending moments & \multicolumn{3}{|c|}{ Distributed transverse load on the span: $q=20 \mathrm{kN} / \mathrm{m}$} \\
\hline$M_{\max }, \mathrm{kNm}$ & 278,3 & 278,2 & 278,18 \\
\hline \multicolumn{4}{|l|}{ Displacement } \\
\hline$v_{\max }, \mathrm{mm}$ & 119,5 & 114,8 & 113,90 \\
\hline \multicolumn{4}{|c|}{ Asymmetric loading } \\
\hline Bending moments & \multicolumn{3}{|c|}{ Distributed transverse load on the span: $q=20 \mathrm{kN} / \mathrm{m}$} \\
\hline$M_{\max }, \mathrm{kNm}$ & 261,6 & 212,3 & 261,55 \\
\hline \multicolumn{4}{|l|}{ Displacement } \\
\hline$v_{\max }, \mathrm{mm}$ & 98,6 & 84,4 & 86,44 \\
\hline Bending moments & \multicolumn{3}{|c|}{$\begin{array}{l}\text { Distributed transverse load on the sub-span: } \\
q=10 \mathrm{kN} / \mathrm{m}\end{array}$} \\
\hline$M_{\max }, \mathrm{kNm}$ & 135,8 & 135,8 & 135,76 \\
\hline \multicolumn{4}{|l|}{ Displacement } \\
\hline$v_{\max }, \mathrm{mm}$ & 75,4 & 71,0 & 71,79 \\
\hline
\end{tabular}

Table 3.5 presents numerical results obtained performing geometrically nonlinear analysis of UDCS bridge structure presented in Fig. 3.10.

Table 3.5 gives the errors of the structural behavior analysis performed applying computational method comparing to the FEA. The errors obtained do not exceed one percentage and are in the desirable limits of accuracy. 
Table 3.5. Accuracy of the proposed method

\begin{tabular}{|c|c|c|c|}
\hline \multicolumn{4}{|c|}{ Symmetric loading } \\
\hline Structural Response & $\begin{array}{l}\text { Simplified } \\
\text { Analysis }\end{array}$ & $\begin{array}{l}\text { FE analysis } \\
\text { with } \\
\text { ANSYS }\end{array}$ & Errors, \% \\
\hline Bending moments & \multicolumn{3}{|c|}{ Distributed transfers load on the span: $q=20 \mathrm{kN} / \mathrm{m}$} \\
\hline$M(z=l / 4), \mathrm{kNm}$ & 278,3 & 277,9 & $-0,12$ \\
\hline$M(z=3 l / 4), \mathrm{kNm}$ & 278,3 & 277,9 & $-0,12$ \\
\hline \multicolumn{4}{|l|}{ Displacement } \\
\hline$v(z=l / 4), \mathrm{mm}$ & 76,6 & 76,3 & $-0,34$ \\
\hline$v(z=3 l / 4), \mathrm{mm}$ & 118,8 & 118,5 & $-0,30$ \\
\hline \multicolumn{4}{|c|}{ Asymmetric loading } \\
\hline Bending moments & \multicolumn{3}{|c|}{$\begin{array}{l}\text { Distributed transfers load on the sub-span: } \\
q=20 \mathrm{kN} / \mathrm{m}\end{array}$} \\
\hline$M(z=l / 4), \mathrm{kNm}$ & 261,7 & 261,6 & $-0,03$ \\
\hline$M(z=3 l / 4), \mathrm{kNm}$ & 261,7 & 261,3 & $-0,13$ \\
\hline \multicolumn{4}{|l|}{ Displacement } \\
\hline$v(z=l / 4), \mathrm{mm}$ & 67,2 & 67,5 & 0,48 \\
\hline$v(z=3 l / 4), \mathrm{mm}$ & 98,3 & 98,0 & $-0,23$ \\
\hline Bending moments & \multicolumn{3}{|c|}{$\begin{array}{l}\text { Distributed transverse load on the sub-span: } \\
q=10 \mathrm{kN} / \mathrm{m}\end{array}$} \\
\hline$M(z=l / 4)(\mathrm{kNm})$ & 135,7 & 135,6 & $-0,09$ \\
\hline$M(z=3 l / 4)(\mathrm{kNm})$ & 135,7 & 135,8 & 0,01 \\
\hline \multicolumn{4}{|l|}{ Displacement } \\
\hline$v(z=l / 4), \mathrm{mm}$ & 43,4 & 43,7 & 0,69 \\
\hline$v(z=3 l / 4), \mathrm{mm}$ & 74,4 & 74,4 & $-0,05$ \\
\hline
\end{tabular}




\subsection{Structural Response Control Analysis of Under-Deck Cable-Stayed Bridge}

\subsubsection{Calculation Model of Simple-Span Under-Deck Cable-Stayed Bridge}

Consider innovative steel structure of simple-span double-level UDCS bridge of four equal spans shown in Fig. 3.10. The connections between the span elements of main girder assumed to be hinged in contrary to structural schemes of conservative UDCS bridges. This development increases a resistance of the main girder for bending about one principle axis with applying effective technique of flexural response control. It should be noted that the effective flexural response control in the considering structure is obtained by using eccentric connections of main girder with the cable-staying system and choosing appropriate length of the strut rather than using the prestressing procedure of the stay cables as usually. The variation in the length of strut determines the changes in the layout of the cable-staying system of the double-level UDCS bridge.

Very few studies have been conducted on an attempt to control structural response of the UDCS structures. A new approach on the flexural response control of the simple-span bridges was proposed by Juozapaitis et al. (2007). The study was performed on the case of UDCS bridge reconstruction with no suspension during exploitation. The simple-span UDCS bridge with mono-strut cable-staying system was considered as shown in Figure 3.12. Proposed technique relies on the approach of the eccentrically anchored cable-staying system, thus arousing the bending moments at the support sections of the main girder. For the simplified linear analysis of the bridge calculation model is made considering individual member of the main girder as shown in Figure $3.12 \mathrm{~b}$ ).

When the height of the cross-section of the girder is constant and assuming (Juozapaitis et al. 2007):

$$
|M(z=0)|=|M(z=l / 2)|
$$

The rational eccentricity may be obtained as (Juozapaitis et al. 2007):

$$
e_{r a c}=\frac{q l^{2}}{16 N_{c}}
$$

and rational bending moment is equal to: 


$$
M_{r a c}=\frac{q l^{2}}{16}
$$

a)
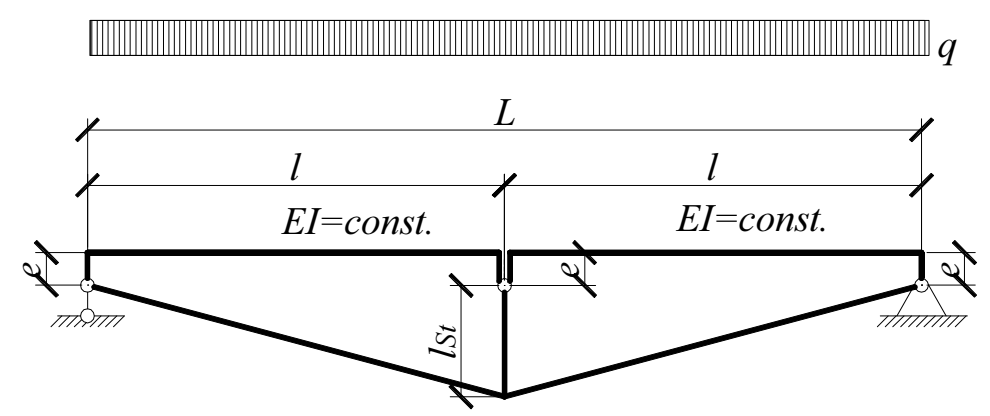

b)

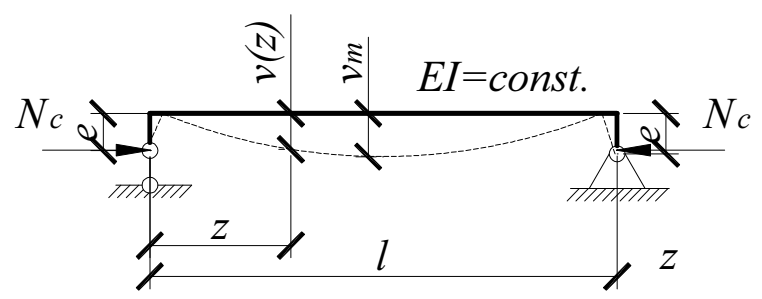

Fig. 3.12. Calculation model of UDCS bridge with eccentrically anchored CS system: a) whole structure; b) individual member

\subsubsection{Linear Evaluation of Structural Response Control}

On the basis of previously presented study the numerical evaluation was performed to present the efficiency of the proposed technique. Figure 3.13 shows that with adopting rational eccentricity for the linear analysis of simplespan UDCS structure with mono cable-staying system the efficient distribution of bending moments can be achieved. By introducing hogging moments at the support sections of the girder the extreme values of the bending moments decrease twice compare to structure without structural response control. This advantage refers to increases in economy due to effective cross-section utilization. 


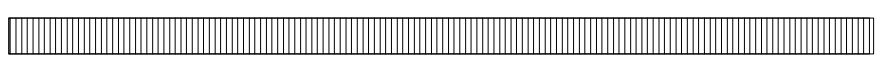

HEA $240 \quad$ HEA 240

a)

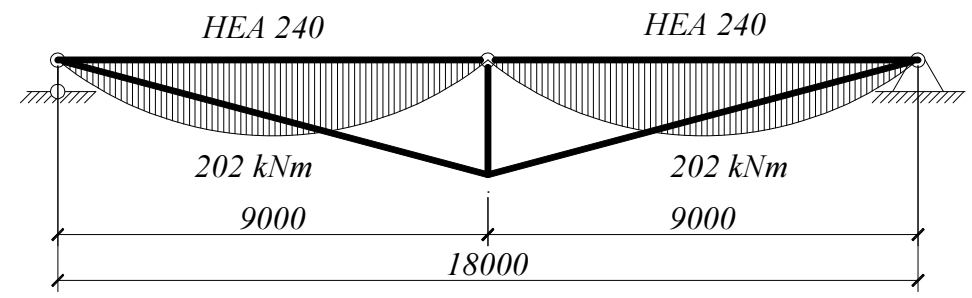

b)

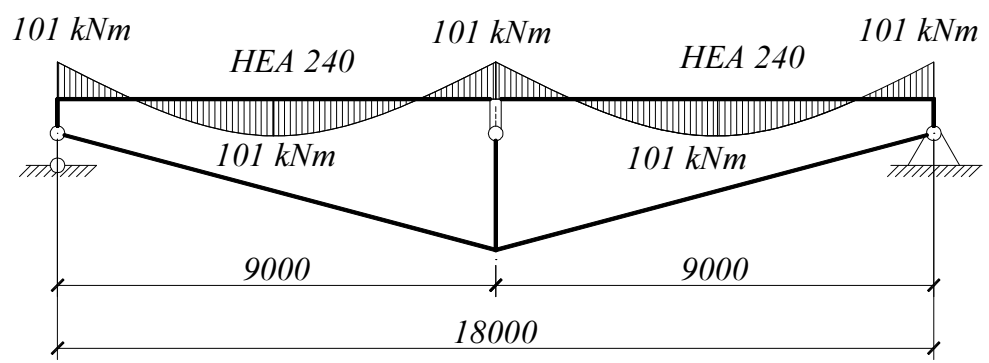

Fig. 3.13. Bending moment's diagram: a) without structural response control;

b) with structural response control

Moreover, the computer-aided analysis was performed using nonlinear solver ANSYS for structural behaviour analysis of the UDCS bridge. Analysis was carried out by varying slenderness parameter $\mathrm{kl}$.

The axial response in UDCS bridge approximately may be accounted as:

$$
N_{c}=\frac{q l^{2}}{8 l_{s t}}
$$

where $L$ is span of the bridge and $l_{S t}$ is the length of the strut as shown in Figure $3.12 \mathrm{a})$.

Table 3.6 shows that UDCS bridges have significant nonlinear behaviour which increases by increasing slenderness parameter $\mathrm{kl}$. Thus, the attempt to adopt rational eccentricities obtained by Equation (3.24) for the nonlinear analysis gives considerable disagreements as presented in Table 3.6. Last column of the Table 3.6 shows that linear analysis for the UDCS bridges can be reasonable for the values of the slenderness parameter less than one. 
Table 3.6. Results of the numerical analysis of the structural behaviour of the UDCS bridge

\begin{tabular}{|c|c|c|c|c|c|c|c|}
\hline$k l$ & $\begin{array}{l}\mathrm{q}, \\
\mathrm{kN} / \mathrm{m}\end{array}$ & $\begin{array}{l}\mathrm{V}_{\text {linear }} \text {, } \\
\mathrm{mm}\end{array}$ & $\begin{array}{l}\mathrm{V}_{\text {nonlinear }} \text {, } \\
\mathrm{mm}\end{array}$ & $\begin{array}{l}\mathrm{v}_{\text {linear }} / \\
\mathrm{v}_{\text {nonlinear }} \\
\% \\
\%\end{array}$ & $\begin{array}{l}\mathrm{M}_{\text {max, }} \\
\text { linear, } \\
\mathrm{kNm}\end{array}$ & $\begin{array}{l}\mathrm{M}_{\text {max }} \\
\text { nonlinear, } \\
\text { kNm }\end{array}$ & $\begin{array}{l}\mathrm{M}_{\text {max,linear }} \\
/ \mathrm{M}_{\text {max }} \\
\text { nonlinear } \\
\%\end{array}$ \\
\hline 1,64 & 20 & 117,1 & 174,1 & 48,61 & 202 & 279 & 28 \\
\hline 1,07 & 20 & 54,0 & 62,0 & 14,87 & 203 & 230 & 12 \\
\hline 0,95 & 20 & 47,2 & 52,1 & 10,31 & 202 & 223 & 9 \\
\hline 0,79 & 20 & 32,1 & 37,2 & 16,20 & 203 & 216 & 6 \\
\hline 0,60 & 20 & 21,2 & 21,9 & 3,42 & 202 & 210 & 4 \\
\hline
\end{tabular}

\subsubsection{Direct Modelling of Structural Response Control}

Preceding section showed that using structural response control for the UDCS bridge with slenderness parameter higher than 1,0 the nonlinear analysis is required. Moreover for the sake of accuracy the effect of imperfections has to be taken into account.

\subsubsection{Accounting for Nonlinearities}

For the accurate contemplation of UDCS structures, the formula for the rational eccentricity derived considering the equilibrium of the beam-column element shown in Figure 3.12 by the approach of moderately large displacement theory. On the basis of previously mentioned theory, the structure is in its deformed state thus the second order effects are accounted.

The deflection $(v)$ is measured from the initially imperfect configuration, and the normal force is constant along the length of the element, thus the moment equilibrium equation becomes:

$$
M(z) "-N_{\mathrm{c}}(v(z)) "+N_{\mathrm{c}} e+q=0
$$

Expressing the relation between internal axial force $\left(N_{\mathrm{c}}\right)$ and flexural rigidity (EI) by Equation (2.7) Equation (3.27) could be rewritten as: 


$$
v(z)^{\mathrm{iv}}+k^{2} v(z)^{\prime \prime}=k^{2} e+\frac{q}{E I}
$$

Introducing Equation (3.10), general solution of Equation (3.28) is:

$$
v(z)=C_{1} \sin k z+C_{2} \cos k z+C_{3} z+C_{4}+e+\frac{q z^{2}}{2 E I k^{2}}
$$

By combining general solution with the boundary conditions for the simply supported steel element shown in Fig. 3.12 b):

$$
\left.\left.\begin{array}{l}
z=0 \\
v=0 \text { and } v^{\prime \prime}=k^{2} e
\end{array}\right\} \text { and } \begin{array}{rl}
z & =l \\
v & =0 \text { and } v^{\prime \prime}=k^{2} e
\end{array}\right\}
$$

the deflections is obtained as:

$$
v=\left(\frac{q l^{4}}{E I(k l)^{4}}-e\right)(\operatorname{tg} k l / 2 \sin k z+\cos k z-1)-\frac{q z l^{3}}{2 E I(k l)^{2}}\left(1-\frac{z}{l}\right)
$$

Accordingly, by Equation (2.4), the moment is given by:

$$
M_{z}=\left(\frac{q l^{2}}{(k l)^{2}}-\frac{E I e(k l)^{2}}{l^{2}}\right)(\operatorname{tg} k l / 2 \sin k z+\cos k z)-\frac{q l^{2}}{(k l)^{2}}
$$

\subsubsection{Effect of Imperfections}

For the case of the direct structural response control, the previously described improvements, such as account for the effect of imperfections should be done. Governing equations for the direct structural response control derived on the calculation model of the mono-strut UDCS bridge presented in Figure 3.14.

Attention is paid to the requirements set for the performance of the direct analysis and, in particular, eccentric application of the axial compression $\left(N_{\mathrm{c}}\right)$. The deflection $(v)$ is measured from the initially imperfect configuration, and the normal force is constant along the length of the element, thus the moment equilibrium equation becomes:

$$
M_{\mathrm{z}} "-N_{\mathrm{c}}\left(v+v_{0}\right) "+N_{\mathrm{c}} e+q=0
$$


a)

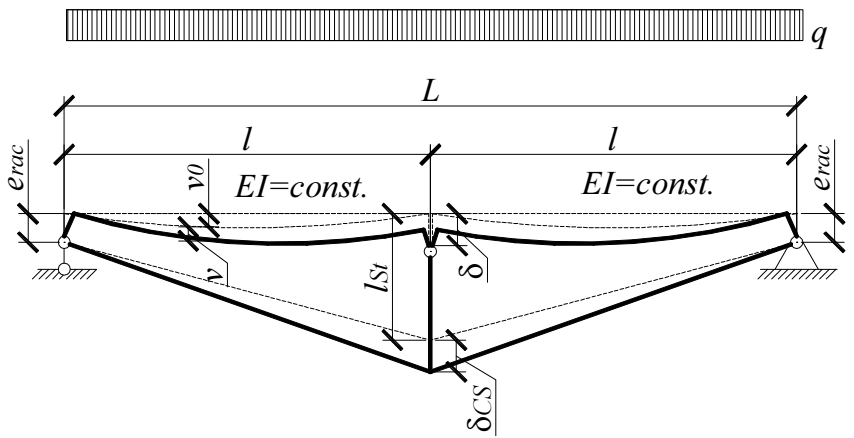

b)

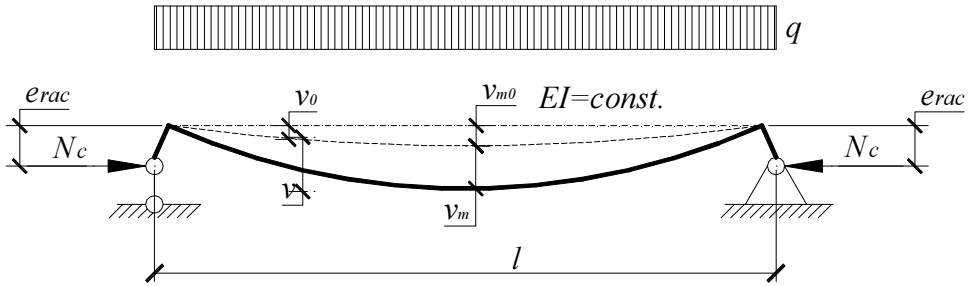

Fig. 3.14. Calculation model of the UDCS bridge accounting for effect of imperfections for structural response control: a) whole structure, b) individual member

Expressing the relation between internal axial force $\left(N_{\mathrm{c}}\right)$ and flexural rigidity ( $E I)$ by Equation (2.7) Equation (3.33) could be rewritten as:

$$
v^{\text {iv }}+k^{2} v^{\prime \prime}+k^{2}\left(v_{0 \mathrm{~m}} \sin \frac{\pi z}{l}\right) "=k^{2} e+\frac{q}{E I}
$$

Introducing Equation (3.10), general solution of Equation (3.34) is:

$$
v=C_{1} \sin k z+C_{2} \cos k z+C_{3} z+C_{4}+n v_{0 \mathrm{~m}} \sin \frac{\pi z}{l}+e+\frac{q z^{2}}{2 E I k^{2}}
$$

By combining general solution with the boundary conditions for the simply supported steel element shown in Fig. 3.14 b):

$$
\left.\left.\begin{array}{l}
z=0 \\
v=0 \text { and } v^{\prime \prime}=k^{2} e
\end{array}\right\} \text { and } \begin{array}{l}
z=l \\
v=0 \text { and } v^{\prime \prime}=k^{2} e
\end{array}\right\}
$$


the deflections is obtained as:

$$
\begin{aligned}
& v=\left(\frac{q l^{4}}{E I(k l)^{4}}-e\right)(\operatorname{tg} k l / 2 \sin k z+\cos k z-1)-\frac{q z l^{3}}{2 E I(k l)^{2}}\left(1-\frac{z}{l}\right)+ \\
& +n v_{0 \mathrm{~m}} \sin \frac{\pi z}{l}
\end{aligned}
$$

Accordingly, by Equation (2.4), the moment is given by:

$$
\begin{aligned}
& M_{z}=\left(\frac{q l^{2}}{(k l)^{2}}-\frac{E I e(k l)^{2}}{l^{2}}\right)(\operatorname{tg} k l / 2 \sin k z+\cos k z)-\frac{q l^{2}}{(k l)^{2}}+ \\
& +\frac{\pi^{2}}{l^{2}} \operatorname{EInv}_{0 \mathrm{~m}} \sin \frac{\pi z}{l}
\end{aligned}
$$

It can be seen that for the case of evaluation of imperfections general Equations (3.37) and (3.38) for the deformational and flexural response, respectively, defers from the Equations (3.31) and (3.32) just with the additional last term.

\subsubsection{Determination of Rational Eccentricity}

As previously mentioned, the simple-span structures have the ineffective distribution of the internal forces: the extreme value of bending moment at the midspan sections and zero at the support sections. The eccentric application of axial force by means of eccentric anchoring of the cable-staying system would evoke bending moments at the support sections.

Assuming previously stated condition (3.23) the rational eccentricity for the direct modelling is:

$$
e_{r a c}=\frac{\pi^{2} n v_{0 \mathrm{~m}} \cos k l / 2}{(k l)^{2}(1+\cos k l / 2)}+\frac{q l^{4}}{E I(k l)^{4}} \frac{(1-\cos k l / 2)}{(1+\cos k l / 2)}
$$

And the rational moment:

$$
M_{r a c}=\frac{\pi^{2} E \operatorname{Inv} 0 \mathrm{~m}}{l^{2}}-\frac{q\left(\cos k l / 2^{-1}\right)+E I e_{r a c}(k l)^{2}}{l^{2} \cos k l / 2}
$$


For the case of nonlinear modelling without imperfections, equations for the rational eccentricity and rational moment can be obtained substituting zero value of the initial imperfections into Equations (3.39) and (3.40).

As for the case of small deflection analysis and accounting for initial imperfections the Equations (3.24 and 3.25) have to be extended such as:

$$
e_{r a c}=\frac{q l^{2}}{16 N_{c}}+0,5 v_{m 0}
$$

and:

$$
e_{r a c}=\frac{q l^{2}}{16}+0,5 v_{m 0} N_{c}
$$

\subsubsection{Variables for Parametric Analysis}

In order to enable a full grasp of all concepts involved in selecting the appropriate $e_{r a c}$ values, some variables still requires further clarification.

An internal axial force in initially straight UDCS structure (see Figure 3.12) for the first iteration may be obtained considering element in its undeformed position:

$$
N_{c}=\frac{q L^{2}}{8 l_{\mathrm{St}}}
$$

Where $L(\mathrm{~m})$ is a span length of the structure and for the case shown in Figure 1 is equal to $L=2 l ; l_{\mathrm{St}}(\mathrm{m})$ is a strut length.

According to double-level UDCS bridge design principles in Section 2.3.5 it follows that an axial force can be obtained as:

$$
N_{c}=\frac{q L_{1}^{2}}{8 l_{\mathrm{St}, 1}}+\frac{q L_{2}^{2}}{8 l_{\mathrm{St}, 2}}
$$

Where $L_{1}$ and $L_{2}$ are the span lengths, $l_{\mathrm{St}, 1}$ and $l_{\mathrm{St}, 2}$ are the length of the struts of the first and second level structural parts respectively.

The span to strut length relation shows that, for the constant span length the axial response of the girder can be partially controlled by varying the length of the strut. It is clear that increase in the length of the strut decreases the axial response. 


\subsubsection{Simple-Span Double- Level Under-Deck Cable-Stayed Bridge}

As a matter of fact, the main objective of this section is to provide a contribution to shed some new light on a number of issues related to the effective utilization of the cross-sections in the design of steel structures. It is well-know that optimum distribution of the internal forces increases efficiency in the structures design. Steel girder of the concerning bridge due to applied transverse distributed load and direct anchoring of cable staying system, is simultaneously subjected by bending and axial force. The proposed technique focuses on the effective flexural control and possibility of partial axial control. Considering bending moment diagram of the conservative multiple-span bridge it is clear that the bending moment distribution would be much effective for the continuous structure than simple-span. For the simple-span structure, the extreme hogging moment appears at the mid-span of the girder and governs the utilization of the cross-section. The proposed method aims to obtain the efficiency in crosssection utilization of the main girder and distribution of the internal forces at different points of the structure (bending moment in the midspan section, bending moment in the support section and axial force). Since the loads acting upon the UDCS bridge depend on its geometry, this technique is iterative and is presented in the flowchart shown in Figure 3.15.

Two models of the considering bridge are generated with the only difference being in the layout of the cable-staying system by means of struts length. The first model of the double-level UDCS bridge with passing cablestaying system shown in Figure 3.16 is modelled using the $3000 \mathrm{~mm}$ strut length for the second level cable-staying systems and $4500 \mathrm{~mm}$ for the first one. For the second model (see Fig. 3.17) strut lengths are $1800 \mathrm{~mm}$ and $5000 \mathrm{~mm}$ for the second and first levels respectively and thus the cable-staying system gets a framing layout. The differences in the length of struts refer to the axial response in the girder and to the one of the base modelling assumption - slenderness parameter. The main girder of the first model has the slenderness parameter of 1,45 obtained after the first iteration performed according to flowchart shown in Fig. 3.13. For the convergence of the axial forces in second calculation model, two iterations were required, and after that slenderness parameter became equal to 1,53 .

Numerical model and analysis. The numerical analysis is performed by means of the FEM code ANSYS, using beam elements for modelling main girder and link for the cable-staying system. Bridge girders contain the initial bow imperfections assumed to be sinusoidal and evaluated by spline with the amplitude rely on a generalized imperfection factor and an elastic-perfectly 
plastic stress-strain law (i.e., no strain hardening) is accounted. To avoid unnecessary modelling difficulties, a 2D model is adopted.

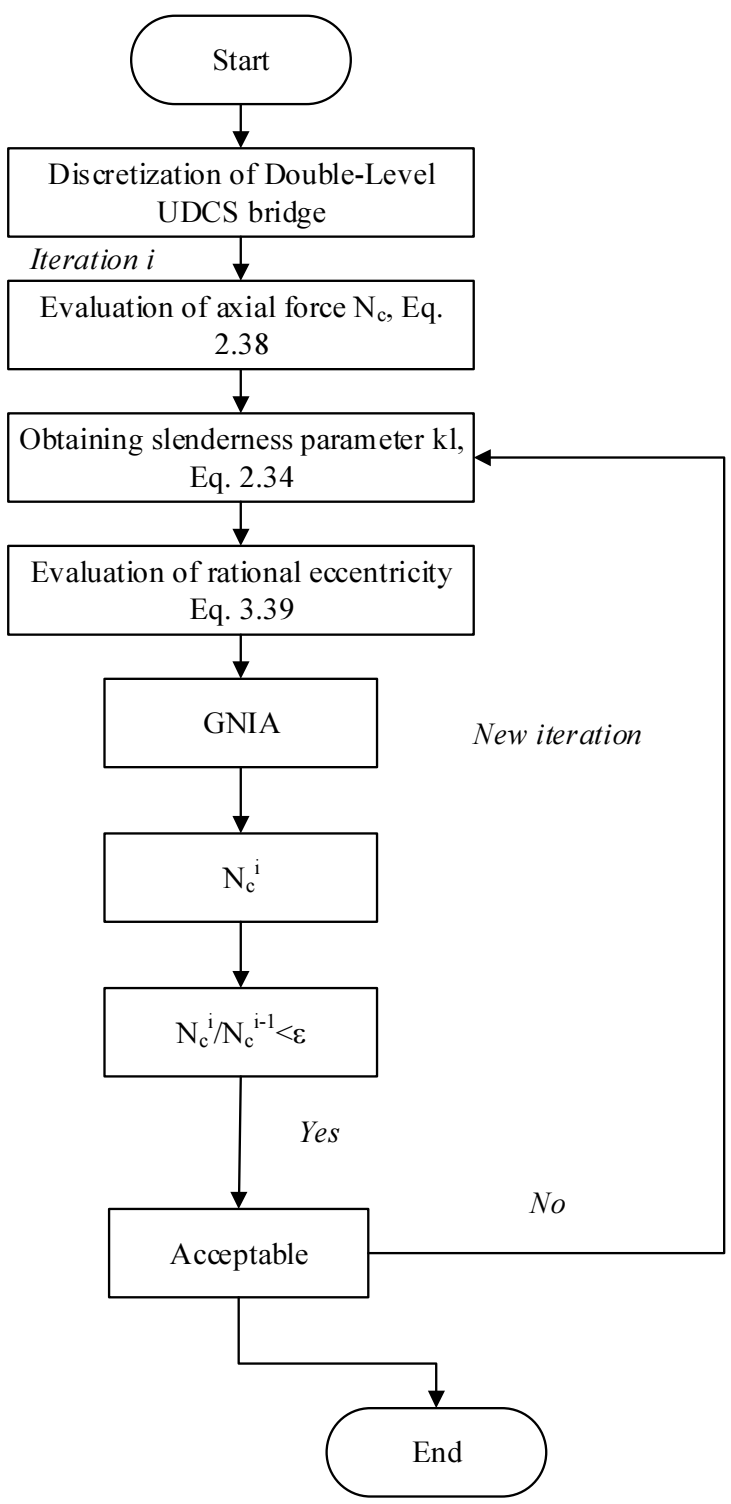

Fig. 3.15. Flowchart for the flexural response control of the double-level UDCS bride 


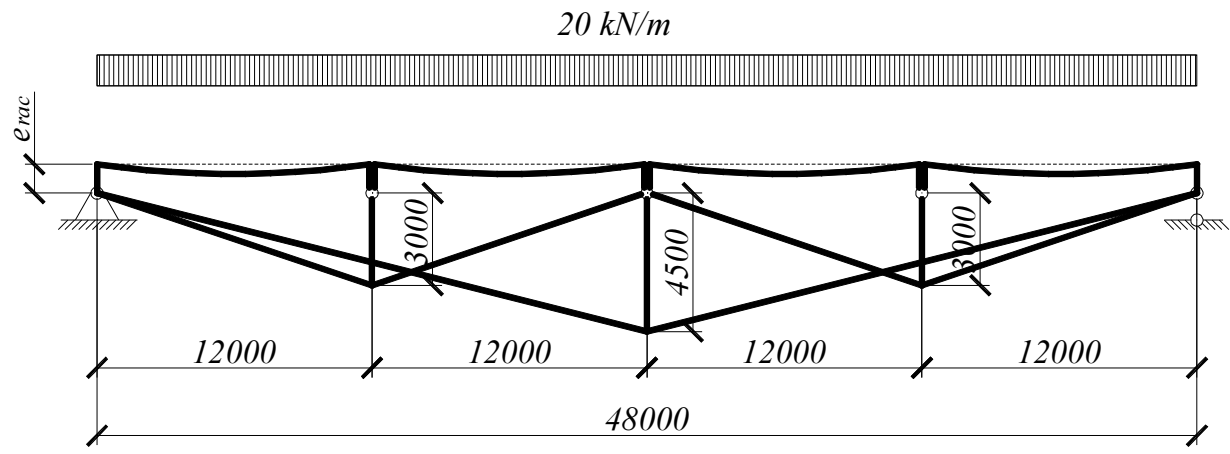

Fig. 3.16. First calculation model: UDCS bridge with passing cable-staying system

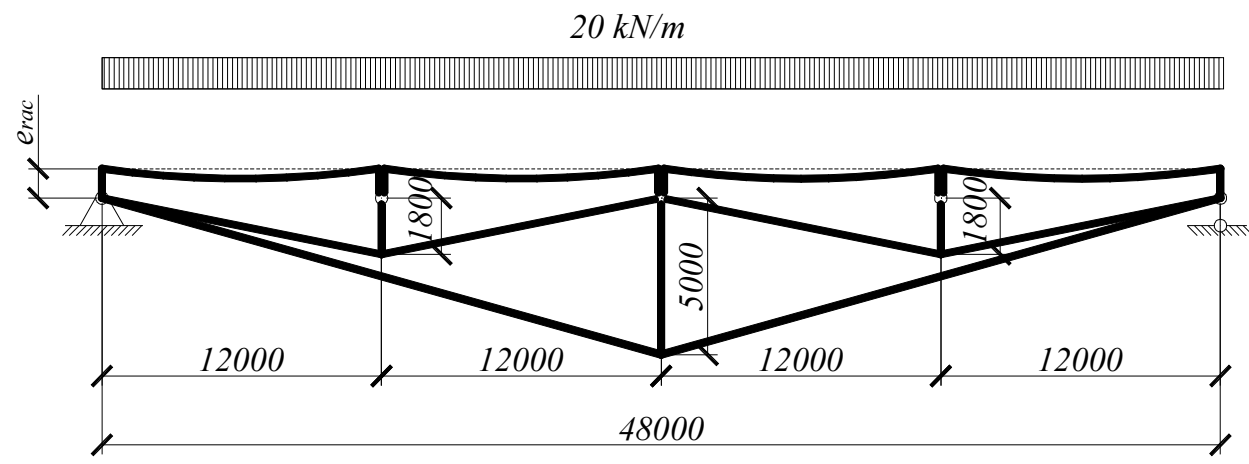

Fig. 3.17. Second calculation model: UDCS bridge with framing cable-staying system

The GNIA performed for the first and second models of the double-level UDCS bridges to obtain flexural response of the girder. The flexural response control procedure performed accordingly by flowchart presented in Fig. 3.13. Convergence will be achieved when the relative difference between two consecutive internal axial forces is smaller than a tolerance $\varepsilon$, which was assumed to be $1 \%$.

Comparative analysis uses the same calculation models of the UDCS bridge without flexural response control by means of centric anchorage of the cablestaying system. 
Results. The flexural response control has been performed by eccentric anchoring of the cable-staying system and the rational eccentricity estimated by Equation (3.37). For the first model, the numerical value of the rational eccentricity $\left(e_{\text {rac }}\right)$ was $122 \mathrm{~mm}$. The relative deference between axial forces in the girder estimated by Equation (3.39) and obtained after analysis performed with ANSYS appeared to be $0.52 \%$ what was less than assumed convergence tolerance, thus just one iteration has been required. The second model of UDCS bridge (see Fig. 3.17) for the first iteration had the rational eccentricity of 112 $\mathrm{mm}$. For the achievement of convergence of the axial forces in the girder, two iterations were required, and finally the rational eccentricity became equal to $111 \mathrm{~mm}$.

Figure 3.16 shows the first model of double-level UDCS bridge to be analyzed (subjected to a transverse distributed load $q$ equal to $20 \mathrm{kN} / \mathrm{m}$ ). The bending moment diagram displayed in Figure 3.16 a)) show the rational moment $\left(M_{r a c}\right)$ values obtained by the non-linear solver of ANSYS and provided by the proposed expression of Equation (3.38). The difference between extreme values of the bending moment equal to $0.36 \%$ thus a proper result of the flexural control is achieved. Moreover, the relative difference between numerical values of rational moment, obtained by Equation (3.38) and non-linear solver ANSYS is $0.06 \%$. This negligible difference shows that presented formula gives an accurate and safe solution.

a)

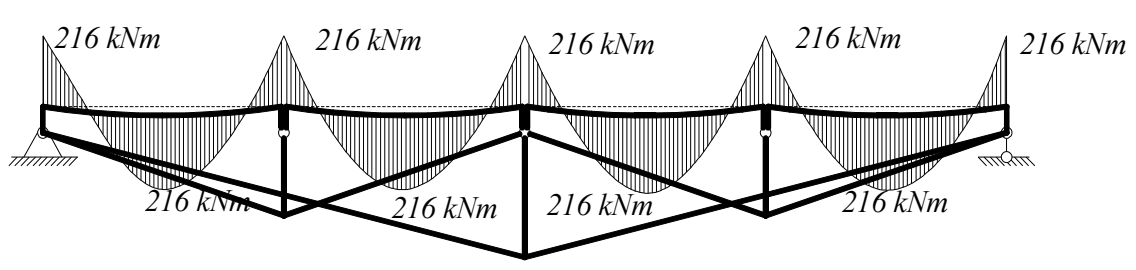

b)

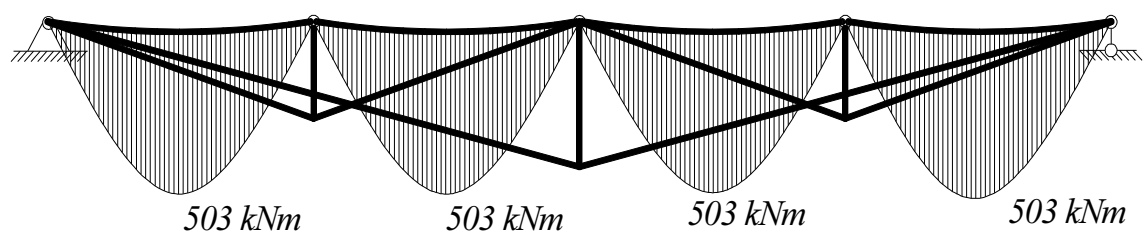

Fig. 3.18. Flexural response of the first model UDCS bridge: a) with flexural response control; b) without flexural response control 
Figures 3.18 a) and 3.18 b) show a comparison between the flexural responses of the UDCS bridge determined by adopting the described rational eccentricity and without it. It is clear that the use of the proposed flexural response control technique determines effective utilization of the cross-section of the girder. Eccentric anchoring of the cable-staying system initiates hogging moments at the supports and decreases bending moments 2,3 times compared to conservative solution of simple-span double-level UDCS bridge.

Finally, by adopting the rationale eccentricity, not just flexural response can be decreased but deformational either. Figures 3.19 a) and 3.19 b) show the comparison between deformations of the double-level UDCS bridge with and without flexural response control respectively. It is obvious that flexural response control makes simple-span bridge more stable in comparison to the same one without flexural response control. Stability is an issue of the high importance concerning bridge design.

a)

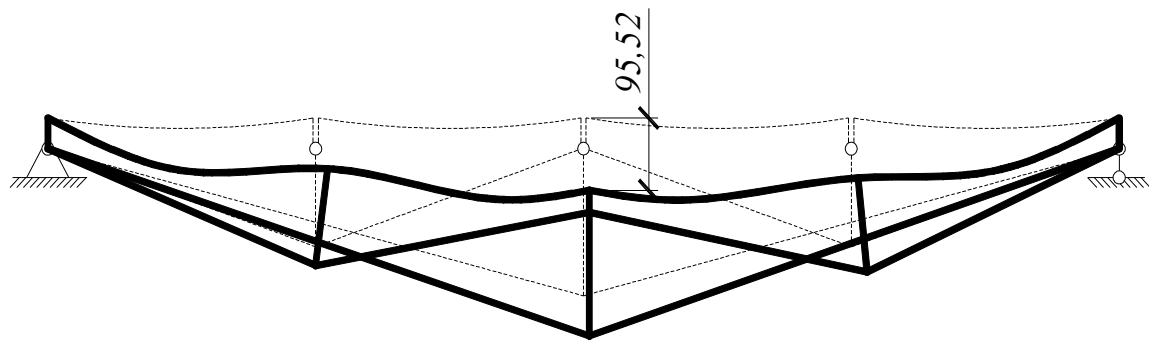

b)

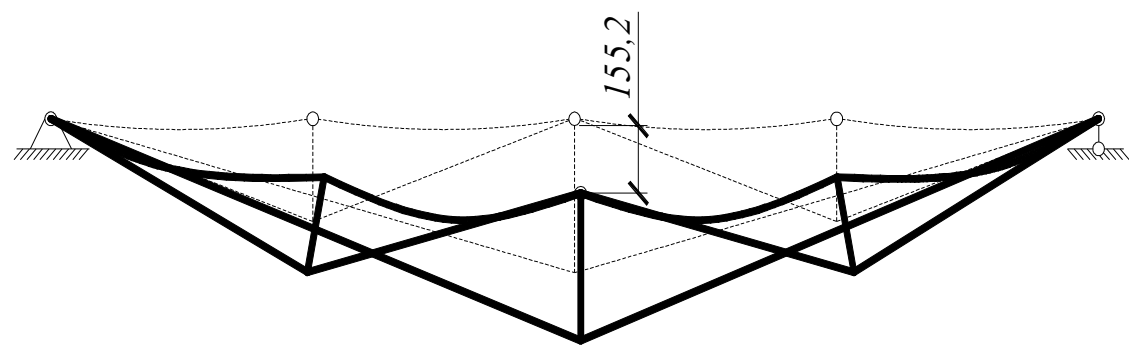

Fig. 3.19. Deformational response of the first model UDCS bridge: a) with flexural response control; b) without flexural response control

Figure 3.20 enables the comparison between the UDCS bridge shown in Figure 3.17 with and without flexural response control respectively. As in a previous example by adopting the rational eccentricity the effective distribution of bending moments obtained, and the extreme value decreased 2,4 times compare to conservative solution. Furthermore, the proposed technique gives an advantage in stability verification as shown in Figure 3.21. 
a)

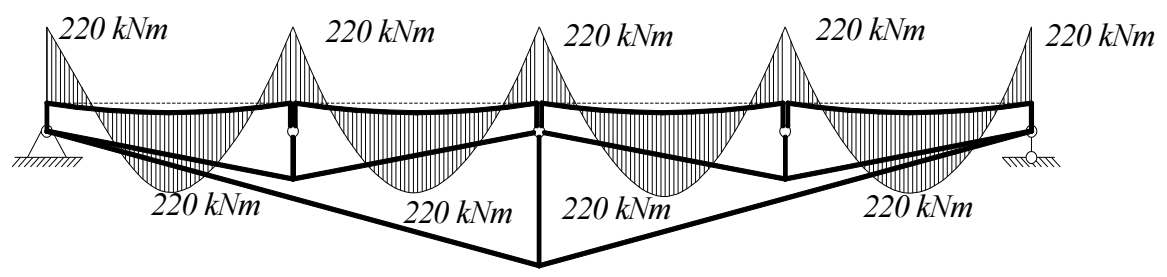

b)

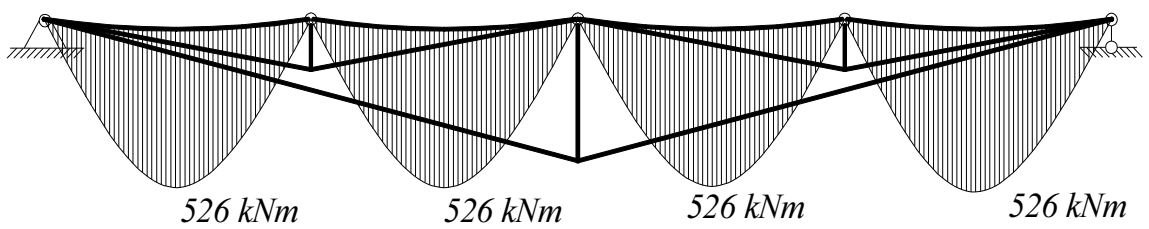

Fig. 3.20. Flexural response of the second model UDCS bridge: a) with flexural response control; b) without flexural response control

a)

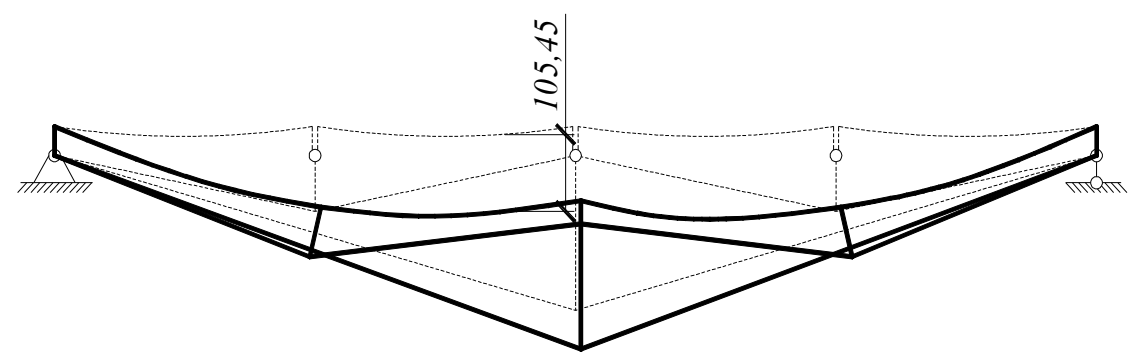

b)

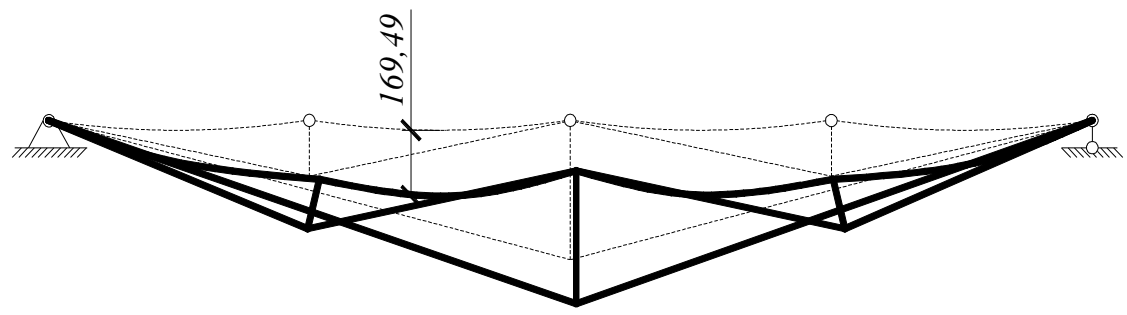

Fig. 3.21. Deformational response of the second model UDCS bridge: a) with flexural response control; b) without flexural response control 
Comparing structural behavior of two examples of the UDCS bridge presented in Figures 3.16 and 3.17 several conclusions can be drawn concerning the influence of the morphology of the cable-staying system on the structural response of the bridge. The variation in length of struts influences the axial response in the girder and slenderness parameter. From the engineering point of view, framing cable-staying system is easier realized than passing one. Figures 3.18 to 3.21 show that with the appropriately chosen strut lengths the structural behavior of both bridges differs negligibly. Thus by adopting appropriate rational eccentricity and geometry of the cable-staying system, the proposed technique can be a powerful tool for the engineers to achieve a better utilization of the cross-sections in bridge design.

Consequently, the deformation at any point of the girder of the double-level UDCS bridge may be estimated by governing Equation (3.39). The accuracy of the results yielded by the application of the formulae to both example models of the bridge by accounting the displacement at the point $z=l / 2$ provided in comparison with values obtained by the non-linear solver of ANSYS. On the basis of this comparative analysis, the relative differences between numerical values of the arbitrary deflections can be declared being less than $1,4 \%$.

\subsubsection{Simple-Span and Semi-Continuous Double-Level Under-Deck Cable-Stayed Bridge}

Numerical evaluation of the flexural response control performed using structural schemes of semi-continuous Double-Level UDCS bridge shown in Figure 3.22 a) and simple-span Double-Level UDCS bridges shown in Figure 3.22 b). The comparison analysis provides the differences between flexural response of the considering structural schemes of the bridge.

GNA was performed using FE code ANSYS. For the case of simple-span bridge the nonlinear modelling of structural response control was performed according previously described technique determining rational eccentricity according Section 3.3.3.3. Structural response control for the semi continuous structure performed applying iterative procedure obtaining appropriate axial rigidity of the cable-staying system. The comparison between obtained flexural response of the considering structures presented in Figure 3.23.

Figure 3.23 shows that simple-span Double-Level UDCS bridge gains the priority against the semi-continuous one due to more efficient moment distribution and the hogging bending moments at the end support sections. Using simple-span structural scheme and controlling structural response of the DoubleLevel UDCS bridge the 1,47 less extreme moments obtained in comparison to semi-continuous structural scheme. 
a)

\section{$20 \mathrm{kN} / \mathrm{m}$}
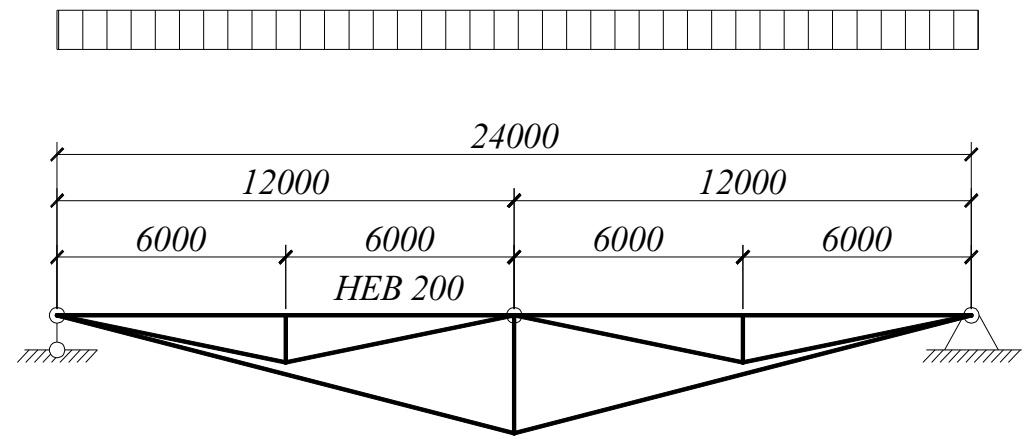

b)

\section{$20 \mathrm{kN} / \mathrm{m}$}

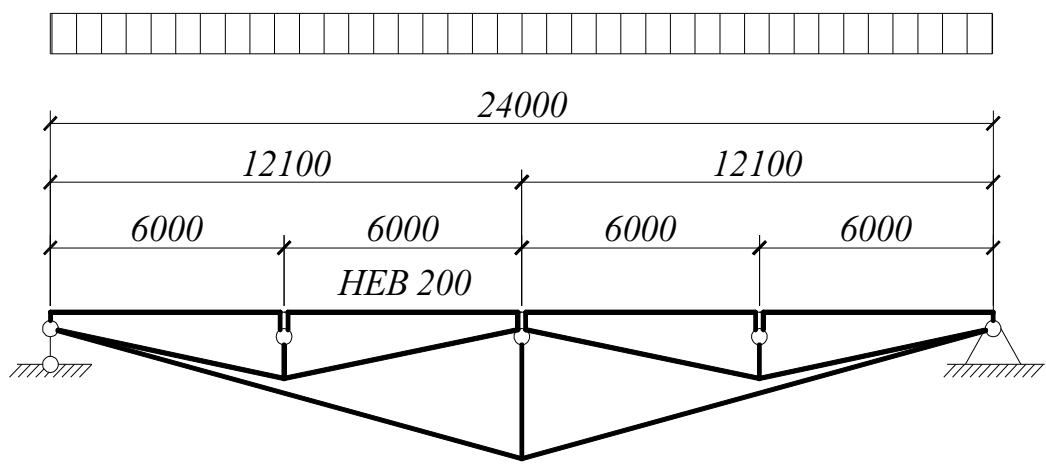

Fig. 3.22. Structural schemes of UDCS bridges: a) semi-continuous; b) simple-span

Preceding study extended for the conventional UDCS bridges increasing the span by the increased number of struts and shifting from the triangle to polygonal elevation. This numerical evaluation seeks in determining the limits of the efficiency of structural response technique which is based on a rational eccentricity, as well as compare and contrast structural schemes of simple-span and continuous structural schemes of the RB of the UDCS bridges with effective bending moment distribution.

There is known algorithm for the structural response control of continuous UDCS bridges. At the first step, the modification in sub-spans length has to be 
made as end sub-spans have to be shorter than intermediate ones. Thus, the lengths of the sub-spans can be accounted as:

$$
\begin{gathered}
l_{1}=\frac{l(1+\sqrt{2})}{2(1+n \sqrt{2})} \\
l_{2}=\frac{l \sqrt{2}}{1+n \sqrt{2}}
\end{gathered}
$$

Where $l_{1}$ and $l_{2}$ are the length of the end and intermediate sub-span, respectively; $l$ is a whole length of the bridge; $n$ is a number of struts.

a)

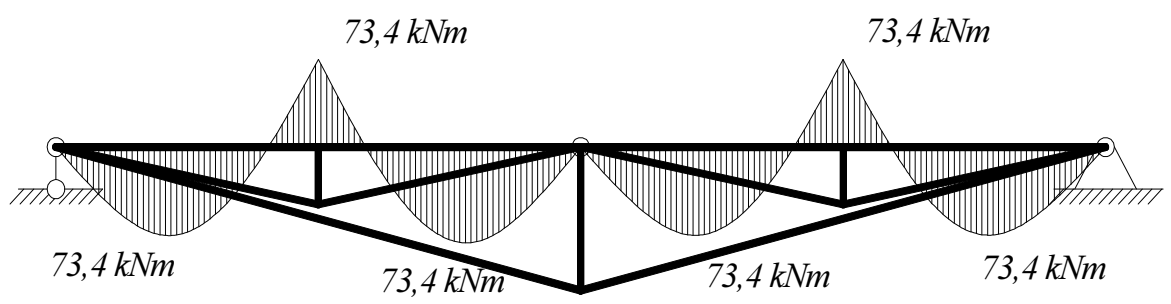

b)

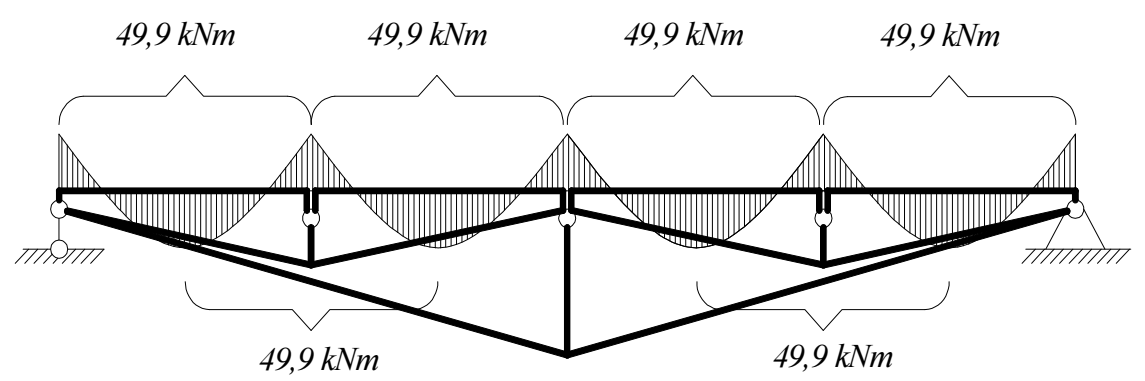

Fig. 3.23. Flexural response control of a) semi-continuous UDCS bridge; b) simplecontinuous UDCS bridge

The rational strut length can be obtained from the static analysis of the beam of the same length as the considering bridge structure $(l)$. As the layout of the cable-staying system has to reflect bending moment diagram in the beam, thus the length of the struts can be obtained as the ratios between bending moments at 
the sections where struts connects the RB. The rational moments are based on the extreme value of the bending moment at the mid-span of the beam which refers to the length of the strut at the mid-span of the bridge. The central deviation of the cable-staying system by means of central strut is assumed on the engineering point of view or the aesthetical requirements for the designing structure. Determination of rational struts length can be expressed as:

$$
\frac{l_{S t, i}}{l_{S t, \text { mid }}}=\frac{M_{i, \text { beam }}}{M_{\text {max }, \text { beam }}}
$$

As the rational geometric parameters are set the structural response of the continuous bridge reflects structural behaviour of the BCIR. For the case of structural response control should be found the rational value of the restoring force at the restraints which is constant for any number of the restraints.

By introducing:

$$
\varphi_{1}(k l)=\frac{1-2 \cos \frac{k l}{2}+\sin \frac{k l}{2} \sin k z+\cos \frac{k l}{2} \cos k z}{k l\left(\sin \frac{k l}{2}+\sin k z\right)}
$$

the rational restoring force can be obtained as:

$$
F_{v b, r a c}=q l \varphi_{1}(k l)
$$

As described in Section 2.3.4 restoring force relays on restrained displacement at the section of indirect support and vice versa, thus the rational displacement can be obtained by introducing:

$$
\varphi_{2}(k l)=\frac{\left[\frac{1}{\cos \frac{k l}{2}}-\frac{(k l)^{2}}{8}-1-F_{v b, r a c}\left(\operatorname{tg} \frac{k l}{2}-\frac{k l}{2}\right) \frac{k l}{q l}\right]}{(k l)^{4}}
$$

as:

$$
\delta_{\text {rac }}=\frac{q l^{4}}{16 E I} \varphi_{2}(k l)
$$

With the rational displacement, the axial rigidity of the cable-staying system can be obtained as described in Section 2.3.4. 
The comparison between numerical results obtained applying appropriate flexural response control technique for the simple-span and continuous conventional UDCS bridge and increasing the number of struts from 1 to 5 was carried out and presented in Figure 3.24.

The case of one strut conventional UDCS bridge refers to previous analysis run on the Double-Level UDCS bridges and gives a high inefficiency of continuous mono-strut cable-staying system.

Figure 3.24 shows that, with the increasing number of struts, the efficiency of the simple-span UDCS bridges decreases compare to the continuous one. Despite decrees in the extreme bending moments the continuous structural scheme of UDCS bridge probably never will excel the simple-span one due to stability issue. Furthermore, the structural response technique based on the rational eccentricity is much more time recipient as the one for the continuous bridges.

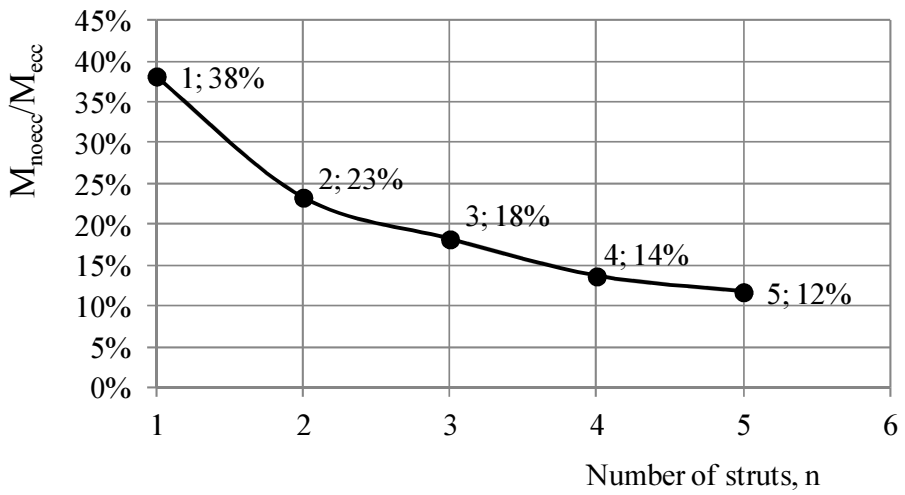

Fig. 3.24. Comparison between structural response control techniques for continuous and simple-span UDCS bridges

\subsection{Practical Guidelines for the Geometrically Nonlinear Analysis of Under-Deck Cable-Stayed bridges}

This section contributes for developing Direct Method and providing the practical guidelines for the GNIA of the UDCS bridges. Designing steel structures the rules for the resistance and serviceability should be applied. Figure 
3.25 summarizes the performed study on the GNIA of beam-column elements in the UDCS bridges and provides practical guidelines for the structural design. It should be noted that this design utilizes effective length as it is hardly predictable for the advanced structures such as UDCS bridges.

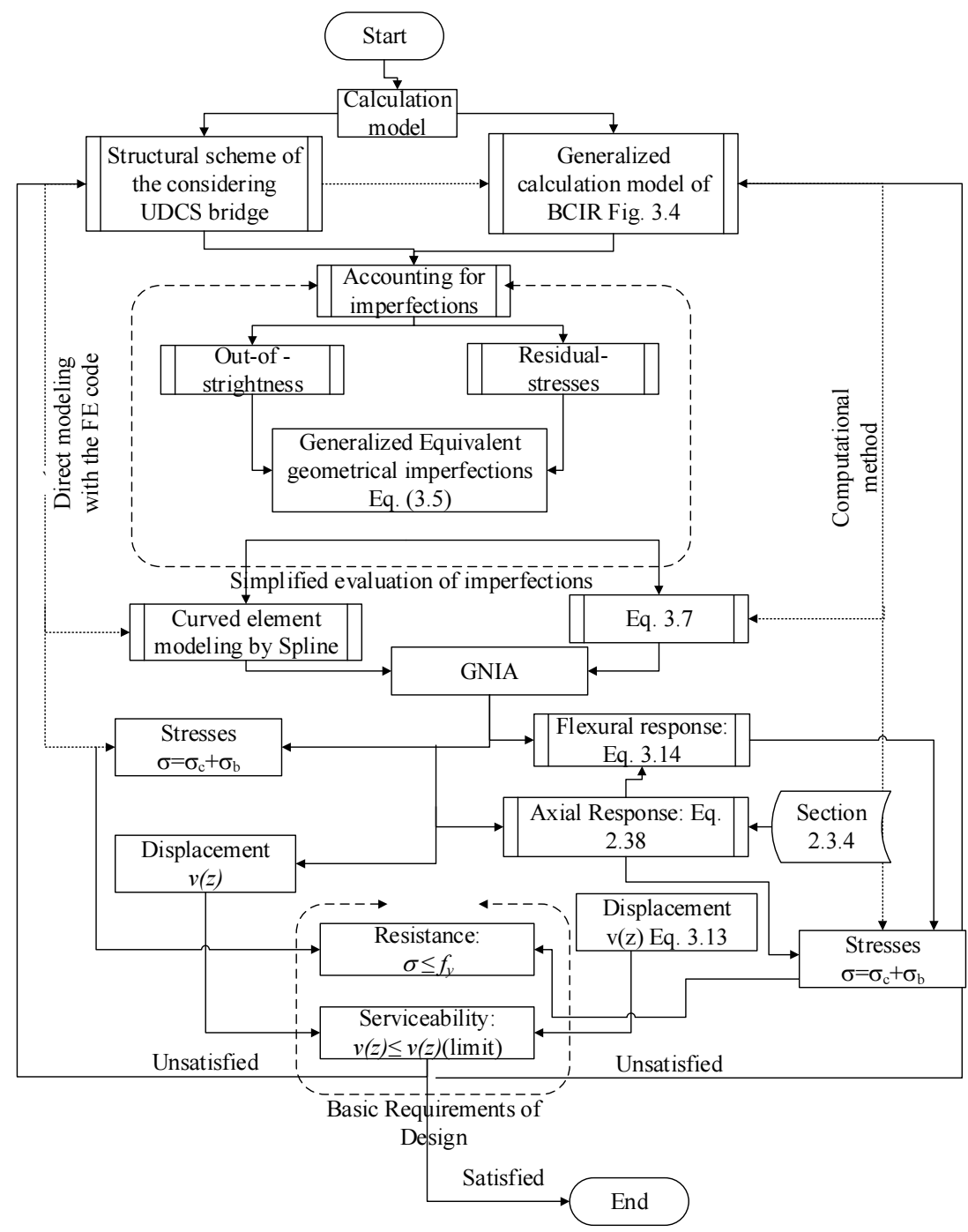

Fig. 3.25. Flowchart of practical guidelines for GNIA for UDCS bridges design where $\sigma_{c}$ and $\sigma_{b}$ is stress due compression and bending, respectively and $f_{y}$ is yield strength. 


\subsection{Concluding Remarks of Chapter 3}

Chapter 3 concludes as follows:

1. The structural response analysis and stability verification of the improved generalized calculation model of BICR has been investigated using the FE nonlinear solver of ANSYS in comparison with the derived governing equation with the approach of Direct Analysis Method. The analytical solution found to be in a good agreement with the results of the finite elements GNIA.

2. The concept of equivalent geometrical imperfections with the approach of the generalized imperfection factor is discussed to simplify the accounting of the initial out-of-straightness and residual stresses. Furthermore, the modelling of the initially imperfect member for the computer aided-analysis described.

3. Evaluation of current design practices of EC3 provided controversial results. For the fundamental case of simple-supported beam-column, the results of the numerical analysis performed using the proposed method and GNIA by FE code ANSYS have to be in a good agreement with the results obtained applying alternative methods based on interaction formulae and equivalent moment concept as the obtained errors have not exceeded $1 \%$. Though, analysing generalized calculation model of BCIR both alternatives provided disagreement from $5 \%$ to $15 \%$ relying on the cross-section sensitivity to the residual stresses. Method 1 appeared to be conservative rather, than Method 2 which provided doubtful safety results compare to GNIA.

4. Comparison analysis of the buckling resistance of the BCIR performing eigenvalue analysis and GNIA presented the drawbacks and draw the limits of the linear buckling based on Euler critical load and relaying buckling shapes.

5. Through the direct numerical analysis of the Double-Level UDCS bridge, the influence of the direction of the imperfections onto the structural behaviour detailed and the most disadvantageous case presented.

6. Effective method of the structural response control for the Double-Level UDCS bridge presented. Proposed method based on the eccentric anchoring of the cable-staying system rather than application of pretension of cable stays as usually. First, the methodology of the proposed method is discussed for the linear assessment of simple-span UNDSC bridge. The base assumption for the structural response control has been developed, and equations for the rational eccentricity and bending moment derived. Secondly, an example is provided that 
illustrates the efficiency of the proposed method. Relevant achievements in bending moment's distribution can be obtained by adopting rational eccentricity. The eccentric anchoring of the cable-staying system evokes hogging moments at the support sections of the RB and by base assumption of the equalization of the extreme values of bending moments significant improvements on the cross-sections utilization may be achieved. Thirdly, direct anchoring of the cable-staying system into the main girder evokes axial forces, and when transverse distributed load is applied the UDCS bridge has been considered under simultaneous action of bending and compression. Axial response of the main girder refers to the possibility of nonlinearities; thus the numerical analysis under variation of the slenderness parameter has been performed. The results showed that with the values of slenderness parameter greater than one considering structure performs in the significant nonlinear behaviour and application of rational eccentricity obtained by linear modelling is inappropriate. Lastly, a basic extension of the proposed structural response control method by nonlinear modelling that accounts for all initial imperfections have been presented. This improvement lets to achieve proficient utilization of cross-sections and efficient distribution of bending moments by application of accurate and appropriate technique.

7. Appropriate structural response control technique for the continuous UDCS structures detailed. The comparison analysis of the semicontinuous and simple-span Double-Level UDCS bridge applying appropriate structural response technique emphasized the efficiency of the structural response control based on rational eccentricity concept with the provided 1,47 times less rational moment value than for the case of semi-continuous structure.

8. Extended numerical study on the structural response control for the continuous and simple-span conventional UDCS bridges showed that the differences between rational bending moments gradually decreases as increasing the number of struts. Though, even for the small differences in the rational flexural response the continuous structural scheme is less acceptable as the procedure of the structural response control is much time recipient than for the simple-span structures. Furthermore, the increasing span of the continuous UDCS bridges refers to the stability issue.

9. Practical guidelines for the structural design of the advanced structures such as UDCS bridges have been provided on the approach of Direct Method. 


\section{Experimental Investigation of Under-Deck Cable-Stayed Bridges}

This chapter presents an experimental investigation of structural behaviour of mono-strut under-deck cable-stayed (UDCS) bridge under symmetric and asymmetric loading. Based on three scale model tests under four symmetric and four asymmetric loadings (tests were doing in pairs for different load cases) and elastic large deformation analysis, the chapter investigates the behaviour of UDCS bridge model according to requirements for geometrically nonlinear analysis with imperfections (GNIA). The results approved the assumptions adopted developing computational method. The analytical and experimental results of flexural and deformational response are in reasonable agreement with each other, which indicates that the ANSYS finite element method (FEM) and computational method adopted in this study are reliable.

\subsection{Objectives and Scope}

All the testing was conducted in the laboratory of Civil Engineering Faculty of Vilnius Gediminas Technical University in 2013. The objective of the 
experimental investigation is to study the structural behaviour of the mono-strut UDCS bridge, in particular:

- The investigation aims to obtain structural behaviour of the structure under symmetric and asymmetric loading.

- Compare the results of the analytical study of ANSYS FE code and proposed computational method.

- Approve the assumptions adopted arranging calculation model and developing computational method.

\subsection{Description of the Test Model}

The structure under observation is a three scale mono-strut UDCS bridge (Figure 4.1 and Annex C) consisting of two parallel situated substructures (Figure 4.2).

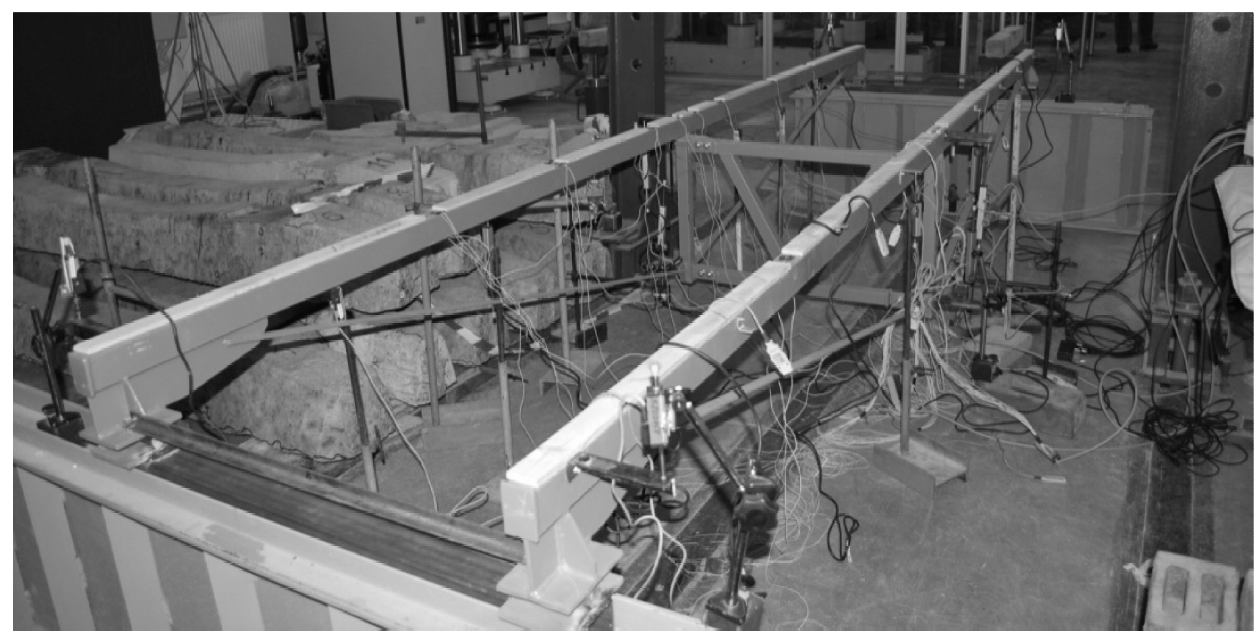

Fig. 4.1. View of Test model

The main element of interest - rigid beam works as a simply supported beamcolumn element with an intermediate elastic restraint by means of strut which stiffness relays on the axial force and displacement of the strut and varies according load case. The struts with the height of $1 / 8$ of the span are situated at the middle of each substructure of the bridge and are hinged connected to the rigid beam. Cable-staying system of each substructure is composed of two stay cables directly anchored to the rigid beam at the support sections and deviated 
by the strut at the midspan. The main parameters of the bridge model substructure are presented in Table 4.1.

Table 4.1. Parameters of the test model

\begin{tabular}{|c|c|c|}
\hline \multicolumn{2}{|l|}{ Parameter } & Test model \\
\hline \multirow{5}{*}{ Overall dimensions } & Total length, mm & 4000 \\
\hline & Left side, $\mathrm{mm}$ & 2000 \\
\hline & Right side, $\mathrm{mm}$ & 2000 \\
\hline & Length of the strut, $\mathrm{mm}$ & 500 \\
\hline & Width, mm & 800 \\
\hline \multirow{3}{*}{ Rigid beams } & $\begin{array}{l}\text { Cross-section area } \\
\square 60 \times 40 \times 2, \mathrm{~mm}^{2}\end{array}$ & 374 \\
\hline & Moment of inertia, $\mathrm{mm}^{4}$ & 184100 \\
\hline & Modulus of elasticity, $\mathrm{N} / \mathrm{mm}^{2}$ & 210000 \\
\hline \multirow[t]{2}{*}{ Struts } & $\begin{array}{l}\text { Cross-section area } \\
\square 40 \times 40 \times 2, \mathrm{~mm}^{2}\end{array}$ & 294 \\
\hline & Modulus of elasticity, $\mathrm{N} / \mathrm{mm}^{2}$ & 210000 \\
\hline \multirow[t]{2}{*}{ Stay cables } & $\begin{array}{l}\text { Cross-section area } \\
\quad-\quad 25 \times 4, \mathrm{~mm}^{2}\end{array}$ & 100 \\
\hline & Modulus of elasticity, $\mathrm{N} / \mathrm{mm}^{2}$ & 210000 \\
\hline
\end{tabular}

Avoiding lateral torsional buckling the rigid beam has been made of rectangular cold formed hollow section less susceptible to torsional deformations. Moreover, in order to obtain the effect of geometrical nonlinearity of the rigid beam the cross section has been chosen such that the slenderness parameter at the maximum loading would be 2,0-2,5 as described in Section 2.3.2. The cross section of the stay cables has been chosen such as to keep as much as possible balanced extreme bending moments under the case of symmetric loading. The block of lateral bracings has been provided to simplify the spatial behaviour of the test model to the studying case of in-plain behaviour of beam-columns.

The boundary conditions of the test model represent the simply-supported element with intermediate elastic restraint. Each substructure of bridge model is free for in plane rotations due to provided steel rollers. One side of each substructure is free for longitudinal movement and the other one is restricted to $55 \mathrm{~mm}$ by providing controllers at the supports as shown in Figure 4.2. At both 
ends of the three scale model, the supports have been restricted for the lateral movement as shown in Figure 4.1.

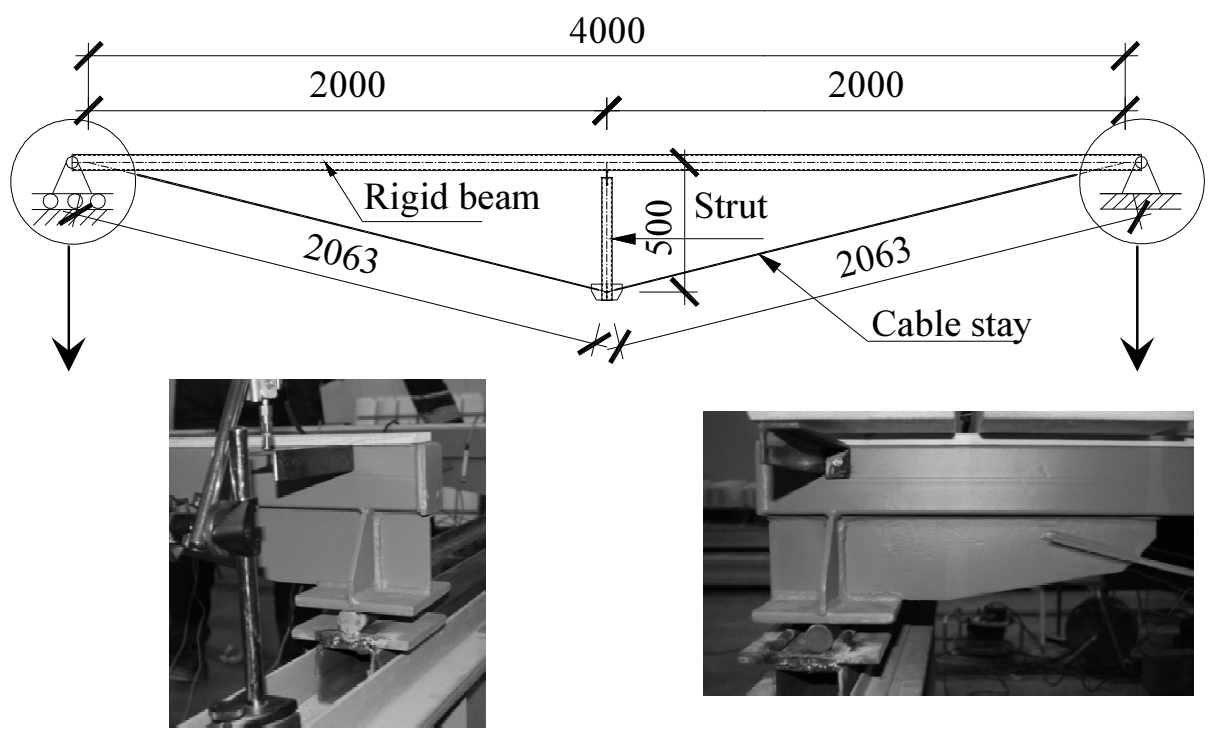

Fig. 4.2. Scheme of experimental model

\subsection{Loads and Load Combinations}

In the testing process, only the vertical loads have been used. Two types of the weights of approximately $25 \mathrm{~kg}$ and $10 \mathrm{~kg}$ have been used to impose the transverse distributed load. Each load case has been performed by steps. For each case, the first step reflects the self-weight of the wooden deck used for transverse load distribution. Total load of each case consists of permanent and imposed loads with the ratio of $1 / 2$ as have been considered during the study. For each case of the symmetric loading, the permanent load has been applied in 5-7 steps using the bigger weights with the constant increment of $400 \mathrm{~kg}$. The imposed load has been applied using the weights of $10 \mathrm{~kg}$ with the constant increment of $125 \mathrm{~kg}$ by means of step. Each step of loading has been performed in a short period of about $2 \mathrm{~min}$. Two different types of asymmetric loading have been imposed reflecting analytical and design procedures. To reflect the analytical procedure, the loads for the both sides of the bridge model have been applied incrementally with the constant ratio of $1 / 2$ except the first step by means of wooden deck (Figure 4.4). To reveal design procedure, the permanent load has been applied in two steps as symmetric loading and two sequent steps reflect 
the imposed load which has been applied just for one side of the bridge model as shown in Figure 4.5.

\begin{tabular}{|l|}
\hline$q_{i}, \mathrm{~N} / \mathrm{mm}$ \\
\hline 4,23 \\
\hline 4,07 \\
\hline $1,07 \ldots 3,9$ \\
2 \\
\hline 1,07 \\
\hline 0,59 \\
\hline 0,10 \\
\hline
\end{tabular}

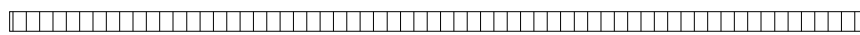
17th step

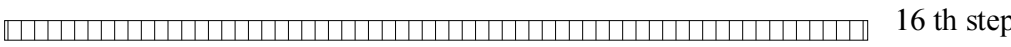

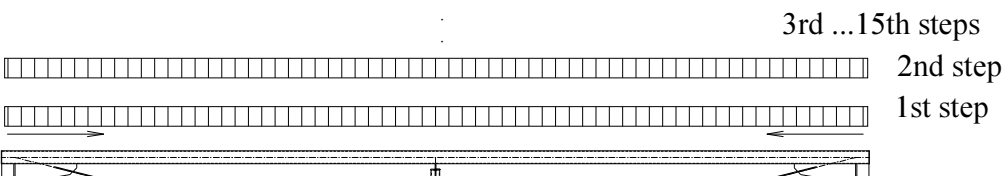

Fig. 4.3. Scheme of symmetric loading

\begin{tabular}{|l|}
\hline$q_{i}$, \\
$\mathrm{N} / \mathrm{mm}$ \\
\hline 2,60 \\
\hline 1,96 \\
\hline 1,34 \\
\hline 0,72 \\
\hline 0,10 \\
\hline
\end{tabular}

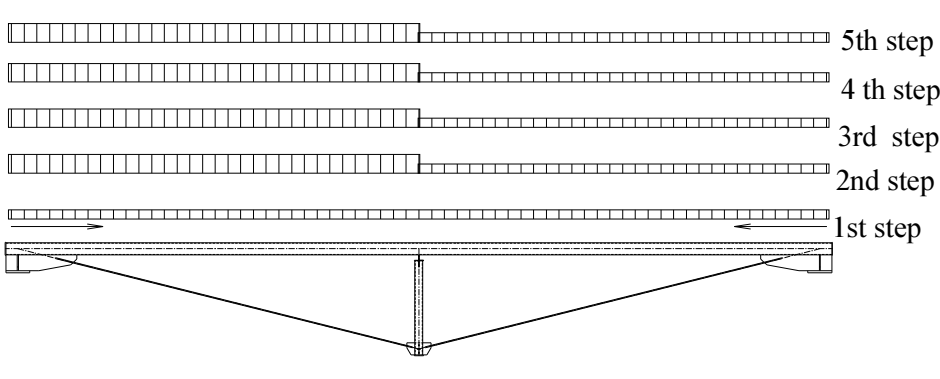

\begin{tabular}{|l|}
\hline $\begin{array}{l}q_{i}, \\
\mathrm{~N} / \mathrm{mm}\end{array}$ \\
\hline 1,37 \\
\hline 1,05 \\
\hline 0,74 \\
\hline 0,42 \\
\hline 0,10 \\
\hline
\end{tabular}

Fig. 4.4. Scheme of analytical asymmetric loading

\begin{tabular}{|l|}
\hline $\begin{array}{l}q_{i}, \\
\mathrm{~N} / \mathrm{mm}\end{array}$ \\
\hline 2,13 \\
\hline 1,82 \\
\hline 1,50 \\
\hline 0,10 \\
\hline
\end{tabular}

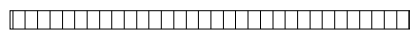

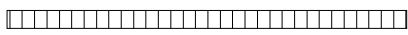

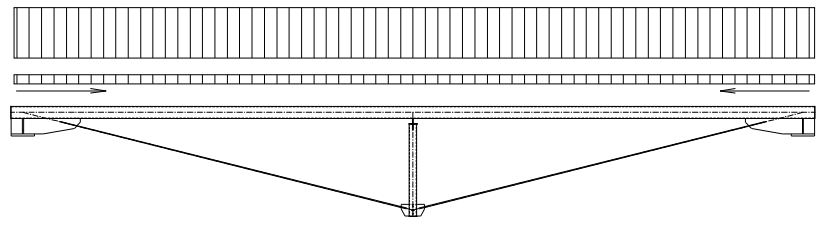

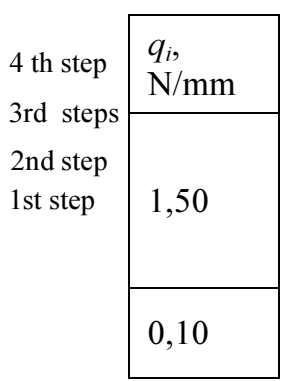

Fig. 4.5. Scheme of design asymmetric loading 


\subsection{Measuring devices}

Two types of sensors (strain gauges (Measurement Group T1-T30) and displacement gauge (Measurement Group I1-I18) have been attached to the test model substructures to capture their structural response under loading as shown in Figure 4.6.

a)

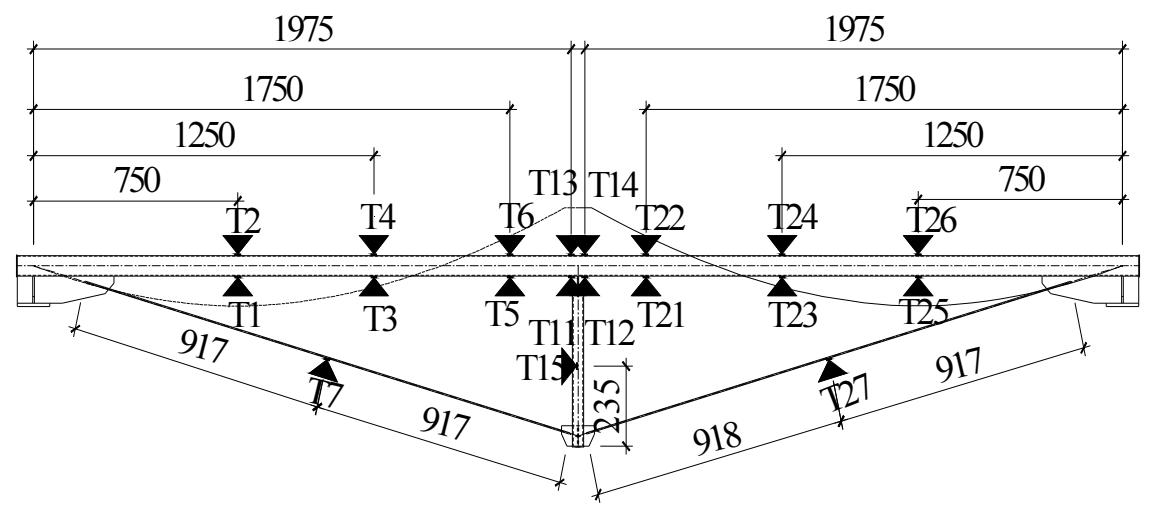

--- predictable bending moments distribution

b)

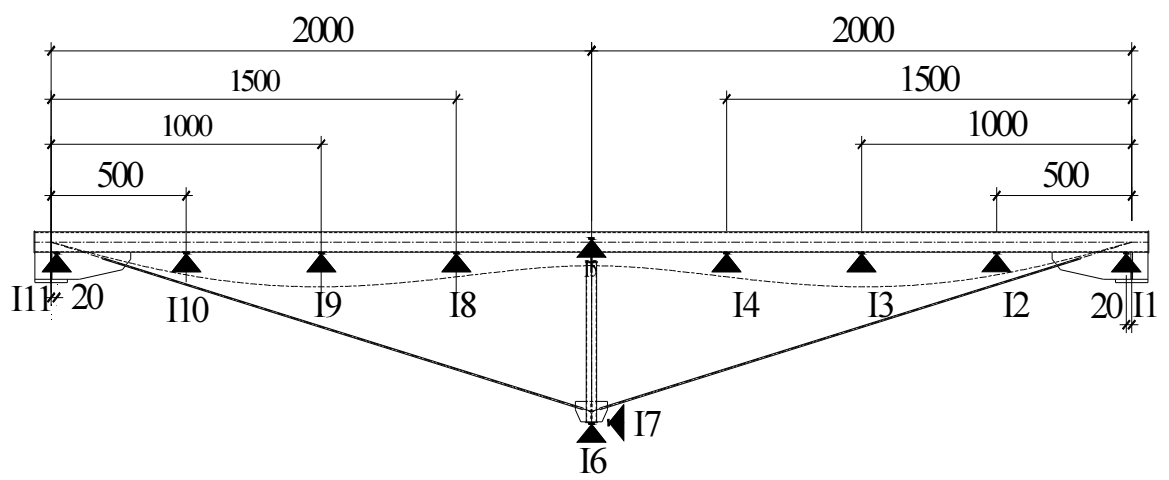

---- predictable displacement

Fig. 4.6. Schemes of arrangement of measuring devices: a) strain gauges,

b) displacement gauges 
12 couple strain gauges have been attached at the top and bottom of the section of the rigid beam and one-by-one on the cable-stays and struts. In total 19 strain gauges have been attached to one of the substructures and 11 to the other one at the distinctive points, as shown in Figure 4.6 and Annex C. The length of the strain gauges $20 \mathrm{~mm}$.

14 devices (accuracy $0,001 \mathrm{~mm}$ ) for measuring vertical displacements of the rigid beam and two-by-two for the vertical and horizontal displacements of the struts have been used. 11 devices have been attached to one of the substructures and 7 additional to the other one at the distinctive points of the test model as shown in Figure 4.6 and Annex C.

Before each step of loading the initial geometrical imperfections have been measured using tightened wire and the calliper (Annex C).

\subsection{Experimental Results}

Every test of the bridge model for different load cases has been done twice ensuring the reliability of the results. Moreover, for each test the strain gauges measurements have been obtained for both loading and reloading cases at the same steps to ensure the validation of assumptions for elastic analysis.

The bending and axial stresses of the beam-column elements of the testing under-deck cable-stayed bridge have been obtained measuring strains at the distinctive points throughout the length of the rigid beam. Accordingly axial stresses of the struts and stay cables have been obtained.

Vertical displacements of the rigid beam and cable-staying system as well as the horizontal displacement of the strut have been measured at each step of the imposed load.

Bending moment diagrams for maximum symmetric transverse loading of $q=$ $4,23 \mathrm{~N} / \mathrm{mm}$ are shown in Table 4.2. The accounted stresses of measured strains during the loading and reloading of the considering case are presented in Annex C. The results obtained during reloading process validate the assumptions of elastic analysis. As seen in Table 4.2, the distribution of bending moments reflects the predictions. The figure includes comparative results of flexural behaviour of the rigid beam obtained during the testing as well as performing geometrically nonlinear analysis with imperfections using nonlinear solver of ANSYS and governing equations of the proposed computational method. Acceptable agreement of the results has been obtained. Greater differences of the extreme value of the sagging moments may be influenced by the connection between rigid beam and strut at the strains measuring sections. 
Table 4.2. Comparative results of flexural response under symmetric loading of $q=4,23$ $\mathrm{N} / \mathrm{mm}$

\begin{tabular}{|l|l|l|l|l|l|}
\hline \multicolumn{3}{|c|}{$\begin{array}{l}2,50 \\
1,00 \\
1,00\end{array}$} \\
0,50
\end{tabular}

Table 4.3 shows exceptionally close agreement between analytical and experimental results of the general stresses. At most of the distinctive points, the errors of the comparative values of the general stresses do not exceed $5 \%$ except points close to the supports. The bigger differences between general stress at those points may be due to the rigidity of the joint and the influence of the supporting plate for the strain gauges attached close to it. The same tendency can be seen in Table 4.2 as bending stresses dominate in the structural behaviour of 
the testing structure. Slightly conservative results of the general stress validate the safety of the GNIA for the case of practical design.

Table 4.3. Comparative results of general stress under symmetric loading of $q=4,23$ $\mathrm{N} / \mathrm{mm}$

\begin{tabular}{|l|l|l|l|l|}
\hline $\mathrm{q}, \mathrm{N} / \mathrm{mm}$ & Gen. Stresses & Experiment & ANSYS & Errors, \% \\
\hline 4,23 & $\sigma_{2, \mathrm{~N} / \mathrm{mm}^{2}}$ & -265 & -298 & -13 \\
\hline 4,23 & $\sigma_{4, \mathrm{~N} / \mathrm{mm}^{2}}$ & -179 & -187 & -5 \\
\hline 4,23 & $\sigma_{6, \mathrm{~N} / \mathrm{mm}^{2}}$ & 162 & 165 & -1 \\
\hline 4,23 & $\sigma_{13, \mathrm{~N} / \mathrm{mm}^{2}}$ & 348 & 360 & -3 \\
\hline 4,23 & $\sigma_{14,} \mathrm{~N} / \mathrm{mm}^{2}$ & 343 & 360 & -5 \\
\hline 4,23 & $\sigma_{22, \mathrm{~N}} / \mathrm{mm}^{2}$ & 162 & 165 & -1 \\
\hline 4,23 & $\sigma_{24, \mathrm{~N} / \mathrm{mm}^{2}}$ & -185 & -187 & -1 \\
\hline 4,23 & $\sigma_{26,} \mathrm{~N} / \mathrm{mm}^{2}$ & -265 & -298 & -13 \\
\hline 4,23 & $\sigma_{10,} \mathrm{~N} / \mathrm{mm}^{2}$ & 208 & 216 & -4 \\
\hline 4,23 & $\sigma_{30,} \mathrm{~N} / \mathrm{mm}^{2}$ & 208 & 216 & -4 \\
\hline 4,23 & $\sigma_{20,} \mathrm{~N} / \mathrm{mm}^{2}$ & 35 & 36 & -4 \\
\hline
\end{tabular}

The agreement between measured and estimated axial stresses of the strut is in a good agreement for all loading cases and have not exceed the difference of 4 $\%$ in comparison to ANSYS results and $6 \%$ in comparison to results of computational method.

Table 4.4 presents even better agreement of the extreme bending moments as preceding Table 4.2. The obtained greater errors close to the support sections are influenced by the rigidity of the joint and supporting plate as have been explained previously. 
Table 4.4. Comparative results of flexural response under symmetric loading of $q=3,44$ $\mathrm{N} / \mathrm{mm}$

\begin{tabular}{|c|c|c|c|c|c|c|}
\hline $\begin{array}{c}2,00 \\
1,50 \\
1,00 \\
0,50 \\
0,00 \\
-0,50 \\
-1,00 \\
-1,50 \neq \\
1\end{array}$ & $\frac{2}{2}$ & 75 & 2000 & 2500 & \multicolumn{2}{|c|}{$3000 \quad 3500$} \\
\hline Moment & Experiment & ANSYS & Method & & $\begin{array}{l}\text { Errors, Method } \\
\%\end{array}$ & $\begin{array}{l}\text { Errors, }{ }^{\text {ANSYS }} \\
\%\end{array}$ \\
\hline $\mathrm{M}_{2,} \mathrm{kNm}$ & $-1,09$ & $-1,18$ & $-1,19$ & & -8 & -9 \\
\hline $\mathrm{M}_{4}, \mathrm{kNm}$ & $-0,67$ & $-0,69$ & $-0,69$ & & -3 & -2 \\
\hline $\mathrm{M}_{6}, \mathrm{kNm}$ & 0,51 & 0,53 & 0,52 & & -3 & -1 \\
\hline $\mathrm{M}_{13}, \mathrm{kNm}$ & 1,44 & 1,49 & 1,51 & & -3 & -5 \\
\hline $\mathrm{M}_{14}, \mathrm{kNm}$ & 1,41 & 1,49 & 1,51 & & -6 & -7 \\
\hline $\mathrm{M}_{22,}, \mathrm{kNm}$ & 0,51 & 0,53 & 0,52 & & -3 & -1 \\
\hline $\mathrm{M}_{24}, \mathrm{kNm}$ & $-0,68$ & $-0,69$ & $-0,69$ & & -2 & -1 \\
\hline $\mathrm{M}_{26}, \mathrm{kNm}$ & $-1,09$ & $-1,18$ & $-1,19$ & & -8 & -9 \\
\hline
\end{tabular}

Initial imperfections of each of the substructure were measured before starting the loading. The initial deformational shape of the substructures approached the form of half of the sine wave. The initial geometrical imperfections appeared to be favourable by means of reverse direction of the displacements of the structure as shown in Annex 3. The measured values of an initial out-of straightness one of the substructures appeared to be around $30 \%$ higher than standardized limiting value of L/1000 (4 mm). The initial out-of straightness of the parallel subsection fitted in the limits provided by steel structures manufacturing standards. 
Table 4.5 presents the deflection shape and comparative results of one of the substructures of the test model. The magnitude of the initial geometrical imperfections for the case presented in Table 4.5 has been $4,1 \mathrm{~mm}$.

Table 4.5. Comparative results of deformational response under symmetric loading of $q=3,44 \mathrm{~N} / \mathrm{mm}$

\begin{tabular}{|l|l|l|l|l|}
\hline $\begin{array}{r}r \\
-11\end{array}$ \\
\hline
\end{tabular}


Table 4.5 shows that the values of the experimental displacement of the rigid beam are in a remarkably close agreement with the analytical results. The inadequate errors of the displacements at the supporting sections appeared due to be due to the influence of the joint. The experimental displacement of the rigid beam at the indirect support by means of strut $\left(\delta_{5}\right)$ corresponds to the displacement of the cable staying system $\left(\delta_{6}\right)$ with the differences of $3 \%$, thus validates the assumption for axial force estimations in Section 2.3.4.

Table 4.6. Comparative results of general stress under symmetric loading of $q=3,44$ $\mathrm{N} / \mathrm{mm}$

\begin{tabular}{|l|l|l|l|l|}
\hline $\mathrm{q}, \mathrm{N} / \mathrm{mm}$ & Gen. Stresses & Experiment & ANSYS & Errors, $\%$ \\
\hline 3,44 & $\sigma_{2,} \mathrm{~N} / \mathrm{mm}^{2}$ & -205 & -238 & -16 \\
\hline 3,44 & $\sigma_{4,} \mathrm{~N} / \mathrm{mm}^{2}$ & -144 & -150 & -5 \\
\hline 3,44 & $\sigma_{6} \mathrm{~N} / \mathrm{mm}^{2}$ & 127 & 131 & -3 \\
\hline 3,44 & $\sigma_{13,} \mathrm{~N} / \mathrm{mm}^{2}$ & 274 & 287 & -5 \\
\hline 3,44 & $\sigma_{14,} \mathrm{~N} / \mathrm{mm}^{2}$ & 269 & 287 & -7 \\
\hline 3,44 & $\sigma_{22,} \mathrm{~N} / \mathrm{mm}^{2}$ & 127 & 131 & -3 \\
\hline 3,44 & $\sigma_{24,} \mathrm{~N} / \mathrm{mm}^{2}$ & -144 & -150 & -4 \\
\hline 3,44 & $\sigma_{26} \mathrm{~N} / \mathrm{mm}^{2}$ & -205 & -238 & -16 \\
\hline 3,44 & $\sigma_{10,} \mathrm{~N} / \mathrm{mm}^{2}$ & 170 & 175 & -3 \\
\hline 3,44 & $\sigma_{30} \mathrm{~N} / \mathrm{mm}^{2}$ & 166 & 175 & -5 \\
\hline 3,44 & $\sigma_{20,} \mathrm{~N} / \mathrm{mm}^{2}$ & -30 & -30 & -1 \\
\hline
\end{tabular}

Table 4.7 presents bending moment's distribution under asymmetric loading. The results presented in Table 4.7 were obtained simulating analytical case of asymmetric loading presented in Figure 4.4 in order to perform comparison analysis. The bending movement's distribution corresponds to the predictions. The measured values of the bending moments are in the good agreement with the estimated of FE code ANSYS. The errors of the extreme 
values of the bending moments for both sides of the substructure are less than 10 $\%$, except increase of the hogging moments at the intermediate section due to asymmetric deformations of the structure causing moments redistribution. Table 4.7 shows that the analytical results are conservative in comparison to experimental ones, as refers to the safety of the FE modelling.

Table 4.7. Comparative results of flexural response under asymmetric loading

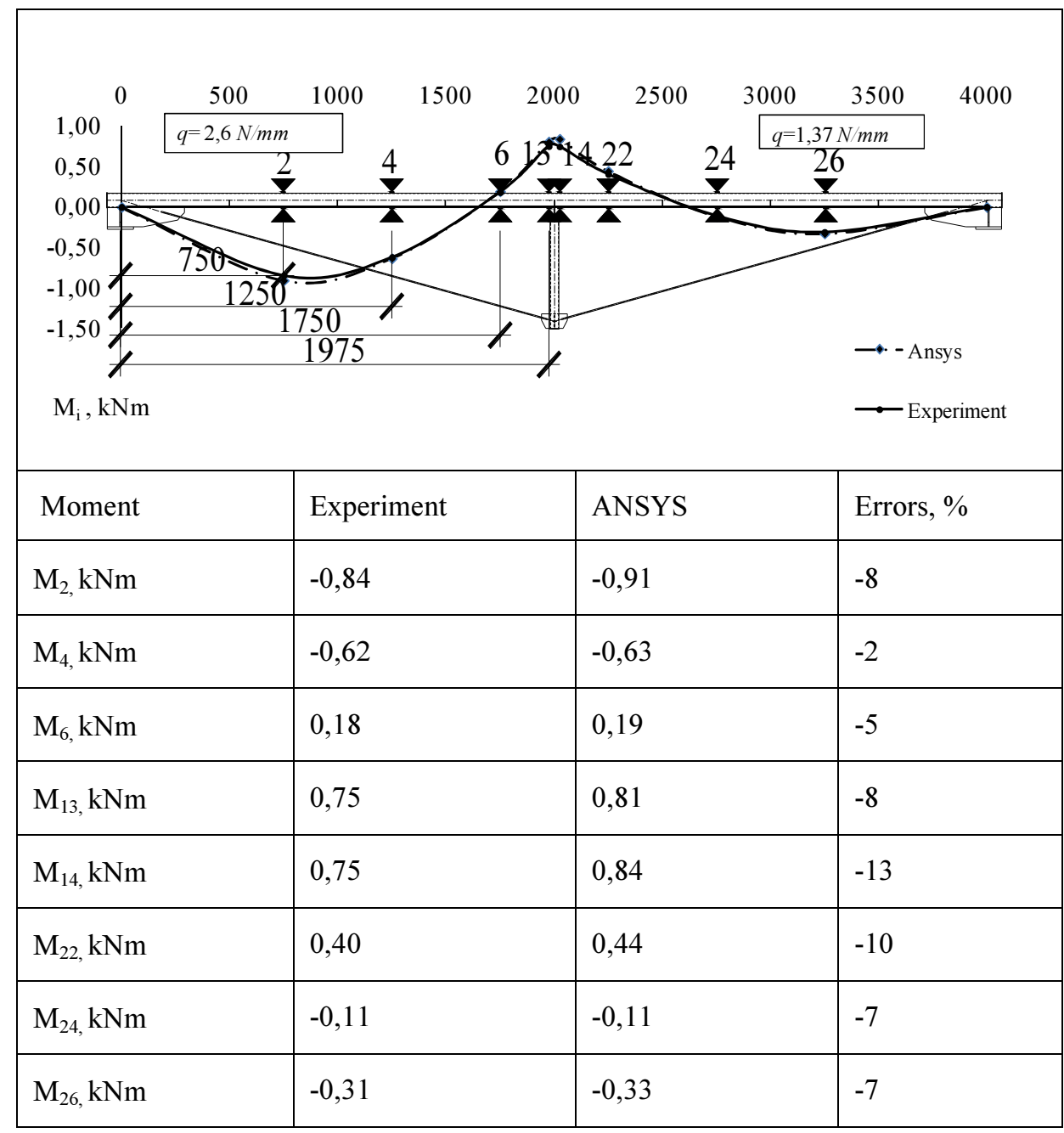

Table 4.8 presents the deformational response of the mono-strut UDCS bridge model under the case of asymmetric loading. The deflection shape of the 
structure presented in Table 4.8 appears to be acceptable and validates the stability of triangle layout of the cable-staying system. The initial out-of straightness of the substructure presented in Table 4.8 was $3,9 \mathrm{~mm}$ and did not exceed the standardized limiting value. The comparative results in the figure are in a satisfactory agreement and validate the performance of the GNIA with the FE code of ANSYS for the structural response analysis of UDCS bridges under the case of asymmetric loading.

Table 4.8. Comparative results of deformational response under asymmetric loading

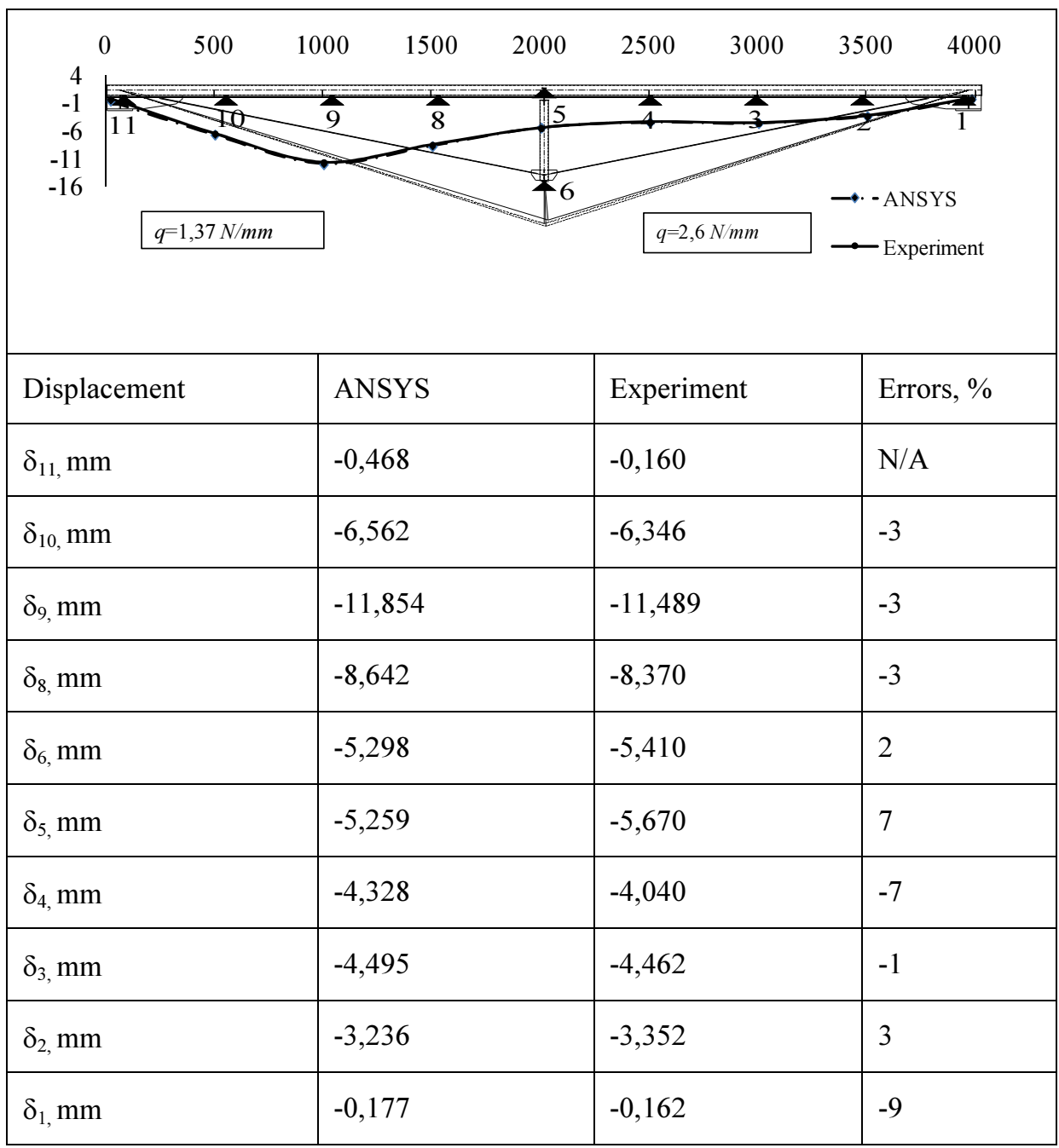


Table 4.9 presents the comparative results of general stress of UDCS bridge model under imposed asymmetric load case. As well as the preceding Table 4.7 resulting in increased differences of comparative sagging bending moments the same tendency can be seen in Table 4.9. As previously explained, due to governing flexural response and the comparative results of the bending moments closely reflects the results of comparative governing stresses. Concluding the errors of the general stresses except that one point do not exceed $10 \%$; thus the analytical results are slightly conservative and in a good agreement with the experimental ones. According to previous conclusion the proposed method of the GNIA is safe for practical design considering both symmetric and asymmetric loading.

Table 4.9. Comparative results of general stress under asymmetric loading

\begin{tabular}{|l|l|l|l|l|}
\hline $\mathrm{q}, \mathrm{N} / \mathrm{mm}$ & Gen. Stresses & Experiment & ANSYS & Errors, \% \\
\hline 2,6 & $\sigma_{2, \mathrm{~N} / \mathrm{mm}^{2}}$ & -137 & -147 & -7 \\
\hline 2,6 & $\sigma_{4, \mathrm{~N} / \mathrm{mm}^{2}}$ & -101 & -109 & -8 \\
\hline 2,6 & $\sigma_{6} \mathrm{~N} / \mathrm{mm}^{2}$ & 30 & 30 & -3 \\
\hline 2,6 & $\sigma_{13,} \mathrm{~N} / \mathrm{mm}^{2}$ & 122 & 132 & -8 \\
\hline 1,37 & $\sigma_{14,} \mathrm{~N} / \mathrm{mm}^{2}$ & 122 & 137 & -13 \\
\hline 1,37 & $\sigma_{22,} \mathrm{~N} / \mathrm{mm}^{2}$ & 66 & 72 & -10 \\
\hline 1,37 & $\sigma_{24,} \mathrm{~N} / \mathrm{mm}^{2}$ & -17 & -18 & -7 \\
\hline 1,37 & $\sigma_{26,} \mathrm{~N} / \mathrm{mm}^{2}$ & -50 & -54 & -7 \\
\hline 1,35 & $\sigma_{10,} \mathrm{~N} / \mathrm{mm}^{2}$ & 100 & 101 & -1 \\
\hline 0,74 & $\sigma_{30} \mathrm{~N} / \mathrm{mm}^{2}$ & 100 & 101 & -1 \\
\hline 1,045 & $\sigma_{20} \mathrm{~N} / \mathrm{mm}^{2}$ & -16 & -17 & -2 \\
\hline
\end{tabular}




\subsection{Concluding Remarks of Chapter 4}

Chapter 4 draws the following conclusions:

1. The experimental bending moment distribution and deformational shape of UDCS bridge model closely reflects the analytical flexural and deformational response obtained both using nonlinear solver of ANSYS and general equations of developed computational method.

2. The comparative values of the measured and estimated bending moments and general stresses are in satisfactory agreement and do not exceed $10 \%$ for both symmetric and asymmetric loading with exceptions at the support sections due to influence of the joints.

3. The comparative values of the measured and estimated vertical displacements are in exceptionally close agreement and do not exceed $7 \%$ for both symmetric and asymmetric loading with exceptions at the support sections due to influence of the joints.

4. Vertical displacement of the cable-staying system corresponds to restrained displacement of the rigid beam with the difference less than 3 $\%$.

5. The comparative values of the measured and estimated axial stresses of the stay cables and struts do not exceed 5\%. 


\section{General Conclusions}

\section{Conclusions}

Present study aims at contributing to a better understanding of the structural response and stability analysis of the beam-column elements in the UDCS bridges and concludes as following:

1. Under the case of asymmetric loading multiple-struts UDCS bridges with the layout of polygonal cable-staying system experience objectionable deflection shape.

2. Major steel structures design specifications alongside the conventional design methods provide advanced alternatives. However, they have the form of recommendations rather than practical guidelines.

3. New arrangement of the cable-staying system for the UDCS bridge have been proposed and refers to deformational response stabilization.

4. Structural behaviour of the rigid beam of the UDCS bridge reflects structural behaviour of the elastically restrained beam-column element. Developed generalized calculation model and a new computational method based on GNA for the accurate and safe structural analysis of the BCIR. Results of the finite element code ANSYS are in close agreement with the analytical ones as relative errors do not exceed 0,11 $\%$. 
5. Evaluation of current design practices of EC3 provided controversial results. For the fundamental case of simple-supported beam-column, the relative errors do not exceed $1 \%$. Though, analysing generalized calculation model of BCIR obtained disagreement from 5\% to $15 \%$ according to the cross-section sensitivity to the residual stresses.

6. Appropriate structural response control technique for the continuous UDCS structures detailed. The comparison analysis of the semicontinuous and simple-span Double-Level UDCS bridge applying appropriate structural response technique emphasized the efficiency of the structural response control based on rational eccentricity concept with the provided 1,47 times less rational moment value than for the case of semi-continuous structure.

7. Practical guidelines for the structural design of the advanced structures such as UDCS bridges have been provided on the approach of Direct Method.

8. The results of experimental investigation approved adopted assumptions and evaluated the accuracy of the proposed method. The comparative values of the measured and estimated general stresses are in satisfactory agreement and do not exceed $10 \%$.

\section{Suggestions for Future Research}

In the future perspective, regarding the author's contribution in developing of UDCS bridges and advanced methods for their structural response and stability, the following may become the issues:

1. Considering arrangement of the structural elements of proposed DoubleLevel UDCS bridge the spans of the structures may be increased proposing other structural forms for the substructures.

2. Accounting for the influence of imperfections the possible variations of initially deformed curvature of the continuous UDCS bridges becomes an issue as directly refers to structural response and stability.

3. In the advanced bridge design, the range of materials for RB can be widen by considering high strength steel with the yield stress limit higher than 450 . 


\section{References}

AASHTO (2010). AASHTO LRFD Bridge Design Specifications, 5th Edition, with 2010 interims, American Association of State and Highway Transportation Officials, Washington, D.C.

Alpsten, G. A. and Tall, L. 1970. Residual stresses in heavy welded shapes. Welding Journal, 49(3).

Al-Shawi, F. A. N. 2001. Stiffness of restraint for steel struts with elastic and supports. Proceedings of the Institution of Civil Engineers - Structures and Buildings, 146(2), 153-159.

Al-Shawi, F. A. N. 1998. Determination of restraint forces for steel struts. Proceedings of the Institution of Civil Engineers - Structures and Buildings, 128(3), 282-289.

American Institute of Steel Construction (AISC) 1989. Allowable Stress Design Specification for Structural Steel Buildings, 9th ed., AISC, Chicago, IL.

American Institute of Steel Construction (AISC) 1993. Load and Resistance Factor Design Specification for Structural Steel Buildings, 2nd ed., AISC, Chicago, IL.

American Institute of Steel Construction (AISC) 1994. Specification for the design, fabrication and erection of structural steel for buildings, load and resistance factor design. AISC, Chicago.

American Institute of Steel Construction (AISC) 2005. Code of Standard Practice for Steel Building and Bridges, AISC 303-05, Chicago, Illinois, USA. 
American Institute of Steel Construction (AISC) 2005a. Specification for Structural Steel Buildings, ANSI/AISC Standard 360/05, AISC, Chicago, Illinois, USA.

American Institute of Steel Construction (AISC) 2010. Specification for Structural Steel Buildings, ANSI/AISC Standard 360/10, AISC, Chicago, Illinois, USA.

American Society of Civil Engineers (ASCE) 1997. Effective Length and Notional Load Approaches for assessing Frame Stability: Implications for American Steel Design. Task Committee on Effective Length, Technical Committee on Load and Resistance Factor Design, Structural Engineering Institute, pp. 442.

Aravinthan, T., Witchukreangkrai, E., and Mutsuyoshi, H. 2005. Flexural behaviour of two-span continuous prestressed concrete girders with highly eccentric external tendons. ACI Structural Journal, 102(3): 402-411.

Aristizabal-Ochoa, D.J. 2001. Non-linear large-deflection-small strain elastic analysis of a beam-column with semi-rigid connections. Journal of Structural Engineering, ASCE, 26(6), 991-1003.

Aristizabal-Ochoa, D. J. 2007. Large deflection and post-buckling behaviour of Timoshenko beam-column with semi-rigid connections including shear and axial effects. Structural Engineering, 26(6), 991-1003.

Arup O., 2009. The design of bridges. The Arup Journal, Arup 2/2009.

Attalla M.R., Deierlein G. G. and McGuire W. 1996. Nonlinear frame analysis with torsional-flexural member behaviour. Proceedings of the Fifth International Colloquium on Stability and Metal Structures, Lehigh University, SSRC, 11-9.

Austin, W.J. 1961. Strength and design of metal beam-columns. Journal of the Structural Division, ASCE, 87(4), 1-32.

Austin, W.J., and Ross, T. J. 1976. Elastic buckling of arches under symmetric loading. Journal of Structural Division, ASCE, 102(2), 1085-1095.

Australian Standard. AS100-1998. Steel structures.

Ayrton, W.E., Perry, J. 1886. On struts. The Engineer, 62, 464.

Banfi, M. 2002. Discusion of stiffness of restraint for steel struts. Proceedings of the Institution of Civil Engineers - Structures and Buildings, 152(3), 298-300.

Barsoum, R. S., and Galagher, R. H. 1970. Finite element analysis of torsional and torsional-flexural stability problems. International Journal for Numerical Methods in Engineering, 2, 335-352.

Bayo, E.; Loureiro, A. 2001. An efficient and direct method for buckling analysis of steel frame structures, Journal of Constructional Steel Research. Elsevier 57(12): 13211336.

Beer, H. and Schulz, G. 1970. Theoretical Bases for the European Buckling Curves, Construction Métallique 7(3): 37-55) (in French). 
Bild S., Chen G., and Trahair, N.S. 1992. Out-of-plane strength of steel beams, ASCE Journal of Structural Engineering, 118(8), 1987-2003.

Bjorhovde, R. and Tall, L. 1971. Maximum column strength and the multiple column curve concept. Fritz Engineering Laboratory Report No. 337.29, Lehigh University.

Bjorhovde, R., Brozzetti, J., Alpesten, G.A., and Tall, L. 1971. Residual stress in thick welded plates. Fritz Engineering Laboratory Report NO 337.13, Lehigh University.

Bjorhovde, R. 1972. Deterministic and Probabilistic Approaches to the Strength of Steel Columns, Ph.D. dissertation, Le-high University, Bethlehem, Pennsylvania, USA.

Bjorhovde, R. 1984. Effect of End Restraint on Column Strength - Practical Applications, Engineering Journal, AISC 20(1): 1-13.

Bjorhovde, R.; Brozzetti, J. and Colson, A. 1988. Connections in Steel Structures: Behaviour, Strength and Design. Elsevier Applied Science, London, England.

Bjorhovde, R.; Colson, A.; Haaijer, G. and Stark, J. W. B. 1992. Connections in Steel Structures II, AISC. Chicago, Illinois, USA.

Bjorhovde, R. 2010. Evolution and State-of Art of Column Stability Criteria, Journal of Civil Engineering and Management. Technika 16(2): 159-165.

Bleich, F. 1952. Buckling Strength of Metal Structures. McGraw-Hill, New York.

Boissonade, N., Greiner, R., Jaspart, J.-P., Lindner, J., Rules for Member Stability in EN 1993-1-1. Background documentation and design guidelines, ECCS TC 8 - Stability. Brussels.

Boissonnade, N., Jaspart, J.-P., Muzeau, J.-P., Villette, M. 2002. Improvement of the interaction formulae for beam columns in Eurocode 3. Computers and Structures, 80, 2375-2385.

Boissonnade, N., Jaspart, J.-P., Muzeau, J.-P., Villette, M. 2004. New interaction formulae for beam-columns in Eurocode 3: The French-Belgian approach. Journal of Constructional Steel Research, 60, 421-431.

Brown, J.B. 2005. Bridges: Three Thousand Years of Defying Nature. Firefly Books, New York, p. 2008.

BS EN10210-2, 2006. British Standard: Hot finished structural hollow sections of nonalloy and fine grain steels Part 2: Tolerances, dimensions and sectional properties. British Standards Institution.

Bureau A, Galea Y, Jaspart J. P, Maquoi R, Muzeau JP, Villette M. Proposal for a revision of Eurocode 3. TC8- ECCS meeting, Timisoara, 1999.

Canadian Standards Association (CSA). 2009. Steel Structures for Buildings, CSA Standard S16-2009, CSA. Mississauga, Ontario, Canada.

Cazet, P. 1992. The steel Ober Argent viaduct (Le viaduct metallique sur l'Oberatgen). Bulletin Ponts Metalliques (OTUA), 15: 97-114. [In French] 
Chan, S. L., Zhou, Z. H. 1995. Second-order elastic analysis of frames using single imperfect element per member. Journal of Structural Engineering, ASCE, 121(6), 939995.

Chan, S. L., Zhou, Z. H. 1998. On the development of a robust element for second-order 'non-linear integrated design and analysis (NIDA)'. Journal Constructional Steel Research, 47, 169-190.

Chan, S. L., Gu, J.-X. 2000. Exact tangent stiffness for imperfect beam-column members. Engineering Structures, 9, 1094-1107.

Chan, S. L., Zhou, Z. H. 2000. Nonlinear integrated design and analysis of skeletal structures. Engineering Structures, 22(3), 246-257.

Chan, S. L., Chui, P.-T. 2000. Non-linear static and cyclic analysis of semi-rigid steel frames. Elsevier Science.

Chen W. F, Atsuta T. 1977. Theory of beam-columns. McGraw-Hill.

Chen, W. F., and Lui, E. M. 1987. Structural stability, theory and implementation. Elsevier, New York.

Chen, W. F. and Lui, E.M. 1991. Stability Design of Steel Frames. CRC Press, Boca Raton, FL.

Chen, S-J. C. and Wang W-C. Moment Amplification Factor for P- $\delta$ Effect of Steel Beam-Column. Journal of Structural Engineering 125(2), 219-223.

Davis, J.M. 1990. In-plane stability of portal frames. Journal of The Structural Engineer, 68(8), 141-147.

De Araujo, R. R., De Andrade, S. A. L., da S. Vellasco, P.C.G., Da Silva, J.G.S., De Lima, L.R.O. 2006. Structural response of pre-stressed stayed steel columns. Stability and Ductility of Steel Structures, 241-248.

Deierlein, G, 2003. Background and Illustrative Examples on Proposed Direct Analysis Method for Stability Design of Moment Frames. Report on behalf of AISC TC10, pp. 17.

Deierlein, G, 2004. Stable Improvements: Direct Analysis Method for Stability Design of Steel-Framed Buildings. Structural Engineer, 24-28.

DIN 18800. Teil 1, Stahlbauten, Bemessung und Konstruktion. Berlin: Beuth Verlag GMBH; 1988.

Duan, L., Sohal, I. S., and Chen, W. F. 1989. On beam-column moment amplification factor. AISC Engineering Journal, 4(26), 130-135.

European Committee for Standardization, ENV 1993-1-1, Eurocode 3: Design of steel structures. Part 1-1: General Rules and rules for buildings, Brussels, 1993.

EN 1993-1-1, Eurocode 3. Design of steel structures. General rules and rules for buildings, CEN, Brussels, 2005. 
Eröz, M., White, D., and DesRoches, R. 2008. Direct Analysis and Design of Steel Frames Accounting for Partially Restrained Column Base Conditions. Journal of Structural Engineering, ASCE, 134(9), 1508-1517.

Fang, L. X., Wong, Y. L., Chan, S.L. 1999. Strength analysis of semi-rigid steel concrete composite frames. Journal of Constructional Steel Research, 52(3), 269-292.

Fukumoto, Y., Aoki T., Kajita, N. 1976. Evaluation of column curves based on probabilistic concept. In Proceedings of the international conference on stability, Preliminary report. Tokyo.

Fukumoto, Y. and Itoh, Y. 1983. Evaluation of Multiple Column Curves from the Experimental Data Base Approach, Journal of Constructional Steel Research 3(3): 2-19.

Fürst, A., and Marti, P. 1999. Experimental tests of precast beams with prestressing below the deck (Versuche an Trägern mit Unterspannung aus vorfabrizierten, vorgespannten Betonzuggliedern). Institut für Baustatik und Konstruktion (IBK), ETH, Zurich, Switzerland [in German].

Galambos, T. V. and Ketter, R. L. 1959. Columns Under Combined Bending and Thrust. Journal of the Engineering Mechanics Division, ASCE, 85(EM2), 135-152.

Galambos, T. V. 1968. Structural Members and Frames. Prentice-Hall International, London, U.K.

Galambos, T. V.; Editor. 1988. Guide to Stability Design Criteria for Metal Structures, 4th Ed. John Wiley \& Sons, New York, NY, USA.

Galambos T. V. 1995. Guide to stability design of metal structures. Wiley.

Galambos, T. V.; Editor. 1998. Guide to Stability Design Criteria for Metal Structures, 5 th Ed. John Wiley \& Sons. New York, NY, USA.

Galambos, T. V. and Surovek, A. E. 2008. Structural Stability of Steel-Concepts and Applications for Structural Engineers. John Wiley \& Sons, New York, NY, USA.

Gambhir, M. L. 2004. Stability Analysis and Design of Structures. Springer-Verlag Berlin Heidelberg Press, Germany.

Gardner, L. 2011.Stability of Steel Beams and Columns (In accordance with Eurocodes and the UK National Annexes). SCI, Berkshire, UK, p.116.

Godfrey, G. B. 1962. The Allowable Stresses in Axially Loaded Steel Struts. The Structural Engineer, 40(3).

Goncalves, R. and Camotim, D. 2001. On the allowance for member imperfections in the design/safety checking of steel frames. In Proceedings of $9^{\text {th }}$ Nordic steel construction conference, 57-64.

Goncalves, R. and Camotim, D. 2004. On the application of beam-column interaction formulae to steel members with arbitrary loading and support conditions. Journal of Constructional Steel Research, 60, 433-450. 
Goncalves, R. and Camotim, D. 2005. On the incorporation of equivalent member imperfections in the in-plane design of steel frames. Journal of Constructional Steel Research, 61, 1226-1240.

Greiner, R., Ofner, R., and Salzgeber, G. 1999. Lateral torsional buckling of beamcolumns: Theoretical background. ECCS-Validation Group, Report 5.

Greiner, R. and Ofner, R. 1999. Validation of design rules for member stability of European Standards-Proposal for buckling rules. In Proceedings of Stability and Ductility of Steel Structures, Romania.

Greiner, R. and Lindner, J. 2000. Proposal for buckling resistance of members: Flexural and lateral torsional buckling. ECCS-Validation Group, Report 7.

Greiner, R. 2001. Background information on the beam-column interaction formulae at Level 1. ECCS TC 8, Paper $N^{o}$ TC 8-2001, Graz University of Technology.

Greiner, R. and Lechner, A. 2002. Elastic-plastic beam-column behaviour within structural systems. ECCS TC 8, Paper $N^{o}$ TC 8-2002-19, Graz University of Technology.

Greiner, R. 2002. Recent developments of the new rules for member stability in Eurocode 3. Proceedings of Stability and Ductility of Steel Structures, Budapest.

Greiner, R., Taras, A. 2006. On the variety of buckling curves, Proceedings of Stability and Ductility of Steel Structures, 1101-1108.

Greiner, R., Lindner, J. 2006. Interaction formulae for members subjected to bending and axial compression in EUROCODE 3-the Method 2 approach. Journal of Constructional Steel Research, 62, 757-770.

Gurfinkel, G. and Robinson, A.R. 1965. Buckling of Elasticity Restrained Column. Journal of the Structural Division, ASCE, 91(ST6):159-183.

Hall, D. H. 1983. Proposed Steel Column Design Criteria, Journal of Structural Engineering, ASCE 109(9): 2086-2096.

Harajli, M., Khairallah, N., and Nassif, H. 1999. Externally prestressed members: evaluation of second-order effects. Journal of Structural Engineering, ASCE, 125(10): 1151-1161.

Hellesland, J. and Bjorhovde, R. 1996a. Restraint Demand Factors and Effective Lengths of Braced Columns, Journal of Structural Engineering, ASCE 122(10): 12161224.

Hellesland, J. and Bjorhovde, R. 1996b. Improved Frame Stability Analysis with Effective Lengths, Journal of Structural Engineering, ASCE 122(11): 1275-1283.

Ho, W. M. G., Chan, S. L. 1993. An accurate and efficient method for large deflection analysis of frames with semi-rigid connections. Journal of Constructional Steel Research, 261, 71-91. 
Holgate, A. 1997. The art of structural engineering. The work of Jörg Schlaich and his team. Edition Alex Menges, Stuttgart, Germany.

Hori, A., Sasagawa, A. 2000. Large deformation of inelastic large space frame I: analysis. Journal of Structural Engineering, AISC, 126(5), 580-588.

Izzudin, B. A., and Smith, D. L. 1996. Large-displacement analysis of elastoplastic thinwalled frames, Part I. and Part II., ASCE Journal of Structural Engineering, 122(8), 905-925.

Jacquet, J. 1970. Column Buckling Tests and Their Statistical Evaluation, Construction Métallique 7(3) (in French).

Janns J, Sedlacek G, Maquoi R, Ungermann D, Kuck J. 1992. Evaluation of test results on columns, beams and beam-columns with cross-sectional classes 1-3 in order to obtain strength functions and suitable model factors. Background report to Eurocode 3 Common unified rules for steel structures.

Jiang X. M., Chen H., and Liew, J. Y. R. 2002. Spread-of-plasticity analysis of threedimensional steel frames. Journal of Structural Steel Research, 58 (2202), 193-212.

Johnson, D. E. 1960. Lateral Stability of Frames by Energy Method. Journal of Engineering Mechanics, 95(4):23-41.

Johnston, B. G. 1966. Editor. Guide to Design Criteria for Metal Compression Members, 2nd Edition. Column Research Council, John Wiley \& Sons, New York, NY, USA.

Johnston, B. G. 1981. Column Buckling Theory: Historical Highlights, Journal of the Structural Division. ASCE, 107(ST-4, April): 649-670.

Jones, S. W.; Kirby, P. A. and Nethercot, D. A. 1980. Effect of Semi-Rigid Connections on Steel Column Strength, Journal of Constructional Steel Research 1(1): 35-46.

Juozapaitis, A., and Kvedaras, A.K. 1999. Innovative structural system of steel roofs. Journal of Constructional Steel Research, 49(2): 213-221.

Juozapaitis, A., Šaučiuvėnas, G., and Nagevičius J. 2007. Strut-framed beam structure for reconstruction of pedestrian bridges, Appears in collections of research articles. Vilnius Gediminas Technical University, Vilnius.

Julian, O. G. and Lawrence, L. S. 1959. Notes on S \& L Nomograms for Determination of Effective Lengths. Unpublished Report, Jackson \& Moreland Engineers, Boston, Massachusetts, USA.

Kala, Z., and Kala, J. 2003. The Statistical Correlation of Material CharacteristicsExperimental and Theoretical Results of Hot-Rolled Steel Beam, Proceedings of International Conference on Metal Structures, Miskolc, Hungary.

Kanchanalai, T. 1977. The design and behaviour of beam-columns in unbraced steel frames. AISI Project No. 189, Report No. 2, Civil Engineering/Structures Research Lab, University of Texas-Austin. 
Kavanagh, T. C. 1962. Effective Length of Framed Column. Transactions, ASCE, 127(II):81-101.

Kim, S.-E, and Chen, W.-F. 1996. Practical advanced analysis for braced steel frame design. Journal of Structural Engineering, ASCE, 122(11), 1266-1274.

Laffanchi, M.; Marti, P. 1999. Zur Konzeption gekrümmter Brücken. Institut fur Baustatik und Konstruktion (IBK), ETH, Zürich, Switzerland.

Liew, J. Y. R., White, D. W., and Chen, W. F. 1991. Beam-Columns design in steel frameworks - Insights on current methods and trends. Journal of Constructional Steel Research, 18(4), 269-308.

Liew, J. Y. R., Chen, H., Chen, W. F. 1993. Second-order refined plastic hinge analysis of frame design. Parts I and II. Journal of Structural Engineering, ASCE, 119(11), 3196-3216.

Liew, J. Y. R., Chen, H., Shanmugam, N.E., Chen, W. F. 2000. Improved nonlinear plastic hinge analysis of space frame structures. Engineering Structures, 22(10), 13241338.

Lindner, J. 2001. Evaluation of interaction formulae at Level 1 approach with regard to ultimate load calculations and test results: Flexural buckling and lateral torsional buckling. Report 2144E, TU Berlin.

Lindner, J. 2003. Design of beams and beam column. Progress in Structural Engineering and Material, 5, 38-47.

Lou, T., Lopes, S., and Lopes, A. 2012. Flexural response of continuous concrete beams prestressed with external tendons, Journal of Bridge Engineering.

Lu, L. W. 1962. A Survey of Literature on the Stability of Frames. Welding Research. Council Bulletin No. 81, September, New York.

Lui, E.M., Chen, W.-F. 1986. Analysis and behaviour of flexibly-jointed frames. Engineering Structures, 8.

Rondal J, Maquoi R. 1980. Le Flambement des Collonnes en Acier. Notice 1091, Chambre Syndicale des Fabricants de Tubes d'Acier, Paris, France; 1980.

Maquoi R, Rondal J. 1982. Sur la force portante des pouters colonnes. Annales des travaux publics de Belgique.

Maquoi R, Boissonnade N, Muzeau J-P, Jaspart J-P, Villette M. 2001. The interaction formulae for beam-columns: a new step of a yet long story. Proceedings of the 2001 SSRC Annual Technical Session \& Meeting, p. 63-88.

Massonnet, C. 1959. Stability consideration in the design of steel columns. Journal of the Structural Division, ASCE, 85(9), 75-111.

McGuire, W. 1968. Steel Structures. Prentice-Hall, Englewood Cliffs, NJ, 1112 pp.

Meek, J. L., and Lin, L.W. 1990. Geometric and material nonlinear analysis of thinwalled beam-columns, Journal of Structural Engineering, ASCE, 116(6), 1473-1490. 
Menn, C., and Gauvreau, P. 1987. Scale model study of an externally prestressed concrete slab bridge. In Proceedings of the International Conference on Cable-stayed Bridges, Bangkok, 919-926.

Menn, C., Gauvreau, P. 1990.Prestressed concrete bridges. Birkhauser Verlag, Basel Switzerland and Boston, $535 \mathrm{p}$.

Mešic, E. 2007. Plastification process of steel frame through discretization of plastic zones. Report in FACTA UNIVERSITATIS, Series :Architecture and Civil Engineering, Vol. 5, No 2, 87-94.

Michalopoulos, A.; Nikolaidis, Th.; Stavroulakis, G.; Baniotopoulos, C. 2005. Passive control of bridges: The double net method, Engineering Structures 27(13): 1835-1842.

Muttoni, A. 1997. Bridges with an innovative static system (Brücken mit einem innovativen statischen system). Schweizer Ingenieur und Architekten, 26: 28-31. [In German.]

Muttoni, A. 2002. Bridges with under-deck cable staying systems (Brücken mit vorgespannter stahlunterspannung). Stahlbau, 71(8): 592-597. [In German.]

Nethercot, D. A. 1994. Frame design incorporating semi-rigid effects. Steel Construction (South Africa), 18(6), 24-27.

Norris, A. C. 2010. A Critical Analysis of the University of Limerick's Living Bridge. Proceedings of Bridge Engineering 2 Conference, UK.

Ofner, R. 1999. Results of a parameter study of steel beams under axial compression and biaxial bending - Comparison with code regulations. In Eurosteel Conference, Prague.

Ofner, R. 2003. Buckling check of members and frame based on numerical simulations. Institute for Steel, Timber and Shell Structures, Graz University of Technology.

Papp, F. and Ivány, M. 2002. Developments in structural design of beam-columns: a review from CAD point of view. SDSS 2002, Proceedings, 13-22.

Park, S., Kim, T., Kim, K., Hong, S.-N. 2010. Flexural behavior of steel I-beam prestressed with externally unbounded tendons, Journal of Constructional Steel Research 66(1): 125-132.

PD 6695-2:2008, Recommendations for the design of Bridges to BS EN 1993.

Peters, T. F. 1987. Transitions in Engineering: G.H. Dufour and the Early $19^{\text {th }}$ Centure/Suspension Bridges. Birkhäuser, p. 244.

Rajasekaran S. and Murray D.W. 1973. Finite element solution of inelastic beam equations, Journal of the Structural Division, ASCE, 99(T6), 1024-1042.

Rondal, J. and Maquoi, R. 1979. Single Equation for SSRC Column Strength Curves, Journal of the Structural Division, ASCE, 105(ST1): 247-250.

Rotter, J.M. 1981. A Simple Approach to Multiple Column Curves. Metal Structures Conference. 
Rotter, J. M. 1982. Multiple Column Curves by Modifying Factors, Journal of the Structural Division, ASCE, 108(ST7): 1665-1669.

Rotter, J. M. 2002. Shell Buckling and Collapse Analysis for Structural Design: The New Framework of the European Standard, Festschrift for Prof. Calladien, Cambridge, 2002.

Ruiz-Teran, A. M. 2005. Unconventional cable-stayed bridges. Structural behaviour and design criteria. Doctoral thesis, University of Cantabria, Cantabria, Spain. [In Spanish]

Ruiz-Teran, A. M and Aparicio, A. C. 2007a. Two new types of bridges: under-deck cable-stayed bridges and combined cable-stayed bridges-the state of the art. Canadian Journal of Civil Engineering 34(8), 1003-1015.

Ruiz-Teran, A. M., and Aparicio, A. C. 2007b. Parameters governing the response of under-deck cable-stayed bridges. Canadian Journal of Civil Engineering, 34(8): 10161024.

Ruiz-Teran, A. M., and Aparicio, A. C. 2007c. Dynamic amplification factors in cablestayed structures. Journal of Sound and Vibration, 300(1-2): 197-216.

Ruiz-Teran, A. M., and Aparicio, A. C. 2008a. Structural behaviour and design criteria of under-deck cable-stayed bridges and combined cable-stayed bridges. Part 1: Single span bridges. Canadian Journal of Civil Engineering, 35(9): 938-950.

Ruiz-Teran, A. M., and Aparicio, A. C. 2008b. Structural behaviour and design criteria of under-deck cable-stayed bridges and combined cable-stayed bridges. Part 2: Multispan bridges. Canadian Journal of Civil Engineering, 35(9): 951-962.

Ruiz-Teran, A. M., and Aparicio, A. C. 2009a. Response of under-deck cable-stayed bridges to the accidental breakage of stay cables. Engineering Structures, 31(7): 14251434.

Ruiz-Teran, A. M., and Aparicio, A. C. 2009b. Verification criteria of the SLS of vibrations for road bridges with slender prestressed concrete decks. In Proceedings of the International FIB Symposium 'Concrete: $21^{\text {st }}$ Century Superhero', London, UK.

Ruiz-Teran, A. M and Aparicio, A. C. 2010. Developments in under-deck and combined cable-stayed bridges. Proceedings of the ICE-Bridge Engineering 163(2), 67-78.

Ruiz-Teran, A. M and Aparicio, A. C. 2011. Nonlinear behaviour of under-deck cablestayed bridges. Proceedings of the $5{ }^{-{ }^{\text {th }}}$ International ACHE Conference on Structures.

Ruiz-Teran, A. M 2010. Unconventional cable-stayed bridges: structural behaviour and design criteria. Structural Concrete 11(1), 25-34.

Saha, G., Banu S. 2007. Buckling load of a beam-column for different end conditions using multi-segment integration technique. Journal of Engineering and Applied Science 2(1), 27-32.

Saito, D., Wadee, M. A. 2009. Buckling behaviour of prestressed steel stayed columns with imperfections and stress limitation. Engineering Structures 31(1), 1-15. 
Saitoh, M., and Okada, A. 1999. The role of string in hybrid string structure. Engineering Structures, 21(8): 756-769.

Salmon, C. G., and Johnson, J. E. 1996. Steel structures, design and behavior. Harper and Row, New York.

Schafer, B. W., Pekoz, T. Computation modeling of cold-formed steel: characterizing geometric imperefctions and residual stresses. Journal of Constructional Steel Research, $47,193-210$.

Schulitz, H. C 2000. Steel Construction Manual. Birkhauser Publishers, Berlin. p. 404.

Sfintesco, D. 1970. Experimental Basis for the European Column Curves, Construction Métallique 7(3). [in French]

Schlaich, M., and Werwigk, M. 2001. The Glacis bridge in Ingolstadt, Germany. In Cable - Supported Bridges: Challenging Technical Limits: Proceedings of the IABSE Conference, Vol. 84, International Association for Bridge and Structural Engineering (IABSE), Zurich.

Serna, M. A., Bayo, E., and Ibanez, J.R. 2009. Imperfections for global analysis of frames: EC3 drawbacks and energy based procedure. In Proceedings of $7^{\text {th }}$ EUROMECH Solid Mechanics Conference, Portugal.

Shayan, S., Rasmussen, K. J. R., and Zhang, H. 2013. On the modelling of residual stress in advanced analysis of steel frames. New Development in Structural Engineering and Construction, Yazdani, S. and Singh, A. (Eds.), ISEC-7, Hawaii.

Strating, J. and Vos, H. 1973. Computer Simulation of the E.C.C.S. Buckling Curves using a Monte-Carlo Method. HERON, 19(2).

Sugimoto, H. and Chen, W.-F. 1982. Small End Restraint Effects on Strength of HColumns, Journal of the Structural Division, ASCE, 108(ST3): 661-681.

Surovek - Maleck, A .E., White, D. W. and Leon, R. T. 2005. Direct Analysis for Design Evaluation of Partially-Restrained Steel Framing Systems. Journal of structural Engineering, ASCE, Vol. 131(9), 1376-1389.

Surovek - Maleck, A. E. and White, D. W. 2004. Alternative Approaches for Elastic Analysis and Design of Steel Frames, I: Overview. Journal of structural Engineering, ASCE, 130(8), 1186-1196.

Surovek - Maleck, A.E. and White, D.W. 2003. Direct Analysis Approach for the Assessment of Frame Stability: Verification Studies. Proceedings, SSRC Annual Technical Sessions, pp. 18.

Taras, A. and Greiner, R. 2010. Analytical derivation of a generalized-slenderness formula for in-plane beam-column design and comparison with interaction-concept formulae, SDSS'Rio 2010 Stability and Ductility of Steel Structures, Batista, E, Vallasco, P., de Lima, L. (Eds.). Rio de Janeiro, Brazil, 595-602.

Teh, L. and Clarke, M. 1999. Plastic-zone analysis of 3D steel frames using beam elements. Journal of Structural Engineering, Vol. 125, No. 11, 1328-1337. 
Timoshenko, S. P. 1966. Theorie de la stabilite elastique. 2nd ed. Dunod.

Timoshenko, S. P. and Gere, J.M. 1961. Theory of elastic stability. Second Edition. McGraw-Hill Book Company.

Torkamani, M. A. M., Sonmez, M.M., Cao, J. 1997. Second-order elastic plane-frame analysis using finite-element method. Journal of Structural Engineering, ASCE, 123(9), $1225-1235$.

Trahair, N. S. and Nethercot, D. A. 1984. Bracing requirements in thin-walled structures Ch.3-Developments in thin walled structures, Ed. J. Rhodes and A. C. Walker. Elsevier Applied Science Publishers.

Trahair, N. S. 1999. Column bracing forces. Australian Journal of Structural Engineering Transactions 2(2-3), 1263-168.

Trahair, N. S., Chan, S.-L. 2003. Out-of-plane advanced analysis of steel structures. Engineering Structures, 25, 1627-1637.

Trahair, N. S., Rasmussen, K .J. R. 2005. Finite-element analysis of the flexural buckling of columns with oblique restraints. Journal of Structural Engineering, ASCE, 131(3), 481-487.

Trahair, N. S., Bradford, M. A., Nethercot, D. A. and Gardner, L. 2008. The behaviour and design of steel structures to EC3. Fourth Edition. Taylor \& Francis, London.

Tsunomoto, M., and Ohnuma, K. 2002. Self-anchored suspended deck bridge. Pedestrian bridge of the Tobu recreation resort. Concrete Structures in $21^{\text {st }}$ Century. Proceedings of the $1^{\text {st }}$ Federation Internationale du Beton (FIB) Congress. In National Report, FIB Congress, Japan, 181-184.

Umezu, K.; Fujita, M.; Yamazaki, J. 1998. Study of a new structural type for prestressed concrete bridges. In Long-Span and High-Rise Structures, in Proc. of the IABSE Symposium, Kobe, Japan: Selected papers, vol. 79, International Association of Bridge and Structural Engineering (IABSE), Zurich, 483-488.

Vega-Posada, C., Areiza-Hurtado, M., Aristizabal-Ochoa, D.J. 2011. Large deflection and post-buckling behaviour of slender beam-column with non-linear end-restraints. International Journal of Non-Linear Mechanics, 46, 79-95.

Villette M. Considerations sur le flambement, proposition de revision de 1_Eurocode 3. Constr Metall, 3, 15-38.

Virlogeux, M., Bouchon, E., Lefevre, J., et al. 1994. A prestressed concrete slab supported from below: The Truc de la Fare Bridge. In Proceedings of the $21^{\text {st }}$ FIP (International Federation for Structural Concrete) Congress, Washington. Association Française pour la construction, Bagheux.

Vrcelj, Z., Bradford, M. A. 2006. Buckling of continuously restrained I-section beamcolumn. Journal of Constructional Steel Research 62(3), 223-230.

Wang, C. M., Ang K. K. 1988. Buckling capacities of braced heavy columns under an axial load. Journal of Computers \& Structures, 28(11), 6563-571. 
Wang, Y. C. and Nethercot, D. A. 1989. Ultimate strength analysis of 3-dimensional braced I-beams. Proceedings of the Institution of Civil Engineers - Part 2, 87(1), 87112.

Wang, C. M., Liew K.M. 1991. Buckling of Columns with Overhang. Journal of Engineering Mechanics, 117(11), 2492-2502.

Wang, C. M., Nazmul I.M. 2003. Buckling of Columns with Intermediate Elastic Restraint. Journal of Engineering Mechanics, 129(2), 241-244.

Watanabe, Y. 2002. Miho museum bridge, Shigaraki, Japan. Structural Engineering International, 12(2): 245-247.

White, D. W. 1986. Material and geometric nonlinear analysis of local planar behaviour in steel frames using interactive computer graphics. Report No. 86-4. Ithaca, NY: Department of Structural Engineering, Cornell University.

White, D. W., Chen, W.F., editors. 1993. Plastic hinge based methods for advanced analysis and design of steel frames. Lehigh University, Bethlehem, Pa: Structural Stability Research Council.

White, D. W., and Clarke, M.J. 1997. Design of beam-columns in steel frames. I: Philosophies and procedures. Journal of Structural Engineering, 123(12), 1556-1564.

White, D. W., and Clarke, M.J. 1997. Design of beam-columns in steel frames. II: Comparison of standards. Journal of Structural Engineering, 123(12), 1565-1575.

White, D. W., Surovek, A. E., Alemdar, B. N., Chang, C-J., Kim, Y. D. and Kuchenbecker G. H. 2006. Stability Analysis and Design of Steel Building Frames Using the 2005 AISC Specification. Steel Structures, 6, 71-91.

White, D. W. and Jung, S.-K. 2003b. Simplified Lateral-Torsional Buckling Equations for Singly-Symmetric I-Section Members. Structural Engineering, Mechanics and Materials Report No. 24b, School of Civil and Environmental Engineering, Georgia Institute of Technology, Atlanta, GA, 29 p.

White, D. W., Surovek - Maleck, A. E. and Kim, S.-C. 2007. Direct Analysis and Design Using Amplified First-Order Analysis, Part 1 - Combined Braced and Gravity Framing Systems. Engineering Journal, ASCE, 44(4) 305-322.

White, D. W. 2012. Steel Bridge Design Handbook: Structural Behaviour of Steel. Report No. FHWA-IF-12-052-Vol. 4, HDR Engineering, Inc., Pittsburgh, 286 p.

Winter, G. et al. 1948. Buckling of Trusses and Rigid Frames, Cornell Univ. Bull. No. 36, Engineering Experimental Station. Cornell University, Ithaca, NY.

Winter, G. 1958. Lateral bracing of Columns and Beams. Journal of Structural Division, AISCE, 84 (ST2) 1561. (Also published in the 1961 ASCE Transactions 125 (Part 1) 809 .

Wen, R. K., and Lange, J. 1981. Curved element for arch buckling analysis. Journal of Structural Engineering, ASCE, 107(11), 2053-2069. 
Wen, R. K., and Lange, J. 1991. Nonlinear curved-beam element for arch structures. Journal of Engineering Mechanics, ASCE, 117(11), 3496-3514.

Wendel, M. S., Richard, E.M. 2000. Non-linear FE analysis of steel-concrete composite structures. Journal of Structural Engineering, ASCE, 126(6), 662-674.

Wong, K. C., Temple, M.C. 1982. Stayed column with initial imperfection. Journal of Structural Division, ASCE, 108(ST 7), 1623-1640.

Wood, R. H. 1974. Effective Lengths of Columns in Multi-Storey Buildings. Journal of Structural Engineering, ASCE, 52(7,8,9):234-244, 295-302, 341-346.

Wu, M. 2008. Analytical method for the lateral buckling of the struts in beam string structures. Engineering Structures, 30(9): 2301-2310.

Xue, W. C., and Liu, Sh. 2009. Design optimization and experimental study on beam string structures. Journal of Constructional Steel Research, 65(1): 70-80.

Yau, C. Y., Chan, S.L. 1994. Inelastic and stability analysis of flexibly connected steel frames by the springs-in-series model. Journal of Structural Engineering, ASCE, 120(10), 2803-2819.

Yong, D. J., Lopez, A. and Serna, M.A. 2006. A Comparative Study of AISC-LRFD and EC3 Approaches to Beam-Column Buckling Resistance. In Proceedings of Stability and Ductility of Steel Structures, Portugal.

Yura, J. A., Helwig, T., Herman, R. and Zhou, C. 2008. Global Lateral Buckling of IShaped Girder System. Journal of Structural Engineering, ASCE, 134(9), 1487-1494.

Yura, J. A. and Widianto 2005. Lateral Buckling and Bracing of Beams - A Reevaluation After the Marcy Bridge Collapse. Proceedings of the Annual Technical Session and Meeting, Montreal, Quebec, Structural Stability Research Council, Univ. of Missouri - Rolla, Rolla, MO, 277-294.

Yura, J. A. 1971. The Effective Length of Columns in Unraced Frames, Engineering Journal, AISC, 8(2): 37-42.

Zhang, N.; Fu, Ch. 2009. Experimental and theoretical studies on composite steel concrete box beams with external tendons, Engineering Structures 31(2): 275-283.

Zhou, Z., Meng, S.-P., and Wu, J. 2009. Stability Analysis of Prestressed Space Truss Structures Based on the Imperfect Truss Element. Steel Structures, 9(3), 253-260.

Ziemian, R. D. and McGuire, W. 2002. Modified Tangent Modulus Approach, a Contribution to Plastic Hinge Analysis. Journal of Structural Engineering, ASCE, 128(10), 1301-1307.

Ziemian, R. D., McGuire, W. and Seo, D. W. 2008. On the Inelastic Strength of BeamColumns under Biaxial Bending. Proceedings-Annual Stability Conference, Structural Stability Research Council, Nashville, TN.

Ziemian, R. D. 2010. Guide to Stability Design Criteria for Metal Structures, $6^{\text {th }}$ Ed., John Wiley \& Sons, New York, NY, USA. 


\section{The List of Scientific Author's Publications on the Subject of the Dissertation}

\section{Papers in the reviewed scientific periodical publications}

Misiūnaite, I.; Daniūnas, A.; Juozapaitis, A. 2012. Unconventional double-level structural system for under-deck cable-stayed bridges, Journal Civil engineering and Management 18(3): 436-443. ISSN 1392-3730 (Thomson ISI Journal List).

Misiunaite, I.; Juozapaitis, A.; Merkevicius, T. 2013. Improvements on the structural response control of unconventional cable-stayed bridges by nonlinear analysis modelling, Metal Constructions 19(1), p. 59-66. ISSN 1993-3517 (Donbas National Academy of civil Engineering and Architecture).

\section{In the other editions}

Misiunaite, I.; Juozapaitis, A. 2013. Direct stability analysis of steel beam-column with an elastic restraints, Research and Applications in Structural Engineering, Mechanics and Computation: proceedings of the fifth international conference on Structural Engineering, Mechanics and Computation: SEMC 2013, Cape Town, South Africa, 2-4 September 2013. Boca Raton: CRC Press, 2013. ISBN 9781138000612. p. 1165-1170. 
Misiunaite, I.; Juozapaitis, A.; Daniunas, A. 2013. Evaluation of requirements for global analysis in EC3 for the structural analysis of the simple-span under-deck cable-stayed bridge, Procedia Engineering. 11th international conference on modern building materials, structures and techniques (MBMST), May 16-17, 2013, Vilnius, Lithuania. Amsterdam : Elsevier Science Ltd, 2013. ISSN 1877-7058. 2013, Vol. 57, p. 781-788. (Thomson ISI Proceedings).

Misiunaite, I.; Juozapaitis, A. 2013. Verifying the stability of unconventional cable-stayed bridges with an innovative approach, New Developments in Structural Engineering and Construction: Seventh International Structural Engineering and Construction Conference (ISEC-7), held on the campus of the University of Hawaii at Manoa, Honolulu, from June 18-23, 2013. Singapore: Research Publishing Services, 2013. ISBN 9789810753542. p. 127-132.

Misiunaite, I.; Juozapaitis, A. 2012. Computational non-linear buckling analysis of an elastically restrained steel beam, Proceedings of the Eleventh International Conference on Computational Structures Technology, Dubrovnik, Croatia, 4-7 September 2012. Stirlingshire: Civil-Comp Press, 2012. ISSN 1759-3433. p. 1-14. 



\section{ANNEXES}

\section{Annex A. Examples of Under-Deck Cable-Stayed Bridges}

This Annex provides examples of recently constructed exclusively steel UDCS bridges.

Table A.1. Example: Living Bridge

\begin{tabular}{|l|l|}
\hline \multicolumn{2}{|c|}{ Living Bridge } \\
\hline Completed in: & 2007 \\
\hline Status: & in use \\
\hline Location: & Limerick, Ireland \\
\hline Structural Type: & UDCS \\
\hline Function/usage: & $\begin{array}{l}\text { Pedestrian bridge } \\
\text { footbridge) }\end{array}$ \\
\hline Technical information \\
\hline
\end{tabular}


Continue of Table A.1

\begin{tabular}{|l|l|}
\hline \multicolumn{2}{|l|}{ Construction materials used } \\
\hline CS system & steel \\
\hline Girders & steel \\
\hline Dimensions & \\
\hline Total length & $330 \mathrm{~m}$ \\
\hline Span lengths & $44 \mathrm{~m}$ \\
\hline
\end{tabular}

Table A.2. Example: Dole Footbridge

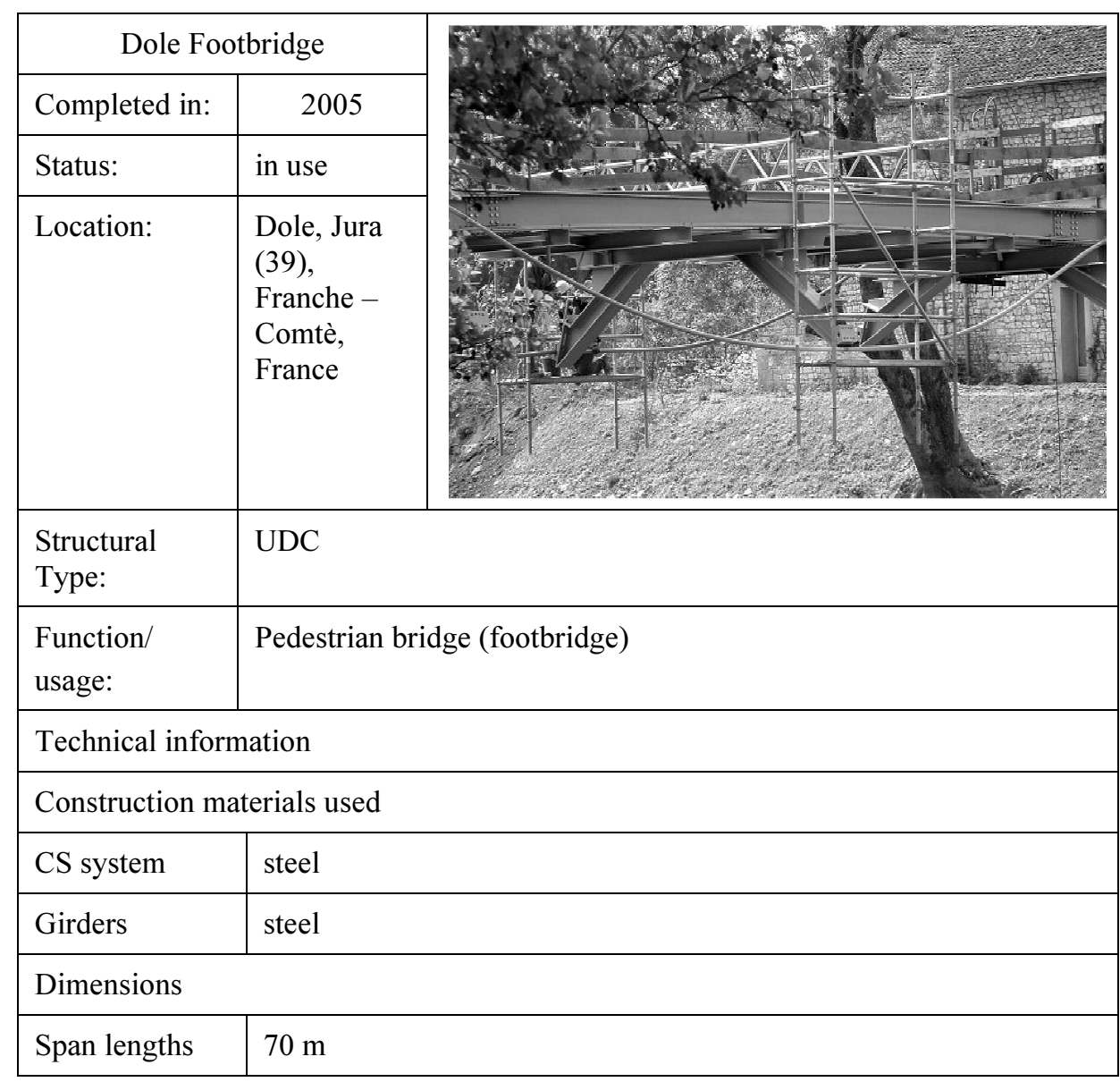


Table A.3. Example: Zouthaven Bridge

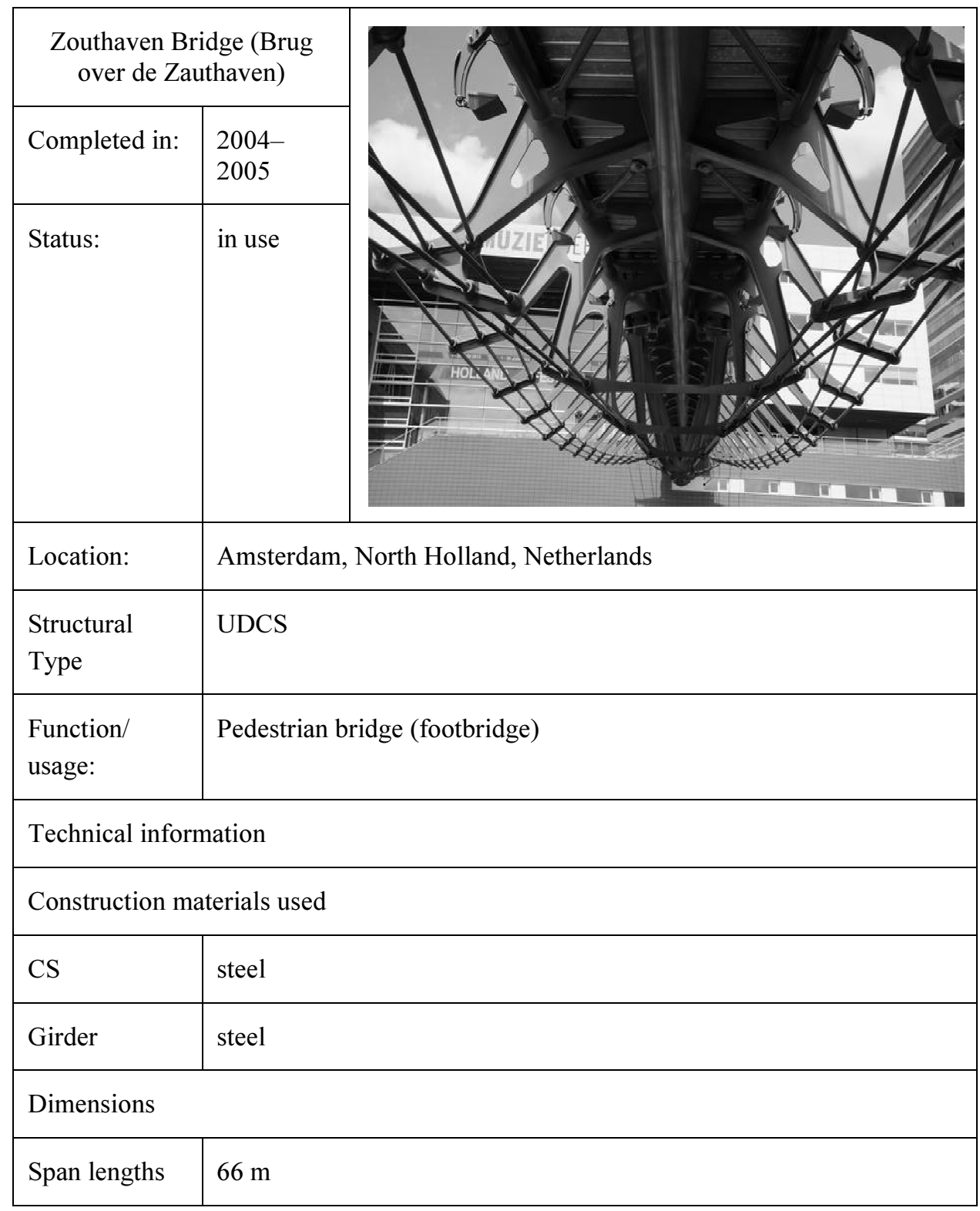


Table A.4. Example: Aubach Footbridge

\begin{tabular}{|l|l|l|}
\hline \multicolumn{2}{|c|}{ Aubach Footbridge } \\
\hline $\begin{array}{l}\text { Completed } \\
\text { in: }\end{array}$ & 2003 \\
\hline Status: & In use \\
\hline Location: & $\begin{array}{l}\text { Montabaur, } \\
\text { Westerwaldkreis, } \\
\text { Rhineland- } \\
\text { Palatinate, } \\
\text { Germany }\end{array}$ \\
\hline $\begin{array}{l}\text { Structural } \\
\text { Type: }\end{array}$ & UDCS \\
\hline $\begin{array}{l}\text { Function/ } \\
\text { usage: }\end{array}$ & Bicycle and pedestrian bridge \\
\hline Construction materials used \\
\hline Pylons & Steel tubes \\
\hline Girders & steel \\
\hline Dimensions & $65,20 \mathrm{~m}$ \\
\hline $\begin{array}{l}\text { Span } \\
\text { lengths }\end{array}$ & $6,6 \mathrm{~m}-2 \mathrm{x} 16,80 \mathrm{~m}-6,4 \mathrm{~m}$ \\
\hline
\end{tabular}


Table A.5. Example: Pasarela Bridge

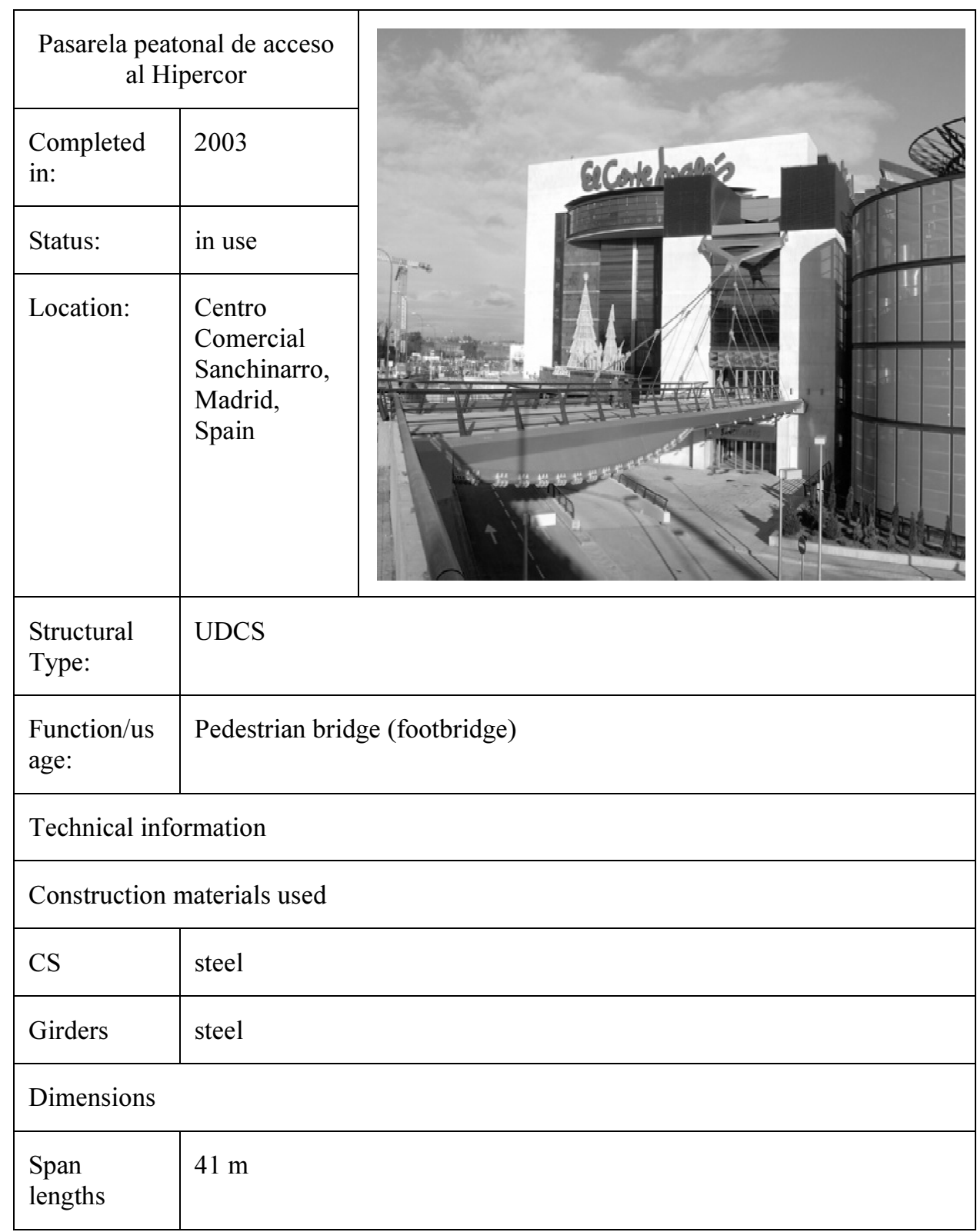


Table A.6. Example: Fröttmaning Subway station Skybridge

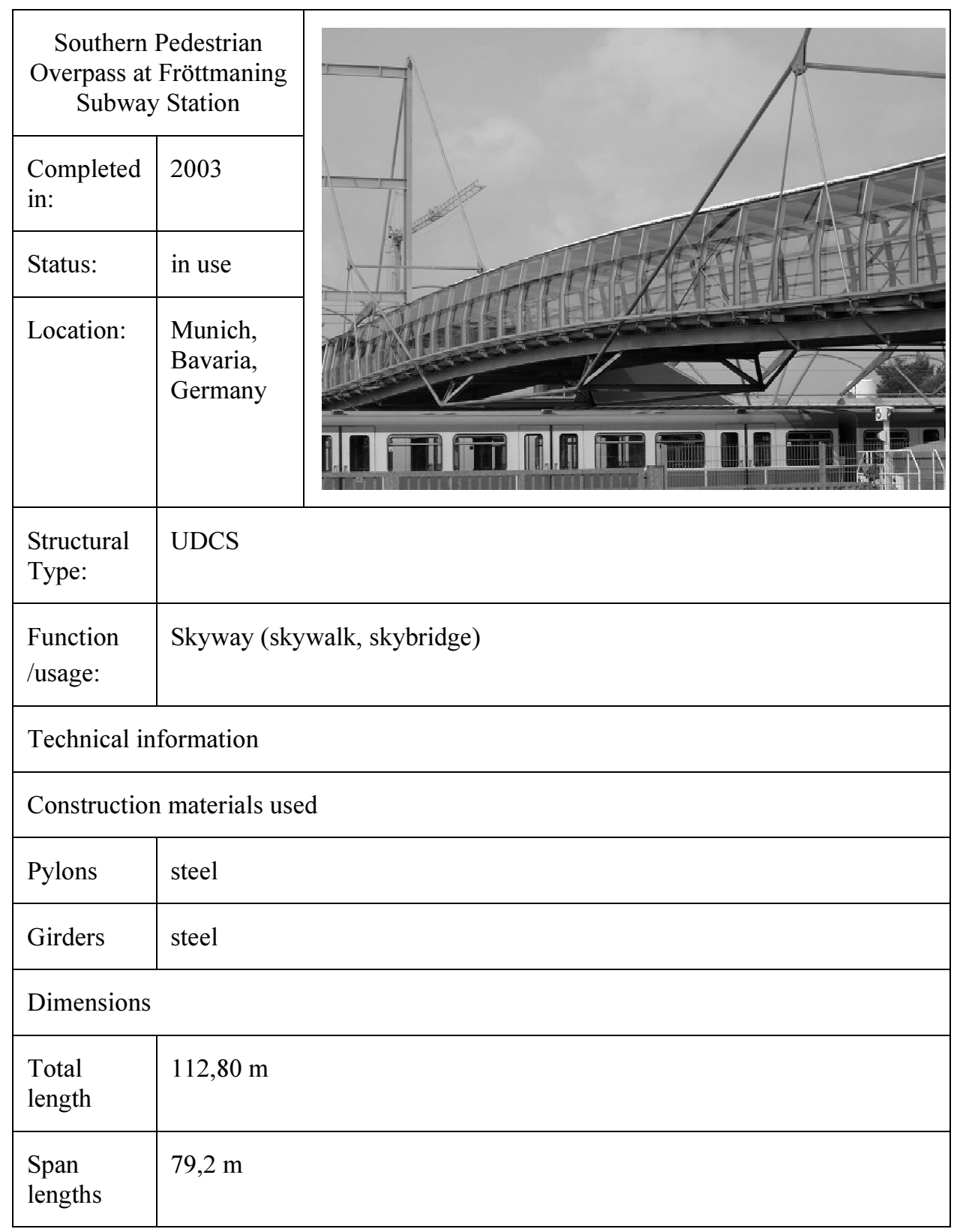


Table A.7. Example: Neuer Bridge

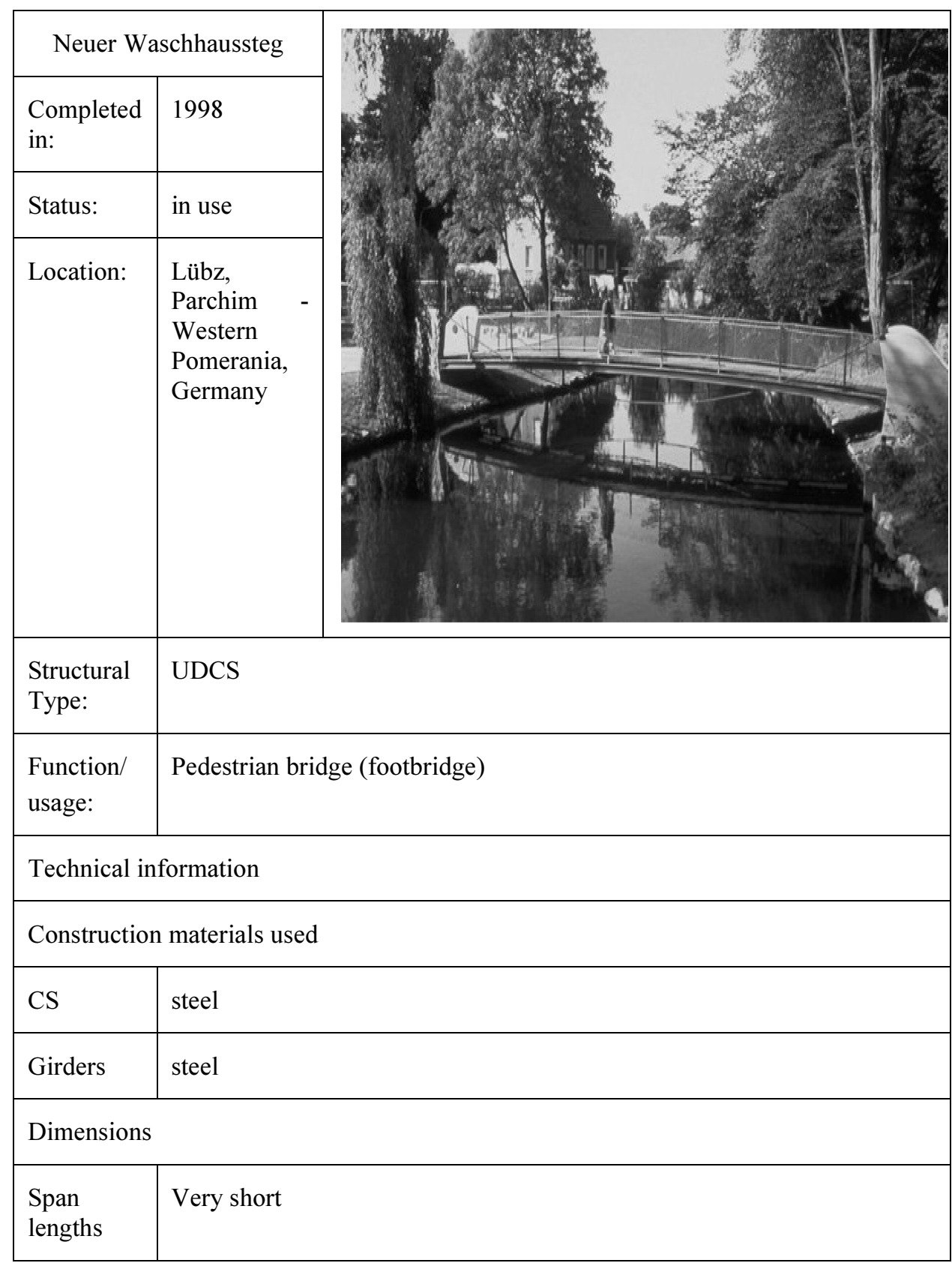


Table A.8. Example: Miho Museum Footbridge

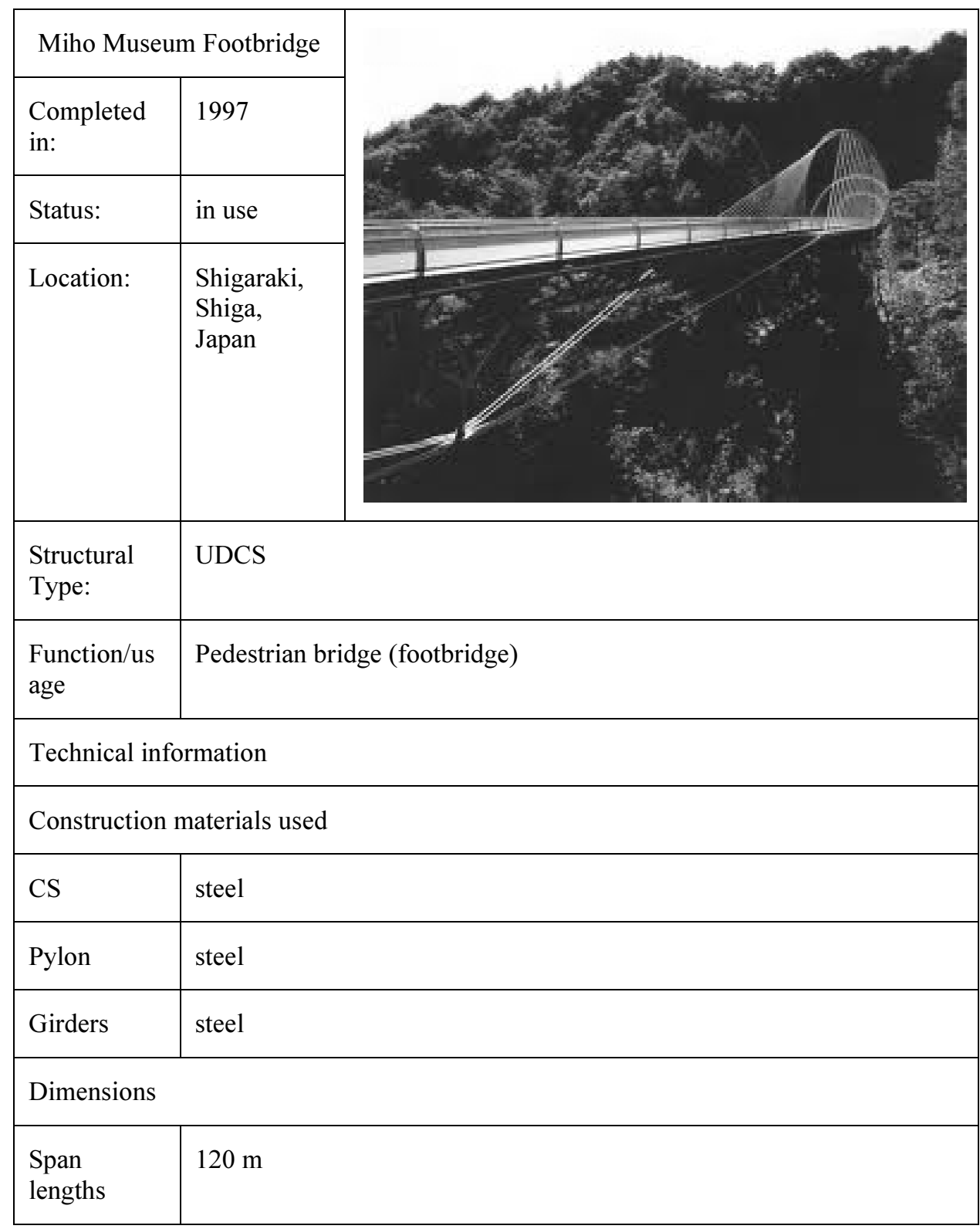




\section{Annex B. Results of Geometrically Nonlinear Analysis with Imperfections on Elastically Restrained Beam-Column}

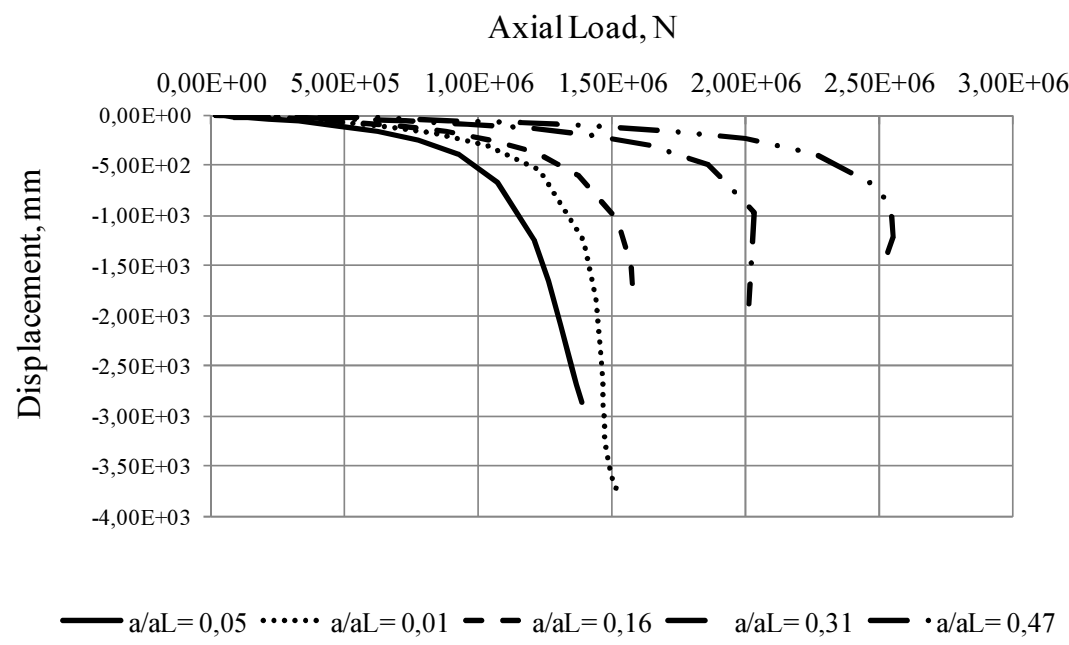

Fig. B.1. GNIA results of BCIR: $0,05 \leq \alpha / \alpha_{L} \leq 0,47$

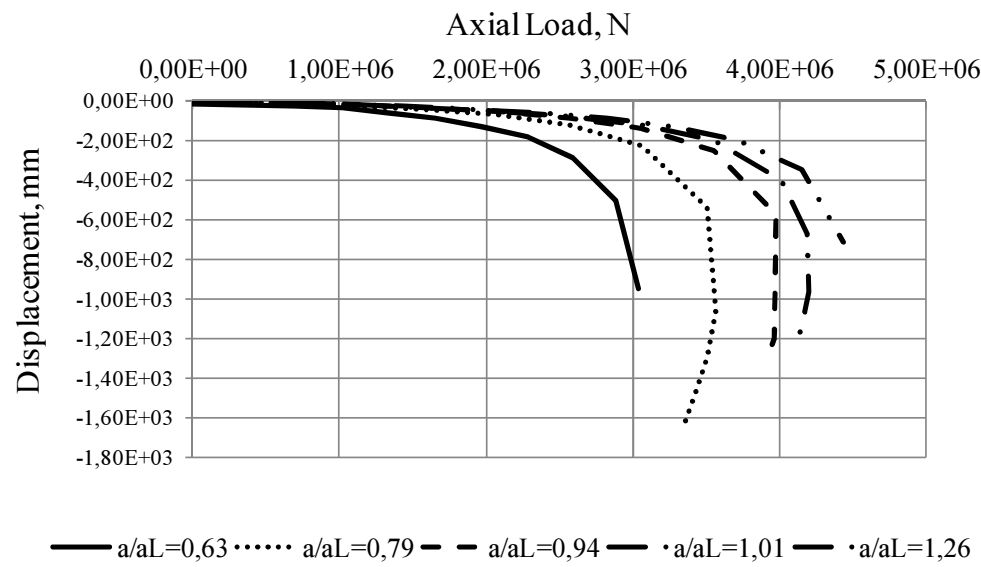

Fig. B.2. GNIA results of BCIR: $0,63 \leq \alpha / \alpha_{L} \leq 1,26$ 


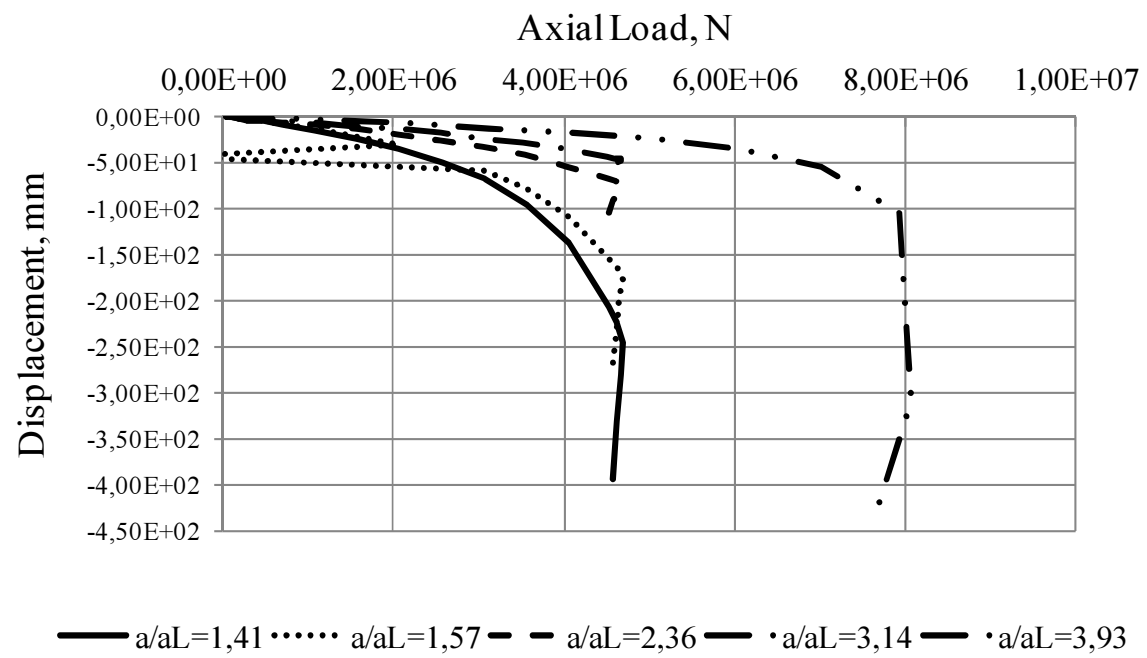

Fig. B.3. GNIA results of BCIR: $1,41 \leq \alpha / \alpha_{L} \leq 3,93$

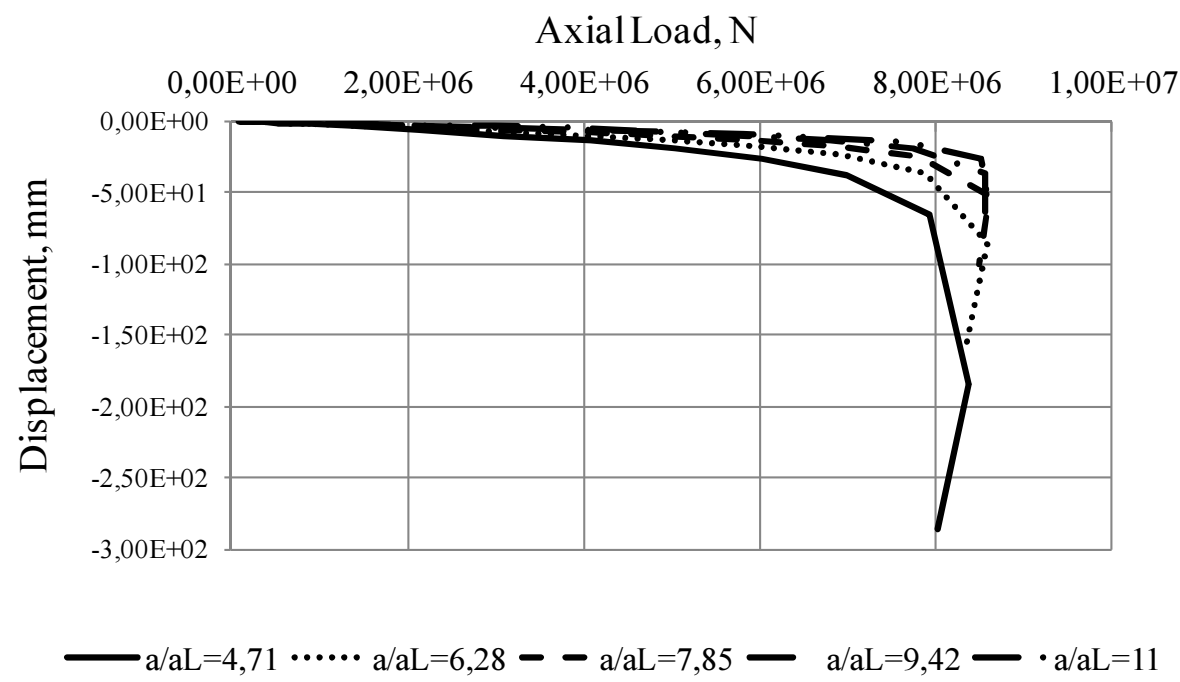

Fig. B.4. GNIA results of BCIR: $4,71 \leq \alpha / \alpha_{L} \leq 11,0$ 


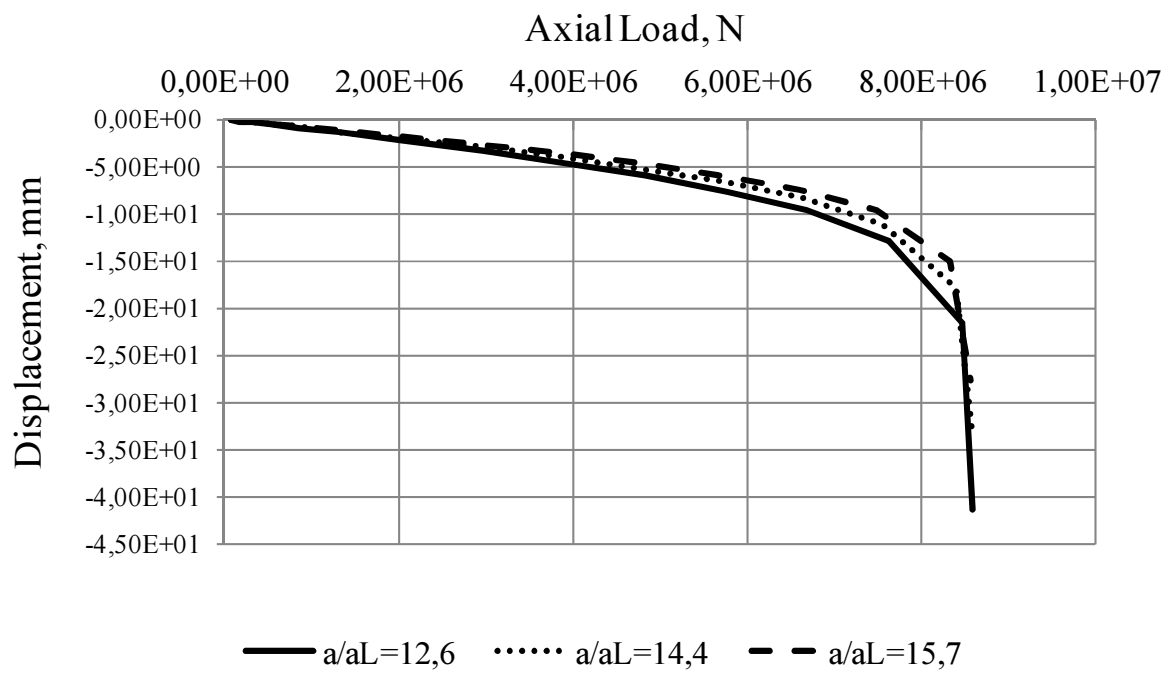

Fig. B.5. GNIA results of BCIR: $12,6 \leq \alpha / \alpha_{L} \leq 15,7$

\section{Annex C. Experimental Results}

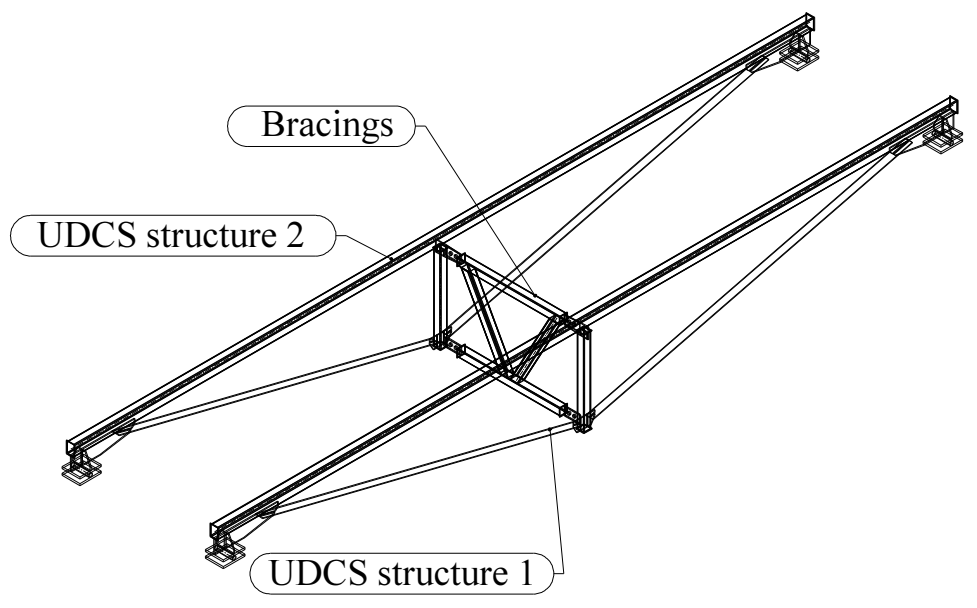

Fig. C.1. Three scale model of mono-strut UDCS bridge 


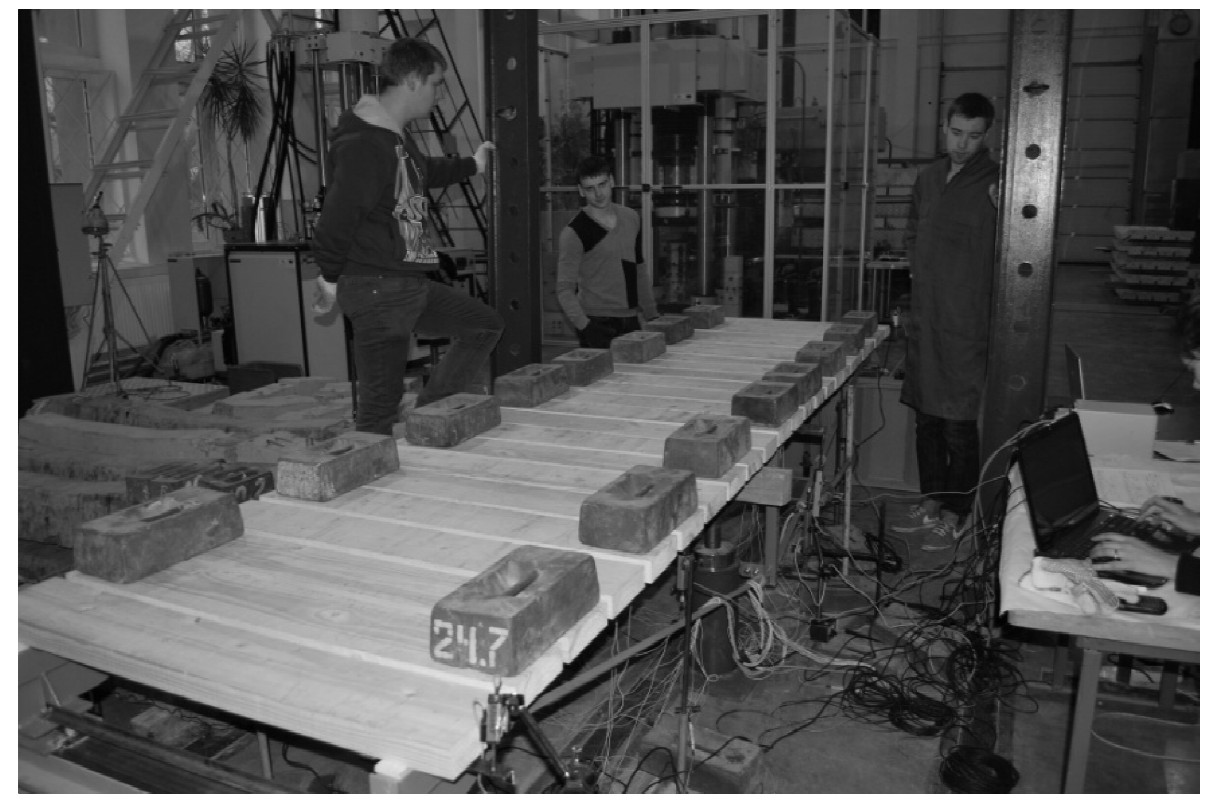

Fig. C.2. $2^{\text {nd }}$ Step of symmetric loading

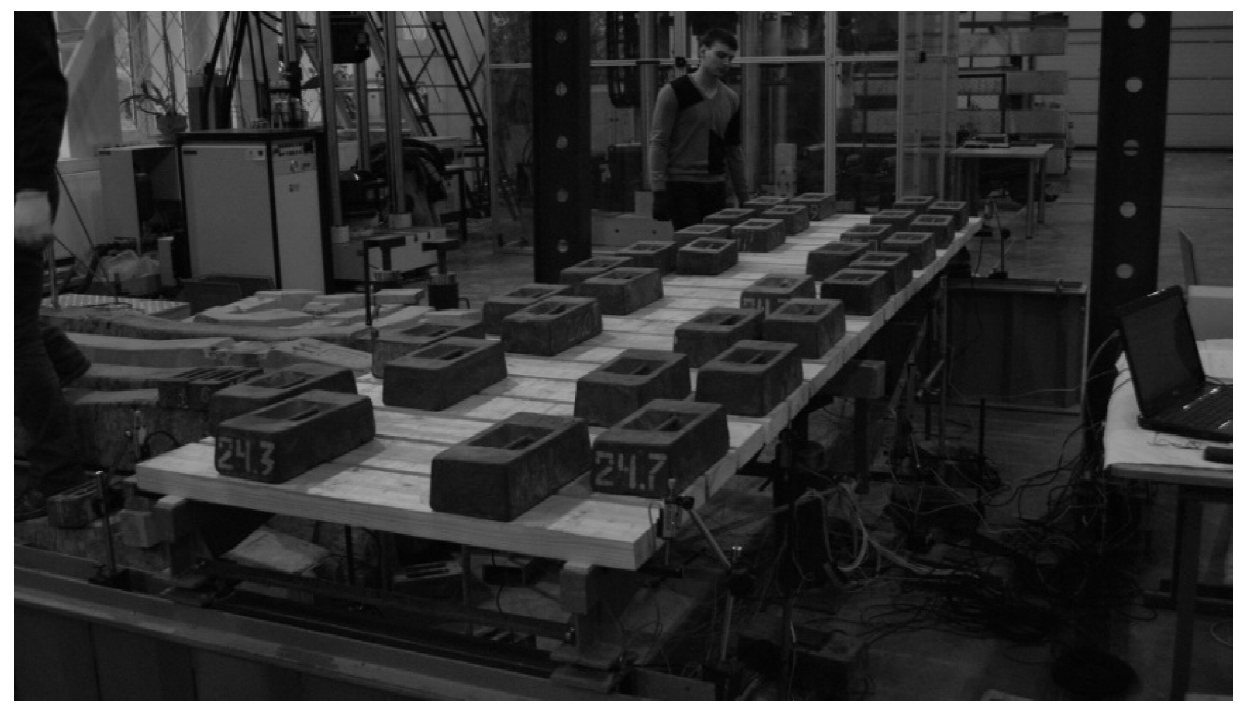

Fig. C.3. $3^{\text {rd }}$ Step of symmetric loading 


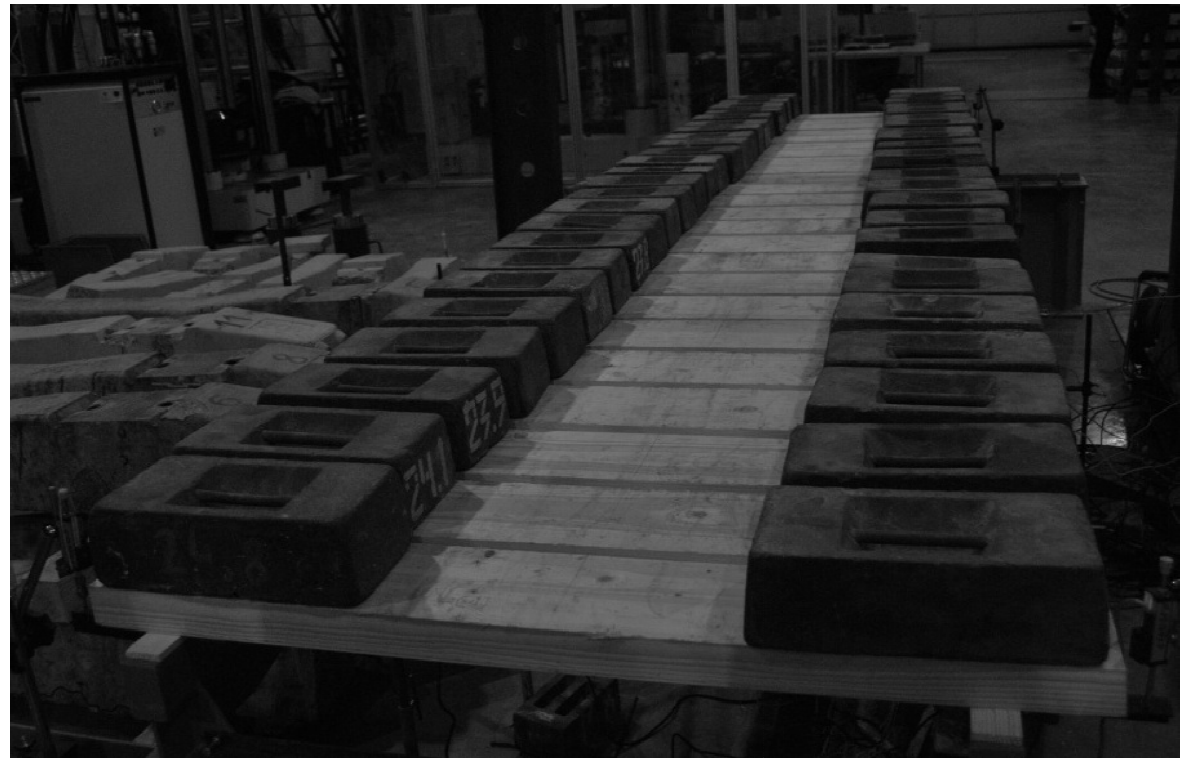

Fig. C.4. $4^{\text {th }}$ Step of symmetric loading

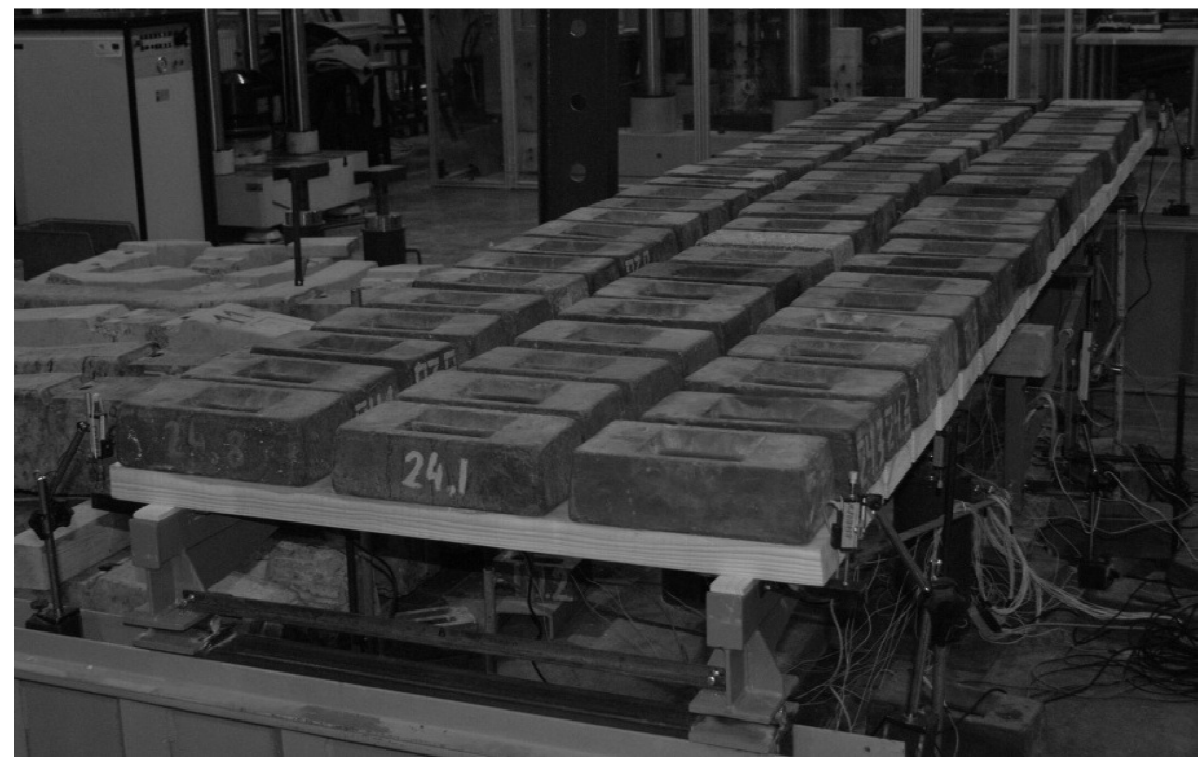

Fig. C.5. $5^{\text {th }}$ Step of symmetric loading 


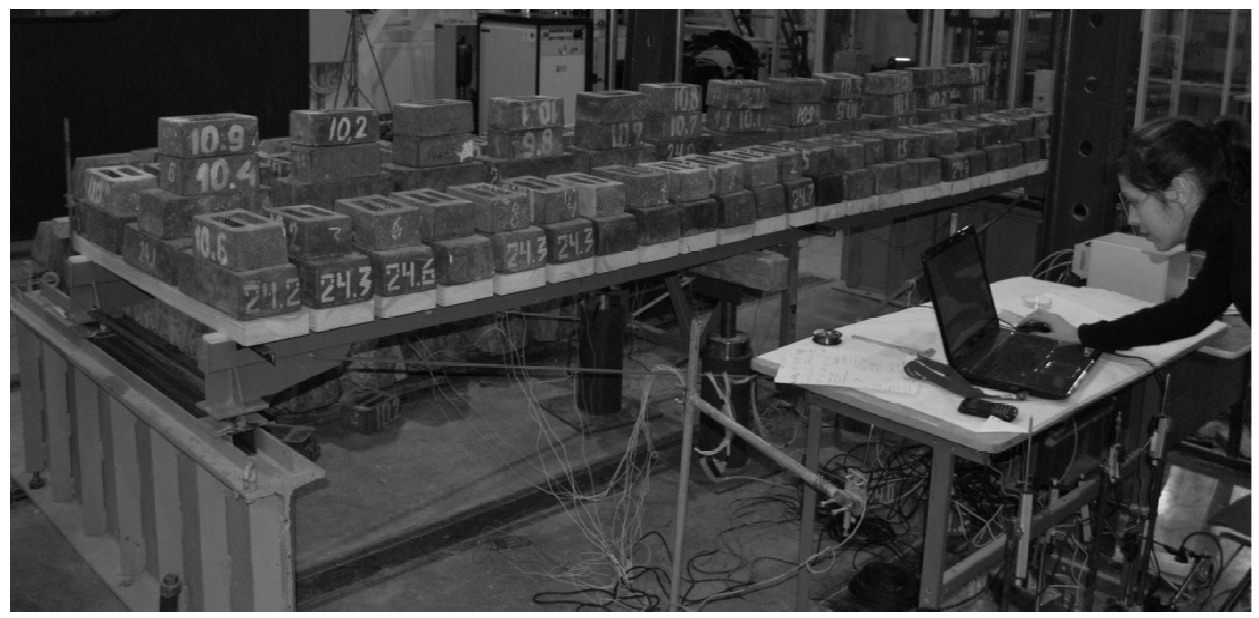

Fig. C.6. Maximum symmetric loading

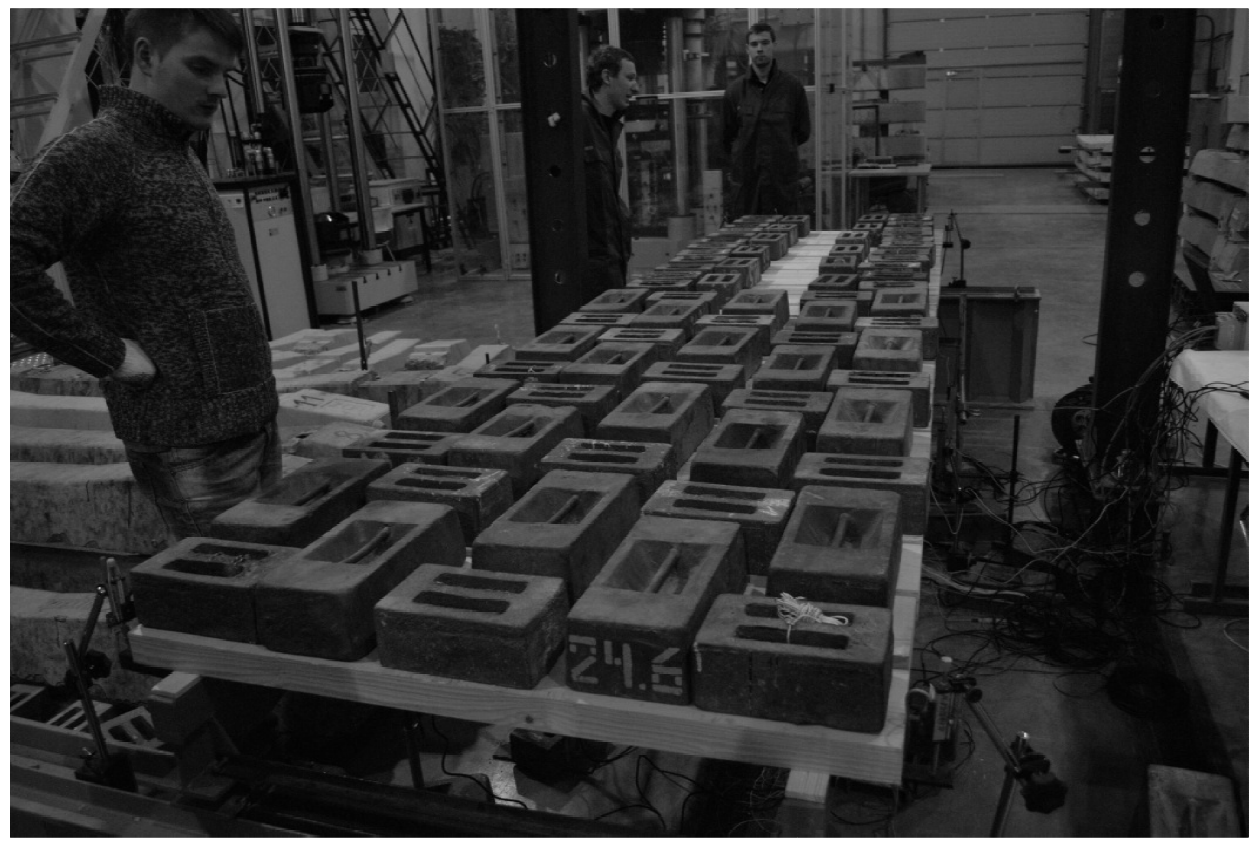

Fig. C.7. Asymmetric loading 


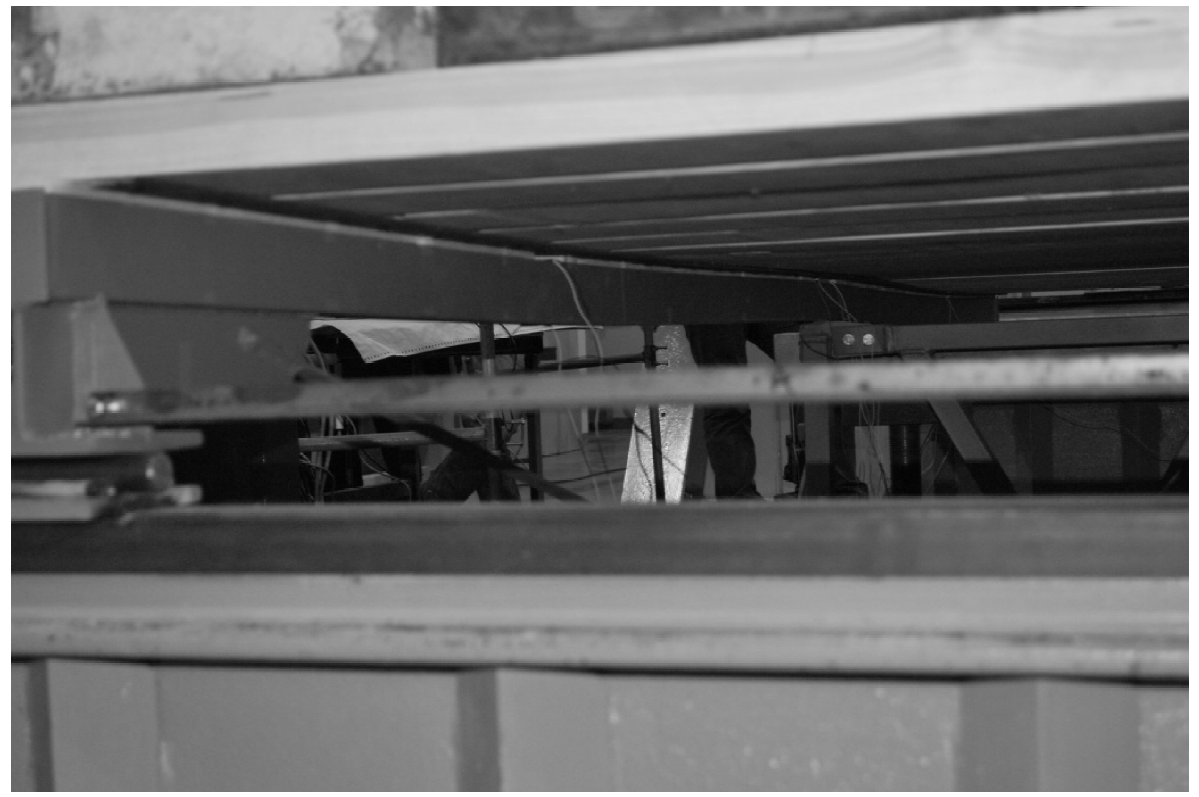

Fig. C.8. Deformational shape of the rigid beam

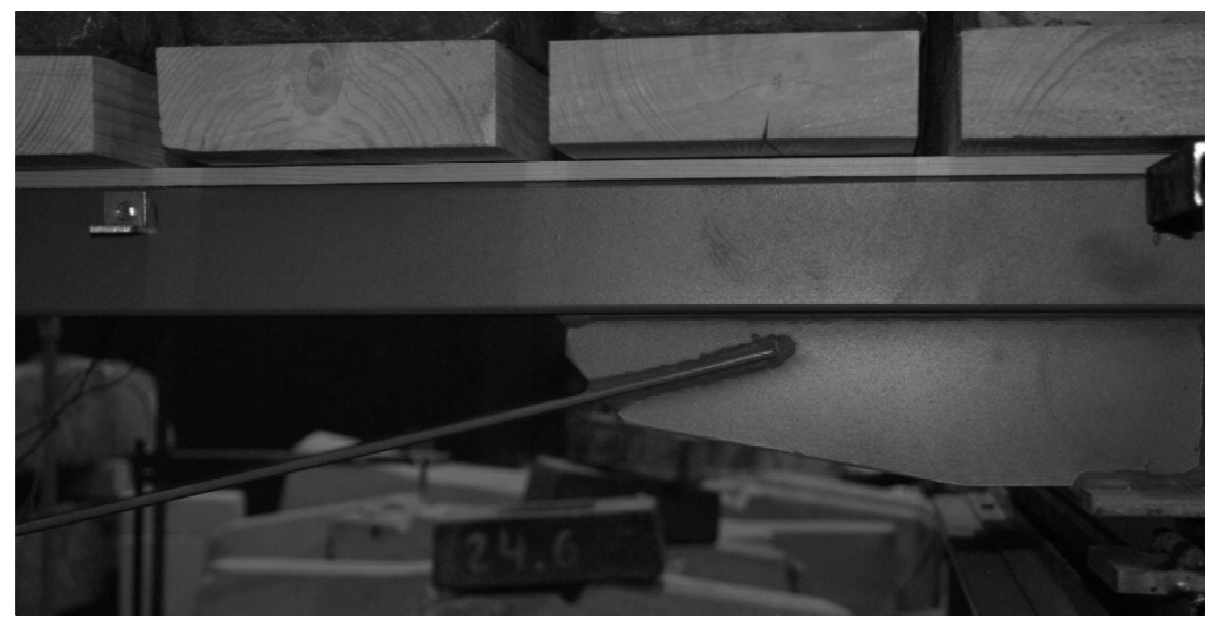

Fig. C.9. Direct anchoring of stay cable at the support section 

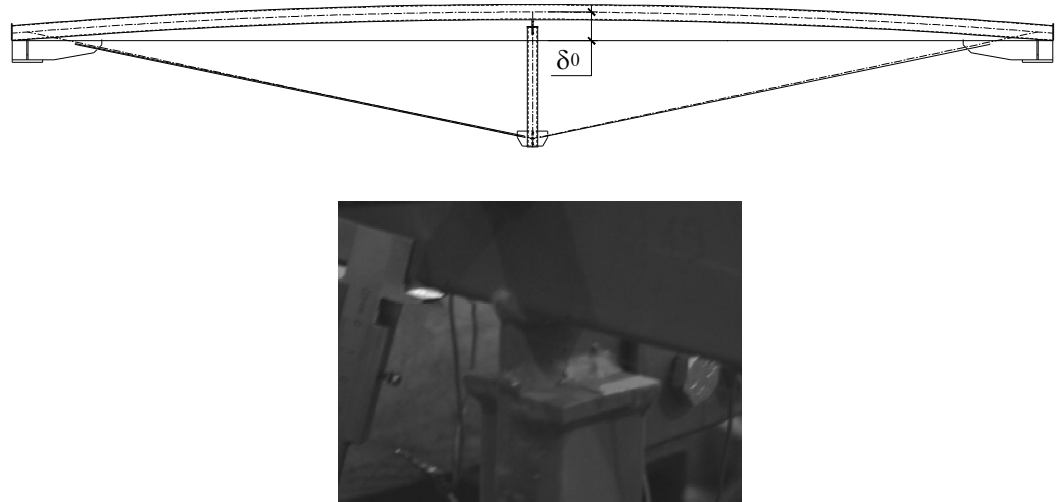

Fig. C.10. Measurement and direction of initial geometrical imperfections

a)

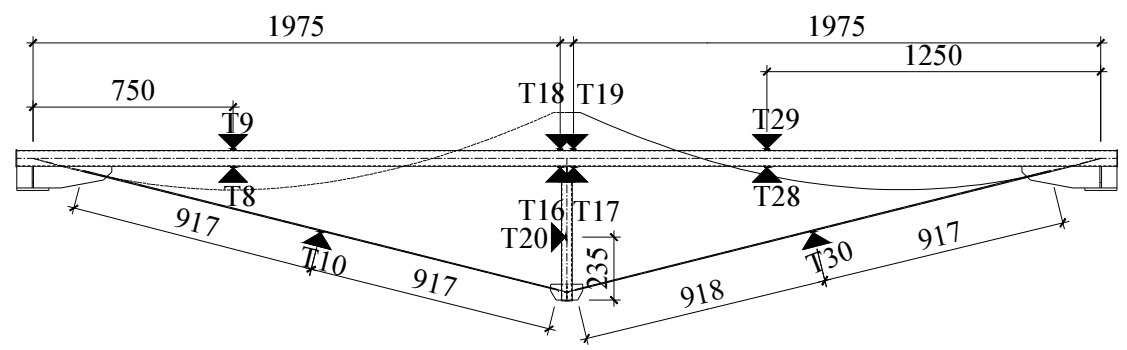

---- predictable bending moments distribution

b)

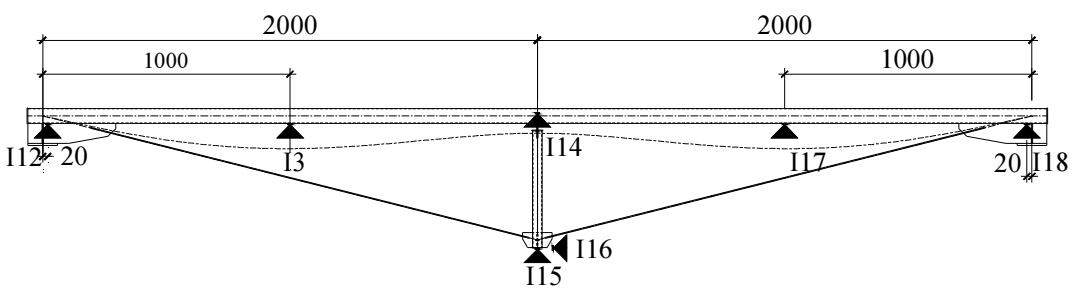

---- predictable displacement

Fig. C.11. Schemes of arrangement of measuring devices (paralel substructure): a) strain gauges, b) displacement gauges 


\begin{tabular}{|c|c|c|c|c|c|c|c|c|c|c|c|c|c|c|c|c|c|c|c|c|}
\hline b & $\stackrel{{ }^{N} E}{z}$ & 0 & $\nabla$ & 9 & 舀 & $\vec{n}$ & 6 & ஜ & 임 & 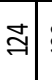 & $\approx$ & 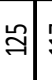 & 氝 & 2. & 이 & 吉 & $\hat{m}$ & $\approx$ & n & $\rightarrow$ \\
\hline है & $\begin{array}{c}{ }^{N} E \\
\sum \\
z\end{array}$ & 0 & T. & ? & ষ্ণ. & 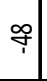 & 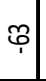 & 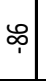 & 宅 & 의 & $\underset{7}{\sharp}$ & 暑 & $\underset{7}{\exists}$ & $\begin{array}{llll} & 0 \\
& 0\end{array}$ & ְִ̣ & g f & ষ্ড & ণ্ণ & Y & 0 \\
\hline z & $\frac{{ }^{N}}{\sum \xi}$ & 0 & 9 & $\rightarrow$ & $=1$ & 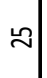 & $\infty$ & 6 & 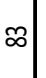 & இ & के & ৪) & $\infty$ & $8:$ & $\mathbb{m}$ & \pm & $\Rightarrow$ & 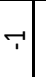 & 9 & 0 \\
\hline $0^{0}$ & $\stackrel{{ }^{N} E}{z}$ & 0 & $\sim$ & 의 & $\Rightarrow$ & 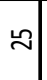 & $\approx$ & 守 & $\stackrel{\infty}{\circ}$ & $\widetilde{\sigma}$ & 8 & $\tilde{6}$ & ூำ & for & m & 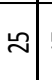 & $\exists$ & a) & $\sim$ & 0 \\
\hline $0_{0}^{ \pm}$ & $\stackrel{\substack{E \\
\Sigma \\
z}}{z}$ & 0 & $m$ & 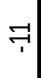 & ণి & శ్ధి & ণ্ণি & นุด & 유 & 号 & ஓ) & $\stackrel{2}{?}$ & $\vec{T}$ & เి & 导 & శి & ণి & 위 & $m$ & 0 \\
\hline $0^{\frac{1}{2}}$ & $\stackrel{{ }^{N} E}{E}$ & 0 & $\begin{array}{l}1 \\
\end{array}$ & 9 & ষ্ণি & श्? & ఫ़े & $\begin{array}{l}\infty \\
1\end{array}$ & 큭 & $\stackrel{\infty}{7}$ & ఫొఝ & 궁 & $\underset{7}{\exists}$ & \& & | & ํำ & 岗 & ণ্ণి & Y & 0 \\
\hline ơ & 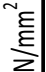 & 0 & $\overrightarrow{7}$ & $\vec{\top}$ & $\underset{1}{\infty}$ & గุ. & 오 & 帛 & த) & 学 & 苯 & 孚 & के) & T. & প. & 号 & f & $\stackrel{m}{?}$ & 으 & 0 \\
\hline ठ⿳亠ें & $\stackrel{\substack{E \\
\xi \\
z}}{z}$ & 0 & $\nabla$ & $\stackrel{\infty}{\sim}$ & $m$ & 字 & 8 & $\infty$ & $\exists$ & 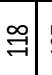 & 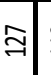 & 学 & $\exists$ & ஜ & छ) & g & 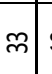 & $\stackrel{\infty}{\sim}$ & $\nabla$ & 0 \\
\hline है & $\begin{array}{l}{ }^{N} E \\
\frac{\xi}{z} \\
z\end{array}$ & 0 & $\sim$ & $\dddot{7}$ & $\mathscr{\tau}$ & $\vec{F}$ & 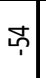 & ๑) & 象 & 号 & 学 & 号 & 웅 & T. & 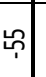 & f & $\underset{\tau}{\sim}$ & $\dddot{?}$ & $\tau$ & 0 \\
\hline क्ञ⿰冫欠 & 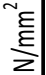 & 0 & in & ㅇ & $\stackrel{m}{m}$ & g) & ष & $\infty$ & 역 & 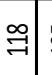 & $\stackrel{\llcorner}{\ni}$ & $\stackrel{\infty}{=}$ & $\exists$ & 85 & छ & 요 & $\stackrel{m}{m}$ & $\vec{\sim}$ & ח & 0 \\
\hline 章 & ${ }^{{ }^{N}} \stackrel{E}{E}_{z}$ & 0 & $\nabla$ & 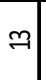 & $\approx$ & $\approx$ & $F$ & ก) & 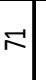 & 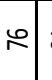 & $\vec{\infty}$ & 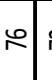 & $\mathbb{N}$ & $n=$ & $\approx$ & $\approx$ & $\approx$ & $\exists$ & $\nabla$ & 0 \\
\hline a & $\frac{{ }^{N}}{\xi \xi}$ & 0 & $\tau$ & का & 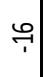 & $\mathbb{T}$ & $\widetilde{r}$ & F & 象 & ర్ధ & ఫ్ర & $\vec{\varphi}$ & 曲 & 狩 & $\widetilde{r}$ & $\underset{T}{*}$ & 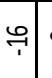 & $\infty$ & $\tau$ & 0 \\
\hline ఫิ & ${ }^{{ }^{N}} \stackrel{\xi}{\xi}$ & 0 & $\neg$ & ب) & 9 & $\exists$ & $\stackrel{9}{9}$ & 교 & $\stackrel{\sim}{\sim}$ & $\stackrel{\sim}{\sim}$ & $\underset{\sim}{\approx}$ & $\stackrel{\sim}{\sim}$ & $\stackrel{\tau}{~}$ & ঙ: & ?.1 & $\dddot{q}$ & 우 & $T$ & $\tau$ & 0 \\
\hline है & $\frac{{ }^{N}}{\xi \xi}$ & 0 & -1 & $\mathscr{\sim}$ & \& & 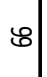 & $\infty$ & $\stackrel{\infty}{\exists}$ & ㅇำ & 영 & 욕 & $\vec{\sigma}$ & 코ำ & శ్తి: & $\infty$ & 6 & f & $\approx$ & $r$ & 0 \\
\hline ह & $\stackrel{{ }^{N} \xi}{\xi}$ & 0 & $n$ & $\mathscr{\sim}$ & 于 & 6 & $\infty$ & త్తి & શิ- & $\widetilde{\Omega}$ & $\stackrel{\Re}{\exists}$ & 0 & 苞 & $\exists$ & $\infty$ & $\mathscr{\bullet}$ & f & $\approx$ & 6 & 0 \\
\hline z) & 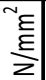 & 0 & $\neg$ & ๆ & $\varphi$ & $\infty$ & 7 & 누 & 9 & 구 & $\approx$ & 구 & 9 & ? & $\Rightarrow$ & $\infty$ & ?무 & $\eta$ & $\rightarrow$ & 0 \\
\hline 烦 & $\frac{{ }^{N} E}{\sum \xi}$ & 0 & 6 & 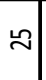 & $\Re$ & 8 & 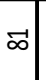 & $\exists$ & $\underset{\exists}{q}$ & થొ & 0 & 苞! & 导 & $\underset{\exists}{\exists}$ & $\mathscr{\infty}$ & 8 & ষ & 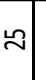 & ( & 0 \\
\hline $0^{\bar{Z}}$ & $\stackrel{\substack{E \\
\xi \\
z}}{z}$ & 0 & 6 & $\mathscr{\sim}$ & 守 & 2 & ১ & 익 & 古 & $\underset{\sim}{\infty}$ & $\mathbb{8}$ & 号 & 윰 & 웍 & $\infty$ & 8 & \& & 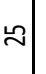 & ๑ & 0 \\
\hline$\stackrel{\text { a }}{\subseteq}$ & 㕫 & 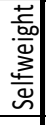 & ఐ & Æ্ల & $\infty$ & ஜ્ळ & : & $\widetilde{\infty}$ & 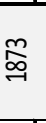 & ริ & ్ㅡㅅ & ğ & 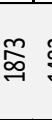 & ơ ơ & : & ळิ & 맴 & 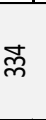 & $\approx$ & 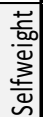 \\
\hline & 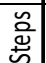 & 0 & -1 & $\sim$ & $m$ & $\nabla$ & $n$ & 6) & $r$ & $\infty$ & $\sigma$ & 의 & $\Rightarrow$ & $\approx=$ & $\nexists$ & $\vec{\exists}$ & 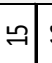 & 9 & $\exists$ & $\stackrel{\infty}{\sim}$ \\
\hline
\end{tabular}

Fig. C.11. Principle stress during symmetric loading (including unloading) 


\begin{tabular}{|c|c|c|c|c|c|c|c|c|c|c|c|c|}
\hline 主 & $\bar{z}{ }^{N} \xi$ & 0 & $\nabla$ & $\stackrel{\infty}{\sim}$ & กิ & 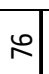 & 훙 & $\approx$ & กี & શ & in & 0 \\
\hline$\sum_{0}^{n}$ & $\bar{z}{ }_{\xi \xi}^{\mathcal{E}}$ & 0 & ᄂ? & $\stackrel{\infty}{p}$ & 유 & 윽 & $\begin{array}{l}\text { g } \\
\text { 1 } \\
\end{array}$ & $\begin{array}{l}\text { 吉 } \\
⿱ \\
\end{array}$ & $\overrightarrow{1}$ & 우 & $\begin{array}{l} \\
\end{array}$ & 0 \\
\hline - & $\bar{z}{ }_{\varepsilon}^{\sim}$ & 0 & 9 & 6 & 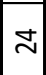 & 寸 & 8 & ษ & $\Delta$ & 几n & 9 & 0 \\
\hline - & $z{ }_{\varepsilon}^{\sim}$ & 0 & $\tau$ & $\infty$ & 역 & 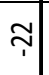 & ్ి & $\underset{\sim}{\sim}$ & 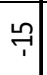 & 9 & $\neg$ & 0 \\
\hline $\overrightarrow{0}^{-}{ }^{+}$ & $\bar{z}{ }_{\varepsilon}^{N}$ & 0 & $m$ & $\underset{\sim}{\grave{T}}$ & ঙ্ণ & $\stackrel{\oplus}{T}$ & 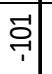 & $\infty$ & 守 & 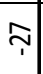 & $m$ & 0 \\
\hline$\underbrace{-} \frac{n}{0}$ & $\bar{z}{ }_{\xi}^{\mathcal{E}}$ & 0 & \begin{tabular}{|l|} 
\\
\end{tabular} & $\stackrel{m}{\varphi}$ & Qి & 号 & ज̂. & 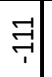 & ஜి & ஜి & ب & 0 \\
\hline \begin{tabular}{|c|}
$\alpha$ \\
0 \\
$b^{2}$ \\
\end{tabular} & $\bar{z}{ }_{\varepsilon}^{\sim}$ & 0 & a & Э & m্ & $\stackrel{\Re}{\uparrow}$ & 익 & ?ִ & ণ্ণ & 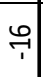 & $\dddot{\eta}$ & 0 \\
\hline$\sum_{0}^{2}$ & $\bar{z}{ }_{\varepsilon}^{\mathcal{E}}$ & 0 & $\nabla$ & $\stackrel{\Omega}{\sim}$ & $\approx$ & $\hat{m}$ & 유 & $\hat{m}$ & $\approx$ & $\exists$ & 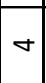 & 0 \\
\hline 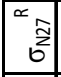 & $\bar{z} \stackrel{N}{\varepsilon}$ & 0 & $\Upsilon$ & 귀 & 우 & 8 & \$ & $\widetilde{\varphi}$ & 안 & $\vec{\top}$ & $\Upsilon$ & 0 \\
\hline$\sum_{0}^{2}$ & $\bar{z}{ }_{\xi \xi}^{N}$ & 0 & 0 & $\stackrel{\infty}{\rightarrow}$ & 2 & 同 & 윳 & $\hat{m}$ & $\stackrel{\infty}{\sim}$ & 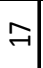 & in & 0 \\
\hline$\sum_{0}^{\overline{2}}$ & $\bar{z}{ }_{\varepsilon}^{N}$ & 0 & $\nabla$ & a & $\approx$ & 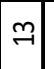 & $\exists$ & $\exists$ & $\exists$ & $\Lambda$ & 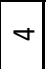 & 0 \\
\hline 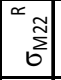 & $\bar{z}^{\sim} \xi$ & 0 & $\tau$ & $\underset{1}{0}$ & $\vec{p}$ & 운 & ஜ & ?ุ & $\widetilde{\Upsilon}$ & $\overrightarrow{7}$ & $\tau$ & 0 \\
\hline $\begin{array}{c}0 \\
0 \\
0 \\
0\end{array}$ & $\bar{z}{ }_{\xi}^{N}$ & 0 & $\tau$ & $\infty$ & $\stackrel{m}{-}$ & $\overrightarrow{7}$ & $\approx$ & $\stackrel{\infty}{\rightarrow}$ & $\overrightarrow{7}$ & क & $m$ & 0 \\
\hline \begin{tabular}{|c|} 
\\
$u_{0}^{2}$ \\
$\sum^{2}$
\end{tabular} & $\bar{z}^{N}{ }_{\xi}^{\varepsilon}$ & 0 & 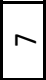 & m & 8 & 矛 & ஜ్తి & 음 & 6 & $\stackrel{\infty}{\infty}$ & $n$ & 0 \\
\hline$\sum_{0}^{\infty}$ & $\bar{z}{ }_{\xi}^{N}$ & 0 & $r$ & $\stackrel{m}{m}$ & छ & ৪ & 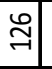 & 엉 & 응 & $\ddot{m}$ & $n$ & 0 \\
\hline $\mid$\begin{tabular}{c|}
0 \\
$\vdots$ \\
0 \\
0
\end{tabular} & $\bar{z} \stackrel{\sim}{\varepsilon}$ & 0 & 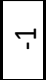 & ب & $\infty$ & $\underset{7}{7}$ & $\begin{array}{l}0 \\
\rightarrow\end{array}$ & 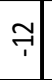 & $\infty$ & ب) & $\neg$ & 0 \\
\hline$\sum_{0}^{2}$ & $\bar{z}^{N} \stackrel{\varepsilon}{\xi}$ & 0 & 0 & m & 6 & ஜ & สิ & ஜூ & $\widetilde{ช}$ & $\ddot{m}$ & 6 & 0 \\
\hline $0_{0}^{m}$ & $\bar{z}{ }_{\xi}^{N}$ & 0 & 0 & 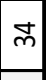 & -1 & ஜ & 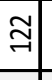 & ล́ & $\widetilde{\sigma}$ & $\ddot{m}$ & 0 & 0 \\
\hline $\begin{array}{l}\frac{\vec{c}}{.00} \\
\vec{x}\end{array}$ & & $\frac{\pi}{\frac{\pi}{00}}$ & $\simeq$ & $\begin{array}{l}m \\
o^{-} \\
0\end{array}$ & $\begin{array}{l}m \\
\text { w } \\
m\end{array}$ & $\tilde{\widetilde{S}}$ & $\begin{array}{l}m \\
\infty \\
\infty \\
n \\
n\end{array}$ & 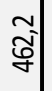 & $\begin{array}{l}m \\
\mathscr{m}^{-}\end{array}$ & $\begin{array}{c}m \\
\overbrace{}^{\circ}\end{array}$ & 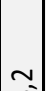 & $\mid \frac{t}{5}$ \\
\hline 苞 & & $\frac{3}{2}$ & $\infty$ & 点 & $\stackrel{\sim}{\approx}$ & 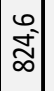 & 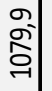 & 唄 & 太- & 吾: & & 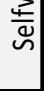 \\
\hline
\end{tabular}

Fig. C.12. Principle stress during asymmetric loading (including unloading) 
STRUCTURAL BEHAVIOUR AND STABILITY OF STEEL BEAM-COLUMN ELEMENTS IN UNDER-DECK CABLE-STAYED BRIDGE

Doctoral Dissertation

Technological Sciences,

CIVIL ENGINEERING (02T)

leva MISIŪNAITÉ

PLIENINIŲ PASPYRINIŲ TILTŲ GNIUŽDOMŲ LENKIAMŲ ELEMENTŲ ITTEMPIỤ DEFORMACIJŲ BŪSENA IR STABILUMAS

Daktaro disertacija

Technologijos mokslai, statybos inžinerija (02T)

201312 23. 16,5 sp. I. Tiražas 20 egz.

Vilniaus Gedimino technikos universiteto leidykla "Technika“,

Sauletekio al. 11, 10223 Vilnius,

http://leidykla.vgtu.It

Spausdino UAB "Baltijos kopija“

Kareivių g. 13B, 09109 Vilnius. 